\title{
Regulation of HPr phosphorylation in Mycoplasma pneumoniae
}

\author{
Dissertation \\ zur Erlangung des Doktorgrades \\ der Mathematisch-Naturwissenschaftlichen Fakultäten \\ der Georg-August-Universität zu Göttingen
}

vorgelegt von

Sven Halbedel

aus Havelberg

Göttingen 2006 
D 7

Referent: Prof. Dr. Jörg Stülke

Korreferent: Prof. Dr. Uwe Groß

Tag der mündlichen Prüfung: 02.11.2006 


\section{Danksagung}

An erster Stelle danke ich ganz herzlich Prof. Dr. Jörg Stülke für die sehr gute Betreuung der vorliegenden Arbeit. Von seiner offenen und fördernden Art haben der Fortgang der Arbeiten und auch ich persönlich sehr profitiert.

Für die Übernahme des Korreferats danke ich Prof. Dr. Uwe Groß. Dem Fonds der Chemischen Industrie danke ich für die finanzielle Unterstützung dieser Arbeit durch ein Kekulé-Stipendium.

Prof. Dr. Richard Herrmann von der Universität Heidelberg und den Mitgliedern seiner ehemaligen Arbeitsgruppe, im Besonderen Elsbeth Pirkl und Dr. Carl-Ulrich Zimmerman, möchte ich für die unkomplizierte Unterstützung beim Aufbau der Mycoplasma-Forschung in unserer Abteilung, sowie für die Überlassung verschiedener Primer, Stämme und Plasmide danken.

Prof. Dr. Michael Hecker und Dr. Susanne Engelmann (Universität Greifswald) danke ich für die freundliche Zusammenarbeit bei der Durchführung der primer-extension-Experimente und der 2DGelelektrophoresen. Für die Durchführung hunderter, damit verbundener Proteinidentifikationen danke ich Dr. Dirk Albrecht (Universität Greifswald).

Julia Busse möchte ich ganz herzlich für ihre tatkräftige Unterstützung bei den meisten Experimenten während der letzten 2 Jahre danken. Im Besonderen aber danke ich ihr für ihre Hilfe beim Aufbau der Transposantenbank und die vielen mühevollen Screens nach diversen Transposon-Mutanten.

Meinem Kollegen und guten Freund Fabian Commichau danke ich für das angenehme und humorvolle Miteinander im Labor und in diversen Göttinger Kneipen, sowie für die vielen gemeinsamen und manchmal abenteuerlichen Trainings- und Rennkilometer auf den Straßen rund um Göttingen und anderswo.

Im Laufe ihrer Laborpraktika haben Claudine Hames, Sebastian Schmidl, Hinnerk Eilers, Polya Vutova und Jasmine Mertens Beiträge zu dieser Arbeit geleistet. Ergebnisse aus der Diplomarbeit von Claudine Hames sind ebenfalls in diese Arbeit eingeflossen. Dr. Matthias Schmalisch war mir besonders zu Beginn dieser Arbeit ein hilfreicher Diskussionspartner und guter Kritiker. Dafür möchte ich ihnen allen an dieser Stelle noch einmal ausdrücklich danken. Allen Mitgliedern des Botchers Lab und der Abteilung, auch allen nicht namentlich genannten, danke ich für die heitere, unverkrampfte Arbeitsatmosphäre mit ihren vielen lustigen Einlagen.

Für die Durchführung zahlreicher DNA-Sequenzierungen danke ich den Mitarbeitern des Göttingen Genomics Laboratory.

Meinen lieben Eltern danke ich für ihre langjährige Unterstützung. Habt darüber hinaus einfach mal Danke für alles!

Sanni, Du weißt, das Beste kommt immer zum Schluss. Du hast mich auf andere Gedanken gebracht und mir den Rücken gestärkt, besonders dann, wenn es im Labor mal nicht so gut lief. Dafür und für so vieles andere mehr ein dickes Danke! 
Content

Content I

List of abbreviations II

List of publications III

Summary 1

Zusammenfassung 3

1. Introduction

A Regulation of carbon catabolism in Mycoplasma pneumoniae 5

B Tools for the genetic analysis of Mycoplasma 12

C Aims of this work 23

2. In vivo activity of enzymatic and regulatory components of the phosphoenolpyruvate:sugar phosphotransferase system in Mycoplasma pneumoniae

3. Dual phosphorylation of Mycoplasma pneumoniae HPr by enzyme I and HPr kinase suggests an extended phosphoryl group susceptibility of HPr

4. MMR: A method for the simultaneous introduction of multiple mutations into the glpK gene of Mycoplasma pneumoniae

5. Probing in vivo promoter activities in Mycoplasma pneumoniae:

A system for the generation of single-copy reporter constructs

6. Regulatory protein phosphorylation in Mycoplasma pneumoniae:

A PP2C-type phosphatase serves to dephosphorylate HPr(Ser-P)

7. Regulation of genes of overflow metabolism in Mycoplasma pneumoniae

8. Discussion

9. References

10. Supplementary material

Curriculum vitae 


\section{List of abbreviations}

\begin{tabular}{|c|c|}
\hline $\mathrm{ABC}$ & ATP binding cassette \\
\hline BSA & bovine serum albumin \\
\hline CCR & carbon catabolite regulation \\
\hline CCR & combined chain reaction \\
\hline DIG & digoxigenin \\
\hline DTT & dithiothreitol \\
\hline E I & enzyme I \\
\hline E II & enzyme II \\
\hline EDTA & ethylenediaminetetraacetic acid \\
\hline FBP & fructose-1,6-bisphosphate \\
\hline fru & fructose \\
\hline glc & glucose \\
\hline glyc & glycerol \\
\hline HEPES & 4-(2-hydroxyethyl)piperazine-1-ethanesulfonic acid \\
\hline HPrK/P & HPr kinase/phosphorylase \\
\hline $\mathrm{IgG}$ & immunoglobulin $\mathrm{G}$ \\
\hline IPG & immobilized $\mathrm{pH}$ gradient \\
\hline IPTG & isopropyl- $\beta-\mathrm{D}-1$-thiogalactopyranoside \\
\hline LB & Luria Bertani \\
\hline MMR & multiple mutation reaction \\
\hline MP & Mycoplasma pneumoniae \\
\hline NAD/NADH & $\beta$-nicotinamide adenine dinucleotide \\
\hline NTA & nitrilotriacetic acid \\
\hline OD & optical density \\
\hline ONP & 2-nitrophenol \\
\hline ONPG & 2-nitrophenyl- $\beta$-D-galactopyranoside \\
\hline PAGE & polyacrylamide gel electrophoresis \\
\hline PCR & polymerase chain reaction \\
\hline PEP & phosphoenolpyruvate \\
\hline PNPP & 4-nitrophenyl phosphate \\
\hline PP2C & protein phosphatase $2 \mathrm{C}$ \\
\hline PPLO & pleuropneumoniae-like organism \\
\hline PRPP & phosphoribosylpyrophosphate \\
\hline PTS & phosphotransferase system \\
\hline PVDF & polyvinylidene difluoride membrane \\
\hline SDS & sodium dodecyl sulfate \\
\hline TCA & tricarboxylic acid \\
\hline TE & Tris-EDTA \\
\hline Tris & tris(hydroxymethyl)aminomethane \\
\hline UV & ultraviolet \\
\hline X-Gal & 5-Bromo-4-chloro-3-indolyl- $\beta$-D-galactopyranoside \\
\hline
\end{tabular}




\section{List of publications}

Halbedel, S., C. Hames, and J. Stülke. 2004. In vivo activity of enzymatic and regulatory components of the phosphoenolpyruvate:sugar phosphotransferase system in Mycoplasma pneumoniae. J. Bacteriol. 186:7936-7943.

Halbedel, S., and J. Stülke. 2005. Dual phosphorylation of Mycoplasma pneumoniae HPr by Enzyme I and HPr kinase suggests an extended phosphoryl group susceptibility of HPr. FEMS Microbiol. Lett. 247:193-198.

Hames, C., S. Halbedel, O. Schilling, and J. Stülke. 2005. MMR: A method for the simultaneous introduction of multiple mutations into the glpK gene of Mycoplasma pneumoniae. Appl. Env. Microbiol. 71: 4097-4100.

Halbedel, S., and J. Stülke. 2006. Probing in vivo promoter activities in Mycoplasma pneumoniae: a system for generation of single-copy reporter constructs. Appl. Environ. Microbiol. 72:1696-1699.

Halbedel, S., J. Busse, S. R. Schmidl, and J. Stülke. 2006. Regulatory protein phosphorylation in Mycoplasma pneumoniae: A PP2C-type phosphatase serves to dephosphorylate HPr(Ser-P). J. Biol. Chem. 281:26253-26259.

Halbedel, S., C. Hames, and J. Stülke. 2006. Regulation of carbon metabolism in the mollicutes and its relation to virulence. J. Mol. Microbiol. Biotechnol. In press.

Halbedel, S., and J. Stülke. Tools for the genetic analysis of Mycoplasma. Int. J. Med. Microbiol. Submitted.

Singh, K., S. Halbedel, B. Görke, and J. Stülke. Control of the phosphorylation state of the HPr protein of the phosphotransferase system in Bacillus subtilis: implication of the protein phosphatase PrpC. In preparation. 


\section{Summary}

The genome of the Gram-positive bacterium Mycoplasma pneumoniae contains only 688 genes. Consequently, it has lost many genes that are necessary for most of the biosynthetic pathways and for many signal perception systems as well. Among the very few regulatory proteins retained is the HPr kinase/phosphorylase (HPrK/P) of the phosphoenolpyruvate:sugar phosphotransferase system. The HPrK/P de-/phosphorylates the small phosphocarrier protein HPr at the regulatory Ser-46 residue in a nutrient-controlled way, triggering a specific gene expression program called carbon catabolite regulation. In earlier studies, the HPrK/P and $\mathrm{HPr}$ of $M$. pneumoniae were purified and characterized biochemically in terms of HPrK/P dependent phosphorylation/dephosphorylation of HPr in vitro. The determination of the crystal structure of the HPrK/P and a site-directed mutagenesis study provided the basis for the mechanistic understanding of this reaction.

For the more detailed physiological characterization of the $\mathrm{HPrK} / \mathrm{P}, M$. pneumoniae was tested in initial experiments for its ability to use those carbohydrates as sources of carbon and energy that were predicted to be metabolizable based on the genome sequence. Carbohydrates that were found to promote growth of $M$. pneumoniae were tested for their impact on the in vivo $\mathrm{HPr}$ phosphorylation pattern. $\mathrm{HPr}(\mathrm{His} \sim \mathrm{P})$ which is generated by enzyme $\mathrm{I}$ of the phosphoenolpyruvate:sugar phosphotransferase system was found in the presence of all tested carbohydrates. A strong stimulation of in vivo $\operatorname{HPr}(\operatorname{Ser}-\mathrm{P})$ synthesis was found when the cells were grown in the presence of glycerol. Under this condition, a substantial portion of the cellular HPr was also present in the doubly phosphorylated form, $\mathrm{HPr}(\mathrm{His} \sim \mathrm{P})(\mathrm{Ser}-\mathrm{P})$. Since both phosphorylation events are mutually exclusive in other bacteria, kinetic experiments with unphosphorylated HPr and the singly phosphorylated forms as substrates for HPrK/P or enzyme I dependent phosphorylation were performed. Both enzymes were found to phosphorylate the singly phosphorylated HPr although at a slower rate. However, the observed reaction rate is sufficient to account for the high intracellular amounts of doubly phosphorylated HPr.

To allow the targeted isolation of gene disruption mutants of $M$. pneumoniae, a novel transposon based strategy called "haystack mutagenesis" was designed. Using this strategy, a $h p r K$ transposon insertion mutant was isolated and proven to be defective in phosphorylation of $\mathrm{HPr}$ at Ser-46 in vivo and in vitro. Surprisingly, $\mathrm{HPr}(\mathrm{Ser}-\mathrm{P})$ dephosphorylation was still operative in the hprK mutant. This observation led to the identification of the PP2C type protein serine/threonine phosphatase $\operatorname{PrpC}$ as the $\mathrm{HPr}(\mathrm{Ser}-\mathrm{P})$ phosphatase in search. PrpC was purified and proven to dephosphorylate $\operatorname{HPr}(\operatorname{Ser}-\mathrm{P})$ in vitro. The role of $\operatorname{PrpC}$ in 
dephosphorylation of $\mathrm{HPr}(\mathrm{Ser}-\mathrm{P})$ was confirmed by analysis of in vivo $\mathrm{HPr}(\mathrm{Ser}-\mathrm{P})$ formation in a $\operatorname{prpC}$ mutant. Dephosphorylation of $\operatorname{HPr}(\mathrm{Ser}-\mathrm{P})$ by another protein phosphatase than HPrK/P represents a novel regulatory mechanism of carbon catabolite regulation. The finding that the expression of the thyA-dhfr-nrdFIE operon is deregulated in the $h p r K$ mutant is a first hint for HPrK/P mediated control of gene expression in M. pneumoniae.

Using a proteomic approach, the $a c k A$ gene coding for acetate kinase and the $l d h$ gene coding for lactate dehydrogenase were identified to be repressed or induced, respectively, in the presence of glycerol. The transcriptional start points of both genes were mapped using primer extension analysis. To test putative promoter fragments in vivo, a reporter system for $M$. pneumoniae that is based on a promoter-less lacZ gene was developed and used to confirm the ack $A$ and the $l d h$ promoter.

Mycoplasmas use the UGA opal codon to code for tryptophan rather than as a stop codon. This has hampered the biochemical analysis of mycoplasma proteins since their codon usage first has to be adapted for expression in heterologous hosts. A strategy called multiple mutation reaction is presented that allows the simultaneous introduction of up to nine $A \rightarrow G$ transitions. This strategy was used to express the full-length $M$. pneumoniae glpK gene which originally contained 10 UGA codons in Escherichia coli. 


\section{Zusammenfassung}

Das Genom von M. pneumoniae enthält lediglich 688 Gene, womit ihm die meisten anabolen Stoffwechselwege sowie der Großteil der für Bakterien üblichen Mechanismen der Signalwahrnehmung und -weiterleitung fehlen. $\mathrm{Zu}$ den wenigen erhalten gebliebenen Regulatoren gehört die HPr-Kinase/Phosphorylase (HPrK/P) aus dem Phosphoenolpyruvat:Zucker-Phosphotransferasesystem. Die HPrK/P phosphoryliert/ dephosphoryliert das Phosphocarrier-Protein HPr am Ser-46 in Abhängigkeit von der externen Nährstoffversorgung und leitet damit ein spezifisches Genexpressionsprogramm, welches als C-Kataboliten-Regulation bekannt ist, ein. In früheren Arbeiten wurden HPr und die HPrK/P von M. pneumoniae aufgereinigt und die allosterische Kontrolle der HPrK/Pabhängigen Phosphorylierung von HPr wurde in vitro charakterisiert. Die Aufklärung der Kristallstruktur der HPrK/P und die Einführung ortsgerichteter Mutationen in das Enzym lieferten eine erste Basis für das mechanistische Verständnis dieser Reaktion.

Für die Charakterisierung der physiologischen Rolle der HPrK/P in M. pneumoniae wurden in dieser Arbeit zunächst C-Quellen, deren Verwertung anhand der Genomsequenz vorhergesagt werden konnte, auf ihre tatsächliche Verwertbarkeit in Wachstumsexperimenten getestet. Anschließend wurde der Einfluss derjenigen C-Quellen, in deren Gegenwart M. pneumoniae wächst, auf den in vivo Phosphorylierungszustand von $\mathrm{HPr}$ untersucht. $\mathrm{HPr}(\mathrm{His} \sim \mathrm{P})$, welches durch Enzym I aus dem Phosphotransferase-System gebildet wird, konnte unter allen Bedingungen nachgewiesen werden. Dagegen wird $\mathrm{HPr}(\mathrm{Ser}-\mathrm{P})$ nur in Gegenwart von Glycerol gebildet. Unter diesen Bedingungen liegt etwa ein Drittel des zellulären HPr außerdem in der doppelt phosphorylierten Form vor. Da sich beide Phosphorylierungsereignisse in anderen Bakterien gegenseitig ausschließen, wurden zeitauflösende Phosphorylierungsstudien mit HPr und seinen einfach phosphorylierten Formen als Substrate für die HPrK/P sowie für Enzym I durchgeführt. Es stellte sich heraus, dass die einfach phosphorylierten Formen von HPr sowohl von HPrK/P als auch von Enzym I mit verringerter Rate als Substrat akzeptiert werden. Anhand dieser Beobachtung konnte die vergleichsweise hohe Menge an doppelt phosphoryliertem HPr erklärt werden.

Für die gerichtete Isolation gewünschter Gendisruptionsmutanten von $M$. pneumoniae wurde eine neuartige, auf der Verwendung eines Mini-Transposons basierende Methode entwickelt. Mithilfe dieser Strategie wurde eine Transposon-Insertionsmutante im hprK-Gen isoliert. Die hprK-Mutante konnte kein $\mathrm{HPr}(\operatorname{Ser}-\mathrm{P})$ mehr bilden, weder in vitro noch in vivo. Überraschenderweise besaßen Zellextrakte der hprK-Mutante noch die Fähigkeit, HPr(Ser-P) zu dephosphorylieren. Diese Beobachtung führte zur Identifizierung der Protein- 
Serin/Threonin-Phosphatase PrpC als neuartiger HPr(Ser-P)-Phosphatase. PrpC wurde aufgereinigt und die Dephosphorylierung von $\operatorname{HPr}(\operatorname{Ser}-\mathrm{P})$ durch $\operatorname{PrpC}$ wurde in vitro nachgewiesen. Diese Daten wurden durch die Untersuchung des in vivo $\mathrm{HPr}$ Phosphorylierungszustands in einer $\operatorname{prpC}$ Mutante verifiziert. Die Dephosphorylierung von $\mathrm{HPr}($ Ser-P) durch eine andere Proteinphosphatase als HPrK/P stellt einen neuartigen Mechanismus der Regulation der C-Kataboliten-Regulation dar. Der Befund, dass die Expression des thyA-dhfr-nrdFIE Operons in der $h p r K$-Mutante dereguliert ist, weist auf die tatsächliche Existenz einer HPrK/P-vermittelten Expressionskontrolle in M. pneumoniae hin. Mithilfe von Proteomanalysen wurden das $a c k A-G e n$ und das $l d h-G e n$ als in Gegenwart von Glycerol reprimierte bzw. induzierte Gene identifiziert. Die Transkriptionsstartpunkte beider Gene wurden mittels Primer-Extension-Analyse kartiert. Um Promotorfragmente auch in vivo auf ihre Aktivität untersuchen zu können, wurde ein Reportersystem für M. pneumoniae entwickelt, welches auf einem promotorlosen lacZ-Gen basiert. Dieses System wurde genutzt, um den $l d h$ - und den $a c k A$-Promotor experimentell zu bestätigen.

Mycoplasmen nutzen das opal-Codon UGA, um für die Aminosäure Tryptophan zu kodieren. Diese Eigenschaft verhindert die Expression von Mycoplasma-Genen in heterologen Wirten, da das UGA-Codon dort als Stopp-Codon gelesen wird. Mithilfe einer neuartigen Strategie, welche die gleichzeitige Einführung von bis zu 9 ortsspezifischen Mutationen in ein DNAFragment erlaubt, wurden 9 UGA-Codons des $M$. pneumoniae glpK-Gens in einem einzigen Schritt in UGG-Codons überführt. Anschließend konnte das glpK-Gen in Escherichia coli exprimiert werden. 


\section{Chapter 1:}

\section{Introduction}

\section{A. Regulation of carbon catabolism in Mycoplasma pneumoniae}

This chapter is part of the following publication:

Halbedel, S., C. Hames, and J. Stülke. 2006. Regulation of carbon metabolism in the mollicutes and its relation to virulence. J Mol Microbiol Biotechnol, in press.

\section{Author contributions:}

This review was written by JS, SH and $\mathrm{CH}$. SH performed the inspection of the mollicute genomes on which the first two chapters are based. 


\section{Abstract}

The mollicutes are cell wall-less bacteria that live in close association with their eukaryotic hosts. Their genomes are strongly reduced and so are their metabolic capabilities. A survey of the available genome sequences reveals that the mollicutes are capable of utilizing sugars as source of carbon and energy via glycolysis. The pentose phosphate pathway is incomplete in these bacteria, and genes encoding enzymes of the tricarboxylic acid cycle are absent from the genomes. Sugars are transported by the phosphotransferase system. As in related bacteria, the phosphotransferase system does also seem to play a regulatory role in the mollicutes as can be concluded from the functionality of the regulatory HPr kinase/ phosphorylase. In Mycoplasma pneumoniae, the activity of HPr kinase is triggered in the presence of glycerol. This carbon source may be important for the mollicutes since it is available in epithelial tissues and its metabolism results in the formation of hydrogen peroxide, the major virulence factor of several mollicutes. In plant-pathogenic mollicutes such as Spiroplasma citri, the regulation of carbon metabolism is crucial in the adaptation to life in plant tissues or the insect vectors. Thus, carbon metabolism seems to be intimately linked to pathogenicity in the mollicutes.

\section{Introduction}

The mollicutes are a group of bacteria that are defined by the lack of a cell wall. Phylogenetically, they are one clade of the Gram-positive bacteria with low GC content of their genomic DNA, i. e. the Firmicutes (Ciccarelli et al., 2006). The most important human pathogen of this group, Mycoplasma pneumoniae, causes community-acquired respiratory infections, but also complications of the central nervous system (Hammerschlag, 2001; Waites \& Talkington, 2004). Unlike their relatives such as Bacillus spp., Clostridium spp., and the lactic acid bacteria, the mollicutes have highly reduced genomes which reflect their distinct evolution and their adaptation to a life in close association with eukaryotic hosts (Ochman \& Davalos, 2006). Indeed, Mycoplasma genitalium is the organism with the smallest genome $(580 \mathrm{~kb})$ that is capable of independent life on artificial media (Fraser et al., 1995). The small genomes of the mollicutes are essential to address and consequently to answer the question which set of genes may be required for independent life (Glass et al., 2006; Hutchison et al., 1999). Moreover, the mollicute genomes are an importing starting point for synthetic biology, i. e. the artificial creation of simple living cells (Pennisi, 2005).

In good agreement with the reduced genomes of the mollicutes is also the absence of obvious virulence factors. However, the mollicutes do cause harm to their hosts, and in many Mycoplasma species this is due to the formation of hydrogen peroxide which is formed 
mainly during the utilization of glycerol (see below). On the other hand, glycerol seems to be an important trigger in $M$. pneumoniae since the only known regulatory protein modification, the phosphorylation of HPr of the phosphotransferase system, is triggered by this carbon source (Halbedel et al., 2004).

With the availability of the complete genome sequences of several mollicutes and the advances in the analysis of carbon metabolism and its importance for pathogenicity we feel the need to review this rapidly evolving research field. For specific aspects of the metabolic pathways in the mollicutes, the reader is referred to earlier reviews (Miles, 1992; Razin et al., 1998).

\section{Central carbon metabolic pathways in mollicutes}

The reductive evolution of the mollicutes is reflected in their catabolic properties. Of the central metabolic pathways, i. e. glycolysis, the pentose phosphate shunt and the tricarboxylic acid (TCA) cycle, only glycolysis seems to be operative in most mollicutes. The activity of glycolysis in the utilization of glucose was first detected in Mycoplasma mycoides. In contrast, the same study revealed the presence of an incomplete glycolytic pathway in Ureaplasma urealyticum that did not allow the utilization of glucose (Cocks et al., 1985). The pentose phosphate pathway of the molllicutes lacks the oxidative part and may serve only to provide the cells with ribose for nucleic acids synthesis (Miles, 1992). The mollicutes are capable of oxidizing pyruvate by the pyruvate dehydrogenase (Constantopoulos and McGarrity, 1987), however, they do not possess a functional TCA cycle (Miles, 1992). An overview of the central carbon metabolic pathways in M. pneumoniae is given in Fig. 1.

With the availability of several complete genome sequences of mollicutes, the enzymatic studies can be complemented by analyses at the genome level. The complete set of genes encoding glycolytic enzymes is present in all analyzed species (see Tab. 1) with the exception of $U$. urealyticum which lacks the pgi gene encoding phosphoglucoisomerase. Moreover, $U$. urealyticum contains a gapN gene encoding a NADP-dependent glyceraldehyde 3-phosphate dehydrogenase rather than the catabolic gapA found in all other mollicutes. As observed for M. genitalium glyceraldehyde 3-phosphate dehydrogenase, the glycolytic kinases of several Mycoplasma species have functions in addition to that in glycolysis: These enzymes can use not only ADP/ ATP but also other nucleoside diphosphate/ triphosphate couples. Thus, these enzymes (phosphofructokinase, phosphoglycerate kinase, pyruvate kinase, and acetate kinase) compensate for the lack of the normally essential $n d k$ gene encoding nucleoside diphosphate kinase that is required for nucleotide biosynthesis (Pollack et al., 2002). 
Tab. 1: Organisms included in this analysis

\begin{tabular}{lll}
\hline Organism & Reference & Acc. No. \\
\hline Mycoplasma pneumoniae & Himmelreich et al., 1996 & NC_000912 \\
Mycoplasma genitalium & Fraser et al., 1995 & NC_000908 \\
Mycoplasma gallisepticum & Papazisi et al., 2003 & NC_004829 \\
Mycoplasma capricolum & unpublished & NC_007633 \\
Mycoplasma hyopneumoniae J & Vasconcelos et al., 2005 & NC_007295 \\
Mycoplasma mobile & Jaffe et al., 2004b & NC_006908 \\
Mycoplasma mycoides subsp. mycoides & Westberg et al., 2004 & NC_005364 \\
Mycoplasma penetrans & Sasaki et al., 2002 & NC_004432 \\
Mycoplasma pulmonis & Chambaud et al., 2001 & NC_002771 \\
Mycoplasma synoviae & Vasconcelos et al., 2005 & NC_007294 \\
Ureaplasma urealyticum & Glass et al., 2000 & NC_002162 \\
Mesoplasma florum & unpublished & NC_006055 \\
Phytoplasma asteris & Oshima et al., 2004 & NC_005303 \\
\hline
\end{tabular}

Glycolysis is not the only source of ATP formation by substrate level phosphorylation in the mollicutes. Pyruvate can be oxydized to acetyl-CoA by pyruvate dehydrogenase in all mollicutes with the exception of $U$. urealyticum. Acetyl-CoA can be further catabolized by phosphotransacetylase and acetate kinase in an additional substrate level phosphorylation resulting in the formation of acetate. An alternative way of pyruvate consumption is its reduction to lactate. The $l d h$ gene encoding lactate dehydrogenase is present in all studied mollicutes with the exception of $U$. urealyticum and Phytoplasma asteris. It is interesting to note that $U$. urealyticum does not possess the complete set of glycolytic genes and lacks also both enzymes that catabolize pyruvate.

Of the genes encoding enzymes of the pentose phosphate pathway only those encoding ribulose-5-phosphate epimerase, ribose-5-phosphate isomerase and transketolase are present in all genomes of the mollicutes. This equipment is sufficient for the synthesis of pentose phosphates for nucleotide biosyntheses. Indeed, the prs gene catalyzing the formation of phosphoribosylpyrophosphate (PRPP) from ribose-5-phosphate is present in M. pneumoniae. PRPP is then used to synthesize nucleotides (McElwain and Pollack, 1987) (see Fig. 1).

In agreement with the biochemical analyses, all genes of the TCA cycle are absent from the genomes of the mollicutes. The only TCA cycle activity observed in several Mycoplasma species, malate dehydrogenase, is attributed to the lactate dehydrogenase encoded by $l d h$ (Cordwell et al., 1997; Manolukas et al., 1988). 


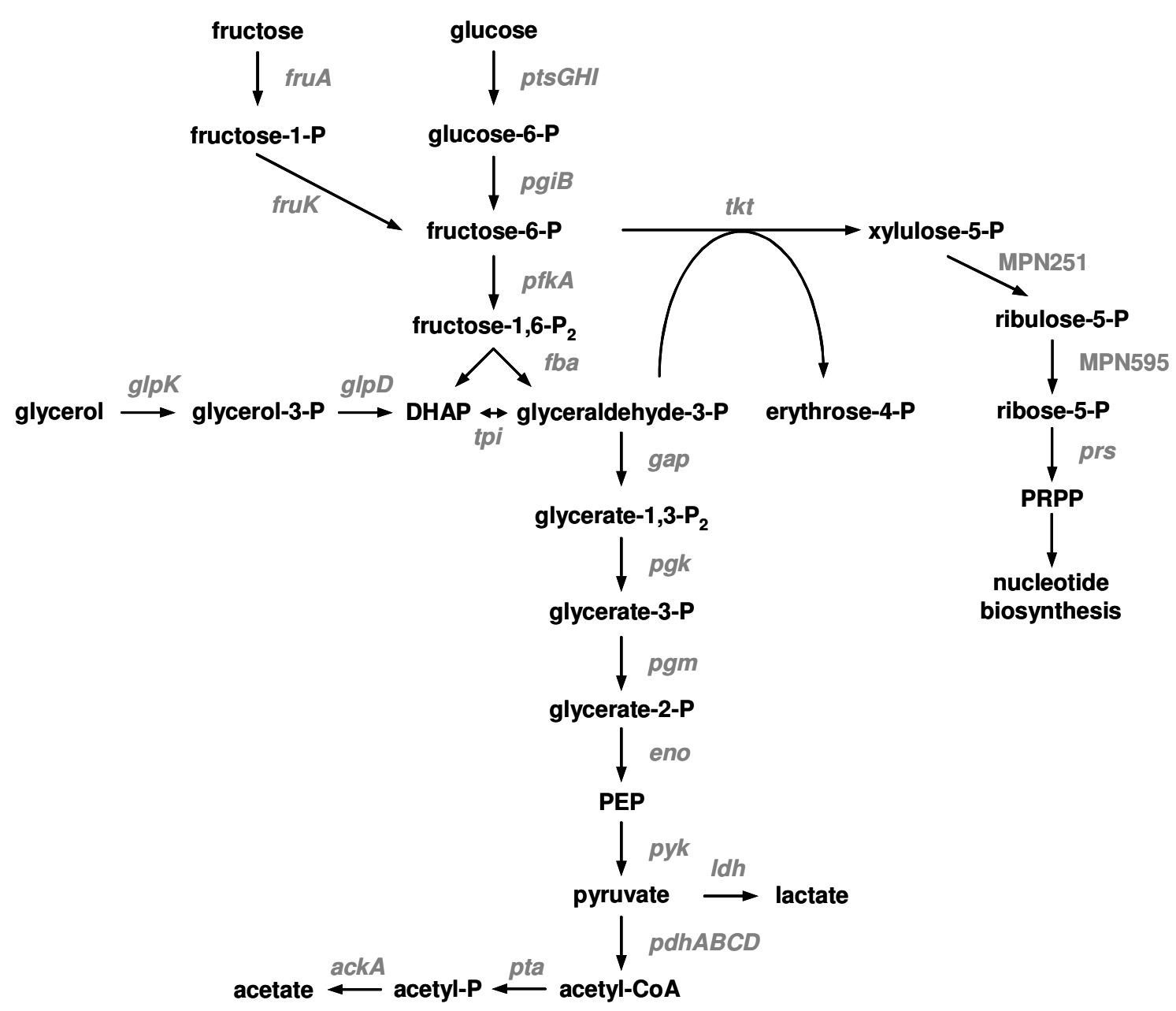

Fig. 1: Central metabolic pathways of $M$. pneumoniae. Glucose, fructose, and glycerol are transported into the cell, phosphorylated and catabolized via glycolysis. Excess carbon is excreted as lactate or acetate. The pentose phosphate pathway is incomplete and serves to generate phosphoribosyl pyrophosphate for nucleotide biosynthesis.

DHAP, dihydroxy acetone phosphate; PEP, phosphoenolpyruvate; PRPP, phosphoribosyl pyrophosphate.

A recent study with $M$. pneumoniae suggested that glucose is the carbon source allowing fastest growth of these bacteria. In addition, M. pneumoniae can utilize glycerol and fructose. Interestingly, mannitol is not used even though the genetic equipment to utilize this carbohydrate seems to be complete. Obviously, one or more of the required genes are not expressed or inactive (Halbedel et al., 2004). Genes for the utilization of glycerol are present in all Mycoplasma species with the exception of $M$. synoviae and are not encoded in the genomes of the Ureaplasma, Phytoplasma, and Mesoplasma species. In all Mycoplasma species that use glycerol, this compound can be transported by the glycerol facilitator encoded by $g l p F$. Interestingly, an ABC transporter specific for glycerol is present in M. mycoides (see below), M. hyopneumoniae, M. gallisepticum, and M. pulmonis. Genes for fructose utilization (encoding a permease of the phosphotransferase system and 1-phosphofructokinase) are present in M. pneumoniae, M. genitalium, M. mycoides, M. penetrans, M. capricolum, and 
Mesoplasma florum. Mannitol utilization genes are present in $M$. pneumoniae, $M$. hyopneumoniae, M. mycoides, M. pulmonis, and M. capricolum. However, as observed with M. pneumoniae, this does not necessarily mean that all these bacteria can utilize mannitol. Indeed, the mannitol permease of $M$. pulmonis is truncated suggesting that it is not active.

$U$. urealyticum lacks the genes to use any of the above-mentioned carbohydrates. Instead, these bacteria possess a transporter for ribose. After phosphorylation, this sugar can be converted to glycerol-3-phosphate and fructose-6-phosphate.

\section{The phosphotransferase system of the mollicutes}

Glucose and fructose (and mannitol, if catabolized) are transported into the cells by the phosphoenolpyruvate:sugar phosphotransferase system (PTS). This system is made up of general soluble components and sugar-specific membrane-bound permeases. The general components, enzyme I and HPr transfer a phosphate group from phosphoenolpyruvate to the sugar permease, which phosphorylates the sugar concomitant to its transport. Glucose permeases are present in all sequenced mollicutes species except $U$. urealyticum and Phytoplasma asteris. Spiroplasma citri, a plant pathogen, can transport trehalose in addition to glucose by a specific PTS permease. Both glucose and trehalose permeases share a common soluble IIA domain that transfers the phosphate group from HPr to the IIB domain of the permease and, ultimately, to the incoming sugar (André et al., 2003) (see below).

The genes encoding enzyme I and HPr, ptsI and $p t s H$, are present in all mollicutes except $U$. urealyticum and $P$. asteris. This is in good agreement with the lack of PTS permeases in these species. In the firmicutes (including the mollicutes) HPr cannot only be phosphorylated by enzyme I, but is also the target of a regulatory phosphorylation by a metabolite-activated protein kinase, HPrK. The gene encoding this kinase is present in all mollicutes that possess a PTS with the exception of M. hyopneumoniae and M. synoviae. Interestingly, there is a gene encoding HPrK and an HPr homolog in U. urealyticum. The latter lacks the site of phosphorylation by enzyme I (His-15) but contains the Ser-46 that is subject to HPrKdependent phosphorylation. A similar protein was also found in the genome of Bacillus subtilis where the encoded protein has exclusively regulatory functions (Galinier et al., 1997). Acholeplasma laidlawii possesses the general PTS components and HPrK, but no sugarspecific permeases suggesting that the PTS is restricted to regulatory functions in this organism (Hoischen et al., 1993).

The phosphorylation of HPr on Ser-46 in the firmicutes leads to carbon catabolite repression. So far, the function of HPrK and of ATP-dependent phosphorylation of HPr have not been 
studied in the mollicutes due to the lack of appropriate mutant strains. In contrast, much work has been devoted to the biochemical characterization of HPrK from M. pneumoniae. Unlike its equivalent from other firmicutes but similar to the pathogen Treponema denticola, this protein is active at very low ATP concentrations and requires glycerol for in vivo activity (Gonzalez et al., 2005; Halbedel et al., 2004; Steinhauer et al., 2002a). As the related proteins, it contains an essential Walker motif for ATP binding. Mutations in this region severely affected both the kinase and the phosphatase activities of the protein (Steinhauer et al., 2002a). Fluorescence studies revealed that the $M$. pneumoniae HPrK has a significant higher affinity for ATP than any other HPrK studied so far. This may explain that it is active even at low ATP concentrations (Merzbacher et al., 2004). The M. pneumoniae HPrK was crystallized and its structure determined. As observed for homologous proteins, it forms a hexamer with the $\mathrm{C}$-terminal domains in the active center. The structures do not give any hints related to the different affinities of the HPrK proteins for ATP (Allen et al., 2003; Nessler et al., 2003). Another feature that distinguishes HPr phosphorylation in $M$. pneumoniae from that in other firmicutes is the high proportion of doubly phosphorylated $\mathrm{HPr}(\mathrm{His} \sim \mathrm{P})($ Ser-P). This HPr species is not formed in the latter bacteria, due to the mutual exclusivity of the two phosphorylation events (Deutscher et al., 1984; Reizer et al., 1998). In M. pneumoniae, both enzymes that phosphorylate HPr have a relaxed specificity, i. e. they phosphorylate both HPr and, to a lesser extent, HPr-P (Halbedel and Stülke, 2005). 


\section{B. Tools for the genetic analysis of Mycoplasma}

This chapter was submitted for publication in:

Halbedel, S., and J. Stülke. Tools for the genetic analysis of Mycoplasma. Int. J. Med. Microbiol., submitted.

Author contributions:

This review was written by SH and JS. 


\begin{abstract}
Although the mycoplasmas have attracted much scientific attention due to the fact that they contain the smallest genomes of any independently viable bacterial species, the detailed genetic analysis of these bacteria has lagged behind the well-analyzed bacterial model organims for a long time. This is caused one the one hand by the use of the UGA codon to code for tryptophan instead as the opal stop codon which had often prevented the expression of full length Mycoplasma genes in heterologous hosts. On the other hand, insufficient efficiency of homologous recombination prevented the targeted disruption of genes in some Mycoplasma species. Only recently, smart screening sytems for the use of transposon based mutagenesis have been developed to circumvent this problem and to allow the targeted isolation of desired transposon insertion mutants. With the availability of several Mycoplasma genome sequences artificial plasmids based on the chromosomal origin of replication were constructed that can now be used for complementation studies and for the stable introduction of foreign genetic material. In this review, we give an overview on recent developments in Mycoplasma genetics that facilitate the genetic manipulation of these interesting organisms.
\end{abstract}

\title{
Introduction
}

The mycoplasmas are cell wall-less bacteria characterized by their extremely reduced genomes. Besides the lack of a cell wall biosynthesis apparatus, mycoplasmas have lost a huge portion of the metabolic and regulatory capacities of an average Gram positive bacterium, thus leaving genomes ranging in size from $580 \mathrm{~kb}$ (Mycoplasma genitalium) to $1358 \mathrm{~kb}$ (Mycoplasma penetrans) (Fraser et al., 1995; Sasaki et al., 2002). This feature made the mycoplasmas a suitable research object for the determination of the minimal gene set required for independent life and prompted attempts to create an artificial cell that is modelled based on the paradigm of M. genitalium devoid of all non-essential genes (Check, 2002; Glass et al., 2006). Since the genes for the tricarboxylic acid cycle and a functional respiration chain have been lost from their genomes, energy conservation is restricted to substrate level phosphorylation via glycolysis and, in some species, arginine hydrolysis (for review see Miles, 1992). As observed for the pathways of the central metabolism, only those regulatory systems have been maintained in mycoplasmas during their reductive evolution that are thought to be indispensable to survive in their natural environment. Among the very few remaining regulators are the heat shock transcription factor $\mathrm{HrcA}$ and the metabolite controlled HPr kinase/phosphorylase of the phosphoenolpyruvate:sugar phosphotransferase system. The two systems are involved in the regulation of heat shock gene expression and in 
the regulated modification of the signal transduction protein HPr, respectively (Weiner et al., 2003; Halbedel et al., 2004; Madsen et al., 2006; Musatovova et al., 2006). As another logical consequence of the reduced coding capacity, rather unrelated enzymatic activities were found to be combined in single enzymes as it was shown for some glycolytic kinases that had acquired nucleoside diphosphate kinase activity to function also in nucleotide metabolism (Pollack et al., 2002).

Beside these interesting peculiarities, the mycoplasmas are pathogens that cause health problems in humans and animals. The human pathogen $M$. pneumoniae colonizes the surfaces of the respiratory tract leading to rather uncomplicated and mild infections especially in young and elder patients (Jacobs, 1997). In contrast, M. mycoides subsp. mycoides small colony variant is the etiological agent of contagious bovine pleuropneumoniae and can cause severe infections leading to major losses in african livestocks of cattle (Thiaucourt et al., 2003). The pathogenicity of several Mycoplasma species was attributed to the production of hydrogen peroxide during normal cell metabolism that causes harm to host tissues by oxidative damage (Almagor et al., 1984; Pilo et al., 2005). To persistently colonize their hosts, mycoplasmas have developed a set of surface exposed adhesins that may undergo phase and size variation to efficiently evade the hosts immune system (for review see Razin, 1999). The detailed genetic analysis of these organims has been hampered for a long time by the lack of genetic tools that (i) allow the efficient expression of UGA containing Mycoplasma genes in heterologous hosts for purification and subsequent biochemical analysis, (ii) that allow the stable introduction of foreign genetic material into a Mycoplasma cell, and (iii) that allow either the targeted construction or the targeted isolation of desired mutant strains.

During the last few years considerable progress has been made in the field of Mycoplasma genetics that made these organims accessible for genetic studies. Here, we will give a compact overview on the tools of mycoplasmal genetics that have long been used and those ones that have recently been developed. Although similar advances have been made in the genetics of spiroplasmas, this subject is outside the scope of this review and for a first impression the reader is referred to the excellent review of Bové et al. (2003).

\section{Heterologous expression of Mycoplasma genes containing UGA codons}

Until the end of the 1970's the genetic code was considered to be universal. With the discovery that UGA codons are used to incorporate tryptophan rather than as opal codons in yeast mitochondria and later in the mycoplasmas as well, this dogma had to be abandoned (Macino et al., 1979; Yamao et al., 1985). This peculiar characteristic of the genetic code was 
thought to be the result of an optimization process of the codon usage in response to the low genomic G/C content. In a first step the UGA opal codon was not longer used leaving UAA to serve as the stop codon of choice besides UAG that occurs with a minor frequency in $M$. pneumoniae (Himmelreich et al., 1996). Secondly, the UGG tryptophan codon was sequentially replaced by the released UGA codon to further optimize the G/C content (Jukes et al., 1987). However, the occurrence of UGA codons in Mycoplasma genes has often prevented their expression in heterologous hosts for detailed biochemical analysis since they are read as opal codons instead of tryptophan codons in Escherichia coli and other expression hosts. To circumvent this problem a variety of different but rather dissatisfying strategies had been employed, including the expression of UGA containing Mycoplasma genes in opal suppressor strains of E. coli (Smiley \& Minion, 1993) or in Spiroplasma citri which also reads the UGA as a tryptophan codon (Stamburski et al., 1991). As long as only few UGA codons are present in a mollicute gene, their sequential replacement by standard site directed mutagenesis strategies might be taken into consideration (Robino et al., 2005). However, the latter approach is time consuming and with an increasing number of UGA codons its increasing expenses make it inappropriate.

Recently, we designed a strategy referred to as multiple mutation reaction (MMR) that allows the simultaneous replacement of multiple UGA codons in a single step reaction (Hames et al., 2005). This strategy is based on the concept of the combined chain reaction (CCR) described by Bi \& Stambrook (1997) where 5' phosphorylated oligonucleotides containing the desired mutations are included in a polymerase chain reaction. During the elongation steps the amplification primers are extended and as the mutation primers are designed to hybridize more strongly to their targets the elongated amplification primers can then be ligated to the $5^{\prime}$ ends of the mutation primer by a thermostable DNA ligase yielding a DNA strand that contains the desired mutation. Using this principle more than one mutation had been introduced simultaneously in ptsG promoter fragments of Bacillus subtilis (Schilling et al., 2004). In fact, we improved this strategy for the simultaneous introduction of up to $9 \mathrm{~A} \rightarrow \mathrm{G}$ transitions to replace 9 UGA codons of the $M$. pneumoniae glpK gene by UGG codons in a single step (Hames et al., 2005). We expect that the number of 9 UGA codons does not mark the upper limit of simultaneous replacements that can be obtained by MMR.

\section{Transposons}

Since many genetic tools the use of which is well-established in model organisms such as $B$. subtilis or E. coli are unavailable for mycoplasmas, transposons are in common use for a 
variety of purposes. In combination with smart screening sytems they were used for the disruption of genes but also as carriers for the introduction of genetic material into the chromosome. For the use in mollicutes the transposons Tn916 and Tn4001 and improved derivatives of them were applied. These transposons have originally been isolated from Enterococcus faecalis and Staphylococcus aureus, respectively, and were shown to have a broad host range (Franke \& Clewell, 1981; Lyon et al., 1984).

The first reports on transposition in mollicutes came from experiments with Mycoplasma pulmonis and Acholeplasma laidlawii for which it was demonstrated that $\operatorname{Tn} 916$ integrates into the chromosome of these organisms (Dybvig \& Cassell, 1987). Later the usability of Tn916 for transformation of various different Mycoplasma species has also been shown (Cao et al., 1994; Voelker \& Dybvig, 1996). Tn916 is a conjugative $18 \mathrm{~kb}$ transposable element that contains the xis-Tn/int-Tn genes for excision/integration followed by the tetM tetracyclin resistance determinant and a set of genes (tra) required for intercellular transfer (Clewell et al., 1995). The ends of Tn916 are made of imperfect inverted repeats identical in 20 out of 26 nucleotides (Clewell et al., 1988). Tn916 does not generate target duplications at its integration site since it tranposes by an excision/integration mechanism that is based on staggered nicks in the donor DNA. Excision from its donor site involves one nick at the transposon end and another one in the complementary strand 6 bp away from the transposon border thereby generating single stranded 6 bp overhangs. Upon excision the transposon religates to form a circular structure with a heteroduplexed $6 \mathrm{bp}$ mismatched so-called coupling sequence. Likewise, a 6 bp mismatched heteroduplex is formed upon religation of the excision site in the donor DNA. This mismatched joint region can become homoduplexed by mismatch repair or replication. Integration of $\mathrm{Tn} 916$ can be regarded as the reversal of the excision process resulting in heteroduplexed $6 \mathrm{bp}$ junctions at the integration site since these sites are only similar but not identical to the coupling sequences and appear to be AT rich. (Scott \& Churchward, 1995; for review see Clewell et al., 1995). Consequently, integration of Tn916 occurs at preferred hot spots making it a less suitable tool for saturating transposon mutageneses (Nelson et al., 1997; Scott et al., 1994). Since Tn916 is a conjugative transposon it can also be introduced in different Mycoplasma species by conjugation with Enterococcus faecalis as the donor (Roberts \& Kenny, 1987; Voelker \& Dybvig, 1996).

Tn4001 in turn is a $4.5 \mathrm{~kb}$ composite transposon consisting of two identical IS256 elements flanking the $a a c-a p h D$ gene conferring gentamicin/kanamycin/tobramycin resistance. $\mathrm{Tn} 4001$ has been used for the transformation of several Mycoplasma species (Lyon et al., 1984; Hedreyda et al., 1993; Mahairas \& Minion, 1989). For integration a staggered cut at the 
acceptor site is made generating $8 \mathrm{bp}$ single stranded overhangs which become double stranded upon integration leading to the typical $8 \mathrm{bp}$ direct repeated target duplications (Byrne et al., 1989, for review see Mahillon \& Chandler, 1998). To increase the stability of transposon insertion mutants, mini-transposons on the basis of $\mathrm{Tn} 4001$ were constructed that have the transposase gene outside the transposable elements to prevent re-excision of the transposon after the first transposition event (Pour-El et al., 2002; Zimmerman \& Herrmann, 2005). For further broadening of the application spectrum of Tn4001 the tetM tetracyclin resistance marker and the cat gene coding for chloramphenicol acetyltransferase, respectively, were introduced in the transposon (Dybvig et al., 2000; Hahn et al., 1999).

Derivatives of $\mathrm{Tn} 4001$ in which unique restriction sites have been introduced can serve as carrier vehicles to incorporate genetic material into the chromosome. In Tn4001mod unique SmaI and BamHI sites were introduced into one of the IS256 insertion sequences (Knudtson \& Minion, 1993), a few more unique restriction sites that can be used for the introduction of a genetic cargo are present in the multiple cloning site of the mini-transposon present on plasmid pMT85 (Zimmerman \& Herrmann, 2005).

\section{Plasmids}

The use of tranposons is accompanied by the problem of changes of the genetic context at the site of integration that may cause incalculable side effects. To avoid this problem, autonomously replicating plasmids have always been the vehicle of choice. In a few early studies the isolation of naturally occuring plasmids from Mycoplasma mycoides subsp. mycoides was reported (Bergemann \& Finch, 1988; Dybvig \& Khaled, 1990). These are small cryptic plasmids with a size in the range of $1.7-1.9 \mathrm{~kb}$ coding for replication functions only (Bergemann et al., 1989; King \& Dybvig, 1992). Based on one of these plamids, pKMK1, two cloning vectors that can be shuttled between Escherichia coli and M. mycoides were developed by combination of pKMK1 with plasmids containing E. coli replicons and the tetM tetracyclin resistance determinant. For one of these vectors, the E. coli origin of replication was lost from the plasmid after a passage in M. mycoides. However, a derivative of the resulting plasmid (pIK $\Delta$ ) that contains an additional erythromycin resistance gene (pIK $\Delta$-erm) can be stably maintained in the presence of selective pressure over a series of passages as an extrachromosomal element making it a suitable tool for the stable introduction of heterologous genetic material into M. mycoides and in other mycoplasmas (King \& Dybvig, 1994a; King \& Dybvig, 1994b). 
The further development of artifical plasmid vectors was stimulated when the first genome sequences became available that allowed the determination of the origins of replication of Mycoplasma chromosomes. Using the chromosomal oriC sequence of $M$. pulmonis containing the dnaA gene coding for the DnaA replication initiation protein and up- and downstream located DnaA box regions Cordova et al. (2002) constructed the shuttle vector pMPO1. This plasmid can replicate in M. pulmonis at least for several passages and can be used for cloning in E. coli. After several rounds of passaging the plasmid tends to integrate into the $M$. pulmonis chromosome at the chromosomal oriC site via homologous recombination. In order to increase the stability of oriC plasmids, the $d n a A$ gene was removed from the $o r i C$ region of the plasmid and replaced by the tetM gene to reduce the extent of identity between the chromosomally encoded oriC and the origin of replication on the plasmid. With this plasmid (pMPO5) M. pulmonis can readily be transformed and more importantly, no integration of the plasmid into the chromosome was observed at least until the $15^{\text {th }}$ broth passage (Cordova et al., 2002). Similarily, plasmid replicons have been constructed that contain the oriC sequences from $M$. mycoides subsp. mycoides large colony and small colony type, $M$. capricolum subsp. capricolum, and M. agalactiae (Chopra-Dewasthaly et al., 2005; Janis et al., 2005; Lartigue et al., 2003). Again, plasmid maintenance could be improved when the length of the oriC regions present on the plasmids was kept to a minimum hampering integration of the plasmids via homologous recombination (Chopra-Dewasthaly et al., 2005). Remarkably, a certain host-specifity was observed for oriC plasmids of all these species making it difficult to predict the oriC of which Mycoplasma will be compatible for driving plasmid replication in which Mycoplasma host (Lartigue et al., 2003). Nevertheless, with the genome sequence of many mycoplasmas at hand, the construction of stably replicating oriC plasmids for any desired Mycoplasma can be expected for the near future.

\section{Targeted gene knockout}

Until very recently, the targeted construction of gene knockout mutants via homologous recombination has only been reported in a few mollicutes such as M. genitalium, $M$. gallisepticum, M. pulmonis and Acholeplasma laidlawii (Cao et al., 1994; Cordova et al., 2002; Dhandayuthapani et al., 1999; Dybvig \& Woodard, 1992). The obvious lack of homologous recombination in other mollicutes such as $M$. pneumoniae has been thought to be the result of insufficient expression of genes involved in initial recombination and resolution of holliday junctions. Indeed, a global survey of expressed genes in M. pneumoniae suggests that the $\operatorname{ruvAB}$ genes coding for the holliday junction DNA helicase are not expressed. To 
improve the selection of rare homologous recombination events in Mycoplasma capricolum subsp. capricolum, oriC plasmids that can be maintained in the cells over several passages have been used. This approach indeed led to the integration of the plasmids into the chromosome by homologous recombination between the gene fragment cloned on the plasmid and the corresponding site on the chromosome. Once integrated into the chromosome copies of the free plasmid were lost after several passages probably as the result of weakened selection pressure in the presence of a chromosomal copy of the resistance gene (Janis et al., 2005).

Nevertheless, in the absence of homologous recombination the only remaining way to obtain gene knockouts is transposon mutagenesis. Due to the randomness of integration it is usually necessary to screen large transposon mutant libraries for the loss or gain of some specific phenotype to isolate a gene knockout of interest. If no screenable phenotype loss or gain can be expected associated with a gene of interest ( $g \circ i$ ) the only known specific feature of the desired gene knockout is the specific DNA junction between the goi and the transposon. Based on this idea a strategy now referred to as "haystack mutagenesis" has been designed that allows the targeted isolation of any viable transposon insertion strain out of an ordered collection of transposon mutants. The consept of haystack mutagenesis is based on a saturated transposon mutagenesis to ensure that each dispensable gene is disrupted at a desired confidence level. The number of individual transposon mutants $n$ that is needed to have a mutant strain in a gene of interest (size $g$ ) included in a collection of transposants with a minimum probability $P$ can easily be calculated using the following formula:

$$
n=\frac{\log (1-P)}{\log \left(1-\frac{g}{l}\right)}
$$

with $l$ as the non-essential genome size.

Once the required number of transposon mutants has been isolated they are arranged in pools of a reasonable size. These pools then can be searched in a PCR screen using a goi specific oligonucleotide and another one specific for the transposon to identify that pool that has the desired goi-Tn junction included. Subsequently, a similar screen on the level of the individual clones of the positive pool will identify the transposon insertion mutant of interest. Based on the obtained PCR fragment sizes it can easily be estimated in the initial screens already in which part of the goi the transposon had integrated. 


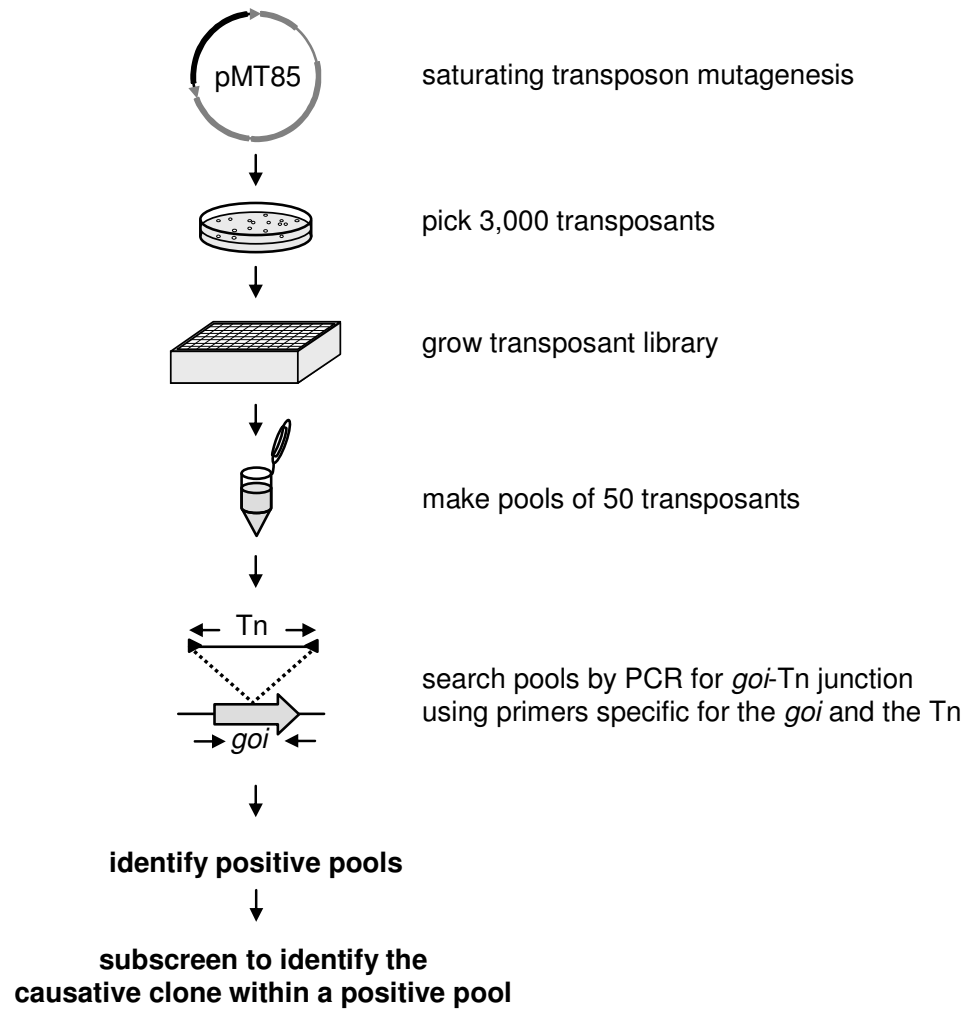

Fig. 2: Illustration of the workflow in a haystack mutagenesis screen. Abbreviations are as follows: Tn - minitransposon, goi - gene of interest. The numbers shown refer to $M$. pneumoniae. They may require alterations with the genome size of the target bacterium. Reference for plasmid pMT85 is Zimmerman \& Herrmann, 2005. For a detailed description see text.

Using this strategy, we have isolated mutants in the hprK gene coding for the HPr kinase/phosphorylase and in the $\operatorname{prpC}$ gene coding for a PP2C protein serine/threonine phosphatase of M. pneumoniae (Halbedel et al., 2006). In the meantime transposon mutants bearing insertions in several other goi's were isolated as well (our unpublished data). The workflow in a haystack mutagenesis screen is depicted in Fig. 2.

Alternative screening approaches for the isolation of transposon mutants in a goi out of a transposon collection are based either on the stepwise identification of single insertion points or the screening of huge numbers of individual transposants for the loss of antigenicity towards a specific antiserum (Janis et al., 2006; Luo et al., 2006). However, these screening methods are both time-comsuming and in the latter case have to be re-adapted for every new goi::Tn insertion mutant. Alternatively, transposon mutant libraries can be screened for mutants that exhibit an interesting phenotype such as loss of gliding motility (Hasselbring et al., 2006).

\section{Reporter sytems}

In the past there has been a couple of studies that have been aimed at the definition of mycoplasmal promoters. Usually, they were based on the determination of transcriptional start 
points using primer extension analysis (Musatovova et al., 2003; Waldo et al., 1999; Weiner et al. 2000). Based on a selection of about 20 experimentally defined promoters Weiner et al. (2000) developed a promoter matrix for the in silico prediction of $M$. pneumoniae promoters. These seem to consist of conserved -10 boxes but lack obvious -35-boxes. Moreover, ribosomal binding sites were not found between the proposed trancriptional start points and the start codons of many $M$. pneumoniae genes. Furthermore, besides such well-established regulatory sytems like the HrcA-mediated heat shock response there is only spare information on regulation of gene expression in mollicutes. This obvious lack of clarity concerning the nature of gene expression/regulation signals in mollicutes can only be answered in experiments that make use of promoter reporter systems. For the analysis of mollicute expression signals, reporter systems based on the promoter-less lacZ gene or on fluorescent proteins have been developed and used. The reporter genes are present either on plasmids or are part of transposable elements.

The first demonstration that the lacZ gene of $E$. coli encoding $\beta$-galactosidase can be functionally expressed in mollicutes came from experiments with Acholeplasma oculi ISM1499 and Mycoplasma gallisepticum (Knudtson \& Minion, 1993). These authors constructed a Tn4001 derivative (Tn4001lac) that is present on plasmid pISM2062lac and has a promoter-less lacZ gene in one of the IS256 elements with its $5^{\prime}$ end in the near vicinity of the transposon boarder. The stop codons that were present in all three reading frames of the IR sequences of the IS256 were mutated to allow inward directed transcription originating from adjacent promoters and the proper expression of translational lacZ fusions. So this transposon can be used for the genome-wide identification of promoter sequences (Knudtson \& Minion, 1993). In addition to this a further Acholeplasma promoter probe vector was developed by the same authors that is based on a promoter-less lacZ gene present on the integrative plasmid vector pISM2050. In front of the lacZ gene multiple restriction sites are located that are available for the construction of translational promoter lacZ fusions (Knudtson \& Minion, 1994). Meanwhile, the lac $Z$ gene has been functionally expressed driven by various mollicute promoters in Mycoplasma gallisepticum, Mycoplasma pulmonis, Mycoplasma arthritidis, and Mycoplasma capricolum as well (Dybvig et al., 2000; Janis et al., 2005; Liu et al., 2000). We developed a plasmid (pGP353) that can be used for the insertion of promoter sequences in front of a promoter-less lac $Z$ gene which is present on a mini-tranpsoson thus giving single and stable insertions. pGP353 was shown to be useful for reporter gene analysis in $M$. pneumoniae and can be expected to be suitable for similar experiments in other mollicutes as well (Halbedel \& Stülke, 2006). 
As it was done with the lacZ gene for the analysis of promoter activities, variants of the green fluorescent proteins were used to measure expression and/or localization of certain fusion constructs. However, in all reported cases the respective fluorescent fusions were constructed in standard cloning vectors and subsequently transferred to certain Mycoplasma transposon delivery vectors (Balish et al., 2003; Kenri et al., 2004; Zimmerman \& Herrmann, 2005). Therefore, at the moment there is no plasmid available that can be used to construct and to incorporate GFP fusions into Mycoplasma species.

\section{Conclusions}

At present all required tools for the application of standard genetics to mycoplasmas are available. The biochemical in vitro analysis of individual proteins is not longer hampered by the peculiar genetic code of these organisms. Thus, proteins with properties that make them interesting research objects from a scientific point of view or let them appear as possible drug targets can be easily studied. Similarily, antigenic surface proteins which are often high molecular weight proteins and thus contain a lot of UGA codons can now easily be produced in heterologous hosts in sufficient amounts to be tested as vaccine candidates. By use of the existing reporter sytems it is possible to refine the mycoplasmal promoter concepts, to discover regulatory DNA sequences and, consequently, to unravel those signal transduction mechanisms that mediate the adaptive responses seen in a wide variety of DNA microarray analyses but that are not yet entirely understood at the molecular level (Madsen et al., 2006; Weiner et al., 2003). To confirm in vitro findings with purified proteins also genetically, targeted disruption of desired genes can presently be carried out in various representatives of the genus Mycoplasma either by homologous recombination or by facilitated screening methods such as haystack mutagenesis that should be applicable to any bacterium that is deficient in homologous recombination but can be subjected to transposon mutagenesis. Finally, gene function can precisely be confirmed by trans-complementation of mutants on the basis of oriC plasmids. It is therefore very exciting to notice the future development of Mycoplasma molecular biology. 


\section{Aims of this work}

For sensing the presence or absence of readily metabolizable carbon sources and for the induction of an adequate gene expression program, bacteria use a signalling pathway known as carbon catabolite regulation. In the firmicutes this involves the metabolite controlled $\mathrm{HPr}$ kinase/phosphorylase (HPrK/P) that phosphorylates the small phosphocarrier protein HPr at a serine residue (Ser-46) under conditions of good energy supply. The serine phosphorylated HPr then interacts with the pleiotropic transcription factor CcpA to form a complex that binds to operator sites of different promoters leading to the activation or repression of respective target genes.

An HPr kinase/phosphorylase is also encoded in the genome sequence of the mollicute Mycoplasma pneumoniae. The HPrK/P of M. pneumoniae is functional in terms of phosphorylation/dephosphorylation of $\mathrm{HPr}$ at the Ser-46 residue. However, its pattern of allosteric control suggested that the protein acts as a constitutive HPr kinase in vivo (Steinhauer et al., 2002a). This finding was attributed to the low $\mathrm{K}_{\mathrm{D}}$ value of the HPrK/P for ATP (Merzbacher et al., 2004). Interestingly, no ccpA-homologous gene was found in the genome sequence of $M$. pneumoniae, raising the question for what purpose the HPrK/P had been retained in this organism.

In order to further characterize the function of the HPrK/P in M. pneumoniae it was therefore intended to analyze its in vivo activity profile. As a prerequisite for these experiments, different growth conditions that might be important for M. pneumoniae in its natural habitate were to be defined. Based on this information, conditions under which $\mathrm{HPr}(\operatorname{Ser}-\mathrm{P})$ is formed in vivo had to be determined. To analyze the impact of the HPrK/P on the global gene expression profile, a $h p r K$ knockout strain had either to be constructed or isolated. Since no techniques that allow the targeted disruption of genes of $M$. pneumoniae were known, a system suitable for the construction/isolation of any predetermined gene knockout mutant had to be designed and to be established first. Once isolated, the $h p r K$ mutant should be analyzed using two-dimensional polyacrylamide gel electrophoresis to identify genes that are expressed in a $h p r K$-dependent manner.

In a second part of this $\mathrm{PhD}$ project such genes with a carbon-source dependent expression were to be identified. The more detailed transcriptional analysis of candidates should provide the basis for a better understanding of regulatory mechanisms of gene expression in $M$. pneumoniae, which lacks the most of the well-established regulatory systems. 


\section{Chapter 2:}

In vivo activity of enzymatic and regulatory components of the phosphoenolpyruvate:sugar phosphotransferase system in Mycoplasma pneumoniae

The work described in this chapter was published in:

Halbedel, S., C. Hames, and J. Stülke. 2004. In vivo activity of enzymatic and regulatory components of the phosphoenolpyruvate:sugar phosphotransferase system in Mycoplasma pneumoniae. J Bacteriol 186: 7936-7943.

Author contributions:

This study was designed by SH and JS. SH performed and interpreted all experiments. $\mathrm{CH}$ contributed to the Northern blot analysis of the $p t s H$ gene in a practical training under the supervision of SH. JS and SH wrote the paper. 


\begin{abstract}
Mycoplasma pneumoniae is a pathogenic bacterium that is highly adapted to life on mucosal surfaces. This adaptation is reflected by the very compact genome and the small number of regulatory proteins. However, M. pneumoniae possesses the HPr kinase/phosphorylase (HPrK/P), the key regulator of carbon metabolism in the Firmicutes. In contrast to the enzymes of other bacteria, the HPrK/P of $M$. pneumoniae is active already at very low ATP concentrations suggesting a different mode of regulation. In this work we studied the ability of $M$. pneumoniae to utilize different carbohydrates and their effects on the activity of the different PTS components. Glucose served as the best carbon source with a generation time of about 30 hours. Fructose and glycerol were also used, but at lower rates and with lower yields. In contrast, M. pneumoniae is unable to use mannitol even though the bacterium is apparently equipped with all the genes required for mannitol catabolism. This observation is probably a reflection of the continuing and ongoing reduction of the M. pneumoniae genome. The general enzymatic and regulatory components of the PTS, i. e. Enzyme I, HPr, and HPrK/P are present under all growth conditions tested in this study. However, HPrK/P activity is strongly increased if the medium contains glycerol. Thus, the control of HPrK/P in vivo differs strongly between M. pneumoniae and the other Firmicutes. This may relate to the specific conditions on lipid-rich cell surfaces.
\end{abstract}

\title{
Introduction
}

Mycoplasma pneumoniae is a pathogen that lives on mucosal surfaces and causes diseases such as mild pneumonia, tracheobronchitis, and complications affecting the central nervous system, the skin and mucosal surfaces (Jacobs, 1997; Lind, 1983). The parasitic lifestyle of this bacterium is reflected by its small and highly compacted genome, its slow growth and its reduced metabolic abilities. With only nine regulatory proteins, $M$. pneumoniae belongs to the organisms with the lowest number of regulators studied so far, suggesting a good adaptation to constant environments (Dandekar et al., 2000; Himmelreich et al., 1996; Razin et al., 1998). In addition to regulatory proteins that are thought to act at the DNA level, we identified the key regulatory protein of carbon metabolism in Gram-positive bacteria, HPr kinase/phosphorylase (HPrK/P) in M. pneumoniae (Nessler et al., 2003; Steinhauer et al., 2002a). Moreover, HPrK/P activity was detected in other Mollicutes such as M. capricolum, M. genitalium and Acholeplasma laidlawii (Hoischen et al., 1993; Zhu et al., 1997).

HPrK/P controls the activity of the HPr protein of the bacterial phosphoenolpyruvate:sugar phosphotransferase system by phosphorylation at a regulatory site, Ser-46. In the Gram- 
positive model organism B. subtilis this phosphorylation interferes with the PEP- and Enzyme I-dependent phosphorylation on His-15 of HPr, which is important for the phosphorylation of transported sugars (Galinier et al., 1998; Reizer et al., 1998). In addition to its role in sugar transport, HPr is the major signal transducer in carbon metabolism in low-GC Gram-positive bacteria (now referred to as Firmicutes, Ludwig et al., 2002). In the absence of glucose, HPr is present either non-phosphorylated or phosphorylated at His-15. If glucose becomes available, a significant part of the cellular HPr pool is phosphorylated on Ser-46, and even some doubly phosphorylated $\operatorname{HPr}(\operatorname{His} \sim \mathrm{P})(\operatorname{Ser}-\mathrm{P})$ was detected (Ludwig et al., 2003; Monedero et al., 2001b; for review see Stülke \& Schmalisch, 2004). HPr(His P) is implicated in sugar transport and is moreover required for the activation of a class of transcription factors and of glycerol kinase in several bacteria (Darbon et al., 2002; Stülke et al., 1998). In contrast, $\mathrm{HPr}(\mathrm{Ser}-\mathrm{P})$ is not able to phosphorylate and thereby activate those enzymes and regulators, but acts rather as a cofactor for the transcription regulator CcpA. The CcpA$\mathrm{HPr}($ Ser-P) complex binds to target sequences in the promoter regions of catabolic and certain anabolic operons to repress or activate their transcription (Deutscher et al., 1995; Ludwig \& Klenk, 2001; Warner \& Lolkema, 2003). Thus, HPrK/P controls the phosphorylation state of HPr and thereby the regulatory activity of this protein. It is therefore crucial to study the activity of HPrK/P itself. In B. subtilis, the enzyme is active as a kinase under conditions of good nutrient supply which are indicated by high ATP and fructose-1,6bisphosphate concentrations. In contrast, phosphorylase activity is triggered by high concentrations of inorganic phosphate, which indicate the absence of good carbon sources (Galinier et al., 1998; Hanson et al., 2002; Jault et al., 2000; Mason et al., 1981; Reizer et al., 1998).

As stated above, several metabolic and regulatory features of the Mollicutes are in good agreement with their adaptation to their nutrient-rich mucosal habitats. This was also observed when we investigated the properties of $M$. pneumoniae $\mathrm{HPrK} / \mathrm{P}$. While the $B$. subtilis enzyme exhibits by default a phosphorylase activity, the M. pneumoniae protein is active as a kinase already at very low ATP concentrations and is barely regulated by fructose1,6-bisphosphate (Hanson et al., 2002; Steinhauer et al., 2002a). These differences were attributed to the different affinities of B. subtilis and M. pneumoniae HPrK/P for ATP. While the former has a $\mathrm{Kd}$ value of about $100 \ldots 300 \mu \mathrm{M}$, the latter has a $\mathrm{Kd}$ value of about $5 \mu \mathrm{M}$, indicating an at least 20-fold increased affinity (Jault et al., 2000; Merzbacher et al., 2004; Pompeo et al., 2003). The high affinity of M. pneumoniae HPrK/P for ATP results in a kinase activity as the apparent default state of this protein in vitro (Steinhauer et al., 2002a). Since 
the $M$. pneumoniae HPrK/P is the only known enzyme of its class with the inversed default activity, we wondered whether the abberant regulation was reflected by the structure of the protein. The determination of the crystal structure revealed that the enzyme is composed of six identical subunits that are arranged as bilayered trimers. Each subunit is made up of a Cterminal domain that contains the ATP-binding P-loop motif and an N-terminal domain of so far unknown function (Allen et al., 2003; Steinhauer et al., 2002b). The structure of the $M$. pneumoniae HPrK/P is very similar to those of HPrK/Ps from Lactobacillus casei and Staphylococcus xylosus suggesting that subtle differences must be responsible for the differential activity patterns (Fieulaine et al., 2003; Márquez et al., 2002; Nessler et al., 2003). Although HPrK/P is one of the very few regulatory proteins of $M$. pneumoniae, it is not essential as revealed by an analysis of randomly generated transposon mutants (Hutchison et al., 1999).

According to the genome sequence of $M$. pneumoniae and the biochemical evidence, these bacteria are able to utilize sugars as carbon sources by glycolysis (Dandekar et al., 2000; Himmelreich et al., 1996; Miles, 1992). As observed for other Firmicutes, the concentration of fructose-1,6-bisphosphate is increased in glycolytically active cells of M. gallisepticum (Egan et al., 1986; Mason et al., 1981). Moreover, enzymes of carbon metabolism seem to be important for other metabolic pathways as well. This is illustrated by the finding that the glycolytic kinases of several Mollicutes are moonlighting in nucleoside metabolism (Pollack et al., 2002).

So far, only very few studies concerning the regulation of carbon metabolism in Mollicutes have been reported. However, this problem is important not only for a better understanding of the biology of these interesting bacteria but also to improve our knowledge of virulence mechanisms of the Mycoplasmas: Recently, the implication of proteins of the phosphotransferase system in M. pneumoniae pathogenicity was demonstrated (Zigangirova et al., 2003). While the regulatory output of the PTS is well understood in E. coli and in the Firmicutes related to $B$. subtilis, nothing is known about regulatory pathways in $M$. pneumoniae. Among the proteins interacting with the different forms of HPr in B. subtilis, only the glycerol kinase is present in

M. pneumoniae, whereas transcription regulators potentially phosphorylated by $\mathrm{HPr}(\mathrm{His} \sim \mathrm{P})$ are not found. Similarly, the transcription factor CcpA that interacts with $\mathrm{HPr}(\mathrm{Ser}-\mathrm{P})$ has no counterpart in the Mollicutes (Himmelreich et al., 1997). Thus, the mechanisms of carbon regulation, if present, must differ drastically from those studied in B. subtilis and its close relatives. 
In this work, we studied the utilization of different carbohydrates by $M$. pneumoniae and found that glucose was the carbon source allowing the fastest growth. To address the relevance of the results obtained with $M$. pneumoniae HPrK/P in vitro, we analyzed the HPr phosphorylation state in vivo. Surprisingly, the enzyme did not exhibit constitutive kinase activity but required the presence of glycerol for HPr phosphorylation. The proteins acting on HPr, i. e. Enzyme I of the PTS and HPrK/P were constitutively present in cell extracts of $M$. pneumoniae. Thus, a novel mode of control seems to modulate the M. pneumoniae HPrK/P activity.

\section{Materials and Methods}

Bacterial strains and growth conditions. Escherichia coli DH5 $\alpha$ and BL21(DE3)/pLysS (Sambrook et al., 1989) were used for overexpression of recombinant proteins. The cells were grown in LB medium containing ampicillin $\left(100 \mu \mathrm{g} \mathrm{ml}^{-1}\right)$. The $M$. pneumoniae strain used in this study was $M$. pneumoniae M129 (ATCC 29342) in the $31^{\text {st }}$ broth passage. $M$. pneumoniae was grown at $37^{\circ} \mathrm{C}$ in $150 \mathrm{~cm}^{2}$ tissue culture flasks containing $100 \mathrm{ml}$ of modified Hayflick medium with the following composition. The basic medium consists of $18.4 \mathrm{~g}$ PPLO broth (Difco), $29.8 \mathrm{~g}$ HEPES, $5 \mathrm{ml}$ 0.5\% phenol red and $35 \mathrm{ml} 2 \mathrm{~N} \mathrm{NaOH}$ per litre. Horse serum (Gibco) and penicillin were included to a final concentration of $20 \%$ and $1000 \mathrm{u} / \mathrm{ml}$, respectively. Carbon sources were added as indicated. For each sugar, several individual culture flasks were inoculated with a biomass of $5 \mathrm{mg}$ (wet weight), and one flask for each condition was harvested at the indicated timepoints and used to determine the fresh weight. For wet weight measurements, cells were washed twice with cold phosphate buffered saline (PBS), scraped into $1.5 \mathrm{ml} \mathrm{PBS}$ and collected by centrifugation (5 min, $15000 \mathrm{~g}, 4^{\circ} \mathrm{C}$ ) in a $2.0 \mathrm{ml}$ microcentrifuge tube. Supernatants were discarded and the pellets were recentrifuged to get rid of all excess liquid. The wet weight of the obtained cell pellet was determined by subtraction of the weight of the tube containing the pellet from that of the empty tube prior to cell collection.

Protein purification. His 6 -HPr (M. pneumoniae), His 6 -Enzyme I (B. subtilis), and StrepHPrK/P (M. pneumoniae) were overexpressed using the expression plasmids pGP217 (Steinhauer et al., 2002a), pAG3 (Galinier et al., 1997), and pGP611 (Merzbacher et al., 2004), respectively. Expression was induced by the addition of IPTG (final concentration 1 $\mathrm{mM})$ to exponentially growing cultures $\left(\mathrm{OD}_{600}\right.$ of 0.8$)$. Cells were lysed using a french press. After lysis the crude extracts were centrifuged at 15,000 $\mathrm{g}$ for $30 \mathrm{~min}$. For purification of Histagged proteins the resulting supernatants were passed over a $\mathrm{Ni}^{2+} \mathrm{NTA}$ superflow column $(5$ 
$\mathrm{ml}$ bed volume, Qiagen) followed by elution with an imidazole gradient (from 0 to $500 \mathrm{mM}$ imidazole in a buffer containing $10 \mathrm{mM}$ Tris/ $\mathrm{HCl} \mathrm{pH} 7.5,600 \mathrm{mM} \mathrm{NaCl}, 10 \mathrm{mM} \beta$ mercaptoethanol). For HPrK/P carrying a N-terminal Strep-tag, the crude extract was passed over a Streptactin column (IBA, Göttingen, Germany). The recombinant protein was eluted with desthiobiotin (Sigma, final concentration $2.5 \mathrm{mM}$ ). For the recombinant HPr protein the overproduced protein was purified from the pellet fraction of the lysate by urea extraction and renatured as described previously (Steinhauer et al., 2002a).

After elution the fractions were tested for the desired protein using 12.5\% SDS PAGE. The relevant fractions were combined and dialysed overnight. Protein concentration was determined according to the method of Bradford (Bradford, 1976) using the Bio-rad dyebinding assay where Bovine serum albumin served as the standard.

Western blot analysis. Purified $\mathrm{His}_{6}-\mathrm{HPr}$ was used to generate rabbit polyclonal antibodies (SeqLab, Göttingen). For Western blot analysis, M. pneumoniae crude cell extracts were separated on $12.5 \%$ SDS polyacrylamide gels. After electrophoresis, the proteins were transferred to a polyvinylidene difluoride membrane (PVDF, BioRad) by electroblotting. HPr was detected with polyclonal antibodies raised against $\mathrm{HPr}$ of $M$. pneunomiae. Antibodies were visualized by using anti-rabbit IgG-AP secondary antibodies (Promega) and the CDP* detection system (Roche Diagnostics).

In vivo HPr phosphorylation was assayed by Western blot analysis as follows. Bacteria were cultivated for 96 h. Cells were washed twice with cold PBS and harvested as described for wet weight measurements. Subsequently, cells were resuspended in $500 \mu$ l of a solution containing $10 \mathrm{mM}$ Tris/ $\mathrm{HCl} \mathrm{pH} 7.5$ and $600 \mathrm{mM} \mathrm{NaCl}$ and disrupted using sonication $(3 \mathrm{x} 10$ sec, $\left.4^{\circ} \mathrm{C}, 50 \mathrm{~W}\right)$. Cell debris was pelleted by centrifugation $\left(10 \mathrm{~min}, 15000 \mathrm{~g}, 4^{\circ} \mathrm{C}\right)$ and the obtained supernatant served as crude extract. Proteins were separated on non-denaturing 10\% polyacrylamide gels. On these gels, phosphorylated HPr migrates faster than the nonphosphorylated protein. $\operatorname{HPr}(\mathrm{His} \sim \mathrm{P})$ was dephosphorylated by incubation of the crude extract for $10 \mathrm{~min}$ at $70^{\circ} \mathrm{C}$. After electrophoresis, the proteins were blotted onto a PVDF membrane. The different forms of HPr were detected using antibodies directed against M. pneunomiae HPr.

In vitro activity assays of HPrK/P and of Enzyme I. HPrK/P activity assays were carried out with $5 \mu \mathrm{g}$ of freshly prepared cell extracts in $20 \mu \mathrm{l}$ assay buffer $(25 \mathrm{mM}$ Tris/ $\mathrm{HCl} \mathrm{pH} 7.5$, $10 \mathrm{mM} \mathrm{MgCl} 2,1 \mathrm{mM}$ dithiothreitol) using purified His ${ }_{6}-\mathrm{HPr}$ (final concentration: $20 \mu \mathrm{M}$ ). The concentration of ATP was $0.5 \mathrm{mM}$. The assays mixtures were incubated at $37^{\circ} \mathrm{C}$ for 120 min followed by thermal inactivation of the enzyme $\left(10 \mathrm{~min}\right.$ at $\left.95^{\circ} \mathrm{C}\right)$. 
For detection of Enzyme I contained in mycoplasmal cell extracts His $_{6}-\mathrm{HPr}(20 \mu \mathrm{M})$, PEP $(0.5 \mathrm{mM})$ and $1 \mu \mathrm{g}$ cell extract were incubated in $20 \mu \mathrm{l}$ assay buffer for $30 \mathrm{~min}$ at $37^{\circ} \mathrm{C}$. When indicated the assay mixture was subjected to an additional incubation step at $70^{\circ} \mathrm{C}$ for $10 \mathrm{~min}$ to hydrolyze $\operatorname{HPr}(\mathrm{His} \sim \mathrm{P})$. The assay mixtures were analyzed on $10 \%$ native polyacrylamide gels as described previously (Hanson et al., 2002). Proteins were visualized by Coomassie staining.

Northern blot analysis. Preparation of total RNA of $M$. pneumoniae was carried out as described by Weiner et al. (2003). Northern blot analysis was performed according to the protocol of Wetzstein et al. (1992). The ptsH Digoxigenin RNA probe was obtained by in vitro transcription with T7 RNA polymerase (Roche Diagnostics) using a PCR-generated fragment obtained with the primer pair SH1 AGAAGATTCAAGTAGTCGTTAAAG)/SH2 CTAATACGACTCACTATAGGGAGATGCTTTAATAGCATTTAGTGCCTC). The reverse primer contained a T7 RNA polymerase recognition sequence (underlined in SH2). In vitro RNA labelling, hybridisation and signal detection were carried out according to the manufacturer's instructions (DIG RNA labeling Kit and detection chemicals; Roche Diagnostics).

\section{Results}

Utilization of different carbon sources by M. pneumoniae. The inspection of the genome sequence of $M$. pneumoniae suggested that the bacteria are able to transport and utilize glucose, fructose, mannitol, and glycerol as sources of carbon and energy. The genes encoding the general components of the PTS, ptsI and ptsH, are present as well as the genes for permeases specific for glucose, fructose, and mannitol. The glucose and fructose permeases are three-domain enzymes with the domain order $\mathrm{CBA}$ and $\mathrm{ABC}$, respectively. In contrast, the putative mannitol permease is composed of a $\mathrm{CB}$ and a separate A protein encoded by $m t l A$ and $m t l F$, respectively. The GlpF protein is a glycerol facilitator. Moreover, M. pneumoniae possesses the enzymes to convert the primary phosphorylation products to intermediates of glycolysis (Dandekar et al., 2000; Himmelreich et al., 1996; see Fig. 3). Since the growth properties of $M$. pneumoniae in the presence of different carbon sources have not been studied previously, we decided to analyse whether M. pneumoniae can use these carbon sources. 


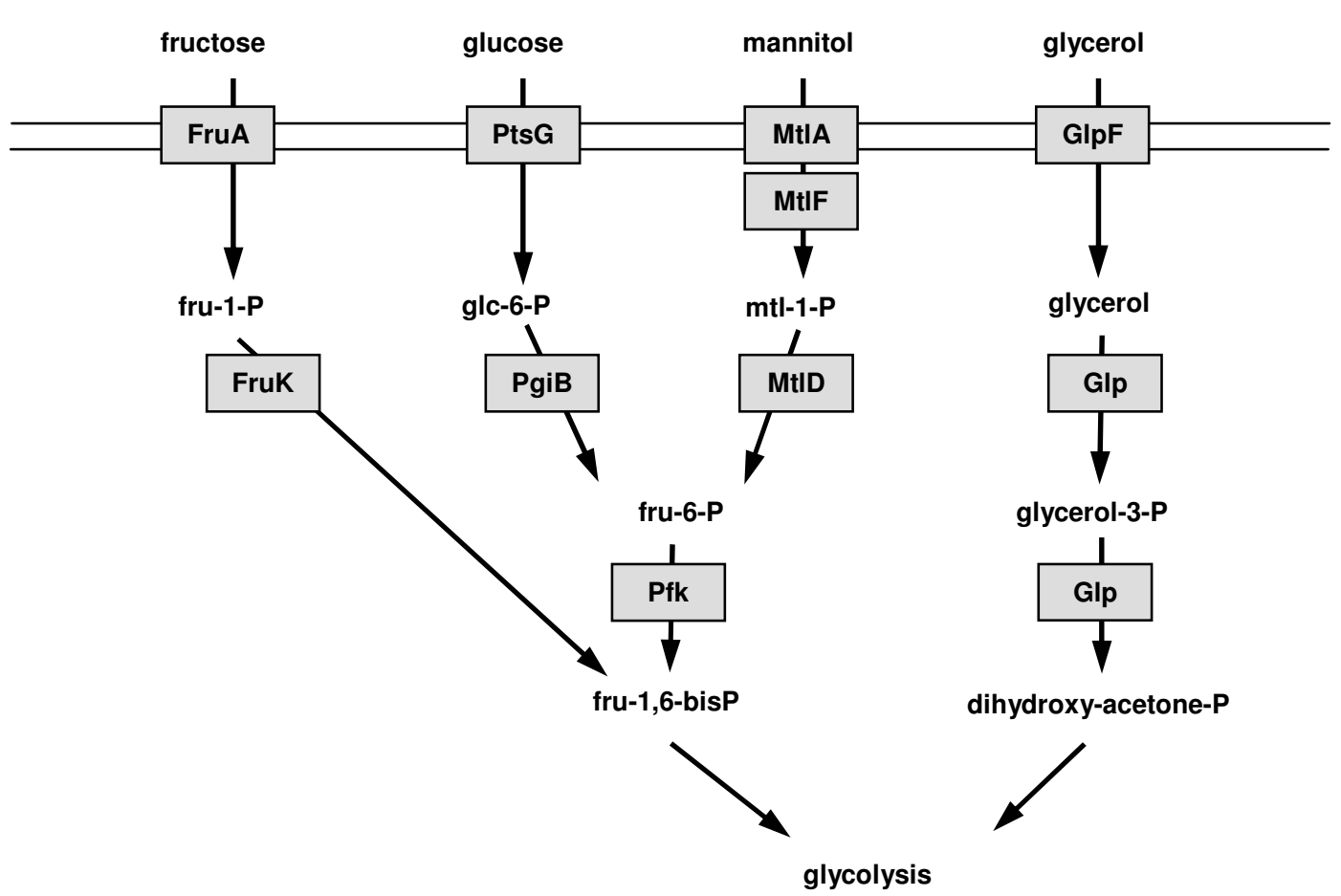

Fig. 3: Systems for the uptake and catabolism of carbohydrates in $M$. pneumoniae as predicted from the genome sequence (Himmelreich et al., 1996). FruA (MPN078) is the EIIABC component specific for fructose, and PtsG (MPN207) the EIICBA component for the uptake of glucose. MtlA (MPN651) and MtlF (MPN653) are the putative EIIBC and EIIA proteins for the transport of mannitol, whereas GlpF (MPN043) is the glycerol uptake facilitator. The glucose-6-phosphate isomerase PgiB (MPN250) and phosphofructokinase Pfk (MPN302) transform glucose-6-phosphate to fructose-1,6-bisphosphate. The 1-phosphofructokinase FruK (MPN079) and the mannitol-1-phosphate dehydrogenase MtID (MPN652) are necessary for the conversion of fructose and mannitol to intermediates of glycolysis. The glycerol kinase GlpK (MPN050) and the glycerol-3-phosphate dehydrogenase GlpD (MPN051) metabolize glycerol to dihydroxyacetone phosphate.

Precultures were obtained with modified Hayflick medium supplemented with glucose. Cells isolated from these cultures were used to inoculate fresh medium containing the different carbon sources. A culture without added sugar served as a control. As shown in Fig. 4, only slight initial growth resulting from residual glucose was observed in the control culture, and growth ceased after two days of incubation. In contrast, cultures incubated in the presence of glucose immediately started to grow and growth continued until a biomass of about $50 \mathrm{mg}$ wet weight per $100 \mathrm{ml}$ of medium was reached on a surface of $150 \mathrm{~cm}^{2}$. The minimal generation time of $M$. pneumoniae in glucose-supplemented medium was determined to be about 30 hrs. With fructose, the bacteria grew as well, however, the yield was significantly lower (about $15 \mathrm{mg}$ wet weight per $100 \mathrm{ml}$ of medium on a surface of $150 \mathrm{~cm}^{2}$ ). In the presence of both glucose and fructose, the growth characteristics were similar to those observed with glucose. With mannitol, no growth was observed suggesting that $M$. pneumoniae is not able to use this carbohydrate, at least under the conditions employed in this study (see Fig. 4A). Glycerol was metabolized by M. pneumoniae, although it seems to be a poor substrate as observed for fructose. Again, the addition of glucose and glycerol resulted in 
higher biomass yields. Thus, among the candidate substrates, glucose was clearly the most efficient, fructose and glycerol were utilized, whereas mannitol did not serve as a carbon source.
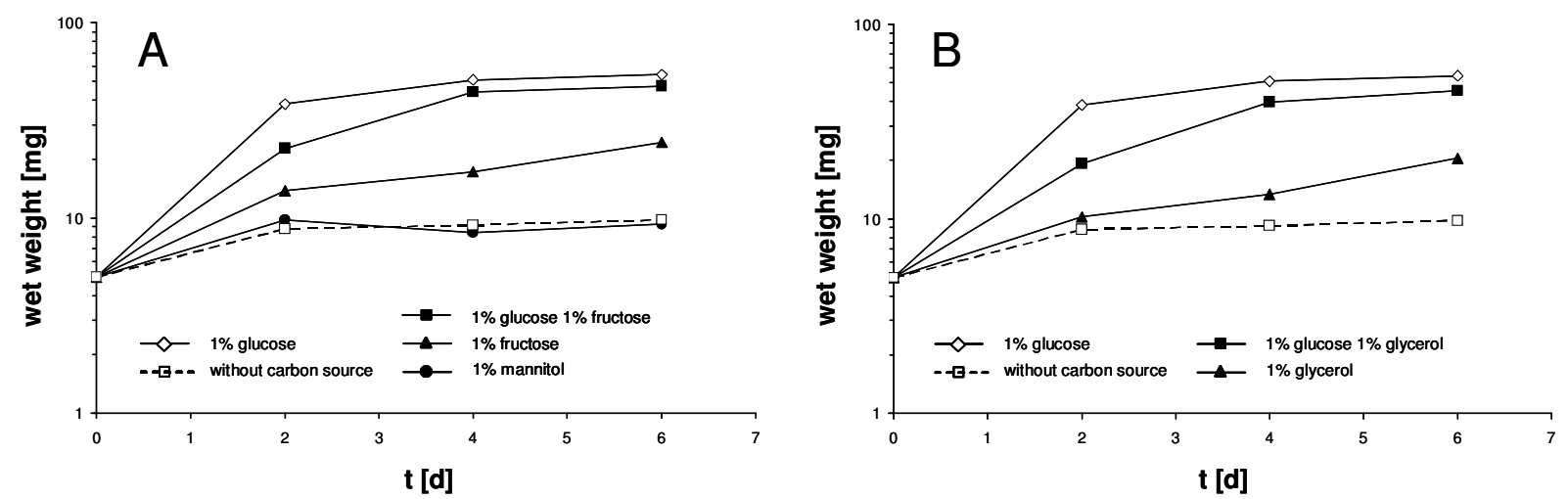

Fig. 4: Growth of M. pneumoniae in modified Hayflick medium containing different carbon sources. $100 \mathrm{ml}$ medium were inoculated with $5 \mathrm{mg}$ of cells and incubated for 2,4 or $6 \mathrm{~d}$ at $37^{\circ} \mathrm{C}$ in $150 \mathrm{~cm}^{2}$ cell culture flasks. Glucose, fructose, mannitol (A), and glycerol (B) were added to a final concentration of $1 \%(\mathrm{w} / \mathrm{v})$. Attached cells were collected by scraping and growth was monitored by determination of the wet weight of the cell pellets. Medium without any additional carbon source served as a negative control. All measurements were done at least twice.

Detection of HPr in M. pneumoniae cells. The growth assays demonstrated that $M$. pneumoniae is able to use sugars that are transported by the PTS. Moreover, the functionality and important role of PTS components for glucose and fructose utilization was already demonstrated in a global mutagenesis study (Hutchison et al., 1999). In Gram-positive bacteria, the HPr protein links sugar transport and different regulatory pathways and is thus the key protein of the PTS. To study the regulation of HPr synthesis and its modifications in M. pneumoniae, we raised rabbit polyclonal antibodies against the His ${ }_{6}$-tagged $M$. pneumoniae HPr. The amounts of HPr present in the cells after growth with different carbon sources were determined by Western blot analysis using crude cell extracts. The antibody reacted with a single protein band that corresponds to the size of the native HPr protein $(9.5$ $\mathrm{kDa}$, Fig. 5). The $\mathrm{His}_{6}-\mathrm{HPr}$ used as a control is larger and migrated somewhat slower. As judged from these experiments, HPr is constitutively synthesized in M. pneumoniae. The cellular amount did not depend on the presence or absence of PTS substrates such as glucose or fructose. This suggests that HPr may be not only required for sugar transport but also for regulatory purposes. 


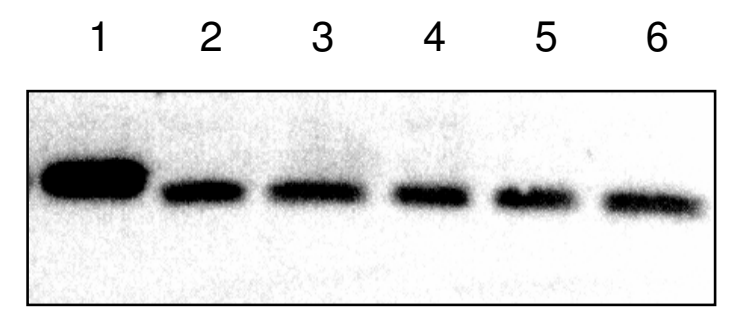

Fig. 5: Western blot analysis of HPr synthesis in M. pneumoniae. Antibodies raised against M. pneumoniae HPr were used to determine the total amounts of HPr in cells grown in the presence of glucose (lane 2), glucose and fructose (lane 3), fructose (lane 4), glucose and glycerol (lane 5) or glycerol (lane 6). The concentrations of the carbon sources were $1 \%(\mathrm{w} / \mathrm{v}) .200 \mathrm{ng}$ of recombinant $\mathrm{His}_{6}$-HPr served as a control (lane 1). His ${ }_{6}$-tagged HPr is somewhat retarded due to its slightly higher molecular weight.

In contrast to most other bacteria, the ptsH and ptsI genes encoding HPr and Enzyme I, repectively, are not clustered in $M$. pneumoniae. The transcription of $p t s H$ was studied by Northern blot analysis (Fig. 6). The major transcript corresponded to a $0.32 \mathrm{~kb}$ mRNA. In addition, two larger minor signals were detected. The $0.32 \mathrm{~kb}$ mRNA has the size expected for the monocistronic $\mathrm{pts} H$ gene, for which promoter and terminator sequences were predicted in silico (Himmelreich et al., 1996; Weiner et al., 2000). The minor signals may result from cross-hybridization with 16S rRNA and a very abundant 550 bp RNA. The nature of this RNA is so far unknown.
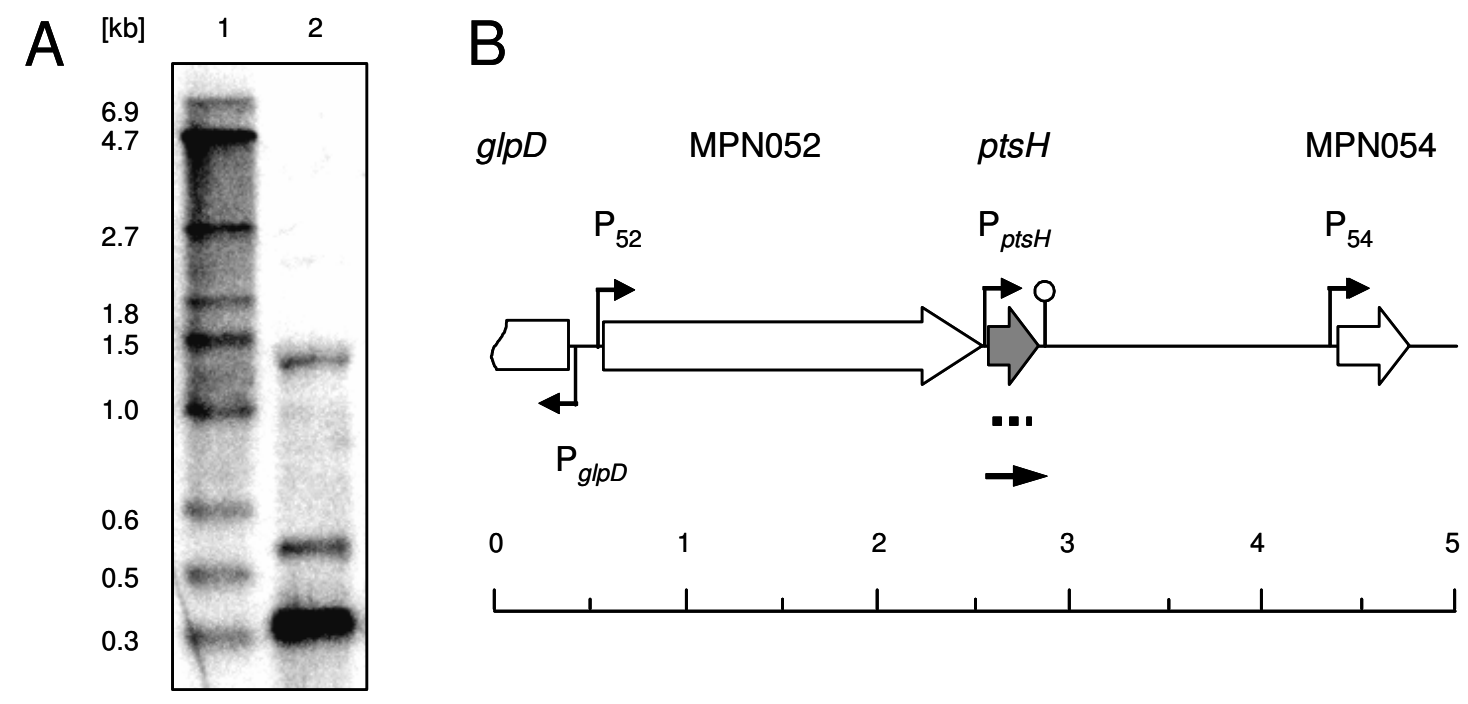

Fig. 6: Transcriptional organisation of the $p t s H$ locus (MPN053) of M. pneumoniae. (A) Northern blot. $10 \mu \mathrm{g}$ of total RNA prepared from cells grown in modified Hayflick medium containing $1 \%$ (w/v) glucose were separated using a $1.5 \%$ agarose gel containing $6 \%$ formaldehyde. After electrophoresis the RNA was transferred onto a nylon membrane and the $p t s H$ mRNA was detected using a Dig-labeled riboprobe specific for $p t s H$ (lane 2). Dig-labeled RNA molecular weight marker I (Roche Diagnostics) served as a standard (lane 1).

(B) Genomic region surrounding the $p t s H$ gene in $M$. pneumoniae. Indicated promotors are experimentally demonstrated (P52) or predicted in silico (Weiner et al., 2000). The position of the riboprobe is indicated by the dotted line. The detected $p t s H$ mRNA is schematically shown as a solid arrow. 
Taken together, our results demonstrate that $p t s H$ is a constitutively expressed monocistronic transcription unit. This finding is in good agreement with the previous observation that $p t s H$ is one of the highly-expressed M. pneumoniae genes (Weiner et al., 2003).

In vivo phosphorylation pattern of $M$. pneumoniae HPr. $M$. pneumoniae $\mathrm{HPr}$ is the target of two distinct phosphorylation events. However, the in vivo activity profile of the two phosphorylating enzymes, HPrK/P and Enzyme I, has so far not been investigated in any Mollicute.

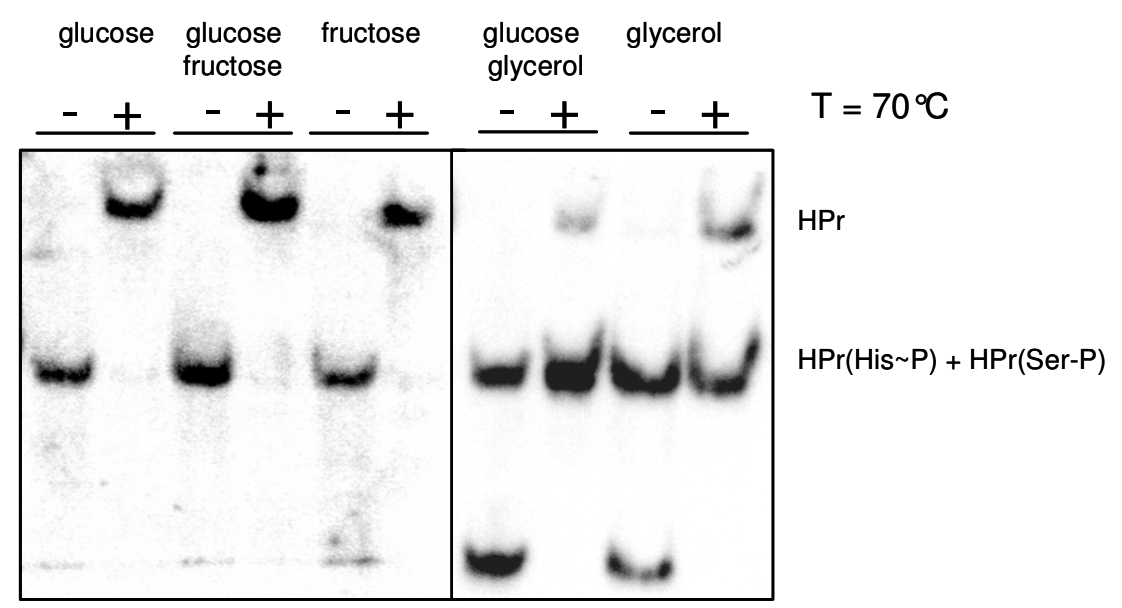

Fig. 7: Western blot for the detection of the different phosphorylation forms of HPr. Crude extracts of $M$. pneumoniae grown in the presence of different carbon sources ( $1 \%$ final concentration) were separated using native gels. For each condition tested a parallel aliquot was incubated for $10 \mathrm{~min}$ at $70^{\circ} \mathrm{C}$ to hydrolyze the heatlabile $\operatorname{HPr}(\mathrm{His} \sim \mathrm{P})$. The different $\operatorname{HPr}$ species $[\mathrm{HPr}, \mathrm{HPr}(\mathrm{His} \sim \mathrm{P}), \operatorname{HPr}(\operatorname{Ser}-\mathrm{P})$ and $\operatorname{HPr}(\operatorname{His} \sim \mathrm{P})(\mathrm{Ser}-\mathrm{P})]$ were detected using polyclonal rabbit antibodies raised against M. pneumoniae His $_{6}$-HPr. $10 \mu \mathrm{g}$ extract were applied to each lane.

To study the in vivo phosphorylation pattern of HPr we made use of the different migration behaviour of HPr carrying no, one or two phosphates in native acrylamide gels. Protein extracts from M. pneumoniae cells grown in modified Hayflick medium with different carbon sources were prepared as described in Materials and Methods, and subjected to native gel electrophoresis. The different forms of HPr were detected by Western blot analysis and the site of phosphorylation was determined by incubation of an aliquot of the cell extract at $70^{\circ} \mathrm{C}$ prior to electrophoresis. While phosphorylation on His-15 is heat-labile, phosphorylation at Ser-46 is not (Fig. 7). In the presence of glucose, essentially all HPr was phosphorylated at His-15 as judged from the complete loss of phosphorylation upon heat exposure. Similar results were obtained with fructose and a mixture of glucose and fructose. Thus, HPr is exclusively phosphorylated by Enzyme $\mathrm{I}$ in the presence of glucose or fructose whereas HPrK/P has no kinase activity under these conditions. If glycerol was present as a carbon source, two phosphorylated forms of HPr were observed, which correspond to singly and doubly phosphorylated forms of the protein. As expected, the doubly phosphorylated form 
disappeared completely after incubation at $70^{\circ} \mathrm{C}$ due to the heat lability of the His-phosphate. Only a small fraction of total HPr was unphosphorylated after heat exposure. These observations indicate that HPr was present to about one third as $\mathrm{HPr}(\mathrm{His} \sim \mathrm{P}), \mathrm{HPr}(\operatorname{Ser}-\mathrm{P})$, and HPr(His $\sim$ P)(Ser-P), respectively. The addition of glucose to glycerol-growing cells did not significantly affect the in vivo phosphorylation pattern of HPr (see Fig. 7). Thus, we may conclude that HPrK/P kinase activity is triggered in the presence of glycerol in vivo, and that it is not affected by glucose.

Detection of HPr phosphorylating enzymes in cell extracts of $M$. pneumoniae. The in vivo phosphorylation experiment suggests that Enzyme I was active under all condition studied here, whereas HPrK/P kinase activity was only detectable in glycerol-grown cells. Therefore, the synthesis or the activity of HPrK/P might be controlled by carbon source availability. To differentiate between these two possibilities, we investigated the presence of enzymatic activity of HPrK/P in M. pneumoniae cells after growth in modified Hayflick medium with different carbon sources. Crude extracts were incubated with HPr and with or without ATP, and the reaction mixture was analyzed by native gel electrophoresis (Fig. 8). None of the extracts was able to phosphorylate HPr in the absence of ATP. In contrast, all extracts contained HPrK/P resulting in the formation of $\mathrm{HPr}(\operatorname{Ser}-\mathrm{P})$. Judged from these results, HPrK/P was present under all conditions. Thus, enzymatic activity rather than expression seems to be regulated.

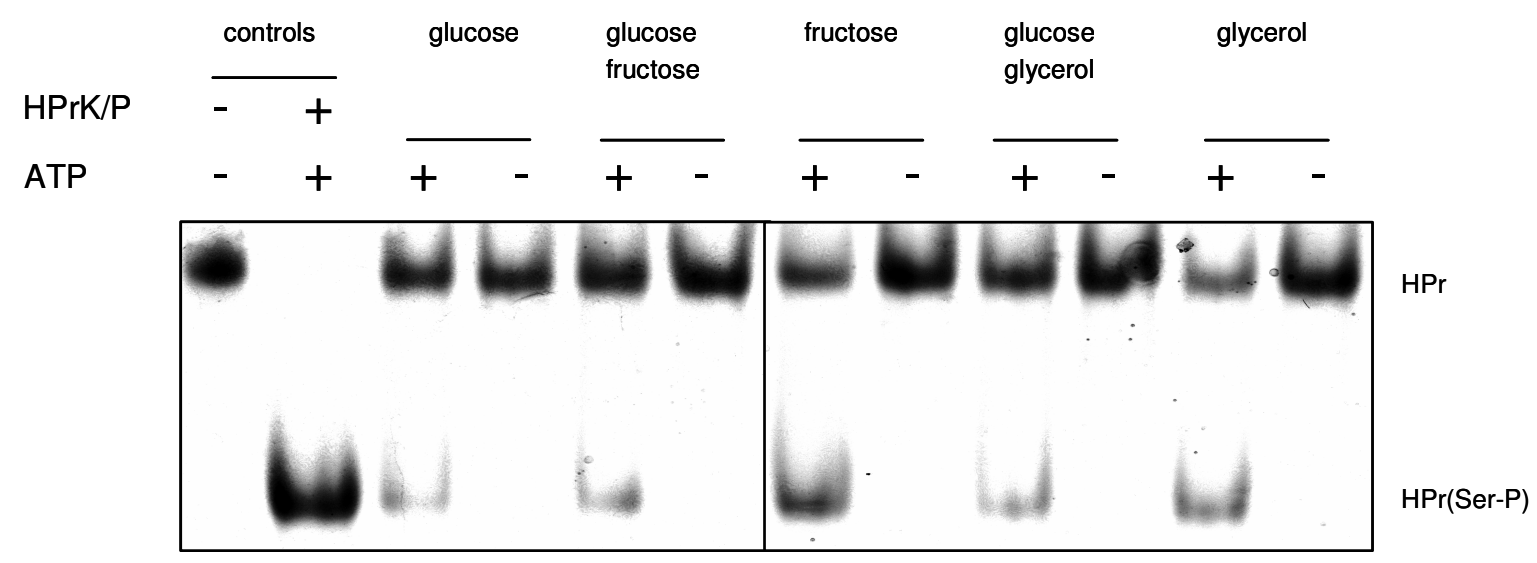

Fig. 8: In vitro phosphorylation assay to detect HPrK/P (MPN223) in $M$. pneumoniae crude extracts. $M$. pneumoniae $\mathrm{His}_{6}-\mathrm{HPr}(20 \mu \mathrm{M})$ was incubated with $5 \mu \mathrm{g}$ of crude extract and $0.5 \mathrm{mM}$ ATP in assay buffer in a final volume of $20 \mu \mathrm{l}$ at $37^{\circ} \mathrm{C}$ for $120 \mathrm{~min}$. Subsequently, the HPrK/P was heat-inactivated by boiling for $10 \mathrm{~min}$. The proteins were analyzed using $10 \%$ native PAGE. M. pneumoniae crude extracts were from cells that had been cultivated in the presence of different sugars as indicated. The first both lanes are positive controls with $M$. pneumoniae $\mathrm{His}_{6}$-HPr (first lane) and $\mathrm{His}_{6}-\mathrm{HPr}$ that had been phosphorylated at Ser-46 in vitro (second lane).

If $M$. pneumoniae cells grow on glucose or fructose, HPr is quantitatively phosphorylated by Enzyme I. In contrast, only a portion of HPr is phosphorylated on His-15 if glycerol is present in the medium (see Fig. 7). We asked therefore, whether Enzyme I was present in lower 
amount in glycerol-grown cells. To address this question, we used the cell extracts from cultures grown with the different carbohydrates and studied the presence of Enzyme I. This was performed by incubating the cell extracts with HPr and PEP as the phosphate donor. To control the reaction, we incubated Enzyme I of B. subtilis with M. pneumoniae HPr.

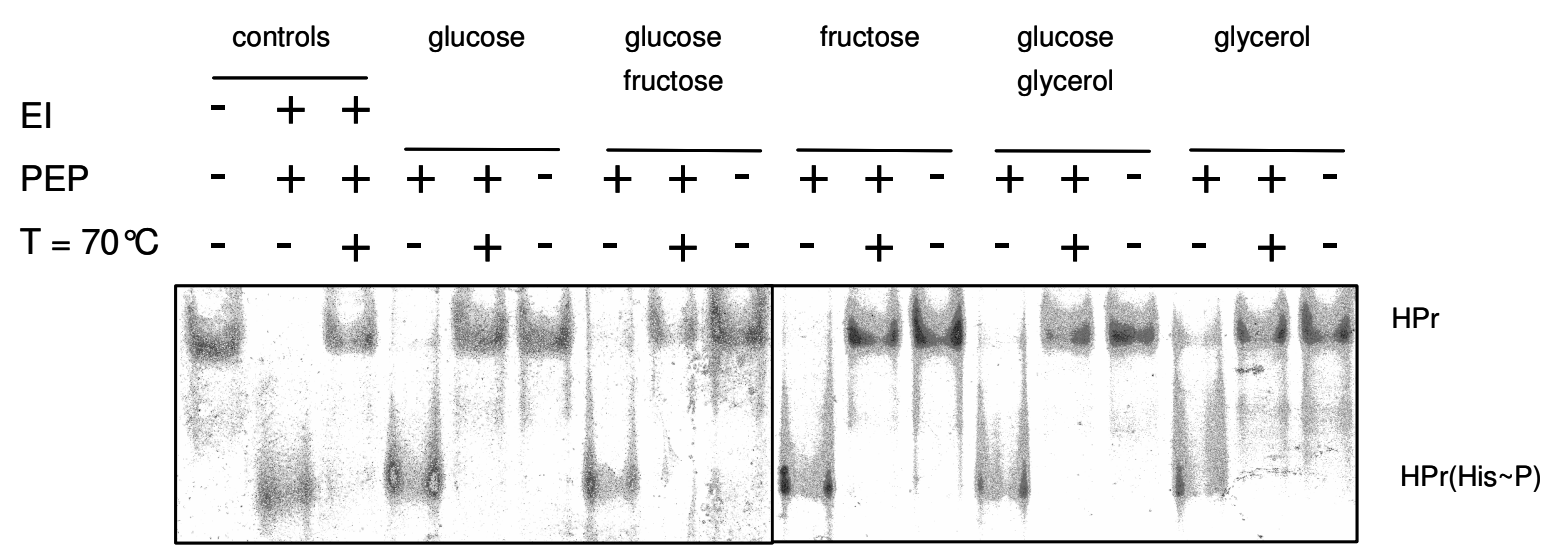

Fig. 9: In vitro phosphorylation assay to detect Enzyme I (MPN627) in M. pneumoniae crude extracts. $M$. pneumoniae His $_{6}-\mathrm{HPr}(20 \mu \mathrm{M})$ was incubated with $1 \mu \mathrm{g}$ of crude extract and $0.5 \mathrm{mM}$ PEP in assay buffer in a final volume of $20 \mu \mathrm{l}$ at $37^{\circ} \mathrm{C}$ for $30 \mathrm{~min}$. Assay mixtures that had been incubated for additional $10 \mathrm{~min}$ at $70^{\circ} \mathrm{C}$ to hydrolyze of the heat-labile HPr(His P) and samples where PEP had been omitted served as negative controls. The proteins were analyzed using $10 \%$ native PAGE. The crude extracts were prepared from cells that had been cultivated in the presence of different sugars as indicated. The first three lanes are positive controls with $M$. pneumoniae His $_{6}-\mathrm{HPr}$ (first lane), in vitro phosphorylated $\mathrm{His}_{6}-\mathrm{HPr}(\mathrm{His} \sim \mathrm{P})$ using B. subtilis Enzyme I (second lane) and the same after $10 \mathrm{~min}$ at $70^{\circ} \mathrm{C}$ (third lane).

As shown in Fig. 9, this resulted in heat-labile phosphorylation of HPr. All cell extracts converted HPr to $\mathrm{HPr}(\mathrm{His} \sim \mathrm{P})$ in the presence of PEP. In contrast, no HPr phosphorylation occurred in the absence of the phosphate donor (Fig. 9). Thus, Enzyme I was present in all cell extracts tested. We may therefore conclude that the partial phosphorylation of HPr by Enzyme I in glycerol-grown cells might result from the competition of HPrK/P and Enzyme I for their common target, HPr.

\section{Discussion}

For growth in artificial media, M. pneumoniae requires the presence of an added carbohydrate. Among the carbohydrates tested in this study, glucose allowed the most rapid growth. In contrast, fructose and glycerol are poor carbon sources for M. pneumoniae. Interestingly, mannitol did not serve as a single carbon source even though the genetic information to use this carbohydrate is complete (see Fig. 3). Two possible explanations for this finding can be envisioned: the $m t l A, m t l F$, or $m t l D$ genes required for mannitol transport and conversion to fructose-6-phosphate might be poorly expressed. This argument is 
supported by the observation that MtlA, the mannitol-specific protein IIBC of the PTS, is not expressed in growing cultures of M. pneumoniae (Jaffe et al., 2004a). Alternatively, one of the genes necessary for mannitol utilization might harbour a mutation that results in loss of the pathway. However, both the loss of expression and enzymatic function would result from mutation(s) that may affect the promoter and the structural genes, respectively. Thus, we may be witnesses of a further step in the reductive evolution of the $M$. pneumoniae genome. There are several indications supporting this idea: . pneumoniae possesses the genes for a putative $\mathrm{ABC}$ transporter for glycerol-3-phosphate with the notable exception of a binding protein. This may explain the inability of $M$. pneumoniae to use glycerol-3-phosphate as the single carbon source (data not shown). Moreover, in M. genitalium the genes for mannitol transport are completely lost. With only $580 \mathrm{~kb}, M$. genitalium may be a step ahead in the path of genome reduction (Fraser et al., 1995; Himmelreich et al., 1997). Genes that are not expressed or encode non-functional proteins are also found in other bacteria: In E. coli, the $b g l$ operon encoding the genes for the transport and utilization of aromatic $\beta$-glucosides is cryptic and requires mutations that activate the promoter (Hall, 1998; Reynolds et al., 1981). The B. subtilis gudB gene encoding a cryptic glutamate dehydrogenase is an example for an enzyme that is inactive due to a mutation of the structural gene (Belitsky \& Sonenshein, 1998). Massive gene decay is also observed in the obligately pathogenic bacterium Mycobacterium leprae (Vissa \& Brennan, 2001).

The need for an external carbon source seen in this study is in good agreement with the results of a global transposon mutagenesis approach with $M$. pneumoniae and M. genitalium: Mutants affecting the fructose permease of the PTS were only obtained if glucose was provided. On the other hand, no mutations affecting the general components of the PTS, i. $e$. Enzyme I and HPr were observed (Hutchison et al., 1999). The general importance of the PTS for M. pneumoniae is also underlined by the observation that Enzyme I and HPr are synthesized under all tested conditions (this study; Jaffe et al., 2004a). Constitutive expression of the general PTS components was also detected in E. coli and B. subtilis. This allows the general PTS proteins to fulfill their different regulatory functions both in the absence and presence of PTS sugars (Vadeboncoeur et al., 2000).

The finding that glucose is the best carbon source for $M$. pneumoniae is in agreement with the fact that this sugar is preferred in many bacteria including E. coli and B. subtilis. Moreover, glucose was detected in nasal secretions of compromised but not of healthy patients (Philips et al., 2003). Thus, this sugar is available for M. pneumoniae in its natural habitats. Similarly, we would expect that glycerol resulting from the degradation of phospholipids is present on 
mucosal surfaces. Indeed, our results indicate that both glucose and glycerol are of special importance for M. pneumoniae: Glucose is the best carbon source, but glycerol is the one that provoked a regulatory output as determined by in vivo HPr phosphorylation assays.

In all organisms studied so far, the kinase activity of HPrK/P is maximal if the bacteria grow in the presence of glucose, i. e. under conditions that cause carbon catabolite repression (Leboeuf et al., 2000; Ludwig et al., 2003; Monedero et al., 2001b; Vadeboncoeur et al., 1991). Moreover, with the exception of the M. pneumoniae HPrK/P, the kinase activity of all these enzymes requires high ATP concentrations due to a low affinity for ATP (Jault et al., 2000; Nessler et al., 2003; Steinhauer et al., 2002a). The results presented in this work indicate that the M. pneumoniae HPrK/P is not only unique in its high affinity for ATP (Merzbacher et al., 2004) but also in its unusual mode of in vivo activity: The enzyme does not respond to the presence of the best carbon source glucose, but its kinase activity is highest if the cells grow in the presence of glycerol. Interestingly, this activity is not affected by glucose as long as glycerol is available. This suggests a specific need for regulation in the presence of glycerol. The availability of glycerol might be an indication for the bacteria that they found their preferred ecological niche: the lipid-rich mucosal surface. If this was the case one would expect significant changes in the global gene expression pattern in $M$. pneumoniae in response to the presence or absence of glycerol. In M. mycoides, induction of cytotoxic $\mathrm{H}_{2} \mathrm{O}_{2}$ production requires the availability of glycerol (Vilei \& Frey, 2001). The use of a sugar as an indication of the nature of the habitat is not unprecedented in bacteria: In Listeria monocytogenes, the availability of the $\beta$-glucoside salicin is an indication that the bacteria are living in soil rather than in the human body. Accordingly, the activity of the regulatory protein BvrA which responds to salicin is mutually exclusive with that of the key activator of L. monocytogenes virulence gene expression, PrfA (Brehm et al., 1999). Moreover, HPr phosphorylation by HPrK/P might be important for triggering glycerol catabolism: In Firmicutes such as Enterococcus faecalis, E. casseliflavus and B. subtilis, glycerol utilization requires a functional PTS even though this substrate is not transported by the PTS. The glycerol kinases of these organisms require HPr-dependent phosphorylation for activity (Darbon et al., 2002). It has been demonstrated that the doubly phosphorylated $\mathrm{HPr}($ His $\sim \mathrm{P})($ Ser-P) can serve as a phosphate donor for the lactose permease of Streptococcus salivarius (Lessard et al., 2003). Thus, it is possible, that double phosphorylation of HPr in the presence of glycerol is required for phosphorylation and concomitant activation of the glycerol kinase of $M$. pneumoniae. 
It will be interesting to study the global changes of gene expression in $M$. pneumoniae in response to the carbohydrate availability and the mechanisms that control the utilization of individual substrates such as glycerol. This work will undoubtedly be helpful in understanding the biology of $M$. pneumoniae as well as the role of carbon metabolism in virulence and pathogenicity. 


\section{Chapter 3:}

\section{Dual phosphorylation of Mycoplasma pneumoniae HPr by enzyme I and HPr kinase suggests an extended phosphoryl group susceptibility of HPr}

The work described in this chapter was published in:

Halbedel, S., and J. Stülke. 2005. Dual phosphorylation of Mycoplasma pneumoniae HPr by Enzyme I and HPr kinase suggests an extended phosphoryl group susceptibility of HPr. FEMS Microbiol Lett 247:193-198.

Author contributions:

All experiment were designed, performed and interpreted by SH. JS and SH wrote the paper. 


\begin{abstract}
In Gram-positive bacteria, the $\mathrm{HPr}$ protein of the phosphoenolpyruvate:sugar phosphotransferase system can be phosphorylated at two distinct sites, His-15 and Ser-46. While the former phosphorylation is implicated in phosphoryl transfer to the incoming sugars, the latter serves regulatory purposes. In Bacillus subtilis, the two phosphorylation events are mutually exclusive. In contrast, doubly phosphorylated HPr is present in cell extracts of Mycoplasma pneumoniae. In this work, we studied the ability of the two single phosphorylated HPr species to accept a second phosphoryl group. Indeed, both Enzyme I and the HPr kinase/ phosphorylase from M. pneumoniae are able to use phosphorylated HPr as a substrate. The formation of doubly phosphorylated HPr is substantially slower as compared to the phosphorylation of free HPr. However, the rate of formation of doubly phosphorylated $\mathrm{HPr}$ is sufficient to account for the amount of $\operatorname{HPr}(\mathrm{His} \sim \mathrm{P})($ Ser-P) detected in M. pneumoniae cells.
\end{abstract}

\title{
Introduction
}

In many bacteria, the carbon supply of the cell is monitored by the phosphotransferase system (PTS) and reflected by different phosphorylation statuses of individual PTS proteins. Bacillus subtilis and other firmicutes use HPr as an indicator of nutrient supply. In these bacteria HPr can be phosphorylated on two sites: His-15 is part of the PTS phosphorylation chain whereas Ser-46 serves as a regulatory phosphorylation site. His-15 is the target of Enzyme I of the PTS. Ser-46 is phosphorylated by the HPr kinase/ phosphorylase (HPrK/P) at the expense of ATP. HPr(His15 P) serves as phosphate donor for the sugar-specific enzymes II and can phosphorylate enzymes such as glycerol kinase and transcription regulators to stimulate their activity. $\mathrm{HPr}(\mathrm{Ser}-\mathrm{P})$, in contrast, does not participate in sugar transport but acts as a cofactor for the transcriptional regulator $\mathrm{CcpA}$ that mediates carbon catabolite repression in the firmicutes (Brückner \& Titgemeyer, 2002; Stülke \& Hillen, 1999).

In B. subtilis, HPr phosphorylation has been studied during growth with or without glucose. In the absence of glucose, HPr is phosphorylated on His-15 by Enzyme I whereas phosphorylation of Ser-46 is predominant in the presence of glucose. While nonphosphorylated HPr was detected under both conditions, only marginal amounts of doubly phosphorylated HPr were present upon growth in glucose (Ludwig et al., 2002). This pattern of phosphorylation results from the control of HPrK/P activity in B. subtilis: If the intracellular concentrations of ATP and fructose-1,6-bisphosphate are high, the enzyme is active as a kinase, whereas phosphorylase activity prevails at low ATP and high phosphate 
concentrations (Jault et al., 2000). In contrast to the observations with B. subtilis, substantial amounts of doubly phosphorylated HPr were found in rapidly growing cells of Streptococci (Thevenot et al., 1995). This is astonishing, since the Streptococcus salivarius HPrK/P is controlled by ATP, fructose-1,6-bisphosphate and inorganic phosphate similar to the enzyme of B. subtilis (Frey et al., 2003).

Biochemical analyses with proteins from B. subtilis revealed that $\operatorname{HPr}(\mathrm{His} \sim \mathrm{P})$ is a poor substrate for HPrK/P. Similarly, HPr phosphorylation at Ser-46 inhibits Enzyme I-dependent phosphorylation about 5000-fold (Deutscher et al., 1984; Reizer et al., 1998). In agreement with the in vivo results and in contrast to those obtained with proteins from B. subtilis, $\mathrm{HPr}(\operatorname{Ser}-\mathrm{P})$ from Streptococcus thermophilus efficiently accepts a phosphate from Enzyme I in vitro (Cochu et al., 2005).

We are interested in the control of carbon metabolism in the mollicute Mycoplasma pneumoniae. Based on in vivo phosphorylation patterns and the ability to use carbohydrates, the general components of the PTS and the permeases for glucose and fructose are functionally expressed whereas mannitol cannot be utilized (Halbedel et al., 2004). The HPrK/P of M. pneumoniae differs in its activity from all other enzymes of this family studied so far in its extremely high affinity for ATP. This results in kinase activity even at very low ATP concentrations in the absence of any other effector (Merzbacher et al., 2004; Steinhauer et al., 2002a). Inspite of these apparent differences in enzyme regulation, the known crystal structures of the HPrK/Ps including that of M. pneumoniae are all very similar to each other (Allen et al., 2003; Nessler et al., 2003). In vivo phosphorylation studies revealed that a significant portion of $\mathrm{HPr}$ (about 30\%) was present in the doubly phosphorylated form (Halbedel et al., 2004). This suggests that the HPrK/P of M. pneumoniae is not only peculiar in its regulation but also in its ability to phosphorylate $\operatorname{HPr}(\mathrm{His} \sim \mathrm{P})$. In this work, we addressed the activities of the enzymes involved in $\mathrm{HPr}$ phosphorylation using phosphorylated HPr as a target. We demonstrate that unlike the enzymes from B. subtilis both Enzyme I and HPrK/P from M. pneumoniae are active on phosphorylated HPr.

\section{Materials and Methods}

Bacterial strains and growth conditions. Escherichia coli DH5 $\alpha$, BL21(DE3)/pLysS (Sambrook et al., 1989) and M15 (Qiagen, Hilden, Germany) were used for overexpression of recombinant proteins. The cells were grown in LB medium containing ampicillin $(100 \mu \mathrm{g}$ $\mathrm{ml}^{-1}$ ). M. pneumoniae M129 in the $31^{\text {st }}$ broth passage was used for preparation of cell extracts as a source of M. pneumoniae Enzyme I. Cells were grown at $37^{\circ} \mathrm{C}$ in $150 \mathrm{~cm}^{2}$ tissue culture 
flasks containing $100 \mathrm{ml}$ of modified Hayflick medium which consists of $18.4 \mathrm{~g}$ PPLO broth (Difco), 29.8 g HEPES, $5 \mathrm{ml} 0.5 \%$ phenol red, $35 \mathrm{ml} 2 \mathrm{~N} \mathrm{NaOH}$ and $10 \mathrm{~g}$ glucose per litre. Horse serum (Gibco) and penicillin were included to a final concentration of $20 \%$ and 1000 $\mathrm{u} / \mathrm{ml}$, respectively. Bacteria were cultivated for $96 \mathrm{~h}$ and cell extracts were prepared as described previously (Halbedel et al., 2004).

Protein purification. His 6 -HPr (M. pneumoniae), His 6 -Enzyme I (B. subtilis), and StrepHPrK/P (M. pneumoniae) were overexpressed using the expression vectors pGP217 (Steinhauer et al., 2002a), pAG3 (Galinier et al., 1997), and pGP611 (Merzbacher et al., 2004), respectively. Expression was induced by the addition of IPTG (final concentration 1 $\mathrm{mM})$ to exponentially growing cultures $\left(\mathrm{OD}_{600}\right.$ of 0.8$)$. Cells were disrupted using a french press. After lysis the crude extracts were centrifuged at $10,000 \mathrm{~g}$ for $30 \mathrm{~min}$. For purification of His-tagged proteins the resulting supernatants were passed over a $\mathrm{Ni}^{2+} \mathrm{NTA}$ superflow column ( $5 \mathrm{ml}$ bed volume, Qiagen) followed by elution with an imidazole gradient (from 0 to $500 \mathrm{mM}$ imidazole in a buffer containing $10 \mathrm{mM}$ Tris/ $\mathrm{HCl} \mathrm{pH}$ 7.5, $600 \mathrm{mM} \mathrm{NaCl}, 10 \mathrm{mM} \beta$ mercaptoethanol). For HPrK/P carrying a N-terminal Strep-tag, the crude extract was passed over a Streptactin column (IBA, Göttingen, Germany). The recombinant protein was eluted with desthiobiotin (Sigma, final concentration $2.5 \mathrm{mM}$ ). For the recombinant HPr protein the overproduced protein was purified from the pellet fraction of the lysate by urea extraction and renatured as described previously (Steinhauer et al., 2002a).

After elution the fractions were tested for the desired protein using 12.5\% SDS PAGE. The relevant fractions were combined and dialysed overnight. Protein concentration was determined using the Bio-rad dye-binding assay where Bovine serum albumin served as the standard.

Preparation of serine phosphorylated HPr. HPr $(20 \mu \mathrm{M})$ was phosphorylated at Ser-46 by Mycoplasma pneumoniae HPrK/P (500 nM) and ATP $(100 \mu \mathrm{M})$ in a total reaction volume of $5 \mathrm{ml}$. The reaction was carried out at $37^{\circ} \mathrm{C}$ for $1 \mathrm{~h}$ in $25 \mathrm{mM}$ Tris- $\mathrm{HCl} 10 \mathrm{mM} \mathrm{MgCl} 21 \mathrm{mM}$ DTT and stopped using a heat step for $10 \mathrm{~min}$ at $95{ }^{\circ} \mathrm{C}$ which simultaneously leads to the denaturation of HPrK/P but does not denature the heat-stable HPr. Denaturated HPrK/P was sedimented by centrifugation $\left(10,000 \mathrm{~g}, 10 \mathrm{~min}, 4^{\circ} \mathrm{C}\right)$ and $\operatorname{HPr}(\operatorname{Ser}-\mathrm{P})$ was enriched approximately fivefold by passing the resulting supernatant through a Vivaspin 15 concentrator (Vivascience, Hannover, Germany). The elimination of HPrK/P and the phosphorylation status of HPr at Ser-46 were checked using denaturing SDS-PAGE and 10\% native polyacrylamide gels (Hanson et al., 2002), respectively. 
Preparation of histidine phosphorylated HPr. $\operatorname{HPr}(20 \mu \mathrm{M})$ was phosphorylated at His-15 using Bacillus subtilis Enzyme I (50 nM) and PEP (500 nM) as the phosphate donor in a total reaction volume of $4 \mathrm{ml}$. The phosphorylation reaction took place during an $1 \mathrm{~h}$ incubation step at $37^{\circ} \mathrm{C}$ in a buffer containing $50 \mathrm{mM}$ Tris- $\mathrm{HCl}, 10 \mathrm{mM} \mathrm{MgCl}_{2}$ and $1 \mathrm{mM}$ DTT. Subsequently, the reaction mixture was subjected to a buffer exchange procedure (i) to reduce the concentration of PEP and (ii) to concentrate the obtained $\operatorname{HPr}(\mathrm{His} \sim \mathrm{P})$. For this purpose the reaction mixture was given on a Vivaspin 15 concentrator and centrifuged at $3000 \mathrm{~g}$ at $4{ }^{\circ} \mathrm{C}$ until the original volume was reduced to $0.5 \mathrm{ml}$. The obtained solution was diluted fivefold and concentrated to a volume of $0.5 \mathrm{ml}$ again. All in all this step was repeated three times. The phosphorylation status of HPr was checked on a $10 \%$ native polyacrylamide gel.

Phosphorylation of HPr and HPr(Ser-P) on His-15. HPr or HPr(Ser-P) (each $20 \mu \mathrm{M})$ were used as the phosphoacceptor in a reaction requiring PEP $(50 \mu \mathrm{M})$ and $5 \mu \mathrm{g}$ of $M$. pneumoniae cell extracts as a source of mycoplasmal Enzyme I in a total volume of $20 \mu$ l. The phosphorylation reaction was allowed to proceed for a defined period of time at $37^{\circ} \mathrm{C}$ and stopped immediately by the addition of $2 \mu 10.5 \mathrm{M}$ EDTA $\mathrm{pH}$ 8.0. The reaction mixture was separated on a $10 \%$ native polyacrylamide gel. Gels were stained with Coomassie stain and the resulting bands were quantificated using the TotalLab ${ }^{\mathrm{TM}}$ v2003.03 software (Nonlinear Dynamics Ltd.).

Serine phosphorylation of $\mathbf{H P r}$ and HPr(His $\sim \mathbf{P})$. In a reverse experiment $\mathrm{HPr}$ and HPr(His P) were the phosphoacceptors for HPrK/P dependent phosphorylation on Ser-46. To achieve serine phosphorylation of unphosphorylated or histidine phosphorylated HPr, HPr or $\mathrm{HPr}($ His $\sim \mathrm{P})($ each $20 \mu \mathrm{M})$ were incubated in the presence of HPrK/P $(400 \mathrm{nM})$ and ATP (100 $\mu \mathrm{M}$ ) for a defined period at $37^{\circ} \mathrm{C}$. The reaction was stopped by adding $2 \mu 1$ of $0.5 \mathrm{M}$ EDTA $\mathrm{pH}$ 8.0. The reaction mixture was separated on $10 \%$ native gels and the proteins were visualized by Coomassie staining. Quantification was done as described above.

\section{Results}

Phosphorylation of HPr(Ser-P) by Enzyme I. In contrast to the situation observed in $B$. subtilis, large amounts of doubly phosphorylated HPr were detected in M. pneumoniae cells grown in the presence of glycerol. Therefore, M. pneumoniae Enzyme I may differ from that of $B$. subtilis in its ability to use $\operatorname{HPr}(\operatorname{Ser}-\mathrm{P})$ as a target for phosphorylation. To test this hypothesis, we prepared $\mathrm{HPr}(\mathrm{Ser}-\mathrm{P})$ and performed in vitro phosphorylation assays with cell extracts from $M$. pneumoniae as a source of Enzyme I. In a previous study, it was demonstrated that M. pneumoniae cells synthesize Enzyme I during growth in the presence of 
glucose (the relevant condition for this work) (Halbedel et al., 2004). As a control, phosphorylation assays were performed with non-phosphorylated HPr. As shown in Fig. 10A, HPr was completely phosphorylated after 20 min incubation in the presence of PEP and the cell extract. This phosphorylation was heat-labile and was not observed in the absence of PEP. These observations provide evidence that the phosphorylation occurred at His-15. Moreover, phosphorylation of HPr by Enzyme I seems to be very efficient since complete phosphorylation was detected after 2 minutes. As observed with non-phosphorylated HPr, $\mathrm{HPr}(\mathrm{Ser}-\mathrm{P})$ was also used as a target of Enzyme I, since a heat-labile and PEP-dependent phosphorylation was detected (Fig. 10B). However, phosphorylation of $\mathrm{HPr}(\mathrm{Ser}-\mathrm{P})$ by Enzyme I was significantly slower than that of non-phosphorylated HPr. After 20 minutes, only $40 \%$ were present as doubly phosphorylated HPr. The densitometric evaluation of the phosphorylation assays revealed that phosphorylation of $\mathrm{HPr}(\operatorname{Ser}-\mathrm{P})$ by Enzyme I is about 25fold slower than that of non-phosphorylated HPr (Fig. 10C). Thus, prior phosphorylation of M. pneumoniae HPr by HPrK/P inhibits Enzyme I-dependent phosphorylation. However, this inhibition is much weaker than that described for B. subtilis.

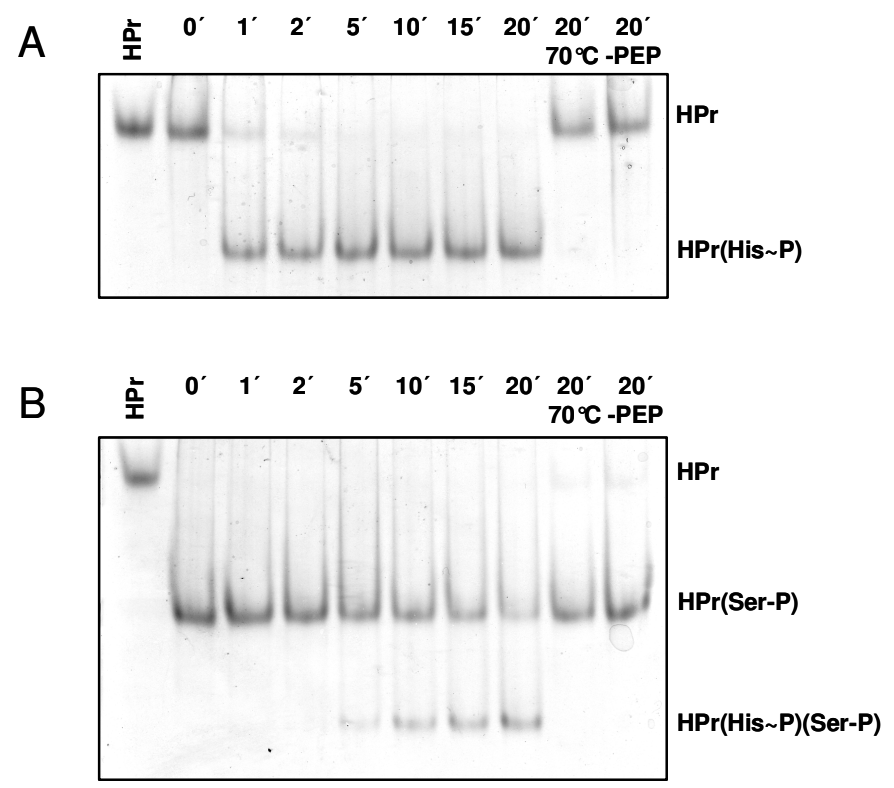

C

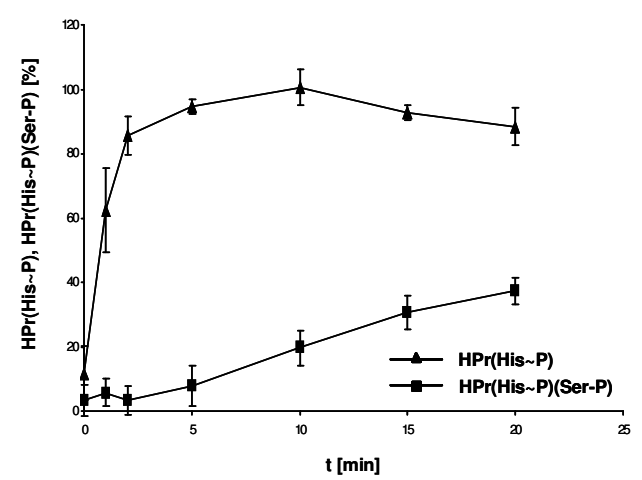

Fig. 10: Kinetics of HPr phosphorylation at His-15.

(A) HPr phosphorylation at His-15 as a function of time using PEP and $M$. pneumoniae cell extracts as source of Enzyme I. The phosphorylation reactions were carried out as described in Materials and Methods for 0 to $20 \mathrm{~min}$ and stopped immediately by the addition of EDTA as a chelating agent. Reaction mixtures without added PEP and such ones that had been incubated for additional $10 \mathrm{~min}$ at $70^{\circ} \mathrm{C}$ to hydrolyze the heat-labile $\mathrm{HPr}(\mathrm{His} \sim \mathrm{P})$ served as negative controls.

(B) Phosphorylation of $\mathrm{HPr}(\mathrm{Ser}-\mathrm{P})$ at His-15 as a function of time as in (A).

(C) The amounts of differently phosphorylated forms of HPr of both experiments were quantified by densitometry and displayed as ratio of total HPr plotted against time. Vertical bars indicate the standard deviation of three independent experiments. 
Phosphorylation of HPr(His $\sim$ P) by HPrK/P. Doubly phosphorylated HPr may be formed by the phosphorylation of $\mathrm{HPr}(\mathrm{Ser}-\mathrm{P})$ by Enzyme I (see above), but also by using HPr(His $\sim \mathrm{P}$ ) as a substrate for HPrK/P. To test this hypothesis, we prepared $\mathrm{HPr}(\mathrm{His} \sim \mathrm{P})$ and used it for in vitro phosphorylation assays with purified $M$. pneumoniae HPrK/P. Again, nonphosphorylated HPr served as a control.

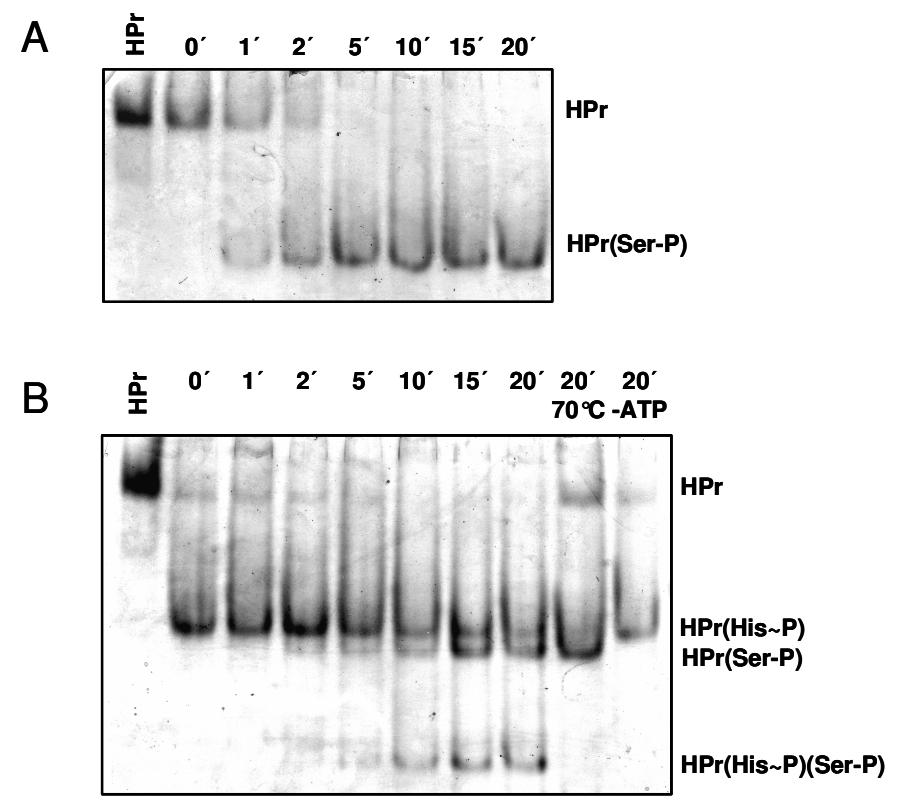

C

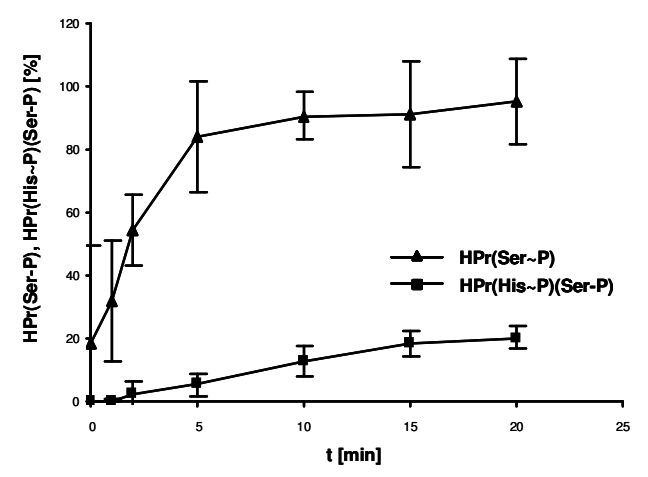

Fig. 11: Kinetics of HPr phosphorylation at Ser-46.

(A) $\mathrm{HPr}$ phosphorylation at Ser-46 as a function of time. The phosphorylation reactions were carried out for 0 to $20 \mathrm{~min}$ and stopped by adding EDTA.

(B) Phosphorylation of $\mathrm{HPr}(\mathrm{His} \sim \mathrm{P})$ at Ser-46 as a function of time as in (A). Reaction mixtures where ATP had been omitted and parallel aliquots that had been incubated for additional $10 \mathrm{~min}$ at $70^{\circ} \mathrm{C}$ to remove the histidine phosphoamidate served as negative controls. Note that $\operatorname{HPr}(\mathrm{His} \sim \mathrm{P})$ and $\operatorname{HPr}(\mathrm{Ser}-$ P) migrate to different positions in the gel suggesting that the two single phosphorylated forms of HPr have different conformations.

(C) The amounts of differently phosphorylated forms of HPr of both experiments were quantified by densitometry and displayed as ratio of total HPr plotted against time. Vertical bars indicate the standard deviation of three independent experiments.

Note that the serine residue phosphorylated by $\mathrm{HPrK} / \mathrm{P}$ (Ser-46) is actually at position 47 in M. pneumoniae HPr.

As shown in Fig. 11A, HPr was readily phosphorylated. This phosphorylation was heat-stable as shown previously (Merzbacher et al., 2004; Steinhauer et al., 2002a). With HPr(His P) as the substrate, the formation of doubly phosphorylated HPr was observed (Fig. 11B). As can be seen in Fig. 11B, $\operatorname{HPr}(\mathrm{His} \sim \mathrm{P})$ seems to be somewhat unstable. The preparation of $\mathrm{HPr}($ His $\sim \mathrm{P})$ gave rise to non-phosphorylated $\mathrm{HPr}$, and after the formation of doubly phosphorylated HPr, $\mathrm{HPr}(\mathrm{Ser}-\mathrm{P})$ was formed. As judged from the amount of the different forms of HPr, the pool of $\operatorname{HPr}(\operatorname{Ser}-\mathrm{P})$ was fed by the phosphorylation of free HPr and the decomposition of the doubly phosphorylated form. The quantitative evaluation of this experiment revealed that non-phosphorylated HPr was completely phosphorylated by HPrK/P 
after 5 minutes. With $\operatorname{HPr}($ His $\sim$ P) as the substrate, only about $20 \%$ of the protein were doubly phosphorylated after 20 minutes (Fig. 11C). The densitometric analysis indicated that the formation of doubly phosphorylated $\mathrm{HPr}$ with $\mathrm{HPr}(\mathrm{His} \sim \mathrm{P})$ as the substrate is about 20 -fold less efficient than the phosphorylation of non- phosphorylated HPr by HPrK/P. As seen with Enzyme I, HPrK/P from M. pneumoniae is much less inhibited by prior phosphorylation of HPr than the B. subtilis HPrK/P.

\section{Discussion}

Among the HPrK/P enzymes studied to detail, the $M$. pneumoniae protein is the only one from an organism that is highly adapted to nutrient-rich human tissues. In contrast to the other enzymes of the family, the M. pneumoniae HPrK/P has several peculiarities: (i) It has a very high affinity for ATP allowing kinase activity even in the absence of glucose in the medium whereas kinase activity in B. subtilis and in Streptococci was only detected in glucose-grown cells (Jault et al., 2000; Ludwig et al., 2002; Merzbacher et al., 2004; Thevenot et al., 1995). (ii) The $M$. pneumoniae $\mathrm{HPrK} / \mathrm{P}$ is unique in its glycerol requirement for in vivo activity suggesting a novel mechanism of control in addition to the residual regulation by glycolytic intermediates (Halbedel et al., 2004; Steinhauer et al., 2002a). Finally, M. pneumoniae shares the high degree of double phosphorylation of HPr with the streptococci whereas the two phosphorylation events are essentially mutually exclusive in B. subtilis (Cochu et al., 2005; Deutscher et al., 1984; Reizer et al., 1998; Thevenot et al., 1995). The complete phosphorylation/ dephosphorylation cycle of M. pneumoniae HPr is depicted in Fig. 12.

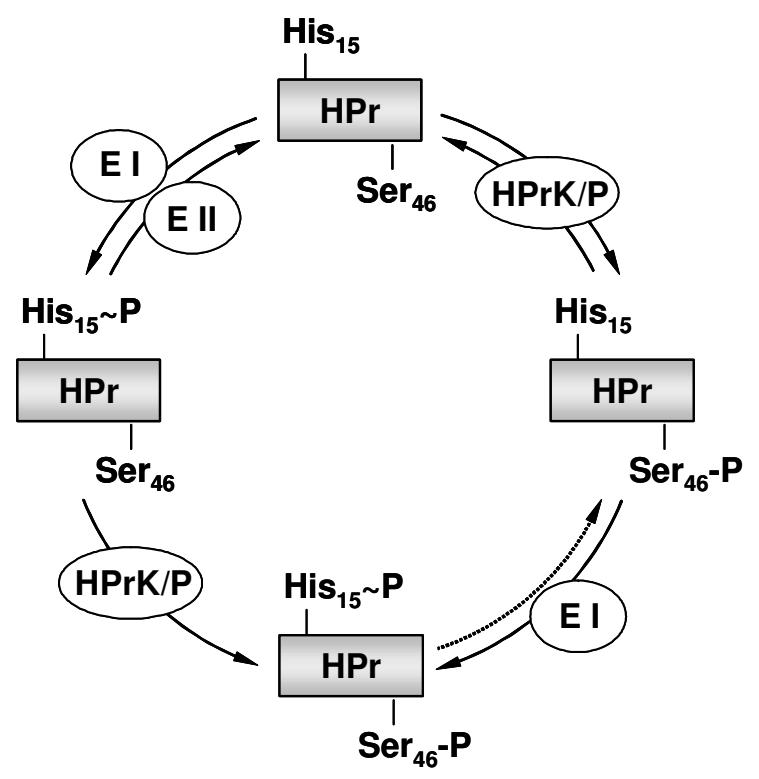

Fig. 12: $\operatorname{HPr}$ phosphorylation cycle in $M$. pneumoniae. HPrK/P phosphorylates HPr at Ser-46 and also catalyzes the dephosphorylation of $\mathrm{HPr}($ Ser-P). Enzyme I (E I) mediates the formation of the phosphoamidate at His-15, whereas the dephosphorylation of $\mathrm{HPr}(\mathrm{His} \sim \mathrm{P})$ occurs during phosphotransfer of the orthophosphate to sugar specific Enzymes II (E II). HPr(Ser-P) serves as substrate in a PEP-requiring reaction to form doubly phosphorylated $\mathrm{HPr}(\mathrm{His} \sim \mathrm{P})(\mathrm{Ser}-\mathrm{P})$. In a reverse manner $\operatorname{HPr}(\mathrm{His} \sim \mathrm{P})$ can be phosphorylated at the serine residue by HPrK/P. The dotted arrow indicates the spontaneous dephosphorylation of doubly phosphorylated HPr at the histidine residue. 
Recently, the first HPrK/P from a phylogenetically distinct bacterium, the spirochaete Treponema denticola, was biochemically characterized. As observed for the M. pneumoniae HPrK/P, the enzyme from this organism has a high affinity for ATP (Gonzalez et al., 2005). Interestingly, $T$. denticola is also highly adapted to human tissues. It was proposed that the HPrK/P proteins from M. pneumoniae and T. denticola have the kinase activity as their default state as an adaptation to nutrient-rich environments (Gonzalez et al., 2005; Steinhauer et al., 2002a).

The differences in the ability to form doubly phosphorylated HPr might originate from different properties of the phosphorylating enzymes, Enzyme I and HPrK/P, or from differences in the HPr structure that make the phosphorylation state of the second site irrelevant. We propose that the latter might be crucial for the acceptance or not of the second phosphorylation: First, both Enzyme I and HPrK/P of B. subtilis are unable to act upon phosphorylated HPr whereas the same set of two enzymes from Streptococcus mutans, Streptococcus thermophilus (Cochu et al., 2005; Thevenot et al., 1995) and M. pneumoniae (this work) was active on phosphorylated HPr. Thus, subtle changes in the structure of HPr might affect the interaction between $\mathrm{HPr}$ and the phosphorylating enzymes to allow or prevent phosphorylation of a substrate molecule that had already been phosphorylated by the other enzyme. The second indication for our hypothesis is derived from the known structures of the complexes of HPr with Enzyme I or HPrK/P. Indeed, the helix capped by His-15 of $B$. subtilis HPr is in direct contact with HPrK/P (Nessler et al., 2003). On the other hand, the determination of the structure of the complex between the N-terminal domain of Enzyme I and HPr from E. coli revealed that Ser-46 directly interacts with Enzyme I (Garrett et al., 1999). For HPr from Enterococcus faecalis, loss of hydrophobic interaction with Enzyme I was described as the major structural effect of Ser-46 phosphorylation (Audette et al., 2000). It will be interesting to determine the structure of M. pneumoniae HPr. A comparison with the known HPr structures is expected to reveal the distinct properties that determine whether the formation of doubly phosphorylated HPr is possible or not. 


\section{Chapter 4:}

\section{MMR: A method for the simultaneous introduction of multiple mutations into the glpK gene of Mycoplasma pneumoniae}

The results described in this chapter were published in:

Hames, C., S. Halbedel, O. Schilling, and J. Stülke. 2005. Multiple-mutation reaction: a method for simultaneous introduction of multiple mutations into the $g l p K$ gene of Mycoplasma pneumoniae. Appl Environ Microbiol 71:4097-4100.

Author contributions:

This study was designed by JS, SH and OS. CH performed all experiments. SH designed the the oligonucleotides and supervised the experimental work that was accomplished by $\mathrm{CH}$ during her diploma thesis. All authors were involved in the interpretation of the collected data and in the writing of the manuscript. 


\begin{abstract}
In Mycoplasma pneumoniae, the UGA opal codon specifies tryptophan rather than a translation stop. This makes it often difficult to express Mycoplasma proteins in E. coli. In this work, we developed a strategy for the one step introduction of several mutations. This method, the multiple mutation reaction (MMR), is used to simultaneously exchange nine opal codons in the M. pneumoniae glpK gene.
\end{abstract}

\title{
Introduction
}

Mycoplasma pneumoniae is a pathogen that lives on mucosal surfaces and causes diseases such as mild pneumonia, tracheobronchitis, and complications affecting the central nervous system, the skin and mucosal surfaces (Jacobs, 1997; Lind, 1983; Waites \& Talkington, 2004). These bacteria possess one of the smallest genomes of any free-living organism known so far. This reduced genome makes Mycoplasma spp. interesting from two points of view: (i) The analysis of these bacteria may help to identify the minimal set of genes that is required for independent life (Hutchison et al., 1999), and (ii) M. pneumoniae and its close relative $M$. genitalium are well suited for the development of the methods of the post-genomic era (Jaffe et al., 2004a; Wasinger et al., 2000). Another interesting aspect of the small genome is the observation that several enzymes of Mycoplasma spp. are moonlighting, i. e. they have multiple unrelated functions (Jeffery, 1999). This was discovered for glycolytic kinases which are also active as nucleoside diphosphate kinases in M. pneumoniae and other Mycoplasma spp. (Pollack et al., 2002).

However, the analysis of proteins from Mycoplasma spp. is hampered by a peculiarity of the genetic code of these bacteria: they use the UGA opal codon to incorporate tryptophan rather than as stop codon as in the universal genetic code (Inamine et al., 1990; Simoneau et al., 1993). Thus, if cloned in E. coli or other hosts the genes from M. pneumoniae may contain many stop codons that prevent heterologous expression. Several strategies have been developed to solve this problem: Some M. pneumoniae genes such as $p t s H$ or hprK do not possess UGA codons, thus no special care is required (Steinhauer et al., 2002a). Expression of mollicute genes in Spiroplasma spp. that read the UGA as a tryptophan codon was reported, however, these bacteria are difficult to handle (Stamburski et al., 1991). E. coli suppressor strains expressing an opal suppressor tRNA were developed, however, they fail if multiple opal codons are present (Smiley \& Minion, 1993). M. pneumoniae genes containing few UGA codons have been expressed in B. subtilis with low efficiency (Kannan \& Baseman, 2000). In cases with only a few opal codons, these were changed by site-directed mutagenesis to allow 
expression in E. coli (Knudtson et al., 1997; Noh et al., 2002). The M. pneumoniae P1 adhesin gene contains 21 opal codons, and a large scale purification of the protein, though highly desired, has so far not been possible. In this case protein fragments were expressed and purified (Chaudhry et al., 2004). Finally, Mycoplasma genes could be synthesized in vitro from oligonucleotides, this strategy is, however, quite expensive. In this work, we present a PCR-based method that allows the simultaneous introduction of several mutations in a single step. Using this strategy, nine of the ten opal codons of the glpK gene from M. pneumoniae were modified, leading to expression of glycerol kinase in E. coli.

\section{Results and Discussion}

Outline of the MMR strategy. Several methods for PCR-based site-directed mutagenesis have been developed. Among these, the combined chain reaction (CCR) (Bi \& Stambrook, 1997; Bi \& Stambrook, 1998) proved to be very rapid and reliable. The principle of this method is the use of mutagenic primers that hybridize more strongly to the template than the external primers. The mutagenic primers are phosphorylated at their $5^{\prime}$ end, and these are ligated to the 3' $\mathrm{OH}$ group of the extended upsteam primers by the action of a thermostable DNA ligase. Moreover, the DNA polymerase employed must not exhibit 5' $\rightarrow$ 3' exonuclease activity to prevent the degradation of the extended primers. In our hands, $P f u$ and $P w o$ polymerases are both well suited (Meinken et al., 2003; Schilling et al., 2004). The original protocol describes the introduction of two mutations simultaneously. In a previous study, we used CCR to mutagenize four distant bases in a DNA fragment in a one-step reaction (our unpublished results).

For the introduction of up to nine mutations in one single experiment, we developed the Multiple Mutation Reaction (MMR). This method requires the efficient binding of all the mutagenic primers to the target DNA. To ensure that extension of a PCR product is not possible beyond the next ( $i$. e e more downstream) mutation site without ligation to the corresponding mutagenic primer, special care needs to be taken for primer design. This is based on an accurate calculation of melting temperatures. For this purpose, the formula $\mathrm{T}_{\mathrm{M}}\left[{ }^{\circ} \mathrm{C}\right]=81.5+16.6\left(\log \left[\mathrm{Me}^{+}\right]\right)+0.41 \mathrm{x}(\% \mathrm{G}+\mathrm{C})-(500 /$ oligo length $)-0.61 \mathrm{x}$ (\% formamide $)$ was used (Meinkoth \& Wahl, 1984). Only bases that match between primer and template were used for the calculation. One consideration was made when designing the mutagenic primers: Ligation was facilitated by placing a $\mathrm{G}$ or $\mathrm{C}$ at the 5 ' end of the oligonucleotide to favour close duplex formation between the primer and the target DNA. The external primers were selected to have melting temperatures considerably lower (about $4^{\circ} \mathrm{C}$ ) than the 
mutagenic primers. The MMR was performed with 2.5 units of $P f u$ DNA polymerase (MBI Fermentas, Lithuania) and 15 units of Ampligase ${ }^{\circledR}$ (Epicentre, Madison, WI) in MMR buffer (20 mM Tris-HCl pH8.5; $3 \mathrm{mM} \mathrm{MgCl}_{2}, 50 \mathrm{mM} \mathrm{KCl}, 0.4 \mathrm{mg} / \mathrm{ml} \mathrm{BSA}, 0.5 \mathrm{mM} \mathrm{NAD}{ }^{+}$) in a total volume of $50 \mu \mathrm{l}$. Conditions for MMR included denaturation at $95^{\circ} \mathrm{C}$ for $30 \mathrm{sec}$, primer annealing at $57^{\circ} \mathrm{C}$ for $30 \mathrm{sec}$ and elongation at $65^{\circ} \mathrm{C}$ for $6 \mathrm{~min}$ for 35 cycles. Initially, the DNA fragment (100 ng) was denatured for $5 \mathrm{~min}$ at $95^{\circ} \mathrm{C} .10 \mathrm{pmol}$ of each primer were used. The sequences and the arrangement of the oligonucleotides used in this study are shown in Tab. 2 and Fig. 13, respectively.

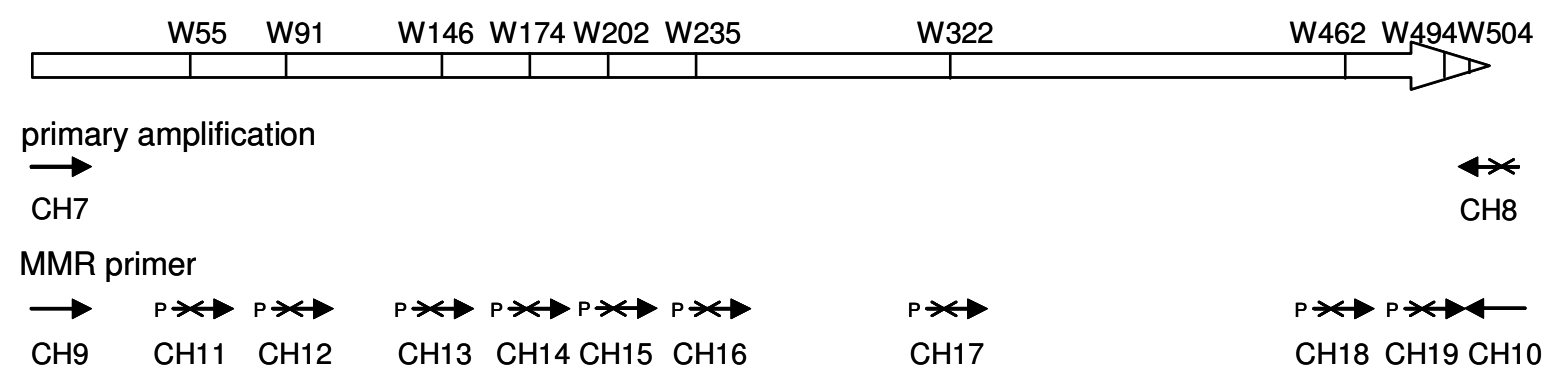

Fig. 13: Strategy for amplification and mutagenesis of the M. pneumoniae glpK gene (MPN050, Himmelreich et al., 1996). The positions of the opal codons in the wild type $g l p K$ gene (indicated by a W followed by the number corresponding to the amino acid) and the position and orientation of the external and mutagenic oligonucleotides are shown. The annealing site of each oligonucleotide is indicated by an arrow, oligonucleotides bearing an $\mathrm{A} \rightarrow \mathrm{G}$ transition were depicted by crossed arrows.

Tab. 2: Oligonucleotides used in this study

\begin{tabular}{clll}
\hline Oligonucleotide & \multicolumn{1}{c}{ Sequence $\left(\mathbf{5}^{\prime} \mathbf{- 3}^{\prime}\right)$} & \multicolumn{1}{c}{ Mutation } & $\mathbf{T}_{\mathbf{M}}\left({ }^{\circ} \mathbf{C}\right)$ \\
\hline CH7 & AAAAGTCGACATGGATCTAAAACAACAATACATTCTTG & none & 59 \\
CH8 & TATAAAGCTTGTCTTAGTCTAAGCTAGCCCATTTTAG & A1512G & 63 \\
CH9 & AAAAGTCGACATGGATCTAAAACAAC & none & 59 \\
CH10 & TATAAAGCTTGTCTTAGTCTAAGCTAG & none & 59 \\
CH11 & phos-GATCCCTTAGAAATTTGGTCAGTCCAATTAG & A165G & 63 \\
CH12 & phos-CCATTGTGTTATGGAACAAAGAAAATGGTTTG & A273G & 62 \\
CH13 & phos-CACTAAGATTGCTTGGATCTTGGAAAATGTTC & A438G & 62 \\
CH14 & phos-CCTGGTTAATTTGGAAACTAACGGGTG & A522G & 63 \\
CH15 & phos-CCATGACATGGTCACAAGAGTTAGGC & A606G & 64 \\
CH16 & phos-TACCGAGTCATTGGTCTACTAGTGC & A705G & 64 \\
CH17 & phos-CCTTAAAGTGGTTAAGGGATAGTCTTAAGG & A966G & 63 \\
CH18 & phos-GCAGTTAATTATTGGAAGGACACTAAACAAC & A1386G & 63 \\
CH19 & phos-GAAATCAAAGCGTTGGAACGAAGCTG & A1482G & 64 \\
\hline
\end{tabular}


Cloning of M. pneumoniae glpK and expression of the protein in E. coli. An analysis of growth behaviour and in vivo protein phosphorylation pattern identified glycerol as a key carbon source associated with regulatory phenomena. This substrate triggered in vivo phosphorylation of the HPr protein of the phosphotransferase system by the metabolite sensitive HPr kinase/phosphorylase (Halbedel et al., 2004; Steinhauer et al., 2002a). We are therefore interested in studying glycerol metabolism and its regulation in more detail. As a first step, we intended to purify the glycerol kinase. This enzyme is known to be a key target of catabolite regulation in Gram-positive bacteria (Darbon et al., 2002; Stülke \& Hillen, 2000). However, the corresponding $g \operatorname{lpK}$ gene contains 10 opal codons and was therefore a good subject for MMR in order to change these codons to tryptophan codons for $E$. coli. The $g l p K$ gene was amplified using the oligonucleotides $\mathrm{CH} 7$ and $\mathrm{CH} 8$ and chromosomal DNA of M. pneumoniae M129 (ATCC 29342) as template. With CH8, the most C-terminal opal codon was replaced by a TGG codon. The amplicon was cloned between the SalI and HindIII sites of the expression vector pWH844 (Schirmer et al., 1997). The resulting plasmid, pGP253 was used as template for MMR with $\mathrm{CH} 9$ and $\mathrm{CH} 10$ as external primers and $\mathrm{CH} 11$ through $\mathrm{CH} 19$ as mutagenesis primers.
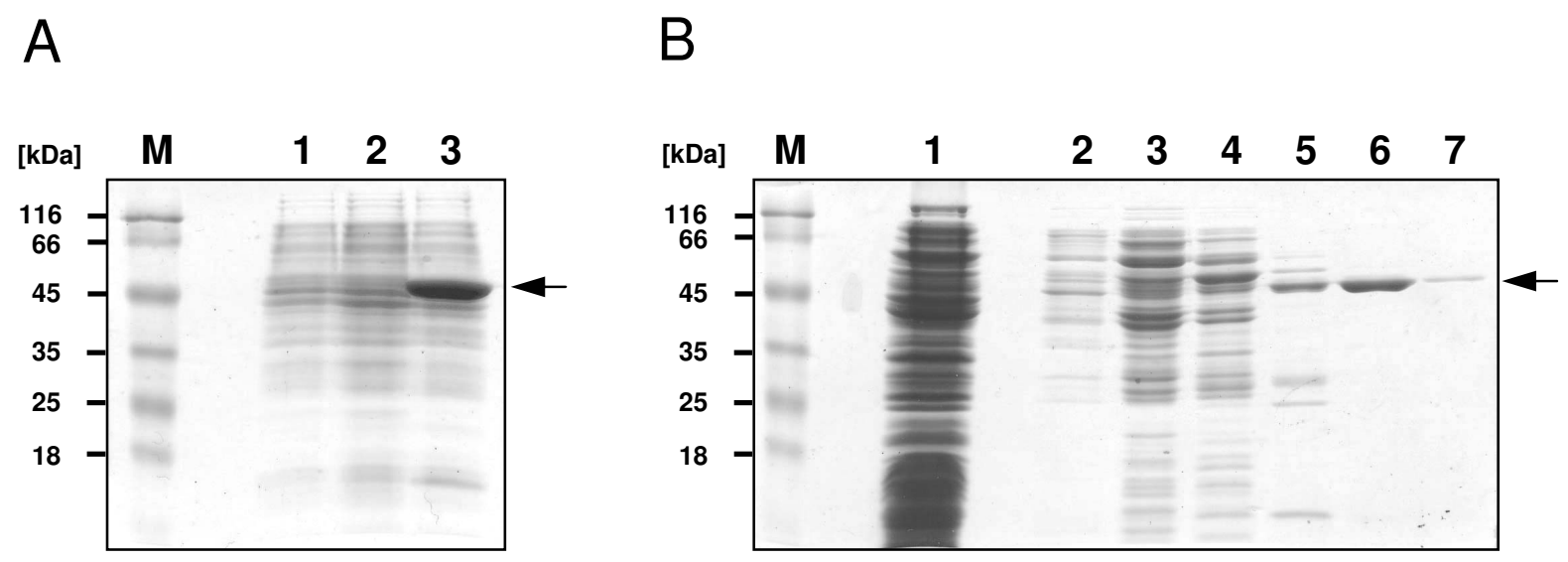

Fig. 14: Overproduction and purification of M. pneumoniae GlpK. (A) SDS-PAGE for detection of His ${ }_{6}$-tagged GlpK in crude extracts of $E$. coli DH5 $\alpha$ bearing either the empty expression vector pWH844 (lane 1), the expression vector including the wild type $g l p K$ allele, pGP253 (lane 2), or the mutated glpK allele, pGP254 (lane $3)$. Cells were grown to an optical density of $\mathrm{OD}_{600}=0.8$ and expression from the IPTG-inducible promoter was induced by addition of $1 \mathrm{mM}$ IPTG (final concentration). After $2 \mathrm{~h}$ cells were harvested and disrupted by sonification. The insoluble fraction was pelleted in a centrifugation step, solubilized using $6 \mathrm{M}$ urea and sample aliquots were separated on a $12 \%$ polyacrylamide SDS gel. (B) SDS-PAGE to monitor the purification of His $6^{-}$ tagged GlpK. Crude extract of the GlpK-expression strain (E. coli DH5 $\alpha$ bearing the plasmid pGP254) that had been grown in the presence of $1 \mathrm{mM}$ IPTG was passed over a $\mathrm{Ni}^{2+} \mathrm{NTA}$ superflow column $(5 \mathrm{ml}$ bed volume, Qiagen) and washed extensively with a buffer containing $10 \mathrm{mM}$ Tris- $\mathrm{HCl} \mathrm{pH} 7.4$ and $200 \mathrm{mM} \mathrm{NaCl}$, followed by elution with an imidazole gradient (from 10 to $500 \mathrm{mM}$ imidazole). Aliquots of the individual fractions were separated on $12 \%$ polyacrylamide SDS gels. Prestained Protein Molecular Weight Marker (Fermentas) served as a standard (M). Lane 1, flow-through, lane 2, $10 \mathrm{mM}$ imidazole; lane 3, $20 \mathrm{mM}$ imidazole; lane 4, $50 \mathrm{mM}$ imidazole; lane 5, $100 \mathrm{mM}$ imidazole; lane 6, $200 \mathrm{mM}$ imidazole; lane 7, $500 \mathrm{mM}$ imidazole. 
Five independent MMR reactions were carried out and the MMR products were individually cloned as a SalI/HindIII fragment into pWH844. The inserts of one clone resulting from each MMR were sequenced. Out of the five candidates, three contained the nine desired mutations without any additional mutations. One plasmid contained seven out of nine mutations, and the fifth plasmid bore all nine mutations and one additional undesired one base pair deletion in one of the primer regions. Plasmids bearing all nine desired, but no additional mutations were designated pGP254. pGP254 allows the expression of M. pneumoniae glycerol kinase fused to a $\mathrm{N}$-terminal hexahistidine sequence under the control of an IPTG-inducible promoter. To test the success of the mutagenesis, we compared the protein content of E. coli cultures carrying either pWH844, pGP253 or pGP254. A prominent band corresponding to an approximate molecular weight of $56 \mathrm{kDa}$ is detectable in the strain bearing pGP254 while no such protein is expressed from pGP253 encoding the unmutated $g l p K$ gene (Fig. 14A). The glycerol kinase was purified to apparent homogeneity by $\mathrm{Ni}^{2+}$-NTA chromatography as described previously (Fig. 14B) (Meincken et al., 2003). Thus, MMR was successful to achieve efficient overproduction of $M$. pneumoniae glycerol kinase for biochemical studies.

This study demonstrates that MMR can be used for the rapid and highly efficient introduction of multiple mutations into a gene. Out of five individual clones, four had the desired mutations. Of these four, only one candidate contained an extra mutation, which was most probably due to an impure oligonucleotide mix. Indeed, other experiments indicated that the quality of the oligonucleotides is the limiting factor for MMR. Obviously, this method is not only useful for the expression of Mycoplasma spp. genes, but also to change codon usage patterns or for any other purpose that requires the introduction of many mutations or combinations of them at the same time. What is the maximum number of mutations that can be introduced by MMR in one single step? Our results suggest that nine mutations are still far from a theoretical limit and we are confident that this method can be even more effective by taking care of the quality of the oligonucleotides (see above) and by using mutagenic primers that alternate between the two strands of the DNA. With this method at hand, even the expression of a functional P1 adhesin gene in E. coli, which has so far been beyond imagination (Chaudhry et al., 2005), now seems feasible. 


\section{Chapter 5:}

\section{Probing in vivo promoter activities in Mycoplasma pneumoniae: A system for the}

generation of single-copy reporter constructs

The work described in this chapter was published in:

Halbedel, S., and J. Stülke. 2006. Probing in vivo promoter activities in Mycoplasma pneumoniae: a system for generation of single-copy reporter constructs. Appl Environ Microbiol 72:1696-1699.

Author contributions:

This study was designed and interpreted by SH and JS. SH performed all experiments. JS and SH wrote the paper. 


\begin{abstract}
The nucleotide sequences that control transcription initiation and regulation in Mycoplasma pneumoniae are poorly understood. In this work, we developed a lacZ-based reporter plasmid that can be used to integrate fusions of promoter fragments to a promoterless lac $Z$ gene into the chromosome of M. pneumoniae.
\end{abstract}

\title{
Introduction
}

Mycoplasma pneumoniae is a human pathogen. The bacteria live on mucosal surfaces of the respiratory tract and cause diseases such as mild pneumonia and tracheobronchitis. In addition, some non-respriratory complications affecting the skin, mucosa, the central nervous system, the heart and other organs were reported (Jacobs, 1997; Lind, 1983; Waites \& Talkington, 2004). During the last few years, M. pneumoniae and related cell wall-less bacteria of the class Mollicutes have attracted considerable scientific interest since these bacteria possess one of the smallest genomes of any free-living organism known so far (Himmelreich et al., 1996). The minimal genetic complement of M. pneumoniae and its close relative, $M$. genitalium, has prompted studies to identify the essential gene set required for independent life (Gil et al., 2004; Hutchison et al., 1999). Moreover, the molecular details of the interaction of M. pneumoniae with the host tissues that lead to pathogenesis are far from being understood. Simlarly, not much is known about gene expression in M. pneumoniae. A few global studies on gene expression in M. pneumoniae have been reported (Jaffe et al., 2004a; Regula et al., 2000; Ueberle et al., 2002; Weiner et al., 2003). In good agreement with the life of M. pneumoniae in a rather constant environment is the small number of regulatory proteins encoded in the genome of these bacteria. While transcription of some individual genes was studied in M. pneumoniae (Benders et al., 2005; Halbedel et al., 2004; Hyman et al., 1998; Inamine et al., 1990; Weiner et al., 2000), nothing is known on regulatory mechanisms in these bacteria.

The molecular analysis of M. pneumoniae has been hampered by three problems: First, the genes of M. pneumoniae and related mollicutes use the UGA opal codon to incorporate tryptophan rather than as a stop codon as in the universal genetic code. This makes it difficult to express proteins from Mycoplasma spp. in heterologous hosts in order to make them available for biochemical analysis (Chaudhry et al., 2004; Inamine et al., 1990). Recently, a method for the simultaneous replacement of multiple opal codons has been developed and used for the expression of M. pneumoniae glycerol kinase in Escherichia coli (Hames et al., 2005). A second major problem is the lack of genetic systems that allow the efficient targeted 
generation of $M$. pneumoniae mutants. Therefore, genetic research with these bacteria depends on the use of mutant strains that have been isolated in conventional screens or even by chance (Waldo et al., 2005; Wilby et al., 2002). Finally, transcription in M. pneumoniae can so far only be studied by RNA-based methods such as transcriptome analyses, Northern blots, reverse transcriptase PCR, or primer extension for the determination of 5 ' ends of transcripts (Benders et al., 2005; Halbedel et al., 2004; Hyman et al., 1988; Inamine et al., 1988; Waldo et al., 1999; Weiner et al., 2000; Weiner et al., 2003). The molecular analysis of transcription regulatory mechanisms has so far not been possible due to the lack of appropriate reporter systems that can be used to study the activity of promoter fragments and their mutant derivatives in vivo. In this study, we report a system for the generation of fusions of $M$. pneumoniae promoters to a promoterless lacZ gene that can be integrated into the $M$. pneumoniae chromosome.

\section{Results and Discussion}

Construction of the M. pneumoniae reporter system. Since no genetic system allowing the targeted integration of DNA fragments into the M. pneumoniae chromosome is available, we made use of a derivative of Tn4001 (Hedreyda et al., 1993), which lacks the transposase gene (mini-Tn4001). The mini-Tn4001 used here contains an origin of replication that functions in E. coli but not in $M$. pneumoniae and a aac-aphD gentamicin resistance gene which can be used to select for gentamicin or kanamycin resistance in $M$. pneumoniae or E. coli, respectively (Rouch et al., 1987). Tn4001 is known to insert randomly into the chromosome of M. pneumoniae (Hutchison et al., 1999). The mini-Tn4001 together with the tnp gene encoding transposase were present on plasmid pMT85 (Zimmerman \& Herrmann, 2005). As the reporter we selected the E. coli lac $Z$ gene encoding $\beta$-galactosidase which is one of the most popular reporter enzymes due to the possibility to get a quick qualitative impression of the enzymatic activity in colonies using plates containing X-Gal and the quantitative assay using ONPG as the chromogenic substrate (Miller, 1972). In addition, lacZ-based reporter systems were already established in other mollicutes such as Acholeplasma oculi, Mycoplasma pulmonis, Mycoplasma arthritidis and Mycoplasma capricolum (Dybvig et al., 2000; Janis et al., 2005; Knudtson \& Minion, 1994). To facilitate cloning of the promoter fragments and their detection in E. coli, we made use of a lacZ gene devoid of a ribosomal binding site. With such a reporter, a Shine-Dalgarno sequence must be provided with the cloned promoter fragment to obtain a functional lac $Z$ fusion. These requirements are met by the lacZ gene present in plasmid pAC5 (Martin-Verstraete et al., 1992). The lacZ gene of 
pAC5 was amplified using the primers SH44 (5'

TATTTAAGTACTATAATAAGGGTAACTATTGCCG) and SH45 (5'

GAACTAGTACATAATGGATTTCCTTAC). The resulting fragment was digested with $B c u \mathrm{I}$ and ScaI (these sites were introduced upon PCR, underlined in the primer sequences) and cloned between the BcuI and OliI sites of pMT85. The resulting plasmid was pGP353 (Fig. 15).

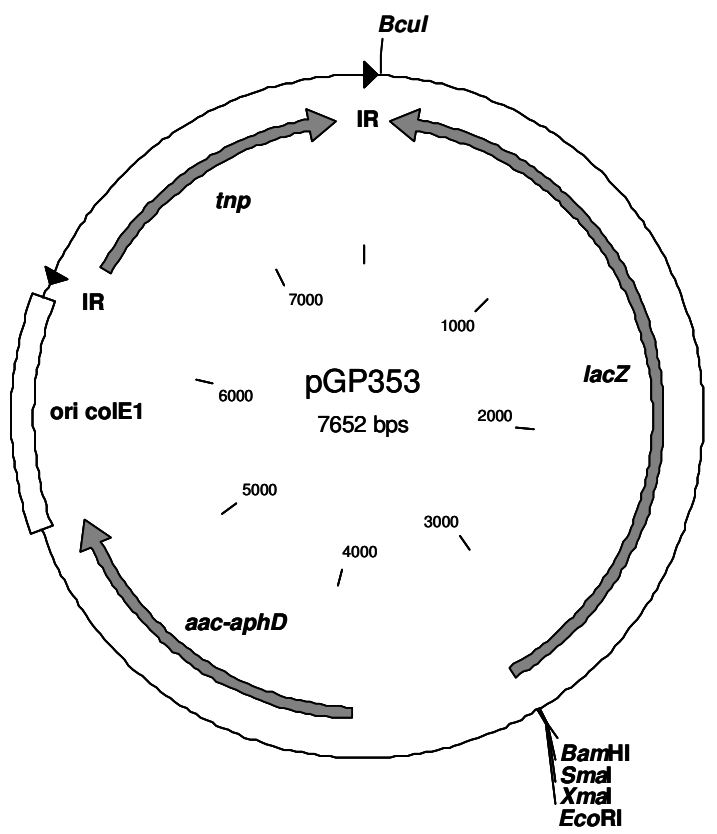

Fig. 15: Map of plasmid pGP353. The plasmid was constructed as described in the text. Abbreviations: IR inverted repeats, tnp - transposase gene, aac-aphD - gentamycin/kanamycin resistance gene, lacZ - $\beta$ galactosidase, ori colE1 - gram-negative origin of replication. Restriction sites available for the construction of translational promoter $l a c Z$ fusions and the $B c u$ I site used to construct pGP353 are indicated.

Construction and analysis of a ldh-lacZ fusion. We are interested in carbon metabolism in M. pneumoniae and its regulation. These bacteria catabolize a few sugars such as glucose, fructose and glycerol via glycolysis but lack a citric acid cycle (Halbedel et al., 2004; Himmelreich et al., 1996). The NADH formed in glycolysis can be re-oxidized by the formation of lactate from pyruvate. The $l d h$ gene (MPN674) encoding lactate dehydrogenase is one of the few genes in $M$. pneumoniae which is transcribed in the opposite direction as compared to the genes located up- and downstream. This suggests that $l d h$ is transcribed monocistronically with a promoter upstream of the gene. Indeed, a primer extension assay revealed the presence of a promoter similar to the consensus sequence of the single $M$. pneumoniae $\sigma$ factor (our unpublished results, Weiner et al., 2000). To fuse the $l d h$ promoter region to the promoterless $l a c Z$ gene present in $\mathrm{pGP} 353$, the region from -160 to +81 relative to the $l d h$ transcription start point was amplified using the oligonucleotides SH46 (5' AGAATTCAAACTGCATCGTGGTATCTG) and $\quad$ SH47 
TAGGATCCGCGTAGAGAAAGCTGGTGC), and cloned between the EcoRI and BamHI sites of pGP353. In the resulting plasmid pGP354 (see Fig. 16), the lacZ gene was fused in frame to the $21^{\text {st }}$ codon of the lactate dehydrogenase gene. The promoter fragment present in pGP354 contains two internal HindIII sites. These sites were used to delete the promoter resulting in plasmid pGP364 (see Fig. 16).

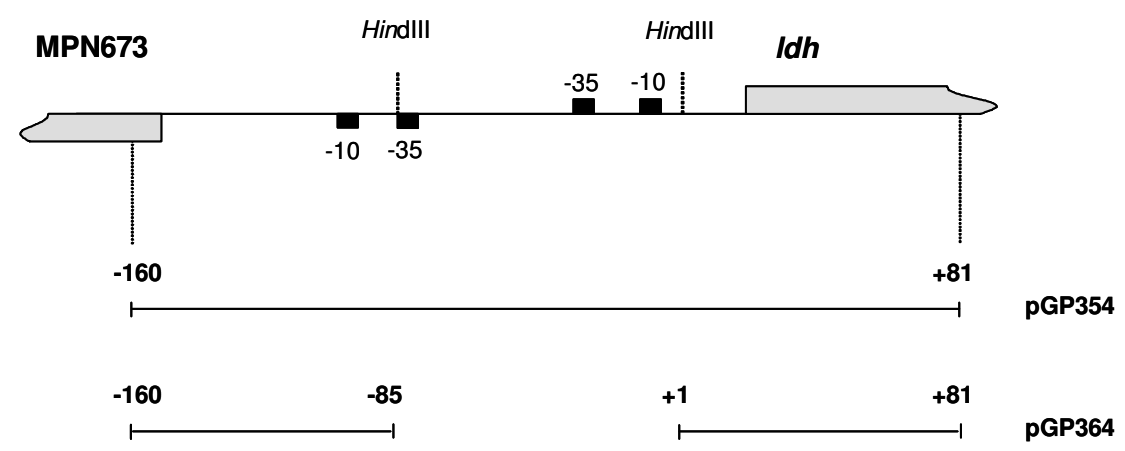

Fig. 16: Scheme of the M. pneumoniae ldh promoter fragments that have been used for the construction of pGP354 and pGP364. Putative -10 and -35-boxes of the $l d h$ gene (MPN674) and the MPN673 gene (conserved hypothetical gene) are indicated (Weiner et al., 2000). Numbering is relative to the transcriptional start point of the $l d h$ gene.

The plasmid pGP353, pGP354, and pGP364 were used to electroporate M. pneumoniae M129 according to the protocol described previously (Catrein et al., 2004). Transformants were selected on plates containing gentamicin with or without X-Gal. On X-Gal-containing plates all transformants obtained with pGP354 formed blue colonies whereas transformants with pGP353 and pGP364 formed white colonies (see Fig. 17A). This was a first indication that the promoter fragment was present in the original fragment and that promoter activity was lost upon deletion of the internal HindIII fragment.

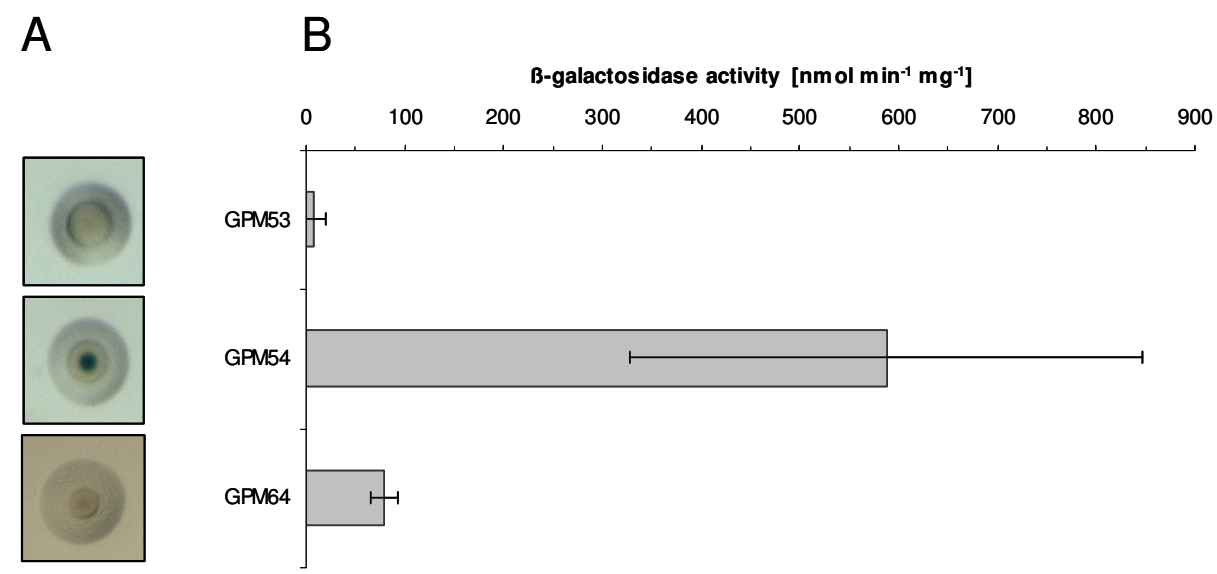

Fig. 17: $\beta$-Galactosidase activity of the the promotorless lacZ gene and two different $l d h$-lacZ fusions in $M$. pneumoniae. (A) Single colonies of $M$. pneumoniae after transformation with pGP353, pGP354 or pGP364 on MP agar plates containing $150 \mu \mathrm{g} / \mathrm{ml} \mathrm{X-Gal} \mathrm{and} 80 \mu \mathrm{g} / \mathrm{ml}$ gentamycin. (B) $\beta$-Galactosidase activity in crude extracts of $M$. pneumoniae that had been transformed either with pGP353, pGP354 or pGP364. Culture were grown in $10 \mathrm{ml}$ of modified Hayflick medium with $80 \mu \mathrm{g} / \mathrm{ml}$ gentamycin for 7 days at $37^{\circ} \mathrm{C}$ and assayed for $\beta$ galactosidase activity. $\beta$-Galactosidase activities were determined at $28^{\circ} \mathrm{C}$ for five individual clones (GPM53/1 through GPM53/5 etc.) obtained for each plasmid and average values are shown as bars. Standard deviations are indicated for each construct. 
To be unbiased in the further analysis, five colonies of each transformation were re-isolated from plates that did not contain X-Gal. These colonies were cultivated in order to obtain DNA for the verification of the presence of the fusion in the M. pneumoniae cells and to prepare cell extracts for the quantitative determination of $\beta$-galactosidase activity. As shown in Fig. 18 , the presence of all three fusions was demonstrated and the M. pneumoniae strains were designated GPM53, GPM54, and GPM64 (transformations with pGP353, pGP354, and pGP364, respectively).

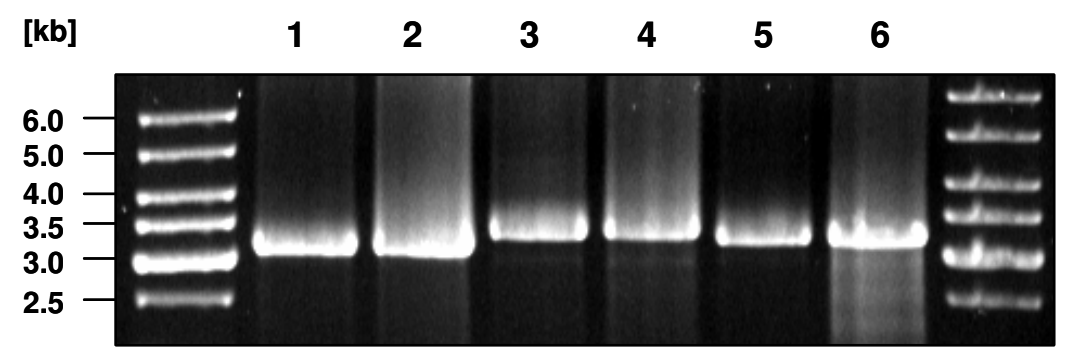

Fig. 18: Agarose gel electophoresis to confirm the presence of the promoterless lac $Z$ gene in strain GPM53/1 (lane 1) and of the ldh-lacZ fusions of pGP354 and pGP364 in strains GPM54/1 (lane 3) and GPM64/1 (lane 5) by colony PCR. Oligonucleotides for the detection of the promoterless lacZ gene in strain GPM53/1 were SH44 and SH45, for the detection of the ldh promoter lacZ fusions in strains GPM54/1 and GPM64/1 the oligonucleotides SH44 and SH46 were used. PCRs with the plasmids pGP353 (lane 2), pGP354 (lane 4) or pGP364 (lane 6) as templates using the respective oligonucleotides served as controls. The colony PCR was performed with all five individual clones from each transformation and gave the same results as those shown here.

To eliminate positional effects of transposon integration at random sites in the chromosome, five individual clones per plasmid were chosen and their $\beta$-galactosidase activities were determined (Miller, 1972) in cell extracts that were prepared as described previously (Halbedel et al., 2004). These individual clones were designated GPM53/1 through GPM53/5 etc. As shown in Fig. 17B, no $\beta$-galactosidase was detectable in the five GPM53 clones. This confirms that the "empty" reporter cloning vector does not confer any expression of the promoterless lac $Z$ gene. In contrast, a high activity was observed in all GPM54 clones containing the $l d h$ promoter and Shine-Dalgarno sequence upstream of the $l a c Z$ gene. This finding demonstrates that the E. coli lacZ gene can be efficiently translated in M. pneumoniae. In the M. pneumoniae GPM64 clones the core of the $l d h$ promoter is deleted from the fragment upstream of $l a c Z$. This resulted in a 7.5-fold reduction of $\beta$-galactosidase activity as compared to the GPM54 clones containing the complete promoter fragment. Even though the transposons inserted at different positions, the $\beta$-galactosidase activities driven by the two DNA fragments were quite consistent as indicated by the standard deviations. 
This study demonstrates that $l a c Z$ fusions can be a useful tool for the for the analysis of promoter fragments of $M$. pneumoniae genes in vivo. They will help to study regulatory events at the molecular level using promoter mutants. Moreover, the blue-white screen can be helpful in the isolation of trans-acting transposon mutants that affect the expression of the gene of interest. 


\section{Chapter 6:}

\section{Regulatory protein phosphorylation in Mycoplasma pneumoniae: A PP2C-type phosphatase serves to dephosphorylate $\mathrm{HPr}(\operatorname{Ser}-\mathrm{P})$}

The work described in this chapter was published in:

Halbedel, S., J. Busse, S. R. Schmidl, and J. Stülke. 2006. Regulatory protein phosphorylation in Mycoplasma pneumoniae: A PP2C-type phosphatase serves to dephosphorylate HPr(Ser-P). J Biol Chem, 281:26253-26259.

\section{Author contributions:}

This study was designed and interpreted by SH and JS. The haystack mutagenesis strategy was designed by SH. SH performed all experiments, but JB contributed substantially to the construction of the transposon mutant library and the isolation of the of the $h p r K$ and the $\operatorname{prpC}$ mutants. SRS helped with the construction of pGP370 and the overproduction of PrpC during his practical training under the supervision of SH. JS and SH wrote the paper. 


\section{Abstract}

Among the few regulatory events in the minimal bacterium Mycoplasma pneumoniae is the phosphorylation of the HPr phosphocarrier protein of the phosphotransferase system. In the presence of glycerol, HPr is phosphorylated in an ATP-dependent manner by the HPr kinase/phosphorylase (HPrK/P). The role of the latter enzyme was studied by constructing a M. pneumoniae hprK mutant defective in HPrK/P. This mutant strain did no longer exhibit HPr kinase activity, but had surprisingly still $\operatorname{HPr}(\operatorname{Ser}-\mathrm{P})$ phosphatase activity. An inspection of the genome sequence revealed the presence of a gene $(\operatorname{prpC})$ encoding a presumptive protein serine/ threonine phosphatase of the PP2C family. The phosphatase PrpC was purified and its biochemical activity in $\operatorname{HPr}(\operatorname{Ser}-\mathrm{P})$ dephosphorylation demonstrated. Moreover, a prpC mutant strain was isolated and found to be impaired in $\operatorname{HPr}(\operatorname{Ser}-\mathrm{P})$ dephosphorylation. Homologues of PrpC are present in many bacteria possessing $\mathrm{HPr}(\mathrm{Ser}-\mathrm{P})$ suggesting that PrpC may play an important role in adjusting the cellular HPr phosphorylation state and thus controlling the diverse regulatory functions exerted by the different forms of HPr.

\section{Introduction}

Bacteria possess highly sophisticated signal transduction systems to survey the nutrient supply in their environment and to respond appropriately. For carbon metabolism, the phosphotransferase system (PTS) has functions comparable to a central processing unit in many bacteria. Small PTS proteins that can be reversibly phosphorylated and specifically interact with a plethora of partners in their different modifications states, are of crucial importance (Postma et al., 1993).

The PTS is composed of two general proteins, enzyme I and HPr, and a set of sugar specific permeases. The primary function of the system is the uptake of sugars coupled to their phosphorylation. The phosphoryl group is derived from phosphoenolpyruvate and is transferred via enzyme I, HPr, and the sugar-specific permease to the incoming sugar (Postma et al., 1993). In addition to its function in carbohydrate transport, the PTS is one of the major regulatory systems in many bacteria. This is due to the different phosphorylation state of PTS proteins in the presence or absence of sugars. In E. coli and other enteric bacteria, the IIA domain of the glucose permease is the key player in signal transduction mediating either inducer exclusion or the stimulation of cyclic AMP synthesis. In contrast, in Gram-positive bacteria with a low GC content (i.e., the firmicutes) as well as in spirochaetes and many proteobacteria, the HPr protein plays the central role in the regulation of carbon metabolism (Stülke \& Schmalisch, 2004). 
In the firmicutes including Bacillus subtilis, Listeria monocytogenes and Mycoplasma pneumoniae, HPr is not only phosphorylated in a PEP-dependent manner on His-15 but also subject to a regulatory phosphorylation by the metabolite-controlled $\mathrm{HPr}$ kinase/phosphorylase (HPrK/P) on Ser-46. While $\mathrm{HPr}(\mathrm{His} \sim \mathrm{P})$ is required for sugar transport, both $\operatorname{HPr}($ His $\sim \mathrm{P})$ and $\operatorname{HPr}(\operatorname{Ser}-\mathrm{P})$ play distinct roles in the regulation of carbon metabolism and virulence. $\mathrm{HPr}(\mathrm{His} \sim \mathrm{P})$ can phosphorylate several transcription regulators and enzymes thereby stimulating their activity (Darbon et al., 2002; Stülke et al., 1998). Moreover, $\mathrm{HPr}($ His $\sim \mathrm{P})$ seems to be required for the activity of the L. monocytogenes virulence transcription factor PrfA (Herro et al., 2005). On the other hand, $\mathrm{HPr}(\operatorname{Ser}-\mathrm{P})$ serves as a cofactor for the pleiotropic transcription factor CcpA that mediates carbon catabolite repression and activation in the firmicutes (Deutscher et al., 1995; Schuhmacher et al., 2004). The phosphorylation state of HPr depends on the nutrient supply of the bacteria. In the absence of glucose, free $\operatorname{HPr}$ and $\operatorname{HPr}(\mathrm{His} \sim \mathrm{P})$ are present in the cells. In contrast, a significant portion of HPr is phosphorylated on Ser-46 if the bacteria grow in the presence of glucose (Monedero et al., 2001b; Ludwig et al., 2002). In B. subtilis, the two phosphorylation events are mutually exclusive. Once formed, $\mathrm{HPr}(\mathrm{His} \sim \mathrm{P})$ can be dephosphorylated by the transfer of the phosphate group back to Enzyme I, to any of a large set of sugar permeases or to one of the regulatory protein targets. In contrast, $\operatorname{HPr}(\operatorname{Ser}-\mathrm{P})$ can only be dephosphorylated by the action of the HPr kinase itself, which exhibits also a phosphorylase activity, depending on the presence or absence of easily metabolizable carbon sources. In contrast to the more common protein phosphatases, the phosphorylase transfers the phosphate group to an inorganic phosphate thus generating pyrophosphate (Mijakovic et al., 2002; Reizer et al., 1998).

We are interested in the regulatory mechanisms of carbon metabolism in M. pneumoniae. These pathogenic bacteria are characterized by their extremely reduced genomes with only a handful of regulatory proteins (Himmelreich et al., 1996). Projects to create artificial life, the so-called minimal genome concept, did recently attract much scientific interest to the investigation of Mycoplasma genitalium, M. pneumoniae and other related cell wall-less bacteria collectively called mollicutes (Glass et al., 2006). One of the few regulatory proteins of $M$. pneumoniae is the HPr kinase/ phosphorylase (HPrK/P) encoded by the hprK gene (Steinhauer et al., 2002a). Unlike its homolog from B. subtilis which exhibits kinase activity only in the presence of high ATP concentrations or if fructose-1,6-bisphosphate is present, the M. pneumoniae enzyme is active as a kinase already at very low ATP concentrations due to its high affinity for ATP (Merzbacher et al., 2004). This feature may reflect the adaptation of M. pneumoniae to nutrient rich human mucosal surfaces (Steinhauer et al., 2002a). The 
structure of the M. pneumoniae HPrK/P has been elucidated, however, the reason for the different control of activities as compared to the homologous enzymes from other organisms has so far remained obscure (Allen et al., 2003; Nessler et al., 2003). Assays of in vivo HPr phosphorylation revealed that HPr is phosphorylated on His-15 but not on Ser-46 if the bacteria grow with glucose or fructose. $\mathrm{HPr}(\operatorname{Ser}-\mathrm{P})$ was detectable only in the presence of glycerol (Halbedel et al., 2004). This finding is in contrast to the previous biochemical analysis of $M$. pneumoniae HPrK/P and still awaits an explanation. Moreover, a substantial portion of HPr is doubly phosphorylated in the presence of glycerol suggesting distinct interaction properties of the proteins involved in HPr phosphorylation (Halbedel \& Stülke, 2005).

The genetic analysis of M. pneumoniae is hampered by the lack of a genetic system. Transposons have been used to obtain mutants (Dybvig et al., 2000; Glass et al., 2006), however, it has so far not been possible to isolate any predetermined desired mutant strains.

In this work, we describe a simple screen for the isolation of $M$. pneumoniae mutants. The analysis of an $h p r K$ mutant revealed the presence of an additional enzyme involved in the dephosphorylation of $\mathrm{HPr}(\mathrm{Ser}-\mathrm{P})$. The corresponding gene prpC (MPN247) was identified and the activity of the encoded protein phosphatase was proven in vitro and in vivo.

\section{Experimental procedures}

Bacterial strains, oligonucleotides and growth conditions. Escherichia coli DH5 $\alpha$ was used for overexpression of recombinant proteins. The cells were grown in LB medium containing ampicillin $\left(100 \mu \mathrm{g} \mathrm{ml}^{-1}\right)$. The $M$. pneumoniae strains used in this study were $M$. pneumoniae M129 (ATCC 29342) in the $33^{\text {rd }}$ broth passage, and its isogenic mutant derivatives GPM51 (hprK::mini-Tn, $\mathrm{Gm}^{\mathrm{R}}$ ) and GPM68 (prpC::mini-Tn, Gm ${ }^{\mathrm{R}}$ ). The oligonucleotides used in this study are listed in Tab. 3. M. pneumoniae was grown at $37^{\circ} \mathrm{C}$ in $150 \mathrm{~cm}^{2}$ tissue culture flasks containing $100 \mathrm{ml}$ of modified Hayflick medium as described previously (Halbedel et al., 2004). Carbon sources were added as indicated. Strains harboring transposon insertions were cultivated in the presence of $80 \mu \mathrm{g} / \mathrm{ml}$ gentamicin.

DNA manipulation and plasmid construction. Transformation of E. coli and plasmid DNA extraction was performed using standard procedures (Sambrook et al., 1989). Enzymatic DNA manipulations and modifications were done as described previously (Ludwig et al., 2002). For the amplification of a C-terminally truncated $\operatorname{hprK}$ allele the oligonucleotides KS9 and SH30 were used. The PCR fragment was digested with SalI and NheI and ligated into the overexpression vector pWH844 (Schirmer et al., 1997) cut with the same enzymes. The 
resulting plasmid was sequenced and named pGP366. In order to overexpress $M$. pneumoniae PrpC (MPN247) we constructed plasmid pGP370 in two steps. First, an $1.5 \mathrm{~kb}$ fragment containing the $M$. pneumoniae MPN247 gene was amplified from chromosomal DNA using the primers SH64 and SH65. As the MPN247 gene contains a TGA codon that codes for tryptophan in $M$. pneumoniae but for an opal codon in E. coli, the PCR fragment was used as template in a CCR mutagenesis (Bi \& Stambrook, 1998) using the amplification primers SH66 and SH67 and the 5'-phosphorylated mutagenic primer SH68 to introduce an A375G transition. The resulting fragment was cloned between the SalI and NheI sites of pWH844. The replacement of the TGA by a TGG codon was verified by DNA sequencing.

Tab. 3: Oligonucleotides used in thi study

\begin{tabular}{ll}
\hline Oligonucleotide & Sequence $\left(\mathbf{5}^{\prime} \rightarrow \mathbf{3}^{\prime}\right)^{\mathbf{a}}$ \\
\hline KS9 & AAAGTCGACATGAAAAAGTTATTAGTCAAGGAG \\
KS10 & ATTAAGCTTGGTCTGCTACTAACACTAGGATTCATCTTTTTTACG \\
SH3 & GAGTACCCGGATTAAAGCGGG \\
SH4 & CTAATACGACTCACTATAGGGAGACATTAACTGGATTTCGGTGCGCTG \\
SH29 & ATGAGTGAGCTAACTCACAG \\
SH30 & CAATACGCAAACCGCCTC \\
SH62 & TAGAATTTTATGGTGGTAGAG \\
SH63 & CTAATACGACTCACTATAGGGAGAACACTATCATAACCACTACC \\
SH64 & GCTTTAGTTGGCAATAATTCC \\
SH65 & CTTCTTCCAGTTGTTGTCG \\
SH66 & AAAGTCGACATGGACAGCACCAACCAAAAC \\
SH67 & AAGCTAGCTTAGTGCCATTGTTTTAAATTAATCAAG \\
SH68 & P-GCAAAACATTTGGACCTTTTGGG \\
SH73 & CTAATACGACTCACTATAGGGAGAGACCATCAGAGCACAACAG \\
\hline a The "P" at the 5' end of oligonucleotide sequences indicates phosphorylation. The sequence of the T7- \\
promotor is underlined in SH4, SH 63 and SH73.
\end{tabular}

Electroporation of M. pneumoniae. M. pneumoniae was transformed with plasmid DNA by electroporation as described previously (Hedreyda et al., 1993). Transposants were selected on PPLO agar containing $80 \mu \mathrm{g} / \mathrm{ml}$ gentamicin and single colonies were transferred into modified Hayflick medium also containing $80 \mu \mathrm{g} / \mathrm{ml}$ gentamicin.

Southern blot analysis. For the preparation of $M$. pneumoniae chromosomal DNA, cells of a $100 \mathrm{ml}$ culture were harvested as described (Halbedel et al., 2004). The cell pellet was resuspended in $750 \mu \mathrm{l} 50 \mathrm{mM}$ Tris/ $\mathrm{HCl} \mathrm{pH}$ 8.0, $25 \mathrm{mM}$ EDTA and RNase A was added to a final concentration of $25 \mu \mathrm{g} / \mathrm{ml}$. After an incubation step at $37^{\circ} \mathrm{C}$ for $15 \min 50 \mu \mathrm{l}$ proteinase $\mathrm{K}(25 \mathrm{mg} / \mathrm{ml})$ and $75 \mu 110 \%$ SDS were added. The mixture was incubated at $50^{\circ} \mathrm{C}$ until the lysate was clarified and subsequently cooled down on ice. To precipitate debris $300 \mu 15 \mathrm{M}$ 
$\mathrm{NaCl}$ were added and the mixture was incubated for 20 minutes on ice. The precipitate was pelleted by centrifugation ( $25 \mathrm{~min}, 15000 \mathrm{~g}, 4^{\circ} \mathrm{C}$ ) and the resulting supernatant was mixed with $500 \mu \mathrm{l}$ isopropanol to precipitate the chromosomal DNA. The DNA pellet was washed with $70 \%$ ethanol and finally resolved in $300 \mu \mathrm{TE}$ buffer. Digests of chromosomal DNA were separated using $1 \%$ agarose gels and transferred onto a positively charged nylon membran (Roche Diagnostics) (Sambrook et al., 1989) and probed with Digoxigenin labelled riboprobes obtained by in vitro transcription with T7 RNA polymerase (Roche Diagnostics) using PCR-generated fragments as templates. Primer pairs for the amplification of $h p r K$, prpC and aac-ahpD gene fragments were SH3/ SH4, SH66/ SH73 and SH62/ SH63, respectively (see Tab. 3). The reverse primers contained a T7 RNA polymerase recognition sequence. In vitro RNA labelling, hybridisation and signal detection were carried out according to the manufacturer's instructions (DIG RNA labeling Kit and detection chemicals; Roche Diagnostics).

Western blot analysis. In vivo HPr phosphorylation was assayed by Western blot analysis as described previously. The different forms of HPr were detected using antibodies directed against M. pneunomiae HPr (Halbedel et al., 2004).

Protein purification. $\mathrm{His}_{6}-\mathrm{HPr}, \mathrm{His}_{6}-\mathrm{HPrK} / \mathrm{P}, \mathrm{His}_{6}-\mathrm{PrpC}$ and the $\mathrm{His}_{6}$-tagged version of the C-terminally truncated HPrK/P were overexpressed using the expression plasmids pGP217 (Steinhauer et al., 2002a), pGP204 (Steinhauer et al., 2002a), pGP370 and pGP366, respectively. Expression was induced by the addition of IPTG (final concentration $1 \mathrm{mM}$ ) to exponentially growing cultures and the proteins were purified using a $\mathrm{Ni}^{2+} \mathrm{NTA}$ superflow column as described previously (Halbedel \& Stülke, 2005). For the recombinant HPr protein the overproduced protein was purified from the pellet fraction of the lysate by urea extraction and renatured as described previously (Steinhauer et al., 2002a).

In vitro activity assays of HPrK/P and of HPr(Ser-P) dephosphorylating enzymes. HPrK/P activity assays in cell extracts and the preparation of $\mathrm{HPr}(\mathrm{Ser}-\mathrm{P})$ were carried out as described previously (Halbedel et al., 2004; Halbedel \& Stülke, 2005). To detect HPr(Ser-P) phosphatase activity in cell extracts, $20 \mu \mathrm{M} \operatorname{HPr}(\operatorname{Ser}-\mathrm{P})$ were incubated with $10 \mu \mathrm{g}$ of cellular protein in $25 \mathrm{mM}$ Tris/ $\mathrm{HCl}, 10 \mathrm{mM} \mathrm{MgCl} 2,10 \mathrm{mM}$ dithiothreitol in a total volume of $20 \mu \mathrm{l}$ for $2 \mathrm{~h}$ at $37^{\circ} \mathrm{C}$ followed by thermal inactivation (Halbedel \& Stülke, 2005). HPr(Ser-P) phosphatase activity of PrpC was assayed in $20 \mu \mathrm{l}$ buffer containing $75 \mathrm{mM}$ Tris/ $\mathrm{HCl} \mathrm{pH} 7.5$, $1 \mathrm{mM} \mathrm{MnCl} 2,1 \mathrm{mM}$ DTT with $20 \mu \mathrm{M} \mathrm{HPr}(\operatorname{Ser}-\mathrm{P})$ and $300 \mathrm{nM}$ His $_{6}-\mathrm{PrpC}_{2}$. The dephosphorylation reaction was allowed to proceed for $15 \mathrm{~min}$ and stopped immediately by thermal denaturation for $10 \mathrm{~min}$ at $95^{\circ} \mathrm{C}$. The assay mixtures were analyzed on $10 \%$ native 
polyacrylamide gels. Proteins were visualized by Coomassie staining. The dephosphorylating activity of $M$. pneumoniae PrpC towards $p$-nitrophenyl phosphate (PNPP) was assayed in a buffer containing $300 \mathrm{mM}$ Tris/HCl $\mathrm{pH} 7.5,1 \mathrm{mM} \mathrm{MnCl}_{2}, 1 \mathrm{mM}$ DTT with $25 \mathrm{mM}$ PNPP and $5 \mu \mathrm{g}$ of purified $\mathrm{His}_{6}$-PrpC in a total reaction volume of $1 \mathrm{ml}$. The reaction was started by the addition of $\operatorname{PrpC}$, carried out for $10 \mathrm{~min}$ at $30^{\circ} \mathrm{C}$ and stopped by the addition of $100 \mu 10.1$ $\mathrm{M}$ EDTA $\mathrm{pH}$ 8.0. The reaction product $p$-nitrophenol was quantified photometrically at a wavelength of $420 \mathrm{~nm}$.

\section{Results}

Isolation of a M. pneumoniae hprK mutant. M. pneumoniae can be subjected to transposon mutagenesis using delivery vectors such as pMT85 (Zimmerman \& Herrmann, 2005). We have designed a strategy, designated "haystack mutagenesis", to isolate any viable desired mutant. This is based on an ordered collection of $M$. pneumoniae transposon mutants and the assumptions that these bacteria contain about 200 non-essential genes and that about 920 clones are required to find a desired mutant with a confidence of $99 \%$. We isolated 2976 individual transposon mutants and grouped them in pools of 50 clones. With this number of mutants, a $h p r K$ mutant is included in the library with a probability of $99.999 \%$. Cells of each pool were used in a PCR to detect the occurrence of products corresponding to junctions between the $h p r K$ gene and the mini-transposon using the oligonucleotides KS10 and SH29 (see Fig. 19A). From one pool that gave a positive signal, colony PCR with the 50 individual mutants resulted in the identification of one hprK mutant. The presence of the transposon insertion in $h p r K$ was verified by Southern blot analysis (Fig. 19B). To test whether this strain contains only one unique transposon insertion, we performed another Southern blot using a probe specific for the $a a c-a p h D$ resistance gene present on the mini-transposon. As shown in Fig. 19B, only one single band hybridizing with this probe was detected, moreover, this fragment had the same size as the NcoI-SmaI fragment hybridizing to the hprK probe (see Fig. 19B). The isolated $h p r K$ mutant strain was designated GPM51. The position of the transposon insertion in the $h p r K$ gene of $M$. pneumoniae GPM51 was determined by DNA sequencing. The $h p r K$ gene was disrupted after its $625^{\text {th }}$ nucleotide resulting in a truncated protein of 208 amino acids with one additional amino acid and the following stop codon encoded by the inserted mini-transposon. Thus, the protein is truncated in the immediate vicinity of the active center of HPrK/P (Allen et al., 2003; Steinhauer et al., 2002a). The position of the transposon insertion and the target duplications are shown in Fig. 19C. 
A

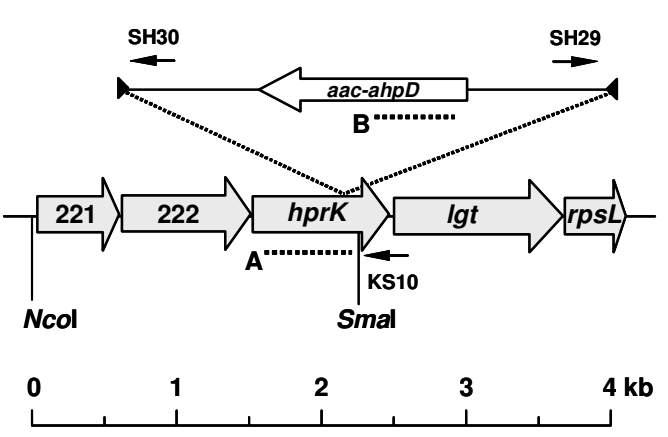

B

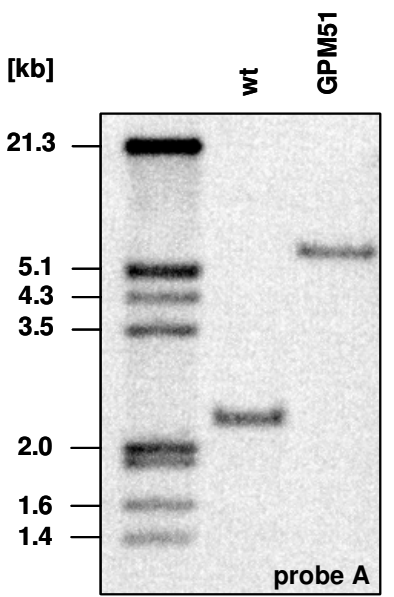

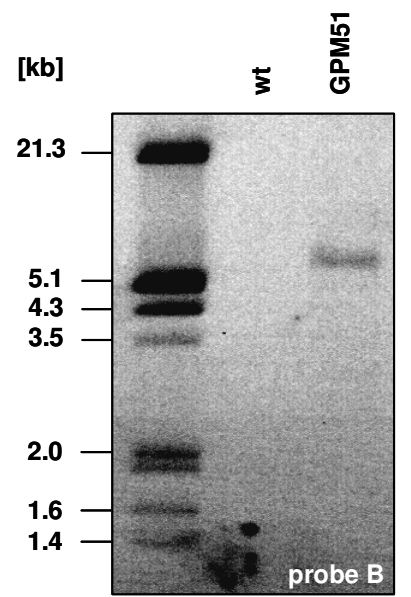

C

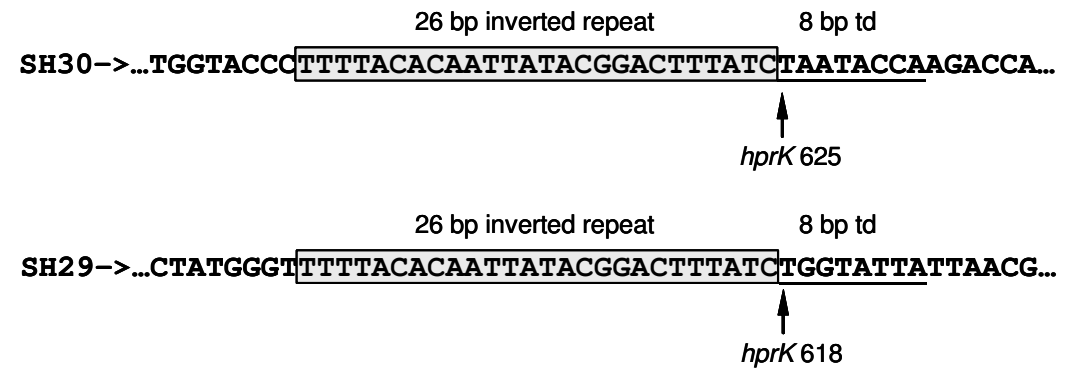

Fig. 19: Isolation of a M. pneumoniae hprK transposon insertion mutant.

(A) Schematical drawing of the genomic region next to the hprK gene in $M$. pneumoniae and site of the transposon insertion in the $h p r K$ knockout strain GPM51. The annealing sites of oligonucleotides used in sequencing reactions for the determination of the transposon insertion site are indicated by arrows. Probes hybridising to internal fragments of the $h p r K$ and the $a a c-a h p D$ genes are depicted as dotted lines. (B) Southern blot to confirm the single insertion of the mini-transposon into the hprK gene of strain GPM51. Chromosomal DNA of the wild type and strain GPM51 was digested using NcoI and SmaI. Blots were hybridized with the $h p r K$ specific probe (left blot) and a probe hybridizing to the aac-ahpD gene of the mini-transposon (right blot). DIG-labeled DNA Molecular Weight Marker III (Roche Applied Science) served as a standard. (C) DNA sequence in the immediate vicinity of the transposon insertion site in strain GPM51. SH30 and SH29 (see Fig. 19A) were used as sequencing primers. The $26 \mathrm{bp}$ long inverted repeats of the mini transposon are boxed and the 8 bp target duplications are underlined.

HPr phosphorylation and dephosphorylation in the hprK mutant. The only known biochemical activities of HPrK/P are the phosphorylation of HPr on Ser-46 and the dephosphorylation of $\mathrm{HPr}(\operatorname{Ser}-\mathrm{P})$. To test the effect of the disruption of the hprK gene on $\mathrm{HPr}$ phosphorylation, we performed in vivo phosphorylation assays. For this purpose, protein extracts of $M$. pneumoniae were subjected to native gel electrophoresis, and the different forms of HPr were detected by Western blotting analysis (Fig. 20A). The different species of HPr could be identified due the heat-lability of the phosphoamidate of $\operatorname{HPr}(\mathrm{His} \sim \mathrm{P})$. As shown in Fig. 20A, two bands of HPr were detected in the wild-type strain. Upon heating, the fastest band disappeared and a new, more slowly migrating band became visible. Thus, three forms of $\mathrm{HPr}$, i. e. $\mathrm{HPr}(\mathrm{Ser}-\mathrm{P}), \mathrm{HPr}(\mathrm{His} \sim \mathrm{P})$, and the doubly phosphorylated $\operatorname{HPr}(\operatorname{Ser}-\mathrm{P})(\mathrm{His} \sim \mathrm{P})$ were 
present in the wild type strain grown in medium containing glucose and glycerol. This observation is in good agreement with previous results (Halbedel et al., 2004). In contrast, only singly phosphorylated HPr was detectable in the hprK mutant strain grown under the same conditions. This band disappeared completely upon heating suggesting that $\mathrm{HPr}(\mathrm{His} \sim \mathrm{P})$ is the only form of HPr present in the hprK mutant strain (see Fig. 20A). Similarly, an analysis of cell extracts revealed ATP-dependent kinase activity on recombinant HPr in the wild type strain but not in the hprK mutant GPM51 (see Fig. 20B). Thus, as expected no HPr kinase activity was detectable in the mutant.

A

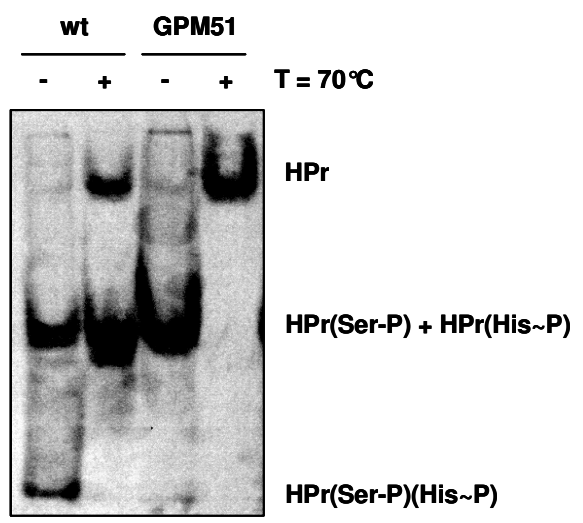

B

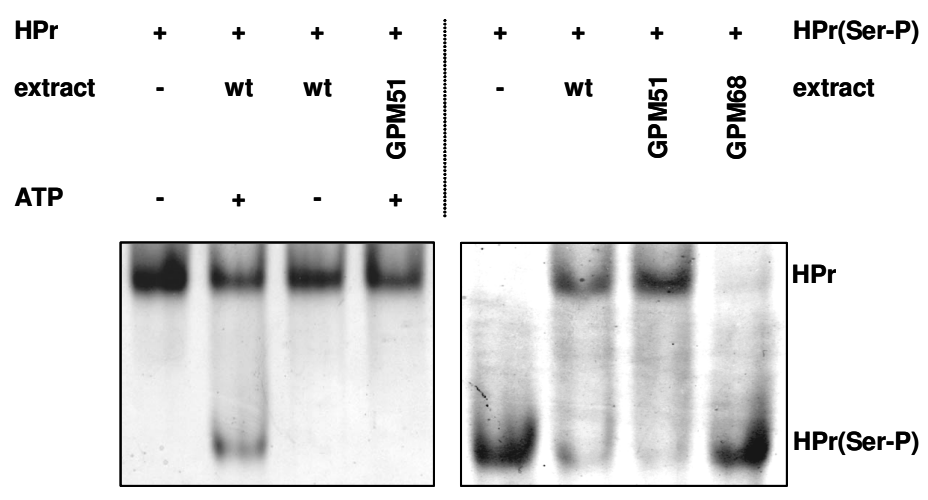

Fig. 20: HPr phosphorylation in the M. pneumoniae hprK mutant.

(A) Native Western blot using a polyclonal anti-HPr antiserum to control the status of HPr phosphorylation in the hprK knockout strain GPM51. Wild type and GPM51 were grown in the presence of glucose and glycerol to provoke HPr(Ser-P) formation (Halbedel et al., 2004). $20 \mu \mathrm{g}$ of each protein extract was subjected to native gel electrophoresis and blotted onto a PVDF membrane. Aliquots of each sample were heated for $10 \mathrm{~min}$ at $70^{\circ} \mathrm{C}$ to hydrolyze the heat-labile $\operatorname{HPr}(\mathrm{His} \sim \mathrm{P})$. (B) In vitro HPr phosphorylation assay with wild type and GPM51 extracts and ATP as phosphate donor to confirm the the loss of HPr kinase activity in GPM51 (left gel). In vitro $\mathrm{HPr}(\mathrm{Ser}-\mathrm{P})$ dephosphorylation assay with extracts of the wild type and the GPM51 and GP68 mutant strains (right gel) as sources of phosphatase activity.

Next, we wanted to determine whether the hprK mutant strain had also lost the HPr phosphatase activity. Since no $\operatorname{HPr}(\operatorname{Ser}-\mathrm{P})$ was present in GPM51, this analysis had to be performed using purified $\mathrm{HPr}(\mathrm{Ser}-\mathrm{P})$ and cell extracts of the wild type and mutant strains. As shown in Fig. 20B, HPr(Ser-P) dephosphorylation was detected in the wild type strain. Surprisingly, complete HPr(Ser-P) dephosphorylation was also observed in the hprK mutant strain GPM51. This finding demonstrates that there is still an active $\operatorname{HPr}(\operatorname{Ser}-\mathrm{P})$ phosphatase even if the hprK gene encoding HPr kinase/phosphorylase is disrupted.

Identification of PrpC as a novel protein phosphatase that targets HPr(Ser-P). Two possible reasons might cause the phosphatase activity observed in M. pneumoniae GPM51: (i) the truncated HPrK/P present in this strain might still have phosphatase activity, or (ii) 
another protein in $M$. pneumoniae might be active in $\mathrm{HPr}(\operatorname{Ser}-\mathrm{P})$ dephosphorylation. To distinguish between these possibilities, we cloned a truncated $h p r K$ allele that is identical to the truncated hprK present in GPM51. This protein was purified and used to assay phosphatase activity using $\operatorname{HPr}(\operatorname{Ser}-\mathrm{P})$ as a substrate. However, while the full-length protein dephosphorylated $\operatorname{HPr}(\operatorname{Ser}-\mathrm{P})$, no activity was detected using the truncated protein (data not shown). This observation suggests that another protein encoded by $M$. pneumoniae might dephosphorylate $\operatorname{HPr}($ Ser-P).

Dephosphorylation of $\mathrm{HPr}(\mathrm{Ser}-\mathrm{P})$ by a protein different from HPrK/P has so far not been reported in any bacterium. A candidate for such a phosphatase is the protein encoded by the open reading frame MPN247, which is annotated as a PP2C-like protein phosphatase (Himmelreich et al., 1996). Since phosphatases of this family dephosphorylate a broad range of protein substrates (Shi, 2004; Obuchowski, 2005), we considered the possibility that the MPN247 gene product was the phosphatase in search. To test this idea, the MPN247 gene was cloned in a way that allowed the subsequent purification of the His-tagged gene product. The fusion protein was purified by affinity chromatography and its activity as a HPr(Ser-P) phosphatase tested. As shown in Fig. 21, complete $\mathrm{HPr}(\operatorname{Ser}-\mathrm{P})$ dephosphorylation was observed in the presence of manganese ions. Thus, the protein enoded by the MPN247 gene exhibits $\operatorname{HPr}(\operatorname{Ser}-\mathrm{P})$ phosphatase activity. Based on the similarity of the deduced protein with the B. subtilis phosphatase PrpC and on the similar genetic arrangement (clustering with a protein Ser/Thr kinase) (Obuchowski et al., 2000), the MPN247 gene was renamed prpC. An alignment of the $M$. pneumoniae PrpC protein with other phosphatases of the PP2C family is shown in Fig. S1. As can be seen, the active sites involved in binding of metal ions and phosphate are highly conserved in all proteins of the family.

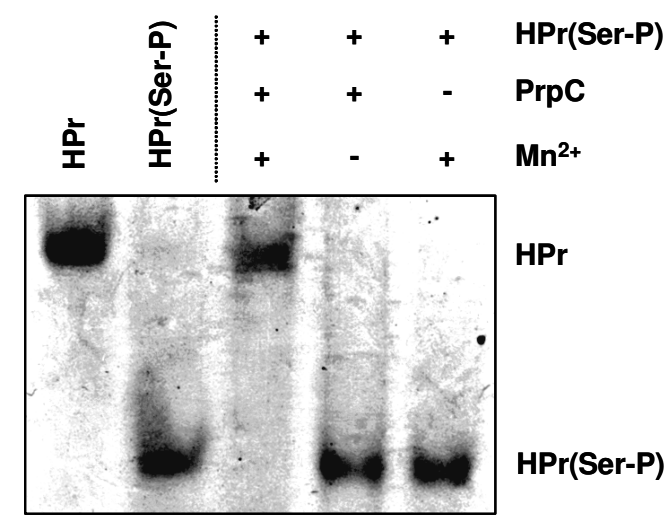

Fig. 21: $\operatorname{HPr}($ Ser-P) dephosphorylation by PrpC.

In vitro $\mathrm{HPr}(\mathrm{Ser}-\mathrm{P})$ dephosphorylation assay using purified $\mathrm{His}_{6}$-PrpC. $20 \mu \mathrm{M}$ HPr(Ser-P) was incubated with $300 \mathrm{nM} \mathrm{His}{ }_{6}-\mathrm{PrpC}$ in a total volume of $20 \mu \mathrm{l}$ for $10 \mathrm{~min}$ at $37^{\circ} \mathrm{C}$ in the presence or absence of $1 \mathrm{mM} \mathrm{MnCl}_{2}$. $\mathrm{HPr}, \mathrm{HPr}(\mathrm{Ser}-\mathrm{P})$ and $\mathrm{HPr}(\mathrm{Ser}-\mathrm{P})$ that has been incubated in assay buffer containing $1 \mathrm{mM} \mathrm{MnCl} \mathrm{M}_{2}$ in the absence of $\mathrm{His}_{6}$-PrpC were used to control the reaction. 
Control of PrpC activity. Protein phosphatases of the $2 \mathrm{C}$ family are regulated by a broad range of different metabolites among them inorganic phosphate and glycerol-2-phosphate (Das et al., 1996; Obuchowski et al., 2000). The regulation of $M$. pneumoniae PrpC was studied using the synthetic substrate $p$-nitrophenyl phosphate (PNPP) or $\mathrm{HPr}(\mathrm{Ser}-\mathrm{P})$. First, we determined the kinetic parameters of PrpC activity with PNPP. The $\mathrm{K}_{\mathrm{M}}$ and $\mathrm{v}_{\max }$ values were found to be $1.14 \pm 0.19 \mathrm{mM}$ and $2.41 \pm 0.69 \mu \mathrm{mol} \mathrm{min}^{-1} \mathrm{mg}^{-1}$, respectively (using a molar extinction coefficient $\left[\varepsilon_{420}\right]$ of $12,500 \mathrm{M}^{-1} \mathrm{~cm}^{-1}$ ). In the presence of inorganic phosphate, the PrpC activity was strongly inhibited in a competitive manner $\left(\mathrm{K}_{\mathrm{i}} 62 \pm 18 \mu \mathrm{M}\right)$, whereas glycerol-2-phosphate caused a weak inhibition (50\% inhibition at $34 \pm 11 \mathrm{mM}$ ) (see Fig. 22A). In contrast, glycerol did not affect PrpC activity. The inhibition of PrpC activity by inorganic phosphate and glycerol-2-phosphate was also observed using the natural substrate, $\operatorname{HPr}($ Ser-P) (see Fig. 22B).

A

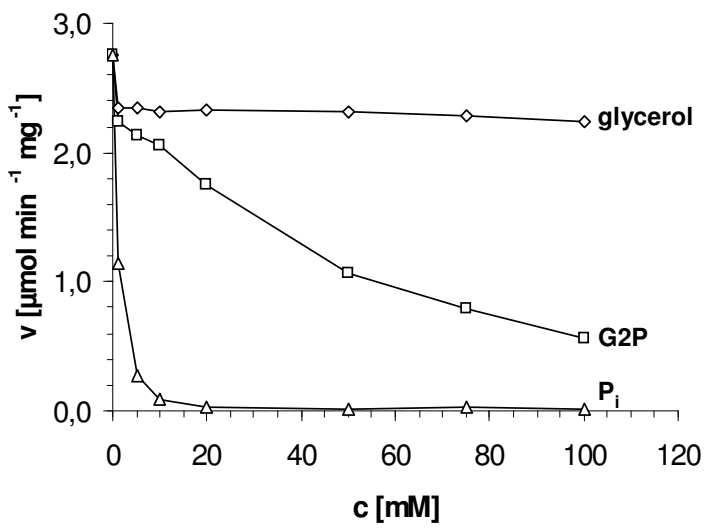

B

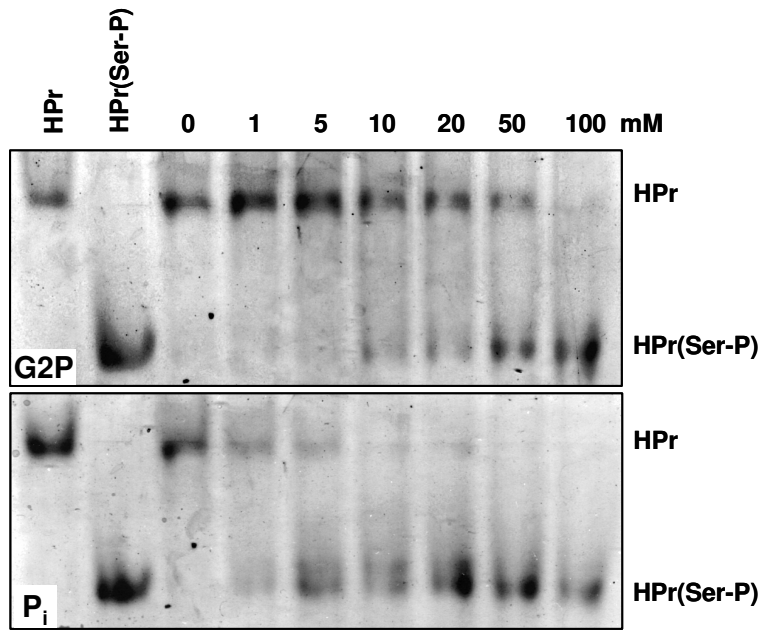

Fig. 22: Allosteric control of PrpC.

(A) Photometric assay with $p$-nitrophenyl phosphate as a synthetic substrate of $M$. pneumoniae His $_{6}-\mathrm{PrpC}_{\text {rp }}$ determine the influence of glycerol-2-phosphate and inorganic phosphate on the reaction rate. Glycerol, which is distinguished from glycerol-2-phosphate by the lack of a phosphate group only, served as a negative control. (B) Native gel electrophoresis to analyze the influence of glycerol-2-phosphate and inorganic phosphate on the activity of M. pneumoniae $\operatorname{PrpC}$ using $\mathrm{HPr}(\mathrm{Ser}-\mathrm{P})$ as the substrate. The concentration of both inhibitors is given once above the upper gel.

HPr phosphorylation in a prpC mutant strain. To confirm the biological role of PrpC, we isolated a $\operatorname{prpC}$ mutant from the mutant library using the oligonucleotides SH67 and SH29 as described for the $h p r K$ mutant. The transposon insertion was verified by Southern blot analysis with probes specific for $\operatorname{prpC}$ and $a a c-a h p D$ to demonstrate disruption of the prpC region and the unique insertion of the transposon, respectively. The insertion had occurred after the $167^{\text {th }}$ nucleotide of $\operatorname{prpC}$ giving rise to a truncated protein (see Fig. S2). The resulting strain was designated GPM68. 
To test the $\operatorname{HPr}(\operatorname{Ser}-\mathrm{P})$ phosphatase activity of the $\operatorname{prpC}$ mutant strain GPM68, HPr(Ser-P) was incubated in the presence of a cell extract of this strain. As shown in Fig. 20B, almost no HPr dephosphorylation was detected in the $\operatorname{prpC}$ mutant strain whereas the phosphatase activity was present both in the wild type and $h p r K$ mutant strains. The residual HPr(Ser-P) dephosphorylating activity seen with cell extracts of the $\operatorname{prp} C$ mutant is probably caused by the presence of a functional HPrK in this strain. However, as HPrK absolutely requires phosphate to be actitve in dephosphorylation of $\mathrm{HPr}(\mathrm{Ser}-\mathrm{P})$ (Steinhauer et al., 2002a), this activity is rather weak because no additional phosphate was included in this assay. This finding suggests that PrpC might be the major player controlling $\mathrm{HPr}(\mathrm{Ser}-\mathrm{P})$ dephosphorylation.

The finding that PrpC is a crucial factor in the control of HPr phosphorylation was supported by an analysis of the in vivo HPr phosphorylation state. In the presence of glucose, fructose or glucose and fructose no $\operatorname{HPr}(\mathrm{Ser}-\mathrm{P})$ was detectable in the wild type and $\operatorname{prpC}$ mutant strains. In contrast, $\mathrm{HPr}(\mathrm{Ser}-\mathrm{P})$ was formed in the presence of glycerol irrespective of the availability of glucose. This is in good agreement with our previous observation that glycerol triggers $\mathrm{HPr}(\mathrm{Ser}-\mathrm{P})$ formation in vivo (Halbedel et al., 2004). If both glycerol and glucose were present in the medium, a larger portion of HPr was present in the doubly phosphorylated form and as $\mathrm{HPr}(\operatorname{Ser}-\mathrm{P})$ in the prpC mutant GPM68 as compared to the isogenic wild type strain (Fig. 23). Thus, PrpC is indeed implicated in the regulation of HPr phosphorylation in living cells of $M$. pneumoniae.

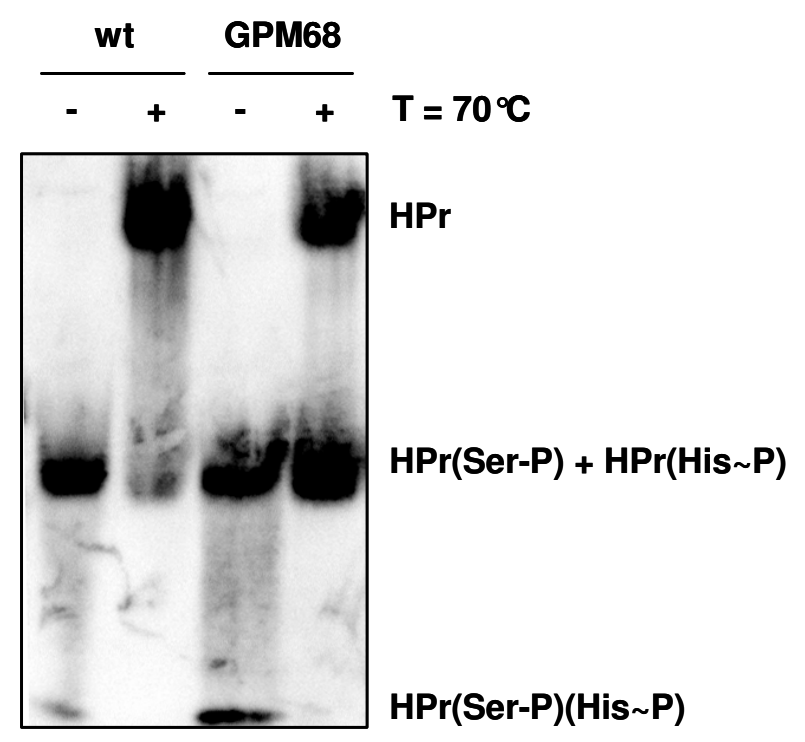

Fig. 23: In vivo HPr phosphorylation pattern in the M. pneumoniae prpC mutant GPM68.

Protein extracts of cultures of the wild type and the GPM68 strain that had been grown in the presence of glucose and glycerol to induce $\operatorname{HPr}(\operatorname{Ser}-\mathrm{P})$ formation were subjected to native gel electrophoresis and electroblotted onto a PVDF membrane. The membrane was detected using an polyclonal rabbit antiserum against M. pneumoniae HPr. For the discrimination of the both singly phosphorylated HPr forms an parallel aliquot of each sample was heat-exposed $\left(10 \mathrm{~min}, 70^{\circ} \mathrm{C}\right)$ to hydrolyze the heat-labile $\mathrm{HPr}(\mathrm{His} \sim \mathrm{P})$. 


\section{Discussion}

M. pneumoniae, M. genitalium and other mollicutes have recently attracted much interest due to their small genomes and the possibility to define the minimal genetic equipment required for independent life. However, while random transposon mutageneses suggested sets of genes that might be essential or not (Glass et al., 2006; Hutchison et al., 1999), it has so far not been possible to test these hypotheses by the directed isolation of mutants. The "haystack mutagenesis" approach developed in this work allows it to obtain any desired viable mutant in an easy way. Our results confirm the previous finding that the $h p r K$ gene is non-essential but they contradict the assignment of prpC (MPN247) as one of the essential genes (Glass et al., 2006; Hutchison et al., 1999). With the transposon mutant library at hand, the essentiality of each of the predicted genes can easily be verified or falsified. Moreover, with the availability of a tool for mutant isolation, the research on $M$. pneumoniae and related species will be significantly accelerated making so far intractable problems accessible for investigation.

The reductive evolution of $M$. pneumoniae has resulted in the loss of nearly all regulatory genes. Among the few regulatory responses observed in $M$. pneumoniae are the induction of heat shock genes upon temperature upshift and the phosphorylation of HPr on Ser-46 in the presence of glycerol (Halbedel et al., 2004; Weiner et al., 2003). The formation of HPr(Ser-P) is catalyzed by the HPrK/P encoded by the hprK gene (Steinhauer et al., 2002a) and this is the only enzyme in $M$. pneumoniae with such an activity. In contrast, dephosphorylation of $\mathrm{HPr}(\mathrm{Ser}-\mathrm{P})$ is not exclusively catalyzed by HPrK as detected using a hprK mutant strain. Surprisingly, an additional enzymatic activity was detected and we showed here that the protein phosphatase PrpC is responsible for this activity. Thus, a novel protein is implicated in controlling the phosphorylation state of HPr. Enzyme I of the PTS phosphorylates His-15 of HPr and this phosphate residue can be transferred to either of the two functional PTS sugar permeases, i. e. the glucose permease or the fructose permease (Halbedel et al., 2004). HPrK/P mediates phosphorylation of Ser-46, but both HPrK/P and PrpC catalyze dephosphorylation of $\operatorname{HPr}(\operatorname{Ser}-\mathrm{P})$. The presence of two different enzymes for this purpose has interesting implications: The phosphatase activity of HPrK/P is triggered if the concentration of inorganic phosphate is high in the cell (Merzbacher et al., 2004; Steinhauer et al., 2002a). It was suggested that these conditions occur if the cells are depleted for nutrients (Mason et $a l .$, 1981). In contrast, PrpC is strongly inhibited by the presence of inorganic phosphate (see Fig. 22). In summary, the intracellular phosphate concentration does not seem to be important for the dephosphorylation of $\operatorname{HPr}(\operatorname{Ser}-\mathrm{P})$ since one of the two enzymes is active under either condition. 
The HPr phosphorylation state is of key importance for the control of carbon metabolism in the Firmicutes: HPr can either serve in sugar transport, it can activate transcriptional regulators and enzymes, and it can be a co-factor of a transcriptional regulator. In the model organism, B. subtilis, HPr is phosphorylated on Ser-46 if the bacteria grow on glycolytically metabolizable carbon sources such as glucose (Ludwig et al., 2002; Monedero et al., 2001b). It has long been believed that HPrK/P is the only protein phosphorylating $\mathrm{HPr}$ or dephosphorylating HPr(Ser-P). Interestingly, only part of HPr is phosphorylated on Ser-46 even if the bacteria grow in the presence of glucose. In contrast, all HPr was converted to $\mathrm{HPr}(\operatorname{Ser}-\mathrm{P})$ in a mutant strain devoid of the transcriptional regulator CcpA (Ludwig et al., 2002). From these data, it was concluded that additional factors might control HPr phosphorylation. It is tempting to speculate that PrpC is the protein searched for. Indeed, PrpC is also present in B. subtilis. In the presence of glucose (low phosphate) it might dephosphorylate a part of $\mathrm{HPr}(\mathrm{Ser}-\mathrm{P})$ which remains available for sugar transport.

PrpC is a member of the family of PP2C protein phosphatases. These enzymes use a broad spectrum of phosphorylated substrates including the articificial substrate PNPP, the PII protein in cyanobacteria (Irmler \& Forchhammer, 2001), or anti-sigma factors and the translation factor EF-G in B. subtilis (Adler et al., 1997; Gaidenko et al., 2002). It will be interesting to analyze the molecular interactions between $\mathrm{HPr}(\operatorname{Ser}-\mathrm{P})$ and $\operatorname{PrpC}$ as well as the physiological roles of this phosphatase in $M$. pneumoniae as well as in other bacteria that possess $\operatorname{HPr}(\mathrm{Ser}-\mathrm{P})$. 


\section{Supplementary data}

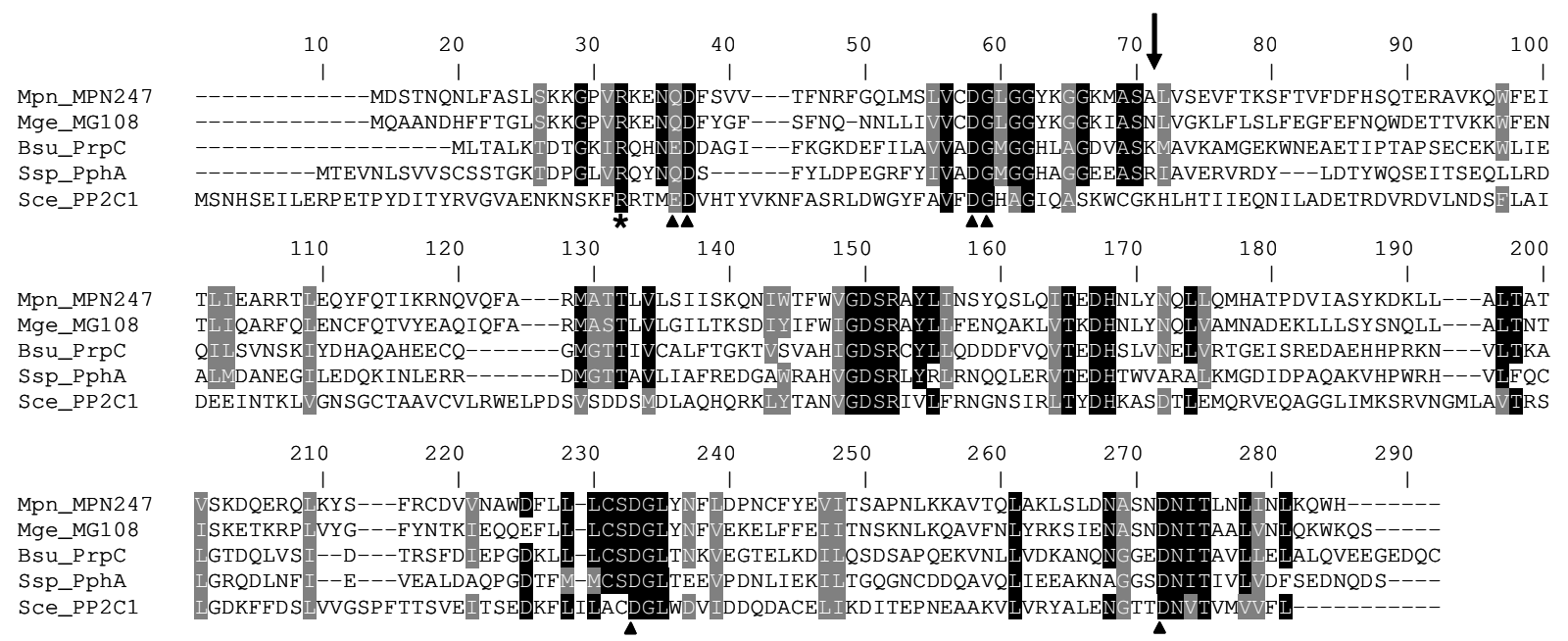

Fig. S1: Multiple sequence alignment of $\operatorname{PrpC}$ from $M$. pneumoniae with orthologuous PP2C phosphatases of other organisms. Black shading indicates $\geq 80 \%$ identity and grey shading stands for $\geq 80 \%$ similarity. Amino acids that constitute the metal binding site are depicted by black triangles. The conserved arginine residue (R19 in $M$. pneumoniae $\operatorname{PrpC}$ ) that is indicated by an asterisk was proposed as the physiological substrate binding site in the human PP2Ca protein (29). The arrow marks the insertion site of the mini-transposon in the $M$. pneumoniae prpC mutant strain GPM68. Abbreviations of organisms and GI numbers of the respective PP2C phosphatases (in brackets) are as follows: Mpn - Mycoplasma pneumoniae (13507986), Mge - Mycoplasma genitalium (12044960), Bsu - Bacillus subtilis (16078639), Ssp - Synechocystis sp. PCC 6803 (1652752), Sce Saccharomyces cerevisiae (1430965).

A

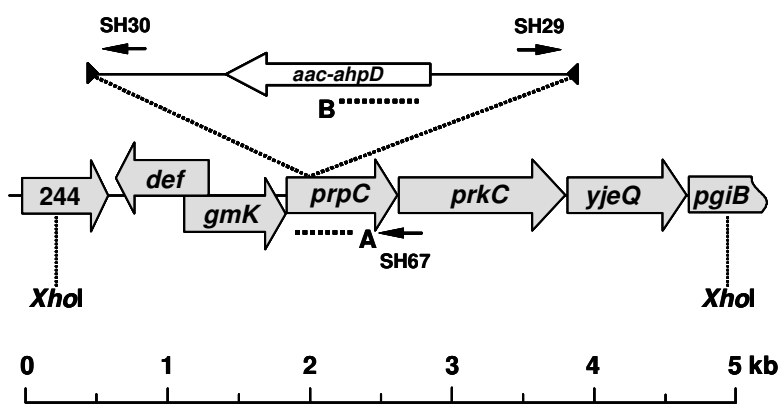

B

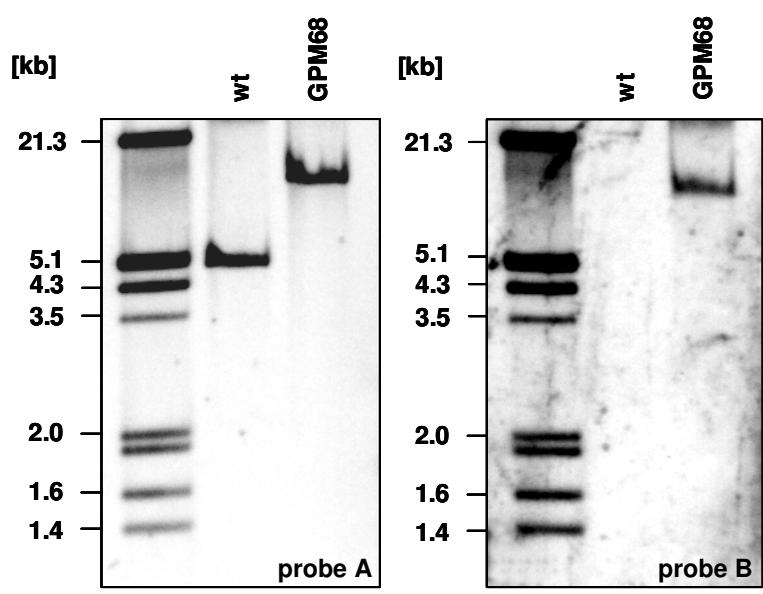

Fig. S2: (A) Genomic region surrounding the $M$. pneumoniae prpC gene and transposon insertion site in the prpC knockout strain GPM68. Annealing sites of DIG-labelled probes specific for the prpC and the $a a c-a h p D$ gene of the mini-transposon are indicated by dotted lines. (B) Southern blot analysis to confirm the single transposon insertion into the $\operatorname{prpC}$ gene of $M$. pneumoniae. Chromosomal DNA of the wild type and the prpC knockout strain GPM68 that had been digested by XhoI was hybridized with a $p r p C$ specific probe (left blot) and with a probe hybridizing to the $a a c-a h p D$ gene of the mini-transposon (right blot). 


\section{Chapter 7:}

Regulation of genes of overflow metabolism in Mycoplasma pneumoniae

Author contributions:

The proteomic analysis shown in Fig. 24 and the primer extension experiment shown in Fig. 27 were done in collaboration with Dr. Susanne Engelmann, University of Greifswald. The construction of the ackA-lacZ fusion and measurements of Ldh activity shown in Fig. 31 and Fig. 32 were performed by Hinnerk Eilers during his practical training under the supervision of the author. 


\begin{abstract}
Although long been considered to be unable to respond to changing environmental conditions, Mycoplasma pneumoniae has recently been shown to respond specifically to the presence of glycerol by formation of $\operatorname{HPr}(\operatorname{Ser}-\mathrm{P})$. In this work we used a proteomic approach to characterize changes in global gene expression in $M$. pneumoniae when grown in the presence of glycerol. The $a c k A$ and $l d h$ genes were found to be expressed in a glycerol-dependent manner. To verify the expression data of both genes, the accumulation of acetate and L-lactate in culture supernatants of $M$. pneumoniae grown in the presence of different carbon sources was monitored. The promoters of both genes were mapped using primer extension analysis and promoter fragments containing the promoter sequences of both genes were verified to drive transcription of a promoter-less lacZ gene in vivo. However, the cloned promoter fragments did not display any differential activity in response to the presence of glycerol that may account for the expression pattern seen on the level of the ackA and the ldh mRNA. Analysis of the $l d h$ transcription pattern in a $l d h$ transposon insertion mutant helped to delineate those regions of the $l d h$ promoter that are responsible for the differential transcription of the $l d h$ gene in response to glycerol.
\end{abstract}

\title{
Introduction
}

Mycoplasmas have attracted much scientific interest during the last few years due to their extremely reduced genomes. Among all organisms, the genome sequence of which is available, the mycoplasmas contain the smallest ones that allow a bacterium to be viable autonomously outside a host. In agreement with their extremely reduced genomes, the number of regulators that are present in these organisms is rather small. It has therefore long been believed that there are almost no regulatory events in these organisms. Among the very few regulators of $M$. pneumoniae are the $\mathrm{HPr}$ kinase/phosphorylase (HPrK/P) of the phosphoenolpyruvate:sugar phosphotransferase system (PTS) and the heat shock transcription factor HrcA. Both proteins are involved in regulatory processes. The DNA binding repressor HrcA was proposed to mediate the derepression of the heat shock genes dnaJ, dnaK, lonA and $c l p B$ upon temperature upshift (Musatovova et al., 2006; Weiner et al., 2003), whereas the HPrK/P mediates the regulated (de-)phosphorylation of the small phosphocarrier protein HPr at a serine residue (Halbedel et al., 2004; Steinhauer et al., 2002a). In firmicutes the formation of $\mathrm{HPr}(\mathrm{Ser}-\mathrm{P})$ by HPrK/P marks the beginning of a signal transduction pathway commonly known as carbon catabolite regulation (Warner \& Lolkema, 2003). Upon phosphorylation at the Ser-46 residue, which is induced by the presence of readily metabolizable carbon sources, 
HPr can interact with the pleiotropic transcription factor CcpA to form a complex that binds to promoters containing so-called cre-sites (Deutscher et al., 1995; Jones et al., 1997; Monedero et al., 2001b; Turinsky et al., 1998). This event leads to the activation or repression of genes that are involved in different central metabolic pathways or in the uptake/metabolism of alternative carbon sources (Blencke et al., 2003; Lorca et al., 2005). The M. pneumoniae $\mathrm{HPrK} / \mathrm{P}$ has a quite unusual pattern of in vivo activity. $\mathrm{HPr}(\mathrm{Ser}-\mathrm{P})$ can be detected in cell extracts of $M$. pneumoniae only when the cells are fed with glycerol whether glucose is present or not (Halbedel et al., 2004). This pattern of $\mathrm{HPr}(\mathrm{Ser}-\mathrm{P})$ formation suggests the existence of a specific cell response when the cells come in contact with glycerol.

Besides glycerol, glucose and fructose can also be utilized as sources of carbon and energy by M. pneumoniae (Halbedel et al., 2004). These carbohydrates are catabolized to pyruvate via glycolysis (Miles et al., 1992). Pyruvate then can be converted to acetyl-CoA by the pyruvate dehydrogenase complex and finally to acetate by the enzymes phosphotransacetylase and acetate kinase (Constantopoulos \& McGarrity, 1987; Muhlrad et al., 1981). Alternatively, pyruvate can be reduced to L-lactate by lactate dehydrogenase (Neimark \& Lemcke, 1972). Both reactions have their specific advantage. While the conversion of pyruvate to acetate yields two additional molecules of ATP and two more molecules NADH per molecule glucose, NADH can be recycled to NAD by the reduction of pyruvate to lactate. The recycling of $\mathrm{NADH}$ can be expected to be a crucial point for the adjustment of $M$. pneumoniae metabolism, since there is no respiration chain that can be used for this purpose (Himmelreich et al., 1996; Pollack et al., 1981). Re-oxidation of NADH can only occur in the course of lactate formation by lactate dehydrogenase or by the enzyme NADH oxidase which converts molecular oxygen to hydrogen peroxide thereby using NADH as the electron donor (Low \& Zimkus, 1973). Similarly, the enzyme glycerol-3-phosphate oxidase of Mycoplasma mycoides was shown to use molecular oxygen rather than NAD as the electron acceptor thereby also producing hydrogen peroxide (Pilo et al., 2005). This molecular feature helps to circumvent NADH overproduction especially during growth in the presence of glycerol. Otherwise, the metabolism of glycerol would lead to the accumulation of NADH since glycerol has to be oxidized first to an aldehyde - normally yielding NADH when a dehydrogenase is used - before it can be introduced into glycolysis. The need for a wellbalanced redox bilance especially during growth in the presence of glycerol again suggests the existence of a cellular response in the presence of this carbon source to ensure an adequately coordinated expression of the two alternative pyruvate metabolizing pathways. 
Hints for transcriptional regulation of mollicute genes come from heat shock experiments (see above) and from a variety of DNA microarray analyses (Madsen et al., 2006; Zimmerman \& Herrmann, 2006; Weiner et al., 2003). With the exception of heat shock, mechanisms underlying the observed effects are far from being understood. On the one hand, this is caused by the fact that $M$. pneumoniae and its relatives lack most of the well-established regulatory systems such as alternative sigma factors or two-component systems (Bornberg-Bauer \& Weiner, 2002; Himmelreich et al., 1996). And on the other hand, the majority of the $M$. pneumoniae genes is arranged in long convergent gene clusters with only short or almost no intergenic sequences (Himmelreich et al., 1997). This suggests that the majority of these genes are transcribed in form of long polycistronic mRNAs that are initiated probably only once in front of these operons. Cotranscription over long distances of clustered genes with partly unrelated function has been demonstrated for the $6.8 \mathrm{~kb} \mathrm{ftsZ}$ gene clusters of Mycoplasma genitalium and M. pneumoniae (Benders et al., 2005). In the case of the $M$. pneumoniae $h m w$ gene cluster cotranscription was even demonstrated for a $13 \mathrm{~kb}$ region containing 10 individual open reading frames (Waldo et al., 1999). Additionally, it seems possible that transcription of most $M$. pneumoniae genes is terminated at poorly defined sites. A hint for this assumption comes from the observation, that there is no decrease in free energy value indicating the absence of mRNA hairpin formation at the expected sites of transcription termination in M. pneumoniae and other mollicutes (Washio et al., 1998). This would explain the general difficulties to get clear results on transcript sizes in Northern hybridizations with M. pneumoniae RNA preparations (Waldo et al., 1999; this work). So far, transcript sizes could be determined by Northern-blot analysis only for the $M$. pneumoniae ptsH gene (Halbedel et al., 2004). Taken together, in M. pneumoniae transcription seems to be initiated preferentially in front of large gene clusters and to be terminated with a low frequence only. These facts greatly reduce the possibilities to regulate transcription of a certain gene at the level of transcriptional initiation.

In this work, we characterized the changes in global gene expression in response to the presence of glycerol at the proteome level. Among the proteins that showed a clear repression during growth in the presence of glycerol was the $a c k A$ gene, coding for acetate kinase. Prompted by this result, the glycerol-dependent expression of the $l d h$ gene, coding for lactate dehydrogenase, was also studied. It turned out, that the $l d h$ gene displays an inversed expression pattern as compared to that of the ackA gene. The promoters of both genes were mapped using primer extension analysis and lac $Z$ reporter fusions. A ldh transposon mutant still shows a regulated expression of the $l d h$ gene on the mRNA level. We conclude, that the 
sequences mediating the regulated expression of the $l d h$ gene must be located upstream of the transposon insertion point of this strain.

\section{Materials and Methods}

Bacterial strains, oligonucleotides and growth conditions. Escherichia coli DH5a (Sambrook et al., 1989) was used as host for all cloning procedures. Transformants were grown in Luria Bertani medium containing $40 \mu \mathrm{g} / \mathrm{ml}$ kanamycin. The $M$. pneumoniae strains used in this study are shown in Tab. 4. M. pneumoniae was cultivated routinely in $100 \mathrm{ml}$ modified Hayflick medium as described previously (Halbedel et al., 2004). The medium was supplemented with different carbon sources as indicated [final concentration of $1 \%(\mathrm{w} / \mathrm{v})$ ] and with $80 \mu \mathrm{g} / \mathrm{ml}$ gentamicin for the transposon mutants. The oligonucleotides used in this study are shown in Tab. 5).

Tab. 4: M. pneumoniae strains used in this study

\begin{tabular}{|c|c|c|}
\hline Strain & Genotype $^{a}$ & Reference $^{\mathrm{a}}$ \\
\hline M129 (ATCC29342) & wild type strain in the $33^{\text {rd }}$ broth passage & \\
\hline GPM69 & $l d h:: \operatorname{Tn}$ & this work \\
\hline GPM54/1...GPM54/5 & $l d h^{\prime}-{ }^{\prime} l a c Z$ & Halbedel \& Stülke, 2006 \\
\hline GPM67/1...GPM67/4 & $a c k A^{\prime}-{ }^{\prime} l a c Z$ & pGP367 $\rightarrow$ M129 \\
\hline
\end{tabular}

${ }^{\text {a }}$ The arrow $(\rightarrow)$ stands for transformation, -'lacZ indicates a translational lacZ fusion.

Tab. 5: Oligonucleotides used in this study.

\begin{tabular}{|c|c|}
\hline Oligonucleotide & Sequence $\left(5^{\prime} \rightarrow 3^{\prime}\right)^{b}$ \\
\hline SH29 & ATGAGTGAGCTAACTCACAG \\
\hline SH30 & CAATACGCAAACCGCCTC \\
\hline $\mathrm{SH} 31$ & GTCAATGCTGGCAGTAGC \\
\hline SH32 & CTAATACGACTCACTATAGGGAGACACCGTTACCCAAGTGAC \\
\hline SH38 & GTAGCACTCATTGGTTCTG \\
\hline SH39 & CTAATACGACTCACTATAGGGAGATTCACCTAACACATATGCTTG \\
\hline SH40 & ACTTTTTTATTTGACTACGTTTC \\
\hline SH41 & ACAATTGGAATTTGATCGAGC \\
\hline $\mathrm{SH} 42$ & TCTTCTGTTCTGCTCTCGG \\
\hline $\mathrm{SH} 43$ & ATGGCAGCGTAGAGAAAGC \\
\hline SH54 & AAAGGATCCATGAAGAGTCTTAAAGTAGCAC \\
\hline SH55 & AAAAGCTTACTAATTCTTATAGTTTAGCTAAC \\
\hline SH58 & AGAATTCGTTAATAATGATGATTGAAGC \\
\hline SH59 & TAGGATCCTTGTGATAATCAAACAATTGG \\
\hline SH62 & TAGAATTTTATGGTGGTAGAG \\
\hline
\end{tabular}




\begin{tabular}{ll}
\hline Oligonucleotide & Sequence $\left(\mathbf{5}^{\prime} \rightarrow \mathbf{3}^{\prime}\right)^{\mathbf{b}}$ \\
\hline SH63 & CTAATACGACTCACTATAGGGAGAACACTATCATAACCACTACC \\
SH76 & CTAATACGACTCACTATAGGGAGACCAATAAAGATAAAGTCGTAATC \\
\hline
\end{tabular}

${ }^{b}$ The sequence of the T7-promoter is underlined in SH32, SH39, SH63 and SH73.

Preparation of cell extracts. After 4 days of incubation at $37^{\circ} \mathrm{C}$ the culture medium was removed from the M. pneumoniae cell layer and the cells were washed twice with $20 \mathrm{ml}$ cold phosphate buffered saline (PBS). After washing cells were collected by scraping into $1.5 \mathrm{ml}$ PBS and subsequent centrifugation $\left(5 \mathrm{~min}, 15,000 \mathrm{~g}, 4^{\circ} \mathrm{C}\right)$. The cell pellet was resuspended in $500 \mu 10 \mathrm{mM}$ Tris/HCl pH 7.5 and the cells were disrupted by sonication $(3 \times 10 \mathrm{~s}, 50 \mathrm{~W}$, $\left.4^{\circ} \mathrm{C}\right)$. Cell debris was sedimented by centrifugation $\left(10 \mathrm{~min}, 15,000 \mathrm{~g}, 4^{\circ} \mathrm{C}\right)$ and the resulting supernatant was centrifuged again $\left(30 \mathrm{~min}, 24,000 \mathrm{~g}, 4^{\circ} \mathrm{C}\right)$ to remove disturbing particles. The protein concentration of the supernatant was determined using the BioRad dye-binding assay with bovine serum albumin as the standard (Bradford, 1972).

Two-dimensional SDS polyacrylamide gel electrophoresis (PAGE). 2D PAGE was done as decribed by Kohler et al. (2003). For separation in the first dimension, IPG strips with a linear $\mathrm{pH}$ range of 3-10 were used (Immobiline ${ }^{\mathrm{TM}}$ DryStrip, Amersham Biosciences). After the gel run the protein spots were visualized by colloidal Coomassie staining and scanned as described by Voigt et al. (2004). Protein spots that showed a regulated expression were cut from the gel and identified by mass spectroscopy as described previously (Eymann et al., 2004).

Determination of $\mathbf{p H}$ in culture supernatants and detection of acetate and L-lactate. For $\mathrm{pH}$ measurements $5 \mathrm{ml}$ of culture supernatant were taken from a growing $100 \mathrm{ml}$ culture. Unattached cells were removed by centrifugation and the $\mathrm{pH}$ was measured using a standard pH meter (Knick, Germany). For the measurements of L-lactate and acetate commercially available kits (R-Biopharm, Germany) were used. All analytical steps were done according to the instructions of the manufacturer.

Analysis of transcription. Preparation of total M. pneumoniae RNA was done as decribed elsewhere (Weiner et al., 2003). Northern blot analysis was done as decribed by Wetzstein et al. (1992). For slot blot analysis serial twofold dilutions of the RNA extract in $10 \mathrm{x}$ SSC (2 $\mu \mathrm{g}$ $-0.25 \mu \mathrm{g}$ ) were blotted onto a positively charged nylon membran using a PR 648 Slot Blot Manifold (Amersham Biosciences). Equal amounts of yeast tRNA (Roche) and $M$. pneumoniae chromosomal DNA served as controls. The RNA was UV-crosslinked on the membrane and hybridization and detection were done according to the protocol of Wetzstein et al. (1992). DIG-labelled riboprobes were obtained by in vitro transcription from PCR 
products that cover ORF internal sequences using T7 RNA polymerase (Roche). The reverse primers used to generate the PCR products contained a T7 promoter sequence (see Tab. 5)

To identify the $5^{\prime}$ ends of $l d h$ and $a c k A$ transcripts the synthetic oligonucleotides SH41 (ackA) and SH43 $(l d h)$ were $5^{\prime}$ labelled radioactively using $\left[\gamma^{32} \mathrm{P}\right] \mathrm{ATP}$. These oligonucleotides were then used in a reverse transcription reaction with SuperScript ${ }^{\mathrm{TM}}$ reverse transcriptase (Invitrogen) and RNA extracts as templates as decribed by Wetzstein et al. (1992). Didesoxyribonucleotide sequencing reactions using the same primer and an appropriate PCR product as the template were done in parallel. The sequencing reactions and the primer extension reaction were separated electrophoretically using $6 \%$ urea-polyacrylamide gels as described by Wetzstein et al. (1992).

Preparation of M. pneumoniae chromosomal DNA and Southern blot analysis. Extraction of chromosomal DNA from $M$. pneumoniae cells was performed as described previously (Halbedel et al., 2006). Digests of chromosomal DNA were separated using 1\% agarose gels and transferred onto a positively charged nylon membrane according to standard protocols (Sambrook et al., 1989). The chromosomal DNA was immobilized on the membrane by UVcrosslinking. Hybridization and detection using DIG-labelled riboprobes was done as decribed elsewhere (Wetzstein et al., 1992). DIG-labelled riboprobes were obtained as described for the Northern blots.

DNA manipulation and plasmid construction. Transformation of E. coli and plasmid DNA extraction was performed using standard procedures (Sambrook et al., 1989). Enzymatic DNA manipulations and modifications were done as described previously (Ludwig et al., 2002). For the construction of a translational $a c k A^{\prime}$-' $^{\prime}$ lac Z fusion a DNA fragment containing the ackA promoter and the first $74 \mathrm{bp}$ of the $a c k A$ open reading frame was amplified by PCR using the oligonucleotides SH58 and SH59. The PCR product was digested with BamHI/EcoRI and cloned into pGP353 (Halbedel \& Stülke, 2006) cut with the same enzymes. The insert of the resulting plasmid was verified by DNA sequencing and the plasmid was designated pGP367. For the amplification of the M. pneumoniae ldh gene the oligonucleotides SH54 and SH55 were used. The PCR fragment was digested with BamHI and HindIII and ligated into the similarly cut overexpression vector pWH844 (Schirmer et al., 1997). The correct sequence of the insert was verified by DNA sequencing and the plasmid was named pGP368.

Protein Purification. His $_{6}$-Ldh was overexpressed in E. coli using the expression plasmid pGP368. Expression was induced by the addition of IPTG (final concentration $1 \mathrm{mM}$ ) to 
exponentially growing cultures, and the protein was purified using a $\mathrm{Ni}^{2+}-\mathrm{NTA}$ superflow column as described previously (Halbedel \& Stülke, 2005)

Electroporation of M. pneumoniae. M. pneumoniae was transformed with plasmid DNA by electroporation as described previously (Hedreyda et al., 1993). Transposants were selected on PPLO agar containing $80 \mu \mathrm{g} / \mathrm{ml}$ gentamicin and single colonies were transferred into modified Hayflick medium also containing $80 \mu \mathrm{g} / \mathrm{ml}$ gentamicin.

Assay of $\boldsymbol{\beta}$-galactosidase activity. LacZ activity in the reporter strains was assayed according to the standard protocol described elsewhere (Miller, 1972). Briefly, cells of a $100 \mathrm{ml}$ culture were harvested as decribed for the preparation of cell extracts for proteomic analysis except that Z-buffer $\left(60 \mathrm{mM} \mathrm{Na}_{2} \mathrm{HPO}_{4} 40 \mathrm{mM} \mathrm{NaH} \mathrm{PO}_{4} 10 \mathrm{mM} \mathrm{KCl} 1 \mathrm{mM} \mathrm{MgSO} 450 \mathrm{mM}\right.$ $\beta$-mercaptoethanol) was used for disruption instead of $10 \mathrm{mM}$ Tris/ $\mathrm{HCl} \mathrm{pH} \mathrm{7.5.} 450 \mu \mathrm{l}$ of Z-buffer was added to $50 \mu \mathrm{l}$ of the lysate and the mixture was preincubated for $5 \mathrm{~min}$ at $28^{\circ} \mathrm{C}$. The reaction was started by the addition of $100 \mu \mathrm{l}$ ONPG solution $(4 \mathrm{mg} / \mathrm{ml})$. As soon as the reaction mixture turned yellow the reaction was stopped by the addition of $250 \mu 11 \mathrm{M}$ $\mathrm{Na}_{2} \mathrm{CO}_{3}$. The absorption was determined photometrically at $\lambda=420 \mathrm{~nm}$.

Assay of Ldh activity. To determine the Ldh activity in cell extracts of M. pneumoniae, cell extracts were prepared as described above. $5 \mu \mathrm{g}$ of cytoplasmic proteins were incubated with $0.7 \mathrm{mM}$ sodium pyruvate and $0.7 \mathrm{mM} \mathrm{NADH}$ in $35 \mathrm{mM}$ phosphate buffer in a total volume of $700 \mu \mathrm{l}$ at room temperature. The conversion of NADH to NAD was monitored in a photometric test at $\lambda=366 \mathrm{~nm}$. For in vitro assays with the purified Ldh, $5 \mu \mathrm{g}$ of the $\mathrm{His}_{6}$-Ldh was used in a total volume of $500 \mu 1$ at otherwise similar conditions.

\section{Results}

\section{Identification of $a c k A$ and $l d h$ as genes showing a regulated expression}

Glycerol was shown to be a carbohydrate that can be utilized by M. pneumoniae. Moreover, glycerol provokes a specific regulatory response in this organism as jugded from the analysis of the in vivo HPr phosphorylation pattern (Halbedel et al., 2004). It was thus tempting to speculate that there might be a HPrK/P-dependent gene expression program in $M$. pneumoniae during growth on glycerol. In order to identify genes with a glycerol-dependent expression pattern, a proteomic analysis was performed. The protein expression pattern of cells that had been grown in the presence of glucose and cells that had been grown in the presence of glucose and glycerol or glycerol alone was compared. The latter two conditions were shown to provoke $\mathrm{HPr}(\mathrm{Ser}-\mathrm{P})$ formation (Halbedel et al., 2004). Samples from cells that had been grown in the presence of fructose served as a negative control. Cells were incubated 
at $37^{\circ} \mathrm{C}$ in modified Hayflick medium supplemented with the above mentioned carbohydrates and harvested after 4 days to prepare cell extracts of the soluble cytoplasmic fraction.

Among the genes that showed a carbohydrate dependent expression in the 2D PAGE analysis was the ackA gene coding for acetate kinase. The expression of ackA was highest when the cells were grown in the presence of glucose as compared to growth in glycerol supplemented medium (see Fig. 24A). This regulation pattern was verified in a slot blot experiment using total M. pneumoniae RNA and a DIG-labelled riboprobe directed against the ackA mRNA. A quantification of the signal intensities obtained with the slot blot analysis revealed that the expression of the ackA gene is almost 4.5-fold repressed during growth in the presence of glycerol. The signal intensities are maximal as long as glucose is present in the medium (Fig. 24B-C).

A ackA

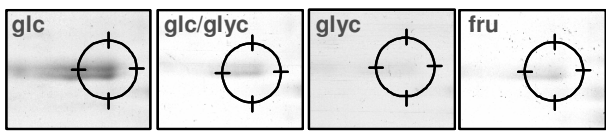

B

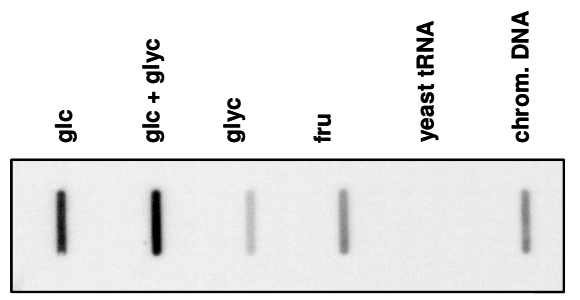

C

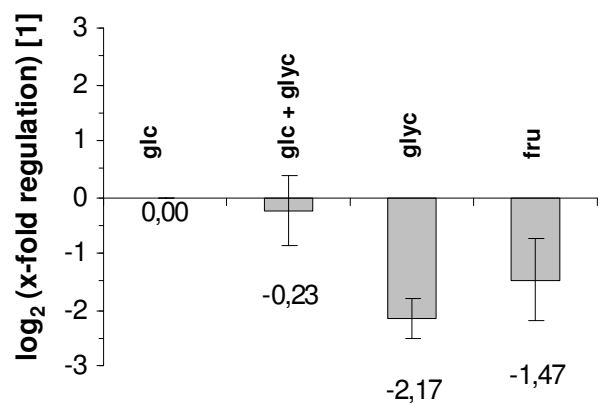

Idh
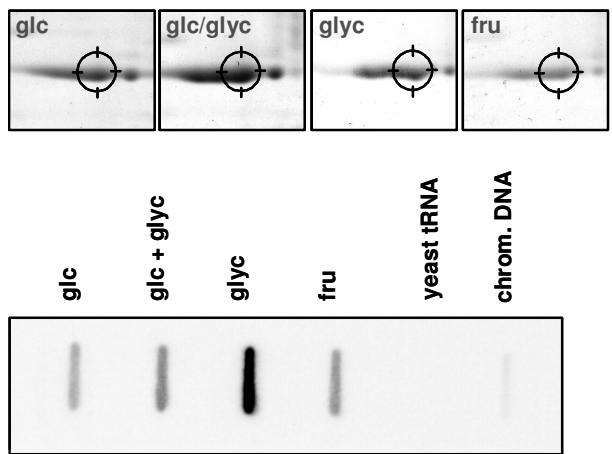

3,0

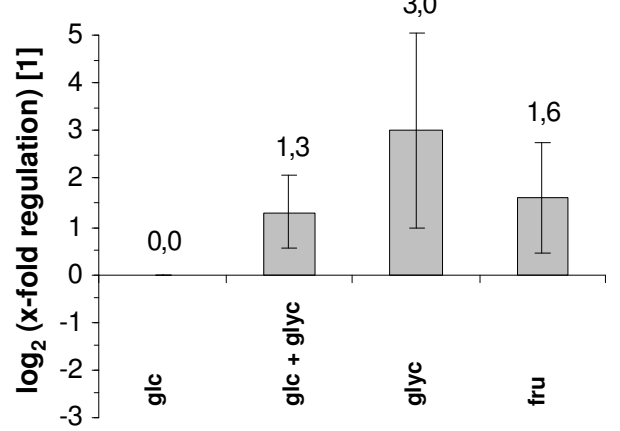

Fig. 24: Carbohydrate dependent expression of the ackA and the $l d h$ gene in $M$. pneumoniae. Carbohydrates that were used to supplement the modified Hayflick medium are indicated. (A) Sections of two dimensional polyacrylamide gels displaying the AckA and the Ldh protein spots in the presence of different carbohydrates. (B) Slot blot to analyze $a c k A$ and $l d h$ expression levels in $M$. pneumoniae grown in the presence of different carbohydrates as in 1A. Riboprobes hybridizing to the ackA and the ldh mRNA were obtained by in vitro transcription from DNA fragments that had been generated by PCR using the primers SH31/SH32 and SH38/SH39, respectively. (C) Densitometric quantification of the slot blot analysis shown in 1B. Expression is given as $\mathrm{X}$-fold induction/repression over the glucose value and was plotted on a log-scale $\left(\log _{2}\right)$. 
In $M$. pneumoniae, pyruvate can be catabolized either to acetate or to lactate. Lactate is made directly from pyruvate by the enzyme lactate dehydrogenase. To test whether the expression of the $l d h$ gene is also regulated by the carbon supply, a slot blot analysis using a DIGlabelled riboprobe hybridizing to the $l d h$ mRNA was performed. Although there was no regulation of $l d h$ expression detectable at the protein level (Fig. 24A), the signal corresponding to the $l d h$ mRNA showed a strong increase when the cells had been grown in the presence of glycerol as compared to all other tested conditions (Fig. 24B). Again, the signal intensities were determined and it turned out, that the transcription of the ldh gene is about eightfold induced during growth in the presence of glycerol (Fig. 24C). Thus, the transcription of the $l d h$ and the $a c k A$ gene is regulated reciprocally.

\section{Detection of acetate and L-lactate in culture supernatants of $M$. pneumoniae.}

The expression pattern of the $a c k A$ and the $l d h$ gene suggested that there might be an similar pattern of acetate and L-lactate synthesis in M. pneumoniae. This hypothesis was tested using commercially available test systems based on the enzymatic conversion of either L-lactate or acetate that are coupled to $\mathrm{NAD}^{+}$consuming reactions.

For a first impression of acid excretion in $M$. pneumoniae, the $\mathrm{pH}$ of culture supernatants was determined. The strongest acidification was observed when the cells were grown in the presence of glucose. According to the slightly reduced growth rate in the presence of glucose and glycerol (Halbedel et al., 2004), the course of acidification was somewhat delayed under this condition. When grown in the presence of glycerol or fructose, $M$. pneumoniae acidifies the culture medium only marginally as compared to the negative control.

In the next step the accumulation of L-lactate in culture supernatants of $M$. pneumoniae was monitored. As shown in Fig. 25B the excretion of L-lactate was maximal when the cells were fed with glucose as the sole carbon source and reached $36.3 \pm 5.0 \mathrm{mM}$. This finding suggests that approximately one third of the offered glucose $(1 \%=55.6 \mathrm{mM})$ was metabolized to Llactate. When the cells were fed with a combination of glucose and glycerol $28.5 \pm 2.3 \mathrm{mM} \mathrm{L}$ lactate were found in the culture supernatants after 6 days of growth. But only background levels of L-lactate were detected when the cells were cultivated in the presence of fructose, or glycerol or when no carbon source had been added. The pattern of lactate synthesis is in good agreement with the pattern of acidification shown in Fig. 25A and the pattern of growth rate observed with M. pneumoniae in the presence of different carbohydrates (Halbedel et al., 2004). However, the induction of the $l d h$ gene during growth in the presence of glycerol does not lead to an increased synthesis of L-lactate. 

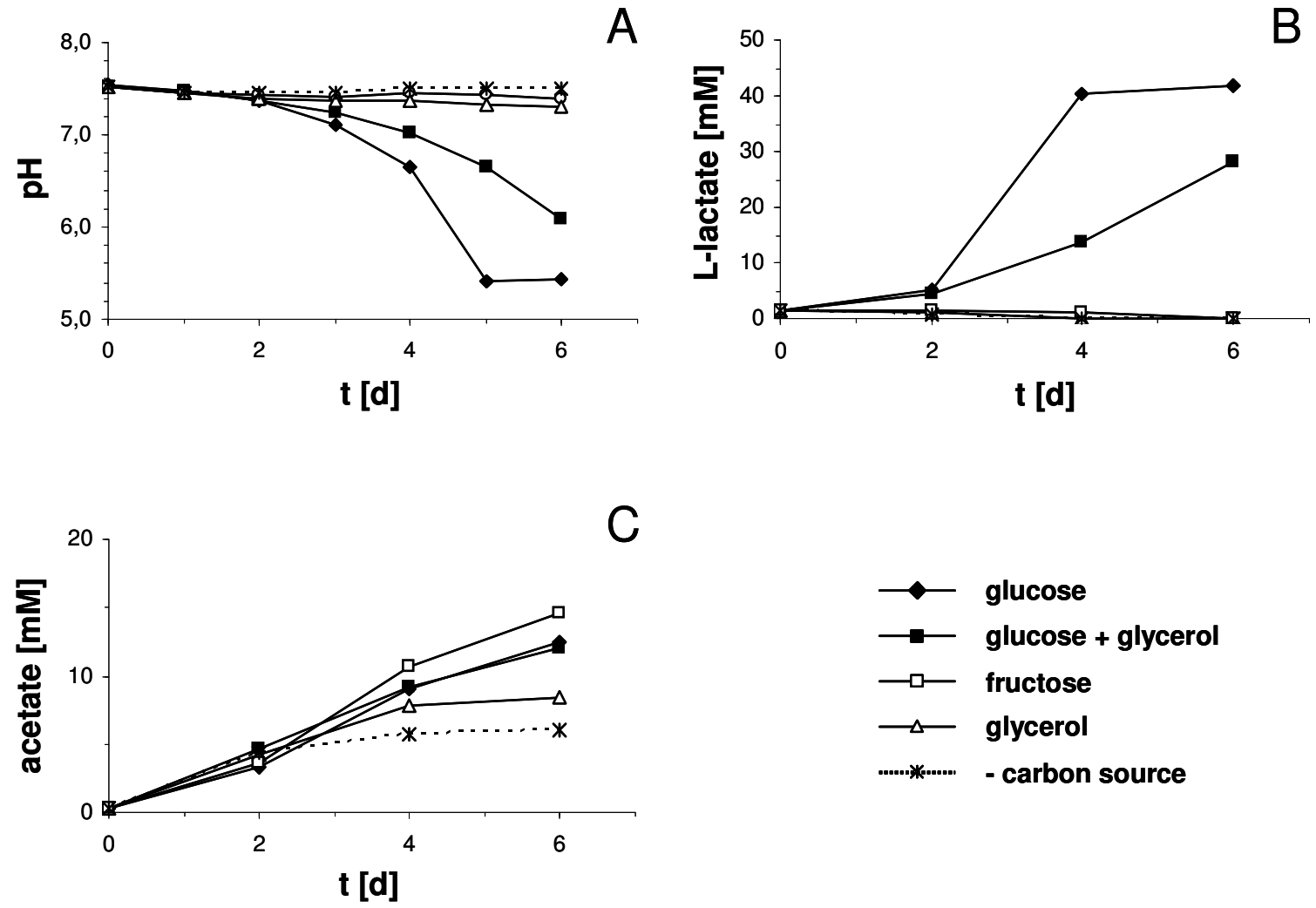

Fig. 25: Acidification and accumulation of L-lactate and acetate in supernatants of M. pneumoniae. Cultures of $M$. pneumoniae were grown in the presence of different carbohydrates as indicated and samples were taken to monitor the $\mathrm{pH}(\mathrm{A})$, the concentration of L-lactate $(\mathrm{B})$ and acetate $(\mathrm{C})$.

When analyzed for the concentration of acetate, culture supernatants of M. pneumoniae showed the highest values (after 6 days of growth), if the cells had been grown in the presence of glucose $(8.8 \pm 3.2 \mathrm{mM})$, glucose/glycerol $(9.9 \pm 1.9 \mathrm{mM})$ or fructose $(11.4 \pm 3.0 \mathrm{mM})$. When glycerol was used as the sole carbon source, the concentration of acetate was somewhat lower $(7.2 \pm 1.1 \mathrm{mM})$. Surprisingly, a high background acetate formation was observed in the absence of any added carbohydrate $(5.0 \pm 1.1 \mathrm{mM})$. This might result from the catabolism of undefined medium components. Taken this background activity into account, a two- to threefold increased acetate concentration was found in supernatants of cells grown in the presence of glucose, glucose/glycerol or fructose as compared to glycerol grown cells. Thus, expression of the $a c k A$ gene and synthesis of acetate show a common pattern of regulation.

\section{Characterization of the $l d h$ and the $a c k A$ transcripts}

As already mentioned above, the majority of all genes of $M$. pneumoniae is arranged in long convergent gene clusters with only very short intergenic distances (Himmelreich et al., 1997). One of the very few genes that is transcribed in the opposite direction as compared to its neighbour genes is the $l d h$ gene (see Fig. 26B). Therefore a monocistronic transcript was 
expected in a Northern blot analysis as the $l d h$ gene needs both its own promoter and an own terminator. When hybridized with a $l d h$ specific riboprobe, $M$. pneumoniae RNA gives a single transcript in a Northern blot with an estimated size of $1 \mathrm{~kb}$ (Fig. 26A). This signal is severely induced when the RNA was prepared from cells cultivated in the presence of glycerol, confirming the result of the $l d h$ slot blot analysis. As the $l d h$ gene is $939 \mathrm{bp}$ in size, one would expect a slightly longer mRNA that also contains additional untranslated sequences at its $5^{\prime}$ and its $3^{\prime}$ ends. The single $1 \mathrm{~kb}$ signal seen in the Northern blot demonstrates that the $l d h$ gene is indeed transcribed as a monocistronic transcription unit and suggests the presence of distinct transcription initiation and termination sites.

The $a c k A$ gene is the first gene of the putative $4.3 \mathrm{~kb}$ ackA-MPN532-clpB operon which is transcribed convergently to the putative upstream MPN534-ruvA-ruvB operon. Both operons are separated from each other by a 341 bp intergenic region containing putative promoter sequences for both operons (Weiner et al., 2000). When analyzed in a Northern blot experiment using an ackA specific riboprobe, M. pneumoniae RNA did not give a clear signal (data not shown) suggesting that the ackA mRNA is either degraded already during the preparation or that the ackA gene is perhaps not transcribed as part of well-defined transcripts.

$$
\text { A }
$$
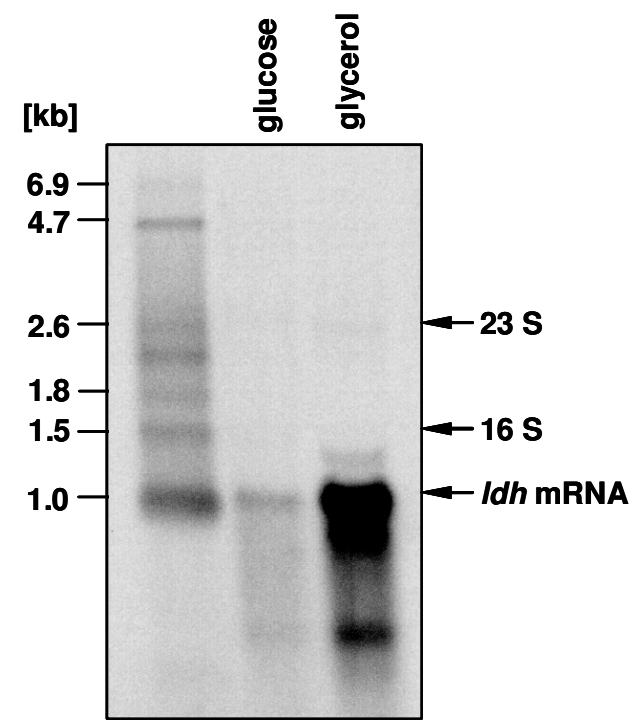

B

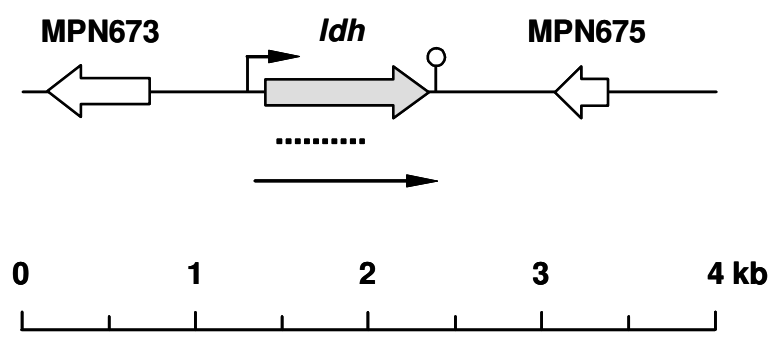

Fig. 26: Transcription of the $M$. pneumoniae $l d h$ gene. (A) Northern blot analysis of $l d h$ transcription. Total RNA of M. pneumoniae cells that had been cultivated in modified Hayflick medium supplemented either with glucose or with glycerol was separated and blotted onto a positively charged nylon membrane. The $l d h$ transcript was detected using a $l d h$ specific riboprobe that hybridizes to an internal part of the $l d h$ mRNA as depicted by the dotted line in 2B. DIG-labelled RNA molecular weight marker I (Roche Diagnostics) served as a standard. (B) Genetic arrangement of the M. pneumoniae ldh locus. The position of the $l d h$ promoter and putative terminator sequences are indicated. The dotted line indicates the position of the $l d h$ riboprobe. 


\section{Determination of the $5^{\prime}$ ends of the $a c k A$ and the $l d h$ mRNAs}

In order to define the $M$. pneumoniae ackA and $l d h$ promoters experimentally, the $5^{\prime}$ ends of both transcripts were determined using primer extension assays. The extension primers SH43 (ldh) and SH41 (ackA) were labelled radioactively and extended in a reverse transcription reaction using $M$. pneumoniae total RNA extracts prepared from cells grown with glucose or glycerol as the templates.

A

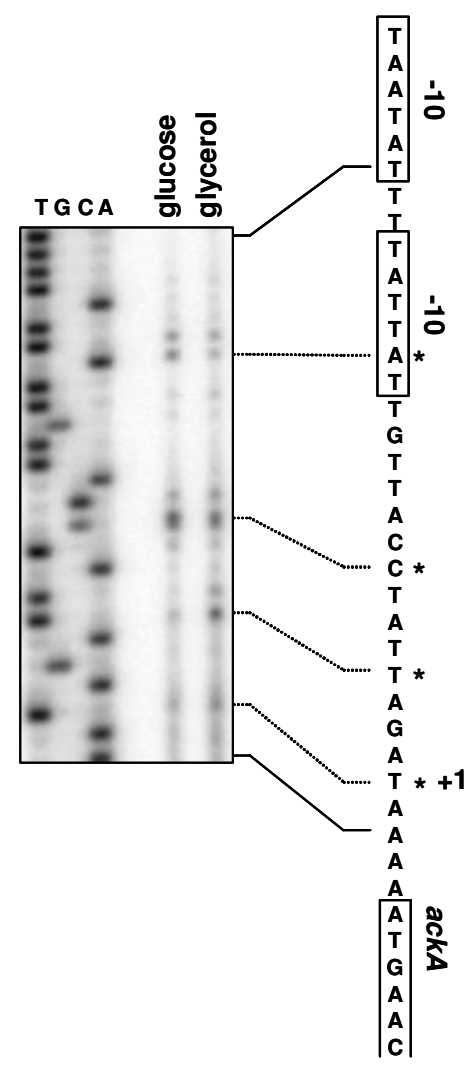

B

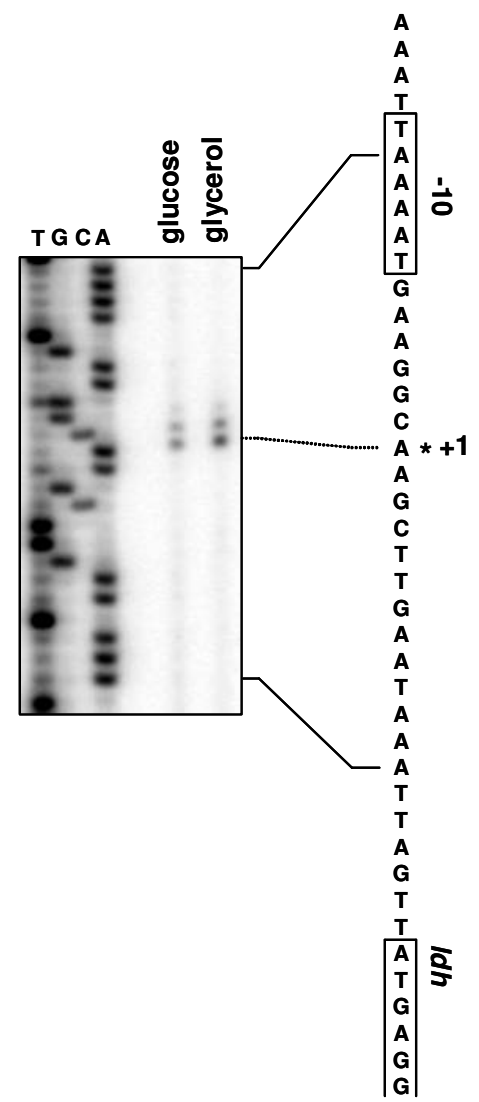

Fig. 27: Determination of the $5^{\prime}$ ends of the M. pneumoniae ackA (A) and ldh (B) mRNA. The synthetic oligonucleotides SH41 (ackA) and SH43 (ldh) were 5'-end labelled using $\left[\gamma^{-32}\right.$ P]ATP and elongated in a primer extension reaction as described by Wetzstein et al. (1992). M. pneumoniae total RNA that was extracted from cells grown in the presence of glucose or glycerol was used as the template. PCR products of the promoter regions of both genes that were obtained with the oligos SH40/ SH41 (ackA) and SH42/ SH43 (ldh) were used as templates in parallel sequencing reactions.

In case of the ackA mRNA 4 major 5' ends were obtained with the SH41 oligonucleotide (see Fig. 27A).With the exception of the first intiation site which lies within the putative -10 box, all of these putative transcription insertion sites fell into the DNA region between the start codon and the proposed -10 box. This suggests that more upstream located sequences may mediate initiation of transcription. Indeed, there is one additional well-conserved -10 box (TAATAT), perfectly matching the $M$. pneumoniae consensus sequence TAA(GT)AT 
(Weiner et al., 2000), just 2 bp in front of the -10 box proposed by the promoter matrix algorithm (see Fig. 27A). The intensities of all elongation signals obtained with RNA from glucose grown cultures as the template were equal when compared to those obtained with RNA from cultures that had been cultivated in the presence of glycerol. This observation indicates that the promoter of the ackA gene is constitutively active.

A single major transcription initiation site was observed for the $l d h$ mRNA. Additional minor elongation products with increased length were also observed (Fig. 27B). Heterogenous transcription start points of that kind have also been described for many other M. pneumoniae mRNAs (Waldo et al., 1999; Weiner et al., 2000). The first nucleotide of the ldh mRNA was determined to be an adenosine. A slight increase in signal intensity of the elongation product resulting from RNA that was prepared from glycerol grown cells suggests, that the activity of the $l d h$ promoter might be somewhat stimulated under this condition. However, although induction ratios calculated from Northern or slot blot hybridizations are often higher as compared to the corresponding data calculated from primer extension analyses (S. Engelmann, personal communication), the increase in signal intensity of the elongation product upon growth in the presence of glycerol- as seen in Fig. 27B - is rather weak.

\section{Analysis of the activity of the $a c k A$ and the $l d h$ promoter}

In order to test whether the regulation pattern of the $a c k A$ and the $l d h$ transcription results from differential promoter activities, reporter constructs were generated for both promoter fragments. The reporter system used for this purpose is based on a promoterless lac Z gene that is located inside the mini-transposon of plasmid pGP353 and had been described in detail previously (Halbedel \& Stülke, 2006). The $l d h$ and $a c k A$ promoter regions chosen for analysis are shown in Fig. 28. For analysis of the in vivo ldh promoter activity plasmid pGP354 (Halbedel \& Stülke, 2006) was used. In case of the $a c k A$ gene a promoter fragment was amplified using the primers SH58/59, digested with EcoRI/BamHI and cloned into the similarly cut reporter plasmid pGP353 to give the plasmid pGP367. The amplified promoter fragments of both genes include the proposed promoter sequences, the experimentally determined transcription initiation sites, the mRNA leaders and the very first amino acid codons of both genes as well (see Fig. 28). The cloning strategy of both fragments generated translational promoter $l a c Z$ fusions that lie inside the mini-transposon of the respective plasmids.

M. pneumoniae was transformed with plasmids pGP354 and pGP367 via electroporation to insert the promoter-lac $Z$ fusions on the mini-transposon at random sites of the chromosome via transposition. M. pneumoniae transformed with the empty reporter vector pGP353 served 
as a negative control. Transformation of $M$. pneumoniae with both reporter plasmids resulted in the appearance of blue colonies on X-Gal containing MP-Agar plates after 14 days of incubation at $37^{\circ} \mathrm{C}$. In contrast, colourless colonies were obtained after transformation with the empty vector. This is the first indication for the presence of sequences driving transcription inside the cloned fragments. For further analysis five clones for each reporter construct were chosen randomly from MP-Agar plates that did not contain X-Gal and were designated GPM54/1 to GP54/5 (Halbedel \& Stülke, 2006) and GPM67/1 to GPM67/4 for ldh and $a c k A$, respectively.

A

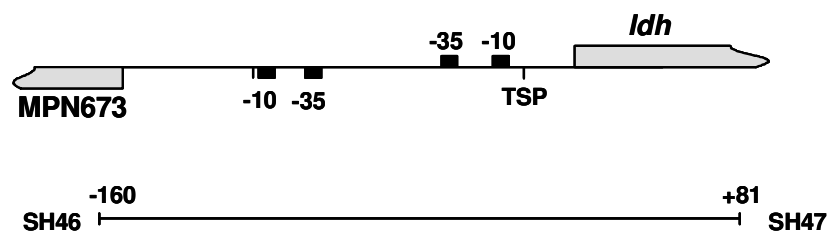

B

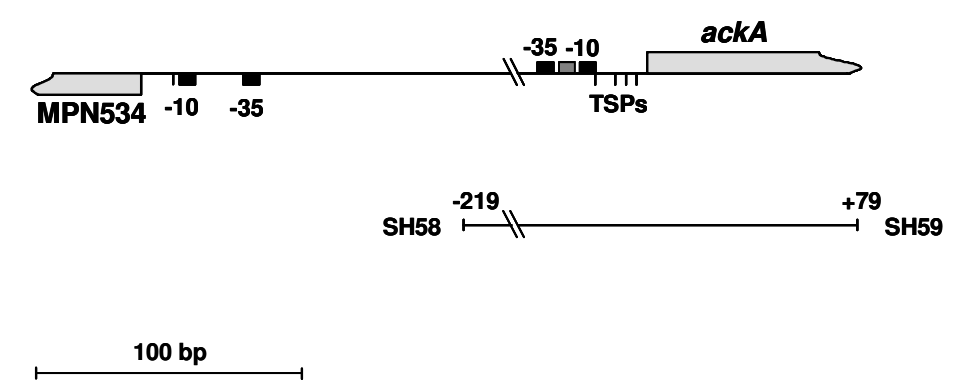

C
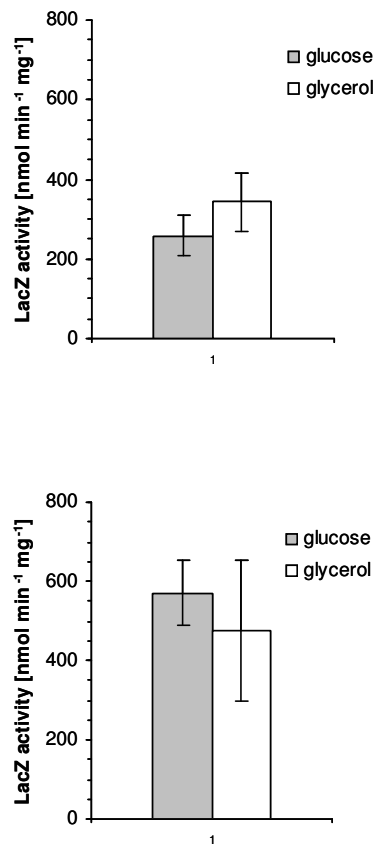

Fig. 28: Analysis of the ackA and the $l d h$ promoter activities in the presence of glucose or glycerol. (A-B) Promoter fragments of the $l d h$ gene (A) and the ackA gene (B) that were chosen to construct the reporter plasmids pGP354 and pGP367, respectively (for details see text). Oligonucleotides that were used to amplify the promoter fragments are indicated. The position of the putative -10 and -35 boxes are drawn as black boxes, the alternatively proposed -10 box of the ackA promoter is illustrated by a grey box. Experimentally determined transcriptional start points (TSPs) are indicated by black lines. Nucleotide numbering in case of the ackA promoter is relative to the most promoter distal transcription initiation site. (C-D) $\beta$-galactosidase activity of reporter strains GPM54/1 through GPM54/5 (ldh, C) and GPM67/1 through GPM67/4 (ackA, D) after growth in the presence of glucose or glycerol as the sole carbon sources.

The reporter strains were grown in modified Hayflick medium supplemented either with glucose or with glycerol as sole carbon sources and harvested after 4 days of incubation. Cells were disrupted by sonication and the resulting soluble protein fraction was tested in a $\beta$ galactosidase activity assay. As shown in Fig. 28C, the $\beta$-galactosidase activity of strains GPM54/1...GPM54/5 was $258 \pm 51 \mathrm{nmol} \mathrm{ONP} \mathrm{min}^{-1} \mathrm{mg}^{-1}$ (Fig. 28C) which is in the same order as described previously (Halbedel \& Stülke, 2006). When grown in the presence of 
glycerol, reporter strains GPM54/1 to GPM54/5 exhibit a minor increase in $\beta$-galactosidase activity $\left(343 \pm 72 \mathrm{nmol} \mathrm{ONP} \mathrm{min}^{-1} \mathrm{mg}^{-1}\right)$. This finding suggests that the chosen $l d h$ promoter fragment is not responsible for the glycerol-dependent induction of the $l d h$ transcription or that induction occurs by a promoter independent mechanism.

A similar result was obtained with the reporter strains GPM67/1 through GPM67/4. When grown in modified Hayflick medium supplemented with glucose, the ackA promoter fragment

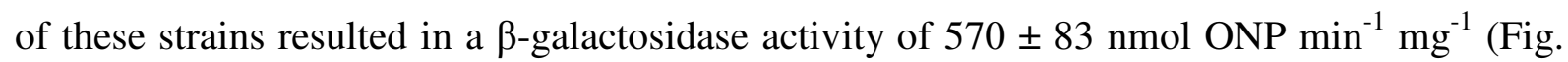
28D). An similar value of $476 \pm 177 \mathrm{nmol} \mathrm{ONP} \mathrm{min}^{-1} \mathrm{mg}^{-1}$ was obtained when the cells were grown in the presence of glycerol as the sole carbon source. Again, the differential expression of the ackA gene that was seen in the 2D-PAGE analysis and with the slot blot experiments is not the result of a regulated promoter activity.

\section{Regulation of $l d h$ transcription in the $l d h::$ Tn strain GPM69}

In order to ensure, that the strongly induced transcript detected with the $l d h$ riboprobe indeed corresponds to a transcript from the $l d h$ locus, a $l d h$ transposon insertion mutant was isolated from the transposon mutant library by haystack mutagenesis (Halbedel et al., 2006). To identify a pool among the 64 pools that contains a $l d h::$ Tn mutant strain, all pools were screened via PCR using the oligonucleotides SH30 and SH54 (see Fig. 29A).

A

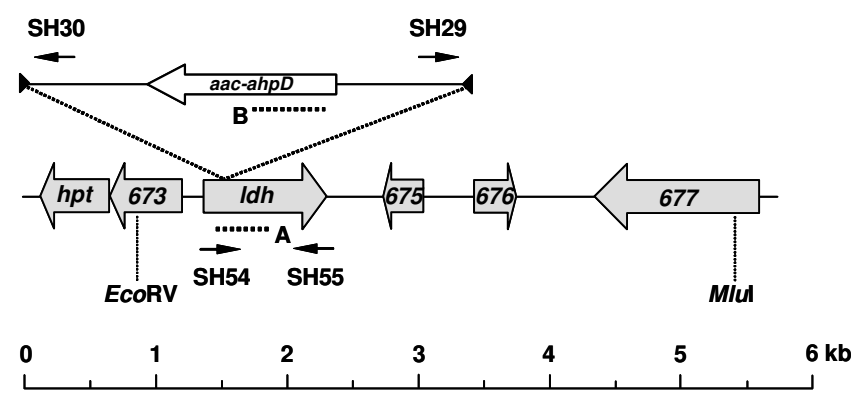

B

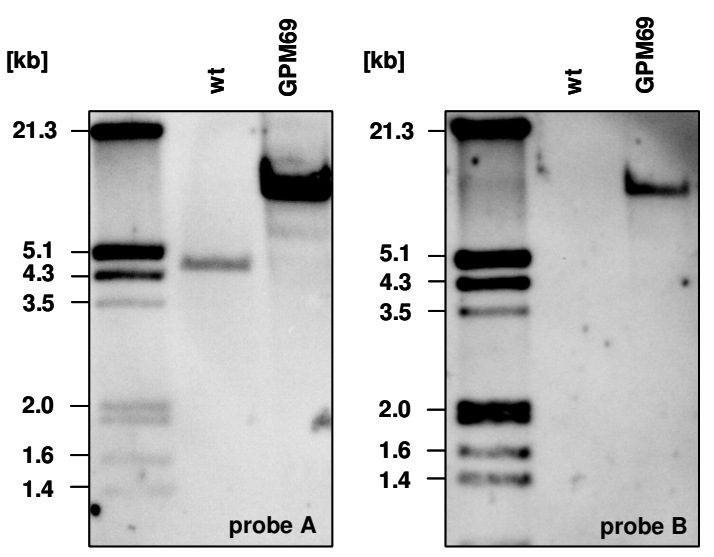

Fig. 29: Southern blot analysis to confirm the unique transposon insertion in the ldh gene of strain GPM69. (A) Genomic region of the $l d h$ gene of $M$. pneumoniae and site of transposon insertion in strain GPM69. Hybridization sites of the riboprobes used to detect the EcoRV/MluI $l d h$ fragment in the Southern blot analyses are indicated by dotted lines. Oligonucleotides used for haystack mutagenesis screens are depicted by solid arrows. (B) Southern blot analysis of EcoRV/MluI digested chromosomal DNA from the wildtype and the $l d h::$ Tn strain GPM69. The digests were separated using a $1 \%$ agarose gel and hybridized with a $l d h$ specific riboprobe (left blot) or with a riboprobe that is specific for the aac-ahpD gene of the mini-transposon (right blot). For the synthesis of the $a a c-a h p D$ specific riboprobe by in vitro transcription a PCR product was used that had been obtained using the primers SH62/SH63. DIG-labelled DNA molecular weight marker III (Roche) served as a standard. 
The pool 8-1 turned out to give a signal in this screen and was re-analyzed in a similar way at the level of its individual clones. Among the members of this pool, clone $8 \mathrm{G} 3$ was identified as the causative one. This clone had to be singled out to eliminate contaminants harboring the wild type $l d h$ allele. After this a clone was obtained that was positive for both $l d h$ transposon junctions (using the primer combinations SH29/SH55 and SH30/54) but negative for the wild type $l d h$ allele (data not shown). To verify the transposon insertion in the $l d h::$ Tn candidate strain, a Southern blot analysis was performed (Fig. 29).

Upon hybridization with a DIG-labelled riboprobe that binds specifically to the $l d h$ gene, wild type chromosomal DNA digested by EcoRV/MluI gives rise to a single band that has the expected size of $4.5 \mathrm{~kb}$ (Fig. 29B). In contrast, no fragment of that size was observed in case of chromosomal DNA from the $l d h::$ Tn indicating the total absence of any wild type $l d h$ allele. Instead of the $4.5 \mathrm{~kb}$ wild type fragment, chromosomal DNA of the $l d h$ mutant digested with $E c o \mathrm{RV} / M l u \mathrm{I}$ shows a single fragment with a significantly increased size of around 8 $10 \mathrm{~kb}$. One would expect a fragment of this size in the $l d h:: \mathrm{Tn}$ strain as the mini-transposon of plasmid pMT85 (Zimmerman \& Herrmann, 2005) that had been used to generate the transposon mutant library has a size of $3.4 \mathrm{~kb}$ thus yielding an EcoRV/MluI ldh fragment of $7.9 \mathrm{~kb}$ in the $l d h:: \mathrm{Tn}$ strain.

In order to make sure that the transposon insertion had occurred only once, a parallel Southern blot was performed and hybridized with a riboprobe specific to the gentamicin resistance gene of the mini-transposon (Fig. 29B). As expected no fragments were observed using wild type chromosomal DNA but a single fragment was detected with chromosomal DNA of the $l d h::$ Tn mutant. This fragment corresponds to the fragment already detected with the $l d h$ specific riboprobe as it has the same size. It can be concluded from these results that the $l d h::$ Tn strain has a single insertion inside the $l d h$ gene.

The site of transposon insertion within the $l d h$ gene was determined by DNA sequencing. The transposon insertion had occured after the $233^{\text {rd }}$ bp of the $l d h$ gene. This insertion can be expected to be lethal for the function of the Ldh protein. The $l d h$ transposon mutant strain was therefore designated GPM69.

To analyze $l d h$ transcription in GPM69, this strain was grown in the presence of glucose or glycerol and total RNA was extracted and analyzed by Northern blot hybridization. To ensure that only such transcripts from the $l d h$ ORF are detected that correspond to the regions lying upstream of the transposon insertion point of strain GPM69 $\left(233^{\text {rd }}\right.$ nucleotide), a new $l d h$ DIG-labelled riboprobe was synthesized by in vitro transcription from a DNA fragment that had been obtained with the primer pair SH54/SH76 as the template. This probe hybridizes 
exclusively to those parts of the $l d h$ mRNA that correspond to nucleotides $1-233$ of the $l d h$ ORF.

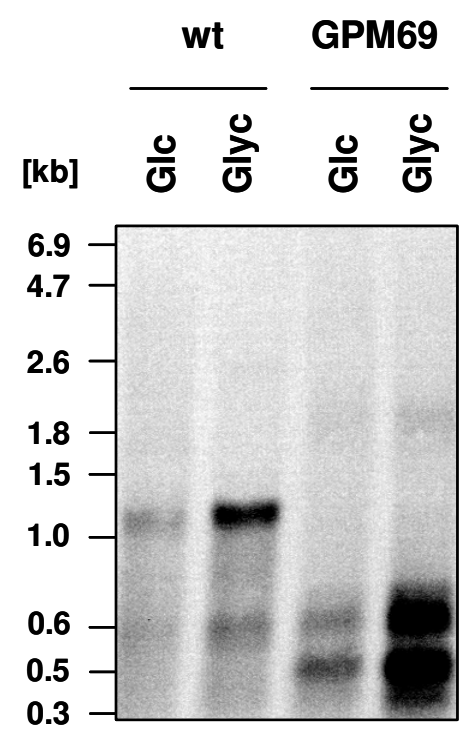

Fig. 30: Regulation of $l d h$ transcription in the $l d h::$ Tn strain GPM69. Total RNA was extracted from the wild type and strain GPM69 that had been cultivated in modified Hayflick medium supplemented with glucose or glycerol. RNA extracts were analyzed by Northern blot hybridization. A DIG-labelled riboprobe that hybridizes exclusively to $l d h$ ORF sequenzes upstream the transposon insertion site of strain GPM69 was used to detect transcripts initiated from the $l d h$ promoter.

As can be seen in Fig. 30 there was no mRNA detectable in strain GPM69 that corresponds to the wild type $l d h$ transcript demonstrating that the glycerol induced $1 \mathrm{~kb}$ mRNA indeed is transcribed from the $l d h$ locus. Moreover, truncated $l d h$ transcripts were detected in GPM69 that did not occur in the wild type, probably resulting from regularly initiated but prematurely terminated $l d h$ transcription. However, the pattern of transcriptional regulation of the $l d h$ locus in response to glycerol is still operative in GPM69. This finding suggests that those sequences mediating the regulated transcription of the $l d h$ gene are probably located upstream of the $233^{\text {rd }}$ bp of the $l d h$ ORF.

\section{In vitro activity of the $M$. pneumoniae L-lactate dehydrogenase}

In order to study the enzymatic activity of M. pneumoniae Ldh, a His ${ }_{6}$-tagged version of the protein was overexpressed in E. coli using the expression plasmid pGP368. The protein was purified from the soluble fraction using a $\mathrm{Ni}^{2+}$-NTA affinity column to apparent homogeneity (data not shown). In a photometric test system with sodium pyruvate as the substrate and NADH as the electron donor the addition of Ldh led to a significant decrease of absorption at $\lambda=366 \mathrm{~nm}$ (see Fig. 31, graph 3). This must be due to the decrease of the NADH concentration in the course of the enzymatic reduction of pyruvate since in the absence of pyruvate no decrease in absorption was observed (graph 1). Similarly, in the absence of the Ldh protein no decrease in absorption was detected (graph 2). This demonstrates that there is no non-enzymatic reduction of pyruvate under the conditions employed in this assay. 


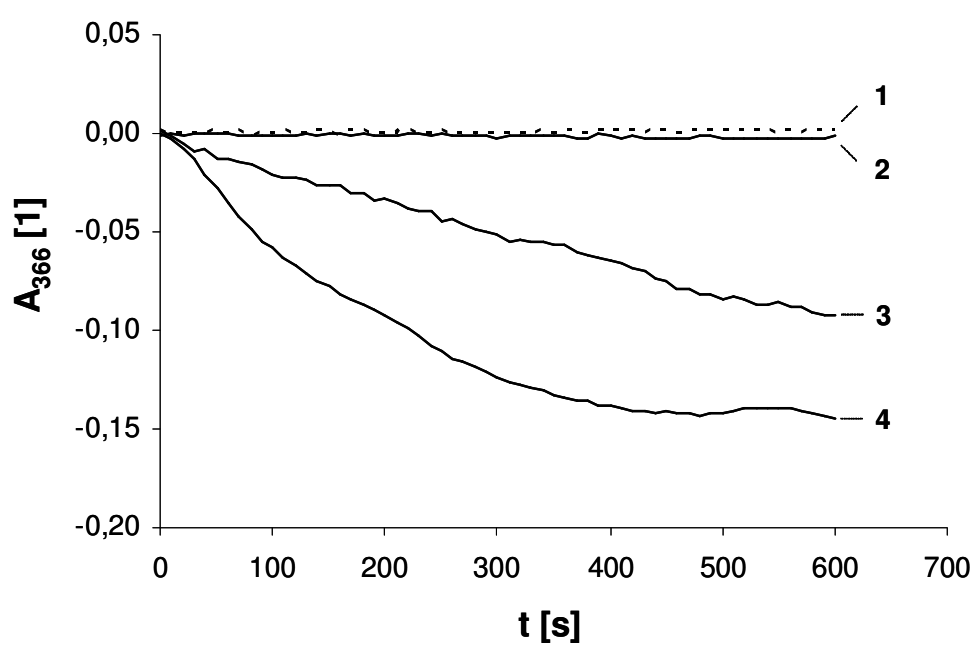

Fig. 31: Activity of the purified M. pneumoniae His $_{6}-\mathrm{Ldh}$. The enzyme was incubated in assay buffer in the presence of various combinations of $\mathrm{NADH}$, sodium pyruvate and fructose-1,6-bisphosphate and the decrease of absorption at $\lambda=366 \mathrm{~nm}$ was monitored in a spectralphotometer. 1 - sample with Ldh, NADH and FBP but without pyruvate; 2 - sample with NADH, pyruvate and FBP but without Ldh; 3 - sample with Ldh, NADH and pyruvate; 4 - sample with Ldh, NADH, pyruvate and $1 \mathrm{mM}$ FBP.

When $1 \mathrm{mM}$ fructose-1,6-bisphosphate (FBP) was added to the assay mixture, the reaction rate increased significantly (graph 4). It can be ruled out that this effect results from NADH dependent reduction of FBP by lactate dehydrogenase as FBP was also included in the control reaction depicted by graph 1 . Under this condition, $i . e$. in the absence of the enzyme but in the presence of $\mathrm{NADH}$, the absorption was constant over the complete period. Taken together, the Ldh protein of $M$. pneumoniae is a functional lactate dehydrogenase and its activity is allosterically activated by FBP.

\section{Intracellular activity of M. pneumoniae $\mathrm{Ldh}$}

As already discussed above, the pattern of $l d h$ transcription is not reflected by the intracellular amount of lactate dehydrogenase as jugded from the proteomic analysis. It was therefore supposed, that only a minor portion of the intracellular Ldh population is represented by the protein spot which was identified to be Ldh (see Fig. 24A). To investigate whether the pattern of intracellular Ldh activity follows the $l d h$ transcription profile, the activity of Ldh in cell extracts of M. pneumoniae grown in the presence of glucose or glycerol was determined.

As shown in Fig. 32, the absorption corresponding to NADH declines when pyruvate and wild type cell extracts were added to the sample. This is due to the oxidation of NADH to NAD in course of the reduction of pyruvate to L-lactate by lactate dehydrogenase. This can be concluded from the finding that in the absence of pyruvate no decrease in absorption was detected. Similarly, no oxidation of NADH was observed when cell extracts of the $l d h$ mutant GPM69 were used. The rate of conversion of pyruvate to L-lactate is the same whether cell 
extracts from cells grown in the presence of glucose or glycerol were used. Obviously, there is no increase in Ldh activity inside the cells when grown in the presence of glycerol as compared to growth in the presence of glucose.

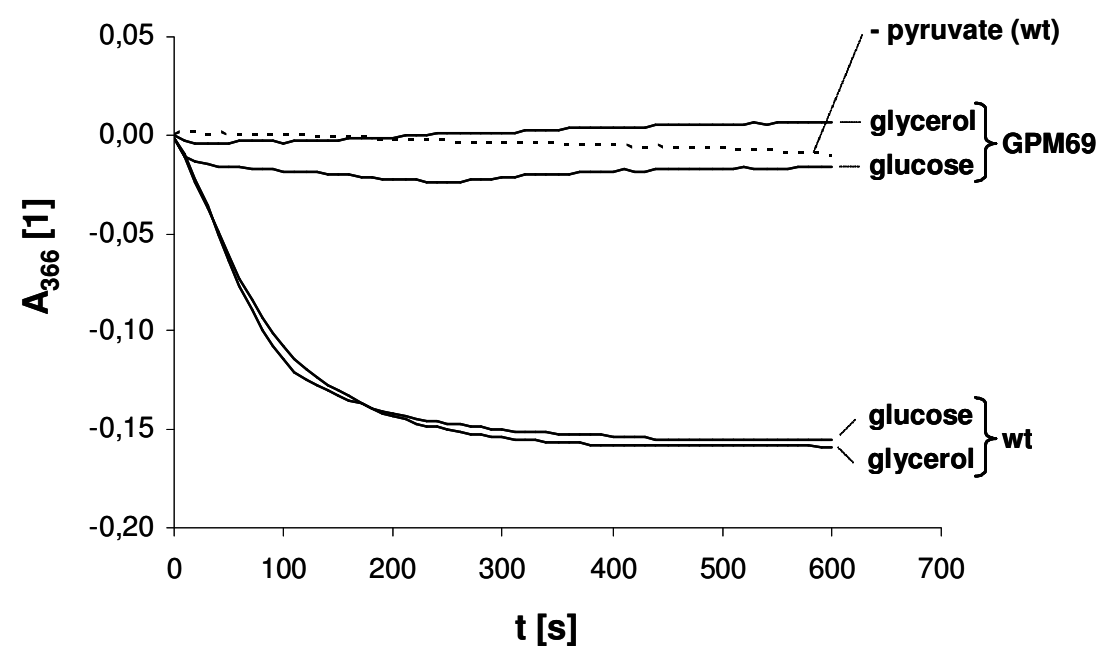

Fig. 32: Activity of lactate dehydrogenase in cell extracts of $M$. pneumoniae. Cultures of the wild type and of the ldh mutant strain GPM69 were grown in the presence of glucose or glycerol. Ldh activity was measured photometrically based on the conversion of NADH to NAD in the presence of pyruvate as the substrate (see Materials and Methods).

\section{Discussion}

Only little information concerning the regulated expression of genes in $M$. pneumoniae is available in the literature. This is not surprising since these bacteria have lost many of their regulatory systems during their reductive evolution leaving only those genes that are absolutely required to survive in a rather constant environment. Nevertheless, even $M$. pneumoniae is thought to be exposed to changes in its habitat. This can be concluded from the finding that a functional heat shock answer is present in $M$. pneumoniae and its relatives that might be necessary to face temperature stress during host's pyrexia (Madsen et al., 2006; Musatovova et al., 2006; Weiner et al., 2003). An additional hint for the assumption that $M$. pneumoniae can indeed respond to altering conditions comes from the observation that the formation of $\operatorname{HPr}(\operatorname{Ser}-\mathrm{P})$ is induced when the bacteria come in contact with glycerol (Halbedel et al., 2004).

$\mathrm{HPr}(\operatorname{Ser}-\mathrm{P})$ is a central signaling molecule in CcpA-mediated carbon catabolite repression in many firmicutes and has also been implicated in alternative signalling routes that work independent of CcpA proteins (Herro et al., 2005; Müller et al., 2006). Furthermore, HPr(Ser$\mathrm{P}$ ) is required for inducer exclusion of non-PTS carbon sources in Lactobacillus casei and Lactobacillus lactis (Dossonnet et al., 2000; Monedero et al., 2001a). This effect has been attributed to a direct inhibitory interaction of $\operatorname{HPr}(\operatorname{Ser}-\mathrm{P})$ with the lactose/proton symporter in 
case of lactose inducer exclusion in Lactococcus brevis (Ye \& Saier, 1995). The glycerol dependent formation of $\mathrm{HPr}(\mathrm{Ser}-\mathrm{P})$ stimulated speculations that $M$. pneumoniae might start a specific cell response upon arrival at its target site of infection as glycerol can be expected to be present in higher amounts on the surfaces of the human lung epithelium.

Using a proteomic approach we identified the $a c k A$ gene to be repressed during growth in the presence of glycerol. Beside this effect a handful of proteins was obviously modified in the presence of glycerol as compared to growth in the presence of glucose alone (data not shown). We noticed this effect, but at the moment we cannot provide any explanation for this observation. However, it again supports the hypothesis that glycerol might be an important signal molecule for $M$. pneumoniae. The ackA gene is expressed at the highest level when the cells are fed with glucose. This is in good agreement with the observation that the growth rate of M. pneumoniae is maximal under this condition, since an additional molecule ATP can be generated from pyruvate when catabolized to acetate (Halbedel et al., 2004; Miles, 1992). Alternatively, pyruvate can be reduced by the enzyme lactate dehydrogenase to give lactate (Miles, 1992). Interestingly, the expression of the corresponding $l d h$ gene is reciprocal when compared to the expression of the $a c k A$ gene. The transcription of the $l d h$ gene is maximal in the presence of glycerol, whereas under this condition the ackA gene seems to be repressed. Conversely, when the ackA gene is trancribed at a maximum rate which occurs in the presence of glucose the $l d h$ gene is only poorly expressed. Interestingly, an induction of $l d h$ transcription was also reported when the cells had been treated with mild concentrations of hydrogen peroxide which had been shown to be a byproduct of glycerol metabolism (Pilo et al., 2005; Zimmerman \& Herrmann, 2006). The regulation pattern of ackA and ldh transcription suggested that each of the two pyruvate catabolic routes is operative only when the other one is repressed. Surprisingly, the pattern of $l d h$ expression did not correspond to the concentration of lactate determined in culture supernatants of $M$. pneumoniae grown in the presence of glucose or glycerol. The pattern of lactate synthesis rather correlates with growth rate, $i$. $e$. when growth is maximal the highest amount of lactate is excreted by $M$. pneumoniae. Like the lactate dehydrogenase of Acholeplasma laidlawii, the lactate dehydrogenase of $M$. pneumoniae needs to be stimulated allosterically by fructose-1,6bisphosphate for full activity (Neimark \& Lemcke, 1972; data not shown). Additionally, the Ldh of A. laidlawii is inhibited by inorganic phosphate (Neimark \& Tung, 1973). Fructose1,6-bisphosphate accumulates intracellularly to high amounts in glucose grown cells of Mycoplasma gallisepticum, whereas inorganic phosphate generally accumulates in starving cells (Egan et al., 1982; Mason et al., 1981) It seems therefore possible, that - although 
induced - the Ldh of M. pneumoniae is not active in the presence of carbon sources that allow only a moderate growth (like glycerol or fructose), since the enzyme is not stimulated by FBP and inhibited by inorganic phosphate. However, although the $l d h$ gene is strongly induced by glycerol at the level of transcription, no increased amount of the Ldh protein was observed on the 2D gels. Accordingly, similar levels of Ldh activity were seen in cell extracts of $M$. pneumoniae whether the cells had been grown in the presence of glucose or glycerol. It is tempting to speculate that the transcription of the ldh mRNA might be induced under this condition to fulfill another important physiological role.

The promoters of the $a c k A$ and the $l d h$ gene were mapped using a primer extension analysis. The putative promoter sequences of the $a c k A$ and $l d h$ genes were proposed by Weiner et al. (2000). According to the promoter model of these authors, the $l d h$ promoter consists of the 35 box TTGGTG and a -10 box TAAAAT. Both boxes are separated from each other by a unusually short $13 \mathrm{bp}$ spacer. As the -10 box is located only $25 \mathrm{bp}$ upstream of the ldh start codon, a short leader sequence with less than $20 \mathrm{nt}$ would be expected. Within this leader sequence no Shine-Dalgarno (SD) sequence can be recognized. Definition of the $M$. pneumoniae consensus SD sequence was problematic as there are only about 20 genes that have sequences in their leader RNA which is complementary to the $3^{\prime}$ end of the $16 \mathrm{~S}$ rRNA (Weiner et al., 2000). For the ackA gene the promoter sequence was proposed to be CTTATT$\mathrm{N}_{10}$-TATTAT preceding the start AUG by only $19 \mathrm{bp}$. As it is the case for the ldh leader RNA, no SD sequence could be determined for the ackA leader RNA. Nevertheless, both promoter fragments containing the putative consensus -10 sequences are able to drive transcription of a promoterless lacZ gene in vivo, confirming their promoter activity and verifying the in silico predictions of Weiner et al. (2000). However, the activity of both promoter fragments turned out to be constitutive. We must therefore speculate that mechanisms other than differential promoter activity cause the regulated expression of the $a c k A$ and the $l d h$ gene. However, at the moment we cannot rule out the possibility that the cloned fragments - although containing the promoter activities - are too short to contain the cis-elements that are needed to show the expected regulation pattern in the $\beta$-galactosidase activity assays as well. In case of the $l d h$ promoter these regions can be specified in more detail since in strain GPM69 the wild type pattern of $l d h$ regulation is still operative. The $l d h$ promoter fragment therefore should be extended until the transposon insertion point and sequentially in the $5^{\prime}$ direction to re-analyze its promoter activity in response to the presence of glycerol. These experiments will undoubtedly improve our knowledge on regulation of gene expression in an organism that lacks most of the well-established regulatory systems. 
Chapter 8:

Discussion 


\section{Regulation of HPrK/P activity}

The HPr kinase/phosphorylase of Mycoplasma pneumoniae exhibits several characteristics that make it a unique representative of the $\mathrm{HPrK} / \mathrm{P}$ protein family. The most striking peculiarities are its high affinity for ATP and its requirement for glycerol to be active in vivo (Halbedel et al., 2004; Merzbacher et al., 2004). It phosphorylates its target competely as soon as the phosphate donor ATP is added above non-limiting concentrations (Steinhauer et al., 2002a). This behaviour distinguishes the M. pneumoniae protein from the HPrK/P protein of B. subtilis and all other studied firmicutes. The B. subtilis HPrK/P requires a 300-fold molar excess of ATP to phosphorylate HPr completely under otherwise similar conditions (Jault et al., 2000). The unusually high affinity for ATP was confirmed by the determination of the dissociation constant $\mathrm{K}_{\mathrm{D}}$ of the HPrK/P-ATP complex which was reported to be 5.4 $\mu \mathrm{M}$. In contrast, the B. subtilis $\mathrm{HPrK} / \mathrm{P}$ has a 50-fold less affnity towards ATP $\left(\mathrm{K}_{\mathrm{D}}=272 \mu \mathrm{M}\right)$ (Jault et al., 2000; Merzbacher et al., 2004). Furthermore, the HPrK/P of B. subtilis needs to be stimulated by fructose-1,6-bisphosphate (FBP) for full activity, whereas the kinase activity of the M. pneumoniae HPrK/P is only marginally activated by FBP (Merzbacher et al., 2004; Reizer et al., 1998). Interestingly, the HPrK/P of the pathogenic spirochete Treponema denticola also has a high affinity for ATP and is only marginally activated by FBP (Gonzalez et al., 2005). HPrK/P proteins that are highly affine for ATP obviously do not require any additional allosteric activation by FBP.

The formation of $\operatorname{HPr}(\operatorname{Ser}-\mathrm{P})$ in cells of B. subtilis occurs when the cells are grown in the presence of readily metabolizable carbon sources such as glucose, fructose or sorbitol (Deutscher \& Saier, 1983; Ludwig et al. 2002; Monedero et al. 2001b; Schmalisch, 2004). This was proposed to be the result of increased intracellular FBP concentrations under these conditions (Ludwig et al. 2002; Monedero et al. 2001b). Since the M. pneumoniae HPrK/P acts as kinase irrespective of the presence or absence of FBP in vitro, the protein was expected to act as a kinase in vivo under all conditions as well (Steinhauer et al., 2002a). This assumption is supported by measurements of the intracellular ATP level in cells of Mycoplasma capricolum. In these bacteria the intracellular concentration of ATP was found to be around $0.2 \mathrm{mM}$ and increases to $1.2 \mathrm{mM}$ when $1 \mathrm{mM}$ glucose was added (Linker \& Wilson, 1985). Within this range of ATP concentration the M. pneumoniae HPrK/P phosphorylates its target HPr in vitro completely (Steinhauer et al., 2002a). However, $\mathrm{HPr}(\operatorname{Ser}-\mathrm{P})$ formation was oberved in M. pneumoniae only when glycerol was added to the culture medium. Several possible reasons that could explain the in vivo pattern of $\operatorname{HPr}(\mathrm{Ser}-\mathrm{P})$ formation were ruled out. (i) The kinase activity of the HPrK/P is not activated allosterically 
by glycerol or glycerol-3-phosphate (data not shown). (ii) The phosphatase activity of the $\mathrm{HPrK} / \mathrm{P}$ is not inhibited either by glycerol or glycerol-3-phosphate (data not shown). (iii) Finally, the $h p r K$ gene seems to be expressed constitutively since HPr kinase activity was detected in cell extracts of $M$. pneumoniae whether the cells have been grown in the presence of glucose, fructose or glycerol (Halbedel et al., 2004). Thus there is no differential expression of the $h p r K$ gene that might explain the differences in $\operatorname{HPr}(\operatorname{Ser}-\mathrm{P})$ formation seen in vivo.

In M. pneumoniae, glycerol is transported into the cell via facilitated diffusion by the glycerol facilitator protein GlpF. In the next step, glycerol is phosphorylated by the enzyme glycerol kinase GlpK to give glycerol-3-phosphate which then can be reduced by the enzyme glycerol3-phosphate dehydrogenase GlpD to yield glyceraldehyde-3-phosphate (Himmelreich et al., 1996; Pilo et al., 2005). The stimulation of HPrK/P by glycerol seems to be triggered in the course of biochemical events prior to the reduction of glycerol-3-phosphate to glyceraldehyde-3-phosphate by GlpD. This can be concluded from experiments with the $g l p D::$ Tn mutant strain GPM52 that was grown in the presence of glucose and glycerol. Under this condition, the induction of $\operatorname{HPr}(\operatorname{Ser}-\mathrm{P})$ formation is still operative in this strain (data not shown). To test, whether the glycerol dependent induction of HPr(Ser-P) synthesis is lost in mutant strains in which the uptake of glycerol or the primary phosphorylation of glycerol are defective, $g l p F::$ Tn and $g l p K::$ Tn strains were searched by haystack mutagenesis. But all attempts to isolate these strains failed. Since the $g l p K$ gene has been described to be an essential gene in both Mycoplasma genitalium and $M$. pneumoniae this outcome is not astonishing (Glass et al., 2006; Hutchison et al., 1999). Even though there are reports that the $g l p F$ gene can be disrupted by transposon insertion (Hutchison et al., 1999), we were not able to identify a clone with a $g l p F::$ Tn junction. However, since transport and metabolism of glycerol seems to be a dispensable capability for M. pneumoniae, the finding of Hutchison et al. (1999) that $g l p K$ is an essential gene raises the suspicion that the glycerol kinase is required for processes other than the catabolic phosphorylation of glycerol.

To explain the induction of $\mathrm{HPr}(\mathrm{Ser}-\mathrm{P})$ synthesis that occurs in M. pneumoniae when the cells come in contact with glycerol, an alternative mechanism can be envisioned. An inhibitor of $\mathrm{HPrK} / \mathrm{P}$ activity that is active during growth in the presence of glucose but inactive when glycerol is catabolized would explain the in vivo $\operatorname{HPr}(\operatorname{Ser}-\mathrm{P})$ pattern and would also be in agreement with the in vitro data of Steinhauer et al. (2002a) and of Merzbacher et al. (2004). The existence of a HPrK/P inhibitor protein had also been hypothesized in B. subtilis to explain the elevated amount of intracellular $\operatorname{HPr}(\operatorname{Ser}-\mathrm{P})$ in a $c c p A$ mutant strain. The 


\section{Discussion}

expression of this inhibitor was suggested to be induced in course of CcpA-dependent carbon catabolite regulation (CCR) to ensure that a certain amount of unphosphorylated HPr is always present and can participate in the uptake of PTS substrates (Ludwig et al., 2002). Interestingly, induction of $\operatorname{HPr}(\operatorname{Ser}-\mathrm{P})$ synthesis during growth in the presence of non-PTS subtrates such as glycerol and sorbitol was also observed in B. subtilis (Schmalisch, 2004). Induction of in vivo HPr(Ser-P) synthesis by external polyols might therefore be a common feature of the firmicutes.

\section{Formation of $\mathrm{HPr}(\mathrm{His} \sim \mathrm{P})($ Ser-P)}

The M. pneumoniae HPrK/P not only has an altered activity pattern but also displays an interesting peculiarity concerning its substrate specifity. It catalyzes the phosphorylation of HPr at the Ser-46 residue wether HPr is phosphorylated at the His-15 residue or not. Similarily, HPr and HPr(Ser-P) are substrates for enzyme I dependent phosphorylation at the His-15 residue. In both cases, the phosphorylation of the singly phosphorylated HPr at the second phosphorylation site is approximately five-fold slower (Halbedel \& Stülke, 2005). Anyway, these reaction rates seem to be sufficient to cause the high proportion of doubly phosphorylated HPr that is found in M. pneumoniae cells when fed with glycerol (Halbedel et al., 2004). In B. subtilis and other Gram positive bacteria both phosphorylation events were reported to be mutually exclusive. The phosphorylation of $\operatorname{HPr}(\operatorname{Ser}-\mathrm{P})$ by enzyme $\mathrm{I}$ is approximately 5000-fold slower than the phosphorylation of the unphosphorylated $\mathrm{HPr}$ (Deutscher et al., 1984). In turn, the phosphorylation of HPr by HPrK/P is strongly inhibited when preincubated with PEP and enzyme I (Reizer et al., 1998). The relaxed specifity of HPrK/P and enzyme I towards the singly phosphorylated HPr can be partly considered as the result of the loss of CcpA-mediated CCR in M. pneumoniae: For Bacillus megaterium the interaction of $\operatorname{HPr}(\operatorname{Ser}-\mathrm{P})$ with $\mathrm{CcpA}$ requires the His-15 to be unphosphorylated since the $\mathrm{N} \delta 1$ atom of the His-15 residue hydrogen bonds to the Asp-296 residue of the corresponding CcpA protein. Phosphorylation of HPr at His-15 would prevent this interaction by steric hindrance and by electrostatic repulsion as well (Schumacher et al., 2004). In the absence of any putative $\mathrm{HPr}(\mathrm{Ser}-\mathrm{P})$ interaction partner such as CcpA or RbsR (Müller et al., 2006), the M. pneumoniae $\mathrm{HPr}$ is not longer exposed to any selective pressure towards the preservation of an intact $\operatorname{HPr}(\operatorname{Ser}-\mathrm{P})$ interaction interface and might thus have acquired mutations that allow double phosphorylation.

For the discrimination between unphosphorylated $\mathrm{HPr}$ and $\mathrm{HPr}(\mathrm{His} \sim \mathrm{P})$, the HPrK/Ps of Staphylococcus xylosus and of Lactobacillus casei have the potential to make use of a minor 


\section{Discussion}

interaction interface. This interface involves the His-15 residue of HPr and the Leu297 and Ile301 residues of the HPrK/P (S. xylosus numbering) (Fieulaine et al., 2002; Maurer et al., 2004). When phosphorylated, the interactions between HPrK/P and HPr involving the His-15 residue of the HPr protein can presumably not be formed. In the M. pneumoniae HPrK/P the amino acid residue that corresponds to position 297 in the S. xylosus protein is a glutamine residue. Thus, an unpolar amino acid side chain is replaced by a polar one that tends to be charged positively at least at low $\mathrm{pH}$. It is tempting to speculate whether it is this specific replacement that makes the $\mathrm{HPr}(\mathrm{His} \sim \mathrm{P})$ more susceptible for $\mathrm{HPrK} / \mathrm{P}$ dependent phosphorylation at the serine residue.

Similarily, for enzyme I the structural basis for the discrimination between HPr and HPr(SerP) is a hydrogen bonding interaction between the Ser-46 residue of HPr and the Glu-84 side chain of enzyme I, as observed in the structure of the E. coli HPr-enzyme I complex (Garrett et al., 1999). The introduction of a phosphate group at Ser-46 would disturb this interaction because of electrostatic repulsion between the phosphate group of Ser-46-P and the negatively charged carboxylate of Glu-84 of enzyme I (Garrett et al., 1999). A glutamate residue is also present at this position of enzyme I of B. subtilis and Streptococcus salivarius (Gagnon et al., 1992; Kunst et al., 1997). Although high amounts of doubly phosphorylated HPr are found in oral streptococci, $\mathrm{HPr}(\mathrm{Ser}-\mathrm{P})$ is a very poor substrate for phosphorylation by enzyme I in these bacteria (Casabon et al., 2006; Cochu et al., 2005). This contradiction can be resolved by the finding that the $S$. salivarius enzyme I requires an acidic $\mathrm{pH}$ to accept $\mathrm{HPr}(\mathrm{Ser}-\mathrm{P})$ for phosphorylation at the histidine residue. At acidic conditions the negative charge of glutamate-84 is neutralized to overcome the electrostatic repulsion of the serine phosphorylated HPr (Casabon et al., 2006). Interestingly, in M. pneumoniae enzyme I a threonine has replaced the glutamate at position 84 of the protein. Thus, the phosphate group of $\mathrm{HPr}(\operatorname{Ser}-\mathrm{P})$ does not come in close contact with the negatively charged amino acid side chain of Glu-84. This structural detail of the M. pneumoniae enzyme I might facilitate the acceptance of $\operatorname{HPr}(\operatorname{Ser}-\mathrm{P})$ as the substrate for phosphorylation at the histidine residue.

The relaxed specifity of both, enzyme I and HPrK/P towards the singly phosphorylated HPr in M. pneumoniae is in good agreement with the growth characteristic observed with this bacterium in the simultaneous presence of glucose and glycerol. Under this condition approximately one third of the cellular HPr is present in the doubly phosphorylated form. When compared to growth in the presence of glucose alone, growth is only marginally delayed in the presence of both carbohydrates (Halbedel et al., 2004). This finding supports the idea that $\mathrm{HPr}(\mathrm{His} \sim \mathrm{P})($ Ser-P) might participate in PTS phosphotransfer with a similar rate 
as $\operatorname{HPr}(\mathrm{His} \sim \mathrm{P})$. Consequenly, the function of $\operatorname{HPr}(\operatorname{Ser}-\mathrm{P})$ can not be seen in the downregulation of PTS mediated sugar uptake as it was proposed for B. subtilis (Ye \& Saier, 1996). For these bacteria it was demonstrated that the presence of glucose severely inhibits the uptake of alternative PTS sugars such as fructose or mannitol. This inhibition was not seen in strains where the wild type $p t s H$ gene was replaced by the $p t s H 1$ allel in which the Ser-46 is changed into a non-phosphorylatable Ala residue (Ye \& Saier, 1996). Similarily, hyperphosphorylation of $\mathrm{HPr}$ at the Ser-46 residue in a B. subtilis ccpA mutant prevents glucose uptake which only can be restored to the normal wild type level by replacing the serine at position 46 by an alanine (Ludwig et al., 2002).

The synthesis of high amounts of doubly phosphorylated HPr was also reported for several oral streptococci (Cochu et al., 2005; Thevenot et al., 1995). In these bacteria lactose is taken up by the lactose $/ \mathrm{H}^{+}$symporter LacS that consists of an intramembrane translocator domain and a cytoplasmic domain that resembles an enzyme IIA domain. The rate of lactose uptake can be inhibited approximately three-fold when the IIA domain of LacS is phosphorylated by $\mathrm{HPr}(\mathrm{His} \sim \mathrm{P})$ at a regulatory histidine residue (Poolman et al., 1995). Surprisingly, the rate of reversible phosphorylation of $\mathrm{LacS}$ is the same whether $\mathrm{HPr}(\mathrm{His} \sim \mathrm{P})$ or $\mathrm{HPr}(\mathrm{His} \sim \mathrm{P})(\mathrm{Ser}-\mathrm{P})$ is used as the phosphate donor (Cochu et al., 2005). This again points towards the possibility that the selective pressure that forces the maintenance of mutually exclusive $\mathrm{HPr}$ phosphorylation events comes from outside the core PTS.

\section{The physiological role of HPrK/P and PrpC in M. pneumoniae}

In the absence of any ccpA orthologous gene, the function of the HPrK/P in $M$. pneumoniae is all but self-evident. Besides the function of $\operatorname{HPr}(\operatorname{Ser}-\mathrm{P})$ in $\mathrm{CcpA}$ mediated CCR, $\mathrm{HPr}(\operatorname{Ser}-\mathrm{P})$ has also been implicated in several CcpA independent mechanisms such as inducer exclusion. For the lactose $/ \mathrm{H}^{+}$symporter of Lactobacillus brevis it was suggested that $\mathrm{HPr}(\mathrm{Ser}-\mathrm{P})$ interacts with this protein to inhibit its transport activity (Ye \& Saier, 1995). Similar functions for $\mathrm{HPr}(\mathrm{Ser}-\mathrm{P})$ have been proposed for the allosteric control of the maltose ABC transporter in Lactococcus casei where maltose uptake is normally prevented in the presence of glucose but not in a hprK mutant under otherwise identical conditions (Dossonnet et al., 2000). In Listeria monocytogenes the $\mathrm{HPr}(\mathrm{Ser}-\mathrm{P})$ was found to influence control of gene expression mediated by the virulence gene regulator PrfA (Herro et al., 2005). The transcription factor PrfA activates the transcription of the hly gene coding for the pore forming hemolysin listeriolysin O (Leimeister-Wächter et al., 1990). During the metabolism of preferred carbon sources such as cellobiose, glucose or fructose the expression of the hly gene is strongly 


\section{Discussion}

repressed suggesting that PrfA is inhibited under these conditions (Milenbachs et al., 1997). This repressive effect was attributed to the formation of $\mathrm{HPr}(\operatorname{Ser}-\mathrm{P})$ which impedes the formation of $\mathrm{HPr}(\mathrm{His} \sim \mathrm{P})$ that was proposed to be the component mediating inhibition of PrfA activity (Herro et al., 2005). However, in M. pneumoniae there are no proteins that might be promising candidates to be targets of allosteric control exerted by HPr and its phosphorylated derivatives. Nevertheless, the $h p r K$ gene had been retained in this organism although it has lost a huge portion of its former metabolic and regulatory capabilities. Thus, the $h p r K$ gene is obviously required for the proper performance of several cellular processes.

In a first attempt to identify $h p r K$ dependent cellular processes, a two dimensional PAGE analysis comparing the cytoplasmic proteome of the wild type and the hprK strain GPM51 was performed. It turned out that in the presence of glucose and glycerol - a condition that is known to provoke $\mathrm{HPr}(\mathrm{Ser}-\mathrm{P})$ formation -4 proteins were significantly less abundant in cell extracts of the $h p r K$ mutant. These proteins were analyzed by mass spectrometry and identified to be the thymidylate synthase ThyA, and the three subunits of the ribonucleotide reductase NrdF, NrdI and NrdE (see Fig. 33A). The genes corresponding to these gene products are arranged in the thyA-dhfr-nrdFIE gene cluster suggesting that they are transcribed as an operon. The protein corresponding to the second gene of this operon, $d h f r$ coding for dihydrofolate reductase, was not identified in our 2D PAGE analyses but presumably shows the same expression defect in the hprK::Tn background as its neighbour genes. The genes of this operon are involved in the biosynthesis of desoxyribonucleotides from ribonucleotides ( $n r d F I E)$ or in the methylation of desoxyuridine monophosphate to give desoxythymidine monophosphate (thyA, dhfr) (see Fig. 33D). Thus, the $M$. pneumoniae thyA gene cluster represents a putative transcription unit that codes for the enzymatic activities that are needed to synthesize the building blocks of DNA from ribonucleotides. The expression defect of the thyA operon was only seen when the cells were grown in the presence of glucose and glycerol. There was no difference in thyA trancription between the wild type and the hprK mutant when grown in the presence of glucose (data not shown). This is in good agreement with the in vivo pattern of $\mathrm{HPr}(\operatorname{Ser}-\mathrm{P})$ formation as the atypical thyA expression is obvious in the hprK mutant only under conditions where the HPrK/P is normally active and phosphorylates HPr at the serine residue. Based on this result the rather theoretical possibility that the $h p r K$ mutant has simply acquired mutations in the promoter region of the thyA operon that lead to a decreased rate of transcription initiation can be ruled out. The finding that the hprK mutant has a growth defect in the presence of glucose and glycerol but not in the presence of glucose alone (H. Eilers, personal communication), can be considered as a further 


\section{Discussion}

hint for the presence of a mechanistic connection between the formation of $\operatorname{HPr}(\operatorname{Ser}-\mathrm{P})$ and the proper expression of the thyA operon.

A

A 12 wild type

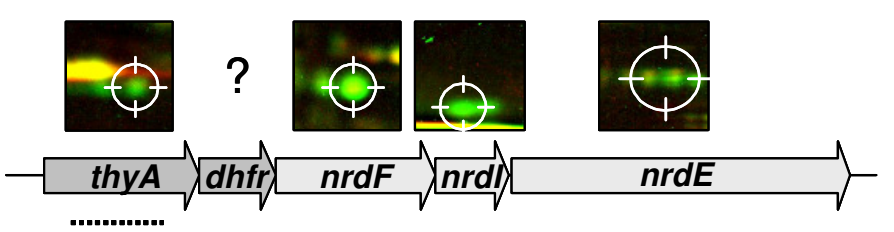

B

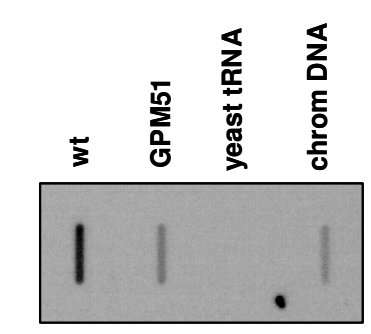

C

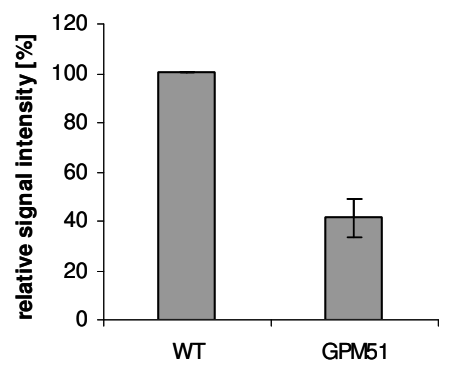

$\mathrm{D}$
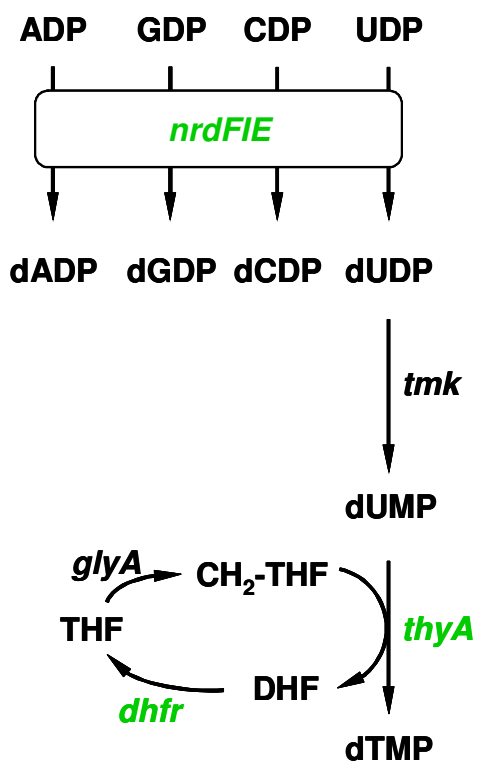

Fig. 33: Expression of the thyA operon in M. pneumoniae wild type and hrpK mutant cells. (A) Sections of falsecouloured fusion images obtained with the software Decodon Delta2D from two-dimensional polyacrylamide gels of the wild type (green) and the hprK mutant GPM51 (red). The proteins ThyA, NrdF, NrdI and NrdE were found to be less expressed in GPM51 and thus they appear as green spots. The genomic arrangement of the genes corresponding to the proteins deregulated in GPM51 is shown. (B) Slot blot analysis with whole RNA extracts of the wildtype and strain GPM51. A dilution series of RNA extracts was blotted onto a positively charged nylon membrane and probed with a DIG-labelled riboprobe specific for an internal part of the thyA ORF as indicated by the dotted line in A. Signals obtained with $2 \mu \mathrm{g}$ of RNA are shown. Yeast tRNA and $M$. pneumoniae chromosomal DNA served as controls. (C) The diagram illustrates the quantification of the thyA specific signal intensities obtained in the adjacent slot blot experiment. (D) Illustration of the biochemicals pathways involved in the biosynthesis of desoxyribonucleotides from ribonucleotides in M. pneumoniae. DHF dihydrofolate, THF - tetrahydrofolate.

Identical effects concerning both growth and thyA expression were also observed in the prpC mutant strain GPM68. Similarily, a decreased thyA expression was detected in this strain in the simultaneous presence of glucose and glycerol (data not shown). The reduced thyA expression is again in good coincidence with a significant growth defect under this condition (H. Eilers, personal communication). Apparently, there is no direct linear correlation between the degree of thy $A$ transcription and the amount of intracellular $\operatorname{HPr}(\operatorname{Ser}-\mathrm{P})$ since in both mutant strains the expression of the thyA operon is reduced as compared to the wild type. This suggests that a precisely adjusted amount of $\mathrm{HPr}(\mathrm{Ser}-\mathrm{P})$ is required for the proper expression of the thyA operon in M. pneumoniae under conditions that provoke the formation of HPr(SerP). Interestingly, the putative promoter in front of the thyA gene is preceded by a rather unusual sequence motif. This motif consists of two direct repeated identical 20-mers 
(GGTTATTAACATTGTTTTAA) separated by a 2 bp spacer and precedes the putative -35 box which has been proposed by Weiner et al. (2000) by 27 basepairs. Experiments in which the promoter region of the thyA operon was tested for interaction with $\mathrm{HPr}(\operatorname{Ser}-\mathrm{P})$ by electrophoretic mobility shift assays gave no clues for a direct binding of $\mathrm{HPr}(\mathrm{Ser}-\mathrm{P})$ to this region. However, it is tempting to speculate that this sequence motif is involved in the coordinated expression of the putative thyA operon.

In $M$. pneumoniae, regulation of transcription in response to different carbohydrates was observed for the $a c k A$ and the $l d h$ gene. The transcription of these genes is either repressed or induced as soon as glycerol becomes available (see chapter 7). This finding stimulated the assumption that the HPrK/P might be the mediator of this regulatory effect. However, analysis of $a c k A$ and $l d h$ transcription in the $h p r K$ mutant revealed that the induction of $l d h$ transcription and repression of $a c k A$ in the presence of glycerol is unaffected whether a functional $h p r K$ gene is present or not (data not shown).

In good agreement with the finding that the HPrK/P has the kinase activity as its preferential mode of action in vitro is the identification of $\operatorname{PrpC}$ as the major $\operatorname{HPr}(\operatorname{Ser}-\mathrm{P})$ phosphatase in cell extracts of $M$. pneumoniae. In crude extracts, the $\operatorname{HPr}(\operatorname{Ser}-\mathrm{P})$ phosphatase activity corresponding to the PrpC protein significantly exceeds that one which corresponds to the HPrK/P (Halbedel et al., 2006). This suggests that the HPrK/P has outsourced its phosphatase function to the previously rather unspecific protein serine/threonine phosphatase PrpC. The HPrK/P PrpC couple of $M$. pneumoniae can therefore be regarded as a paradigm of molecular co-evolution. As glycerol can be expected to be available for $M$. pneumoniae by lipase mediated break-down of surfactant phospholipids, the formation of $\mathrm{HPr}(\mathrm{Ser}-\mathrm{P})$ is presumably induced when the cells have arrived their target site of infection. Under this condition, PrpC ensures that a certain portion of HPr keeps always unphosphorylated at the serine residue and thus can participate in processes where the phosphate group at Ser-46 would otherwise be disturbing. This hypothesis can directly be deduced from the finding that the $\operatorname{prp} C$ mutant has a growth defect in the presence of glucose and glycerol (see above). Thus, under this particular condition the presence of PrpC confers an advantage to $M$. pneumoniae as the presence of the HPrK/P does as well. It would be interesting to decipher the molecular links that cause the growth defects of the $h p r K$ and the $\operatorname{prpC}$ mutants since this will undoubtedly help to understand why these genes are still present and what physiological purpose they serve in M. pneumoniae. 


\section{Outlook}

After more than two decades of research since the identification of the HPrK/P, our knowledge concerning its allosteric control and its physiological function in the model organism B. subtilis has become pretty comprehensive. In pathogens such as M. pneumoniae and the spirochete $T$. denticola $\mathrm{HPrK} / \mathrm{P}$ proteins were also identified and characterized in vitro (Steinhauer et al., 2002a; Gonzalez et al., 2005). In case of M. pneumoniae, the observed in vivo pattern of $\mathrm{HPr}(\mathrm{Ser}-\mathrm{P})$ formation suggested for the first time a connection between the pathogenicity of a bacterium and the synthesis of $\operatorname{HPr}(\operatorname{Ser}-\mathrm{P})$ (Steinhauer et al., 2002a; this work). In Listeria monocytogenes $\mathrm{HPr}(\operatorname{Ser}-\mathrm{P})$ has meanwhile also been implicated mechanistically in the regulation of virulence genes (Herro et al., 2005).

For a more detailed understanding of this interconnection, the mechanisms of glycerol dependent $\operatorname{HPr}(\operatorname{Ser}-\mathrm{P})$ formation in $M$. pneumoniae should be characterized. In order to identify $M$. pneumoniae genes the products of which modulate HPrK/P activity, the $M$. pneumoniae system should be reconstituted first in $B$. subtilis. In a second step a $M$. pneumoniae genomic library could be expressed in a $B$. subtilis strain containing the $M$. pneumoniae HPrK/P and a CCR responsive lacZ-fusion. Clones that exhibit abnormal $\beta$ galactosidase activity under normally repressing or non-repressing conditions can be expected to harbor genes that either inhibit or activate the HPr kinase. Additionally, it would be interesting to see, whether the formation of $\operatorname{HPr}(\operatorname{Ser}-\mathrm{P})$ is indeed triggered when $M$. pneumoniae comes in contact with the surfaces of pneumocytes. The analysis of HPr(Ser-P) synthesis in a $g l p F$ mutant would help to verify the connection between glycerol metabolism and $\operatorname{HPr}(\operatorname{Ser}-\mathrm{P})$ formation. Finally, all mutants that are shown to be impaired in $\mathrm{HPr}(\operatorname{Ser}-\mathrm{P})$ formation should be tested for virulence attenuation using appropriate cell culture or animal models. For a refinement of our view on $h p r K$ dependent gene expression in M. pneumoniae, DNA microarrays rather than two-dimensional gels should be used. The construction of DNA microarrays has recently been started in our laboratory and their application will surely lead to the identifaction of new members of the presently still hypothetical $h p r K$ regulon. 


\section{References}

Adler, E., A. Donella-Deana, F. Arigoni, L. A. Pinna, and P. Stragier. 1997. Structural relationship between a bacterial developmental protein and eukaryotic PP2C protein phosphatases. Mol. Microbiol. 23:57-62.

Allen, G. S., K. Steinhauer, W. Hillen, J. Stülke, and R. G. Brennan. 2003. Crystal structure of HPr kinase/phosphatase from Mycoplasma pneumoniae. J. Mol. Biol. 326: 1203-1217.

Almagor, M., I. Kahane, and S. Yatziv. 1984. Role of superoxide anion in host cell injury induced by Mycoplasma pneumoniae infection. A study in normal and trisomy 21 cells. J. Clin. Invest. 73:842-847.

André, A., W. Maccheroni, F. Doignon, M. Garnier, and J. Renaudin. 2003. Glucose and trehalose PTS permeases of Spiroplasma citri probably share a single IIA domain, enabling the spiroplasma to adapt quickly to carbohydrate changes in its environment. Microbiology 149:2687-2696.

Audette, G. F., R. Engelmann, W. Hengstenberg, J. Deutscher, K. Hayakawa, J. W. Quail, and L. T. J. Delbaere. 2000. The 1.9 Á resolution structure of phospho-serine $46 \mathrm{HPr}$ from Enterococcus faecalis. J. Mol. Biol. 303:545-553.

Balish, M. F., R. T. Santurri, A. M. Ricci, K. K. Lee, and D. C. Krause. 2003. Localization of Mycoplasma pneumoniae cytadherence-associated protein HMW2 by fusion with green fluorescent protein: implications for attachment organelle structure. Mol. Microbiol. 47:49-60.

Belitsky, B. R., and A. L. Sonenshein. 1998. Role and regulation of Bacillus subtilis glutamate dehydrogenase genes. J. Bacteriol. 180:6298-6305.

Benders, G. A., B. C. Powell, and C. A. Hutchison 3rd. 2005. Transcriptional analysis of the conserved ftsZ gene cluster in Mycoplasma genitalium and Mycoplasma pneumoniae. J. Bacteriol. 187:4542-4551.

Bergemann, A. D., and L. R. Finch. 1988. Isolation and restriction endonuclease analysis of a Mycoplasma plasmid. Plasmid 19:68-70.

Bergemann, A. D., J. C. Whitley, and L. R. Finch. 1989. Homology of Mycoplasma plasmid pADB201 and staphylococcal plasmid pE194. J. Bacteriol. 171:593-595.

Bi, W., and P. J. Stambrook. 1997. CCR: a rapid and simple approach for mutation detection. Nucl. Acids Res. 25:2949-2951. 
Bi, W., and P. J. Stambrook. 1998. Site-directed mutagenesis by combined chain reaction. Anal. Biochem. 256:137-140.

Blencke, H. M., G. Homuth, H. Ludwig, U. Mäder, M. Hecker, and J. Stülke. 2003. Transcriptional profiling of gene expression in response to glucose in Bacillus subtilis: regulation of the central metabolic pathways. Metab. Eng. 5:133-149.

Bornberg-Bauer, E., and J. Weiner 3rd. 2002. A putative transcription factor inducing mobility in Mycoplasma pneumoniae. Microbiology 148:3764-3765.

Bové, J. M., J. Renaudin, C. Saillard, X. Foissac, and M. Garnier. 2003. Spiroplasma citri, a plant pathogenic mollicute: relationships with its two hosts, the plant and the leafhopper vector. Annu. Rev. Phytopathol. 41:483-500.

Bradford, M. M. 1976. A rapid sensitive method for the quantification of microgram quantities of protein utilizing the principle of protein dye binding. Anal. Biochem. 72: $248-254$

Brehm, K., M.-T. Ripio, J. Kreft, and J.-A. Vázquez-Boland. 1999. The $b v r$ locus of Listeria monocytogenes mediates virulence gene repression by $\beta$-glucosides. J. Bacteriol. 181:5024-5032.

Brückner, R., and F. Titgemeyer. 2002. Carbon catabolite repression in bacteria: choice of the carbon source and autoregulatory limitation of sugar utilization. FEMS Microbiol. Lett. 209:141-148.

Byrne, M. E., D. A. Rouch, and R. A. Skurray. 1989. Nucleotide sequence analysis of IS256 from the Staphylococcus aureus gentamicin-tobramycin-kanamycin-resistance transposon Tn4001. Gene 81:361-367.

Cao, J., P. A. Kapke, and F. C. Minion. 1994. Transformation of Mycoplasma gallisepticum with Tn916, Tn4001, and integrative plasmid vectors. J. Bacteriol. 176:4459-4462.

Casabon, I., M. Couture, K. Vaillancourt, and C. Vadeboncoeur. 2006. Synthesis of HPr(Ser-P)(His P) by enzyme I of the phosphoenolpyruvate: sugar phosphotransferase system of Streptococcus salivarius. Biochemistry 45:6692-6702.

Catrein, I., R. Dumke, J. Weiner 3rd., E. Jacobs, and R. Herrmann. 2004. Crosscomplementation between the products of the genes P1 and ORF6 of Mycoplasma pneumoniae subtypes 1 and 2. Microbiology 150: 3989-4000.

Chambaud, I., R. Heilig, S. Ferris, V. Barbe, D. Samson, F. Galisson, I. Moszer, K. Dybvig, H. Wroblewski, A. Viari, et al. 2001. The complete genome sequence of the murine respiratory pathogen Mycoplasma pulmonis. Nucl. Acids Res. 29:2145-2153. 
Chaudhry, R., N. Nisar, B. Hora, S. Reddy, and P. Malhotra. 2004. Expression and immunological characterization of carboxy terminal region of $\mathrm{P} 1$ adhesin protein of Mycoplasma pneumoniae. J. Clin. Microbiol. 43: 321-325.

Check, E. 2002. Venter aims for maximum impact with minimal genome. Nature 420:350.

Chopra-Dewasthaly, R., M. Marenda, R. Rosengarten, W. Jechlinger, and C. Citti. 2005. Construction of the first shuttle vectors for gene cloning and homologous recombination in Mycoplasma agalactiae. FEMS Microbiol. Lett. 253:89-94.

Ciccarelli, F. D., T. Doerks, C. von Mering, C. J. Creevey, B. Snel, and P. Bork. 2006. Toward automatic reconstruction of a highly resolved tree of life. Science 311:12831286.

Clewell, D. B., S. E. Flannagan, Y. Ike, J. M. Jones, and C. Gawron-Burke. 1988. Sequence analysis of termini of conjugative transposon Tn916. J. Bacteriol. 170:30463052 .

Clewell, D. B., S. E. Flannagan, and D. D. Jaworski. 1995. Unconstrained bacterial promiscuity: the Tn916-Tn1545 family of conjugative transposons. Trends Microbiol. 3:229-236.

Cochu, A., D. Roy, K. Vaillancourt, J.-D. Lemay, I. Casbon, M. Frenette, S. Moineau, and C. Vadeboncoeur. 2005. The doubly phosphorylated form of $\mathrm{HPr}, \mathrm{HPr}(\operatorname{Ser}-\mathrm{P})(\mathrm{His} \sim \mathrm{P})$, is abundant in exponentially growing cells of Streptococcus thermophilus and phosphorylates the lactose transporter LacS as efficiently as $\mathrm{HPr}(\mathrm{His} \sim \mathrm{P})$. Appl. Env. Microbiol. 71:1364-1372.

Cocks, B. G., F. A. Brake, A. Mitchell, L. R. Finch. 1985. Enzymes of intermediary carbohydrate metabolism in Ureaplasma urealyticum and Mycoplasma mycoides subsp. mycoides. J. Gen. Microbiol. 131:2129-2135.

Constantopoulos, G., and G. J. McGarrity. 1987. Activities of oxidative enzymes in Mycoplasmas. J. Bacteriol. 169:2012-2016.

Cordova, C. M., C. Lartigue, P. Sirand-Pugnet, J. Renaudin, R. A. Cunha, and A. Blanchard. 2002. Identification of the origin of replication of the Mycoplasma pulmonis chromosome and its use in oriC replicative plasmids. J. Bacteriol. 184:5426-5435.

Cordwell, S. J., D. J. Basseal, J. D. Pollack, and I. Humphery-Smith. 1997. Malate/ lactate dehydrogenase in mollicutes: evidence for a multienzyme protein. Gene 195:113-120. 
Dandekar, T., M. Huynen, J. T. Regula, B. Ueberle, C. U. Zimmerman, M. A. Andrade, T. Doerks, L. Sánchez-Pulido, B. Snel, M. Suyama, et al. 2000. Re-annotating the Mycoplasma pneumoniae genome sequence: adding value, function and reading frames. Nucl. Acids Res. 28:3278-3288.

Darbon, E., P. Servant, S. Poncet, and J. Deutscher. 2002. Antitermination by GlpP, catabolite repression via CcpA and inducer exclusion triggered by $\mathrm{P} \sim \mathrm{GlpK}$ dephosphorylation control Bacillus subtilis glpFK expression. Mol. Microbiol. 43:10391052 .

Das, A. K., N. R. Helps, P. T. W. Cohen, and B. Barford. 1996. Crystal structure of the protein serine/threonine phosphatase $2 \mathrm{C}$ at $2.0 \AA$ A resolution EMBO J. 15:6798-6809.

Deutscher, J., and M. H. Saier Jr. 1983. ATP-dependent protein kinase-catalyzed phosphorylation of a seryl residue in HPr, a phosphate carrier protein of the phosphotransferase system in Streptococcus pyogenes. Proc. Natl. Acad. Sci. USA 80:6790-6794.

Deutscher, J., U. Kessler, C. A. Alpert, and W. Hengstenberg. 1984. Bacterial phosphoenolpyruvate-dependent phosphotransferase system: P-ser-HPr and its possible regulatory function. Biochemistry 23:4455-4460.

Deutscher, J., E. Küster, U. Bergstedt, V. Charrier, and W. Hillen. 1995. Protein kinasedependent $\mathrm{HPr} / \mathrm{CcpA}$ interaction links glycolytic activity to carbon catabolite repression in Gram-positive bacteria. Mol. Microbiol. 15:1049-1053.

Dhandayuthapani S., W. G. Rasmussen, and J. B. Baseman. 1999. Disruption of gene mg218 of Mycoplasma genitalium through homologous recombination leads to an adherence deficient phenotype. Proc. Natl. Acad. Sci. USA 96:5227-5232.

Dossonnet, V., V. Monedero, M. Zagorec, A. Galinier, G. Perez-Martinez, and J. Deutscher. 2000. Phosphorylation of HPr by the bifunctional HPr kinase/P-ser-HPr phosphatase from Lactobacillus casei controls catabolite repression and inducer exclusion but not inducer expulsion. J. Bacteriol. 182:2582-2590.

Dybvig, K., and G. H. Cassell. 1987. Transposition of gram-positive transposon Tn916 in Acholeplasma laidlawii and Mycoplasma pulmonis. Science 235:1392-1394.

Dybvig, K., and M. Khaled. 1990. Isolation of a second cryptic plasmid from Mycoplasma mycoides subsp. mycoides. Plasmid 24:153-155.

Dybvig, K., and A. Woodard. 1992. Construction of recA mutants of Acholeplasma laidlawii by insertional inactivation with a homologous DNA fragment. Plasmid 28:262-266. 
Dybvig, K., C. T. French, and L. L. Voelker. 2000. Construction and use of derivatives of transposon Tn4001 that function in Mycoplasma pulmonis and Mycoplasma arthritidis. J. Bacteriol. 182:4343-4347.

Egan, W., M. Barile, and S. Rottem. 1986. ${ }^{31} \mathrm{P}-\mathrm{NMR}$ studies of Mycoplasma gallisepticum cells using a continuous perfusion technique. FEBS Lett. 204:373-376.

Eymann, C., A. Dreisbach, D. Albrecht, J. Bernhardt, D. Becher, S. Gentner, le T. Tam, K. Büttner, G. Buurman, C. Scharf, et al. 2004. A comprehensive proteome map of growing Bacillus subtilis cells. Proteomics. 4:2849-2876.

Fieulaine, S., S. Morera, S. Poncet, V. Monedero, V. Gueguen-Chaignon, A. Galinier, J. Janin, J. Deutscher, and S. Nessler. 2001. X-ray structure of HPr kinase: a bacterial protein kinase with a P-loop nucleotide-binding domain. EMBO J. 20:3917-3927.

Franke, A. E., and D. B. Clewell. 1981. Evidence for a chromosome-borne resistance transposon (Tn916) in Streptococcus faecalis that is capable of "conjugal" transfer in the absence of a conjugative plasmid. J. Bacteriol. 145:494-502.

Fraser, C. M., J. D. Gocayne, O. White, M. D. Adams, R. A. Clayton, R. D. Fleischmann, C. J. Bult, A. R. Kerlavage, G. Sutton, J. M. Kelley, et al. 1995. The minimal gene complement of Mycoplasma genitalium. Science 270:397-403.

Frey, N., S. Nessler, S. Fieulaine, K. Vaillancourt, M. Frenette, and C. Vadeboncoeur. 2003. The HPr(Ser) kinase of Streptococcus salivarius: a hexameric bifunctional enzyme controlled by glycolytic intermediates and inorganic phosphate. FEMS Microbiol. Lett. 224:67-72.

Gagnon, G., C. Vadeboncoeur, R. C. Levesque, and M. Frenette. 1992. Cloning, sequencing and expression in Escherichia coli of the ptsI gene encoding enzyme I of the phosphoenolpyruvate:sugar phosphotransferase transport system from Streptococcus salivarius. Gene 121:71-78.

Gaidenko, T., T. J. Kim, and C. W. Price. 2002. The PrpC serine-threonine phosphatase and PrkC kinase have opposing physiological roles in stationary-phase Bacillus subtilis cells. J. Bacteriol. 184:6109-6114.

Galinier, A., J. Haiech, M.-C. Kilhoffer, M. Jaquinod, J. Stülke, J. Deutscher, and I. Martin-Verstraete. 1997. The Bacillus subtilis crh gene encodes a HPr-like protein involved in carbon catabolite repression. Proc. Natl. Acad. Sci. USA 94:8439-8444. 
Galinier, A., M. Kravanja, R. Engelmann, W. Hengstenberg, M.-C. Kilhoffer, J. Deutscher, and J. Haiech. 1998. New protein kinase and protein phosphatase families mediate signal transduction in bacterial catabolite repression. Proc. Natl. Acad. Sci. USA 95:1823-1828.

Garrett, D. S., Y.-J. Seok, A. Peterkofsky, A. M. Gronenborn, and G. M. Clore. 1999. Solution structure of the 40,000 $M_{\mathrm{r}}$ phosphoryl transfer complex between the N-terminal domain of enzyme I and HPr. Nature Struct. Biol. 6:166-173.

Gil, R., F. J. Silva, J. Peretó, and A. Moya. 2004. Determination of the core of a minimal bacterial gene set. Microbiol. Mol. Biol. Rev. 68: 518-537.

Glass, J. I., E. J. Lefkowitz, J. S. Glass, C. R. Heiner, E. Y. Chen, and G. H. Cassell. 2000. The complete sequence of the mucosal pathogen Ureaplasma urealyticum. Nature 407:757-762.

Glass, J. I., N. Assad-Garcia, N. Alperovich, S. Yooseph, M. R. Lewis, M. Maruf, C. A. Hutchison 3rd, H. O. Smith, and J. C. Venter. 2006. Essential genes of a minimal bacterium. Proc. Natl. Acad. Sci. USA 103:425-430.

Gonzalez, C. F., A. J. Stonestrom, G. L. Lorca, and M. H. Saier Jr. 2005. Biochemical characterization of phosphoryl transfer involving HPr of the phosphoenolpyruvatedependent phosphotransferase system in Treponema denticola, an organism that lacks PTS permeases. Biochemistry 44:598-608.

Gough, J. A., and N. E. Murray NE. 1983. Sequence diversity among related genes for recognition of specific targets in DNA molecules. J. Mol. Biol. 166:1-19.

Hahn, T., E. A. Mothershed, R. H. Waldo 3rd, and D. C. Krause. 1999. Construction and analysis of a modified Tn4001 conferring chloramphenicol resistance in Mycoplasma pneumoniae. Plasmid 41:120-124.

Halbedel, S., C. Hames, and J. Stülke. 2004. In vivo activity of enzymatic and regulatory components of the phosphoenolpyruvate:sugar phosphotransferase system in Mycoplasma pneumoniae. J. Bacteriol. 186:7936-7943.

Halbedel, S., and J. Stülke. 2005. Dual phosphorylation of Mycoplasma pneumoniae HPr by Enzyme I and HPr kinase suggests an extended phosphoryl group susceptibility of HPr. FEMS Microbiol. Lett. 247:193-198.

Halbedel, S., and J. Stülke. 2006. Probing in vivo promoter activities in Mycoplasma pneumoniae: a system for generation of single-copy reporter constructs. Appl. Environ. Microbiol. 72:1696-1699. 
Halbedel, S., J. Busse, S. R. Schmidl, and J. Stülke. 2006. Regulatory protein phosphorylation in Mycoplasma pneumoniae: A PP2C-type phosphatase serves to dephosphorylate HPr(Ser-P). J. Biol. Chem. 281:26253-26259.

Hall, B. 1998. Activation of the $b g l$ operon by adaptive mutation. Mol. Biol. Evol. 15:1-5.

Hames, C., S. Halbedel, O. Schilling, and J. Stülke. 2005. MMR: A method for the simultaneous introduction of multiple mutations into the glpK gene of Mycoplasma pneumoniae. Appl. Env. Microbiol. 71: 4097-4100.

Hammerschlag, M. R. 2001. Mycoplasma pneumoniae infections. Curr. Opin. Infect. Dis. 14:181-186.

Hanson, K. G., K. Steinhauer, J. Reizer, W. Hillen and J. Stülke. 2002. HPr kinase/phosphatase of Bacillus subtilis: expression of the gene and effects of mutations on enzyme activity, growth and carbon catabolite repression. Microbiology 148:18051811.

Hasselbring, B. M., C. A. Page, E. S. Sheppard, and D. C. Krause. 2006. Transposon mutagenesis identifies genes associated with Mycoplasma pneumoniae gliding motility. J. Bacteriol. 188:6335-6345.

Hedreyda, C. T., K. K. Lee, and D. C. Krause. 1993. Transformation of Mycoplasma pneumoniae with Tn4001 by electroporation. Plasmid 30: 170-175.

Herro, R., S. Poncet, P. Cossart, C. Buchrieser, E. Gouin, P. Glaser, and J. Deutscher. 2005. How seryl-phosphorylated HPr inhibits PrfA, a transcription activator of Listeria monocytogenes virulence genes J. Mol. Microbiol. Biotechnol. 9:224-234.

Himmelreich, R., H. Hilbert, H. Plagens, E. Pirkl, B. C. Li, and R. Herrmann. 1996. Complete sequence analysis of the genome of the bacterium Mycoplasma pneumoniae. Nucl. Acids Res. 24:4420-4449.

Himmelreich, R., H. Plagens, H. Hilbert, B. Reiner, and R. Herrmann. 1997. Comparative analysis of the genomes of the bacteria Mycoplasma pneumoniae and Mycoplasma genitalium. Nucl. Acids Res. 25:701-712.

Hoischen, C., A. Dijkstra, S. Rottem, J. Reizer, and M. H. Saier Jr. 1993. Presence of protein constituents of the gram-positive bacterial phosphotransferase regulatory system in Acholeplasma laidlawii. J. Bacteriol. 175:6599-6604.

Hutchison, C. A. 3rd, S. C. Peterson, S. R. Gill, R. T. Cline, O. White, C. M. Fraser, H. O. Smith, and J. C. Venter. 1999. Global transposon mutagenesis and a minimal mycoplasma genome. Science 286:2165-2169. 
Hyman, H. C., R. Gafny, G. Glaser, and S. Razin. 1988. Promoter of the Mycoplasma pneumoniae rRNA operon. J. Bacteriol. 170:3262-3268.

Inamine, J. M., S. Loechel, and P. C. Hu. 1988. Analysis of the nucleotide sequence of the P1 operon of Mycoplasma pneumoniae. Gene 73:175-183.

Inamine, J. M., K. C. Ho, S. Loechel, and P. C. Hu. 1990. Evidence that UGA is read as tryptophan codon rather than as a stop codon by Mycoplasma pneumoniae, Mycoplasma genitalium, and Mycoplasma gallisepticum. J. Bacteriol. 172:504-506.

Irmler, A., and K. Forchhammer. 2001. A PP2C-type phosphatase dephosphorylates the PII signaling protein in the cyanobacterium Synechocystis PCC 6803. Proc. Natl. Acad. Sci. USA 98:12978-12983.

Jacobs, E. 1997. Mycoplasma infections of the human respiratory tract. Wien. Klin. Wochenschr. 109:574 - 577.

Jaffe, J. D., H. C. Berg, and G. M. Church. 2004a. Proteogenomic mapping as a complementary method to perform genome annotation. Proteomics 4:59-77.

Jaffe, J. D., N. Stange-Thomann, C. Smith, D. DeCaprio, S. Fisher, J. Butler, S. Calvo, T. Elkins, M. G. FitzGerald, N. Hafez, et al. 2004b. The complete genome and proteome of Mycoplasma mobile. Genome Res. 14:1447-1461.

Janis, C., C. Lartigue, J. Frey, H. Wróblewski, F. Thiaucourt, A. Blanchard, and P. Sirand-Pugnet. 2005. Versatile use of oriC plasmids for functional genomics of Mycoplasma capricolum subsp. capricolum. Appl. Env. Microbiol. 71: 2888-2893.

Janis, C., G. Gourgues, J. Frey, A. Blanchard, and P. Sirand-Pugnet. 2006. Selected inactivation of the gene encoding the lipoprotein $\mathrm{Q}$ in Mycoplasma mycoides subsp. mycoides small colony. Proceedings of the International Organisation of Mycoplasmology, Cambridge, UK.

Jault, J. M., S. Fieulaine, S. Nessler, P. Gonzalo, A. Di Pietro, J. Deutscher, and A. Galinier. 2000. The HPr kinase from Bacillus subtilis is a homo-oligomeric enzyme which exhibits strong positive cooperativity for nucleotide and fructose 1,6bisphosphate binding. J. Biol. Chem. 275:1773-1780.

Jeffery, C. J. 1999. Moonlighting proteins. Trends Biochem. Sci. 24:8-11.

Jones, B. E., V. Dossonnet, E. Küster, W. Hillen, J. Deutscher, and R. E. Klevit. 1997. Binding of the catabolite repressor protein CcpA to its DNA target is regulated by phosphorylation of its corepressor HPr. J. Biol. Chem. 272:26530-26535.

Jukes, T. H., S. Osawa, A. Muto, and N. Lehman. 1987. Evolution of anticodons: variations in the genetic code. Cold. Spring. Harb. Symp. Quant. Biol. 52:769-776. 
Kannan, T. R., and J. B. Baseman. 2000. Expression of UGA-containing Mycoplasma genes in Bacillus subtilis. J. Bacteriol. 182:2664-2667.

Kenri, T., S. Seto, A. Horino, Y. Sasaki, T. Sasaki, M. Miyata. 2004. Use of fluorescentprotein tagging to determine the subcellular localization of Mycoplasma pneumoniae proteins encoded by the cytadherence regulatory locus. J. Bacteriol. 186:6944-6955.

King, K. W., and K. Dybvig. 1992. Nucleotide sequence of Mycoplasma mycoides subspecies mycoides plasmid pKMK1. Plasmid 28:86-91.

King, K. W., and K. Dybvig. 1994a. Mycoplasmal cloning vectors derived from plasmid pKMK1. Plasmid 31:49-59.

King, K. W., and K. Dybvig. 1994b. Transformation of Mycoplasma capricolum and examination of DNA restriction modification in M. capricolum and Mycoplasma mycoides subsp. mycoides. Plasmid 31:308-311.

Knudtson, K. L., and F. C. Minion. 1993. Construction of Tn4001lac derivatives to be used as promoter probe vectors in mycoplasmas. Gene 137:217-222.

Knudtson, K. L., and F. C. Minion. 1994. Use of lac gene fusions in the analysis of Acholeplasma upstream gene regulatory sequences. J. Bacteriol. 176: 2763-2766.

Knudtson, K. L., M. Manohar, D. E. Joyner, E. A. Ahmed, and B. C. Cole. 1997. Expression of the superantigen Mycoplasma arthridis mitogen in Escherichia coli and characterization of the recombinant protein. Infect. Immun. 65:4965-4971.

Kohler, C., C. von Eiff, G. Peters, R. A. Proctor, M. Hecker, and S. Engelmann. 2003. Physiological characterization of a heme-deficient mutant of Staphylococcus aureus by a proteomic approach. J. Bacteriol. 185:6928-6937.

Kunst, F., N. Ogasawara, I. Moszer, A. M. Albertini, G. Alloni, V. Azevedo, M. G. Bertero, P. Bessieres, A. Bolotin, S. Borchert, et al. 1997. The complete genome sequence of the gram-positive bacterium Bacillus subtilis. Nature 390:249-256.

Lartigue, C., A. Blanchard, J. Renaudin, F. Thiaucourt, and P. Sirand-Pugnet. 2003. Host specificity of mollicutes oriC plasmids: functional analysis of replication origin. Nucl. Acids Res. 31:6610-6618.

Leboeuf, C., L. Leblanc, Y. Auffray, and A. Hartke. 2000. Characterization of the ccpA gene of Enterococcus faecalis: identification of starvation-inducible proteins regulated by cсpA. J. Bacteriol. 182:5799-5806.

Leimeister-Wachter, M., C. Haffner, E. Domann, W. Goebel, and T. Chakraborty. 1990. Identification of a gene that positively regulates expression of listeriolysin, the major virulence factor of Listeria monocytogenes. Proc. Natl. Acad. Sci. U S A 87:8336-8340. 
Lessard, C., A. Cochu, J. D. Lemay, D. Roy, K. Vaillancourt, M. Frenette, S. Moineau, and C. Vadeboncoeur. 2003. Phosphorylation of Streptococcus salivarius lactose permease (LacS) by $\mathrm{HPr}(\mathrm{His} \sim \mathrm{P})$ and $\mathrm{HPr}(\mathrm{Ser}-\mathrm{P})(\mathrm{His} \sim \mathrm{P})$ and effects on growth. J. Bacteriol. 185:6764-6772.

Lind, K. 1983. Manifestations and complications of Mycoplasma pneumoniae disease: a review. Yale J. Biol. Med. 56:461-468.

Linker, C., and T. H. Wilson. 1985. Cell volume regulation in Mycoplasma gallisepticum. J. Bacteriol. 163:1243-1249.

Liu, L., K. Dybvig, V. S. Panangala, V. L. van Santen, and C. T. French. 2000. GAA trinucleotide repeat region regulates M9/pMGA gene expression in Mycoplasma gallisepticum. Infect. Immun. 68:871-876.

Lorca, G. L., Y. J. Chung, R. D. Barabote, W. Weyler, C. H. Schilling, and M. H. Saier Jr. 2005. Catabolite repression and activation in Bacillus subtilis: dependency on CcpA, HPr, and HprK. J. Bacteriol. 187:7826-7839.

Low, I. E., and S. M. Zimkus. 1973. Reduced nicotinamide adenine dinucleotide oxidase activity and $\mathrm{H}_{2} \mathrm{O}_{2}$ formation of Mycoplasma pneumoniae. J. Bacteriol. 116:346-354.

Ludwig, H., N. Rebhan, H.-M. Blencke, M. Merzbacher, and J. Stülke. 2002. Control of the glycolytic gapA operon by the catabolite control protein A in Bacillus subtilis: a novel mechanism of CcpA-mediated regulation. Mol. Microbiol. 45:543-553.

Ludwig, H., H.-M. Blencke, M. Schmalisch, C. Detsch, M. Merzbacher, and J. Stülke. 2003. Positive regulation of gene expression by the catabolite control protein CcpA in Bacillus subtilis. p. 181-186. In P. Dürre, and B. Friedrich (eds.), Regulatory Networks in Prokaryotes. Horizon Scientific Press, Norfolk.

Ludwig, W., and H.-P. Klenk. 2001. Overview: a phylogenetic backbone and taxonomic framework for prokaryotic systematics. p. 49-65. In D. R. Boone, R. W. Castenholz, and G. M. Garrity (eds.) Bergey's Manual of Systematic Bacteriology, $2^{\text {nd }}$ ed., vol. 1. Springer, New York.

Luo, W., Z. Cao, C. T. French, H. Yu, and K. Dybvig. 2006. Development of genetic sytems for study of $M$. arthritidis. Proceedings of the International Organisation of Mycoplasmology, Cambridge, UK.

Lyon, B. R., J. W. May, and R. A. Skurray. 1984. Tn4001: a gentamicin and kanamycin resistance transposon in Staphylococcus aureus. Mol. Gen. Genet. 193:554-556. 
Macino, G., G. Coruzzi, F. G. Nobrega, M. Li, and A. Tzagoloff. 1979. Use of the UGA terminator as a tryptophan codon in yeast mitochondria. Proc. Natl. Acad. Sci. USA 76:3784-3785.

Madsen, M. L., D. Nettleton, E. L. Thacker, R. Edwards, and F. C. Minion. 2006. Transcriptional profiling of Mycoplasma hyopneumoniae during heat shock using microarrays. Infect. Immun. 74:160-166.

Mahairas, G. G., and F. C. Minion. 1989. Random insertion of the gentamicin resistance transposon Tn4001 in Mycoplasma pneumoniae. Plasmid 21:43-47.

Mahillon, J., and M. Chandler. 1998. Insertion sequences. Microbiol. Mol. Biol. Rev. 62:725-774.

Manolukas, J. T., M. F. Barile, D. K. F. Chandler, and J. D. Pollack. 1988. Presence of anaplerotic reactions and transamination, and the absence of the tricarboxylic acid cycle in mollicutes. J. Gen. Microbiol. 134:791-800.

Márquez, J. A., S. Hasenbein, B. Koch, S. Fieulaine, S. Nessler, R. B. Russell, W. Hengstenberg, and K. Scheffzek. 2002. Structure of the full-length HPr kinase/ phosphatase from Staphylococcus xylosus at $1.95 \AA$ resolution: mimicking the product/substrate of the phosphotransfer reactions. Proc. Natl. Acad. Sci. USA 99:34583463.

Martin-Verstraete, I., M. Débarbouillé, A. Klier, and G. Rapoport. 1992. Mutagenesis of the Bacillus subtilis "-12, -24" promoter of the levanase operon and evidence for the existence of an upstream activating sequence. J. Mol. Biol. 226: 85-99.

Mason, P. W., D. P. Carbone, R. A. Cushman, and A. S. Waggoner. 1981. The importance of inorganic phosphate in regulation of energy metabolism of Streptococcus lactis. J. Biol. Chem. 256:1861-1866.

Maurer, T., S. Meier, N. Kachel, C. E. Munte, S. Hasenbein, B. Koch, W. Hengstenberg, and R. Kalbitzer. 2004. High-resolution structure of the histidine-containing phosphocarrier protein (HPr) from Staphylococcus aureus and characterization of its interaction with the bifunctional HPr kinase/phosphorylase. J. Bacteriol. 186:59065918.

McElwain, M. C., and J. D. Pollack. 1987. Synthesis of deoxyribomononucleotides in mollicutes: dependence on deoxyribose-1-phosphate and $\mathrm{PP}_{\mathrm{i}}$. J. Bacteriol. 169:36473653. 
Meinken, C., H.-M. Blencke, H. Ludwig, and J. Stülke. 2003. Expression of the glycolytic gapA operon in Bacillus subtilis: differential syntheses of proteins encoded by the operon. Microbiology 149:751-761.

Meinkoth, J., and G. Wahl. 1984. Hybridization of nucleic acids immobilized on solid supports. Anal. Biochem. 138: 267-284.

Merzbacher, M., C. Detsch, W. Hillen, and J. Stülke. 2004. Mycoplasma pneumoniae HPr kinase/phosphorylase: assigning functional roles to the P-loop and the HPrK/P signature sequence motif. Eur. J. Biochem. 271:367-374.

Mijakovic, I., S. Poncet, A. Galinier, V. Monedero, S. Fieulaine, J. Janin, S. Nessler, J. A. Marquez, K. Scheffzek, S. Hasenbein, et al. 2002. Pyrophosphate-producing protein dephosphorylation by HPr kinase/phosphorylase: a relic of early life? Proc. Natl. Acad. Sci. USA 99:13442-13447.

Milenbachs, A. A., D. P. Brown, M. Moors, and P. Youngman. 1997. Carbon-source regulation of virulence gene expression in Listeria monocytogenes. Mol. Microbiol. 23:1075-1085.

Miles, R. J. 1992. Catabolism in mollicutes. J. Gen. Microbiol. 138:1773-1783.

Miller, J. 1972. Experiments in molecular genetics. Cold Spring Harbor Laboratory, Cold Spring Harbor, N. Y.

Monedero, V., O. P. Kuipers, E. Jamet, and J. Deutscher. 2001a. Regulatory functions of Serine-46-phosphorylated HPr in Lactococcus lactis. J. Bacteriol. 183:3391-3398.

Monedero, V., S. Poncet, I. Mijakovic, S. Fieulaine, V. Dossonnet, I. Martin-Verstraete, S. Nessler, and J. Deutscher. 2001b. Mutations lowering the phosphatase activity of HPr kinase/phosphatase switch off carbon metabolism. EMBO J. 20:3928-3937.

Muhlrad, A., I. Peleg, J. A. Robertson, I. M. Robinson, and I. Kahane. 1981.Acetate kinase activity in mycoplasmas. J. Bacteriol. 147:271-273.

Musatovova, O., S. Dhandayuthapani, and J. B. Baseman. 2003. Transcriptional starts for cytadherence-related operons of Mycoplasma genitalium. FEMS Microbiol. Lett. 229:73-81.

Musatovova, O., S. Dhandayuthapani, and J. B. Baseman. 2006. Transcriptional heatshock response in the smallest known self-replicating cell, Mycoplasma genitalium. J. Bacteriol. 188:2845-2855.

Müller, W., N. Horstmann, W. Hillen, and H. Sticht. 2006. The transcription regulator RbsR represents a novel interaction partner of the phosphoprotein HPr-Ser46-P in Bacillus subtilis. FEBS J. 273:1251-1261. 
Neimark, H., and M. C. Tung. 1973. Properties of a fructose-1,6-diphosphate-activated lactate dehydrogenase from Acholeplasma laidlawii type A. J. Bacteriol. 114:10251033.

Neimark, H., and R. M. Lemcke. 1972. Occurrence and properties of lactic dehydrogenases of fermentative mycoplasmas J. Bacteriol. 111:633-640.

Nelson, K. E., D. L. Richardson, and B. A. Dougherty. 1997. Tn916 transposition in Haemophilus influenzae Rd: preferential insertion into noncoding DNA. Microb. Comp. Genomics 2:313-321.

Nessler, S., S. Fieulaine, S. Poncet, A. Galinier, J. Deutscher, and J. Janin. 2003. HPr kinase/phosphorylase, the sensor enzyme of catabolite repression in Gram-positive bacteria: structural aspects of the enzyme and the complex with its protein substrate. J. Bacteriol. 185:4003-4010.

Noh, E. J., S. W. Kang, Y. J. Shin, D. C. Kim, I. S. Park, M. Y. Kim, B. G. Chun, and B. H. Min. 2002. Characterization of Mycoplasma arginine deiminase expressed in E. coli and its inhibitory regulation of nitric oxide synthesis. Mol. Cells 13:137-143.

Obuchowski, M., E. Madec, D. Delattre, G. Boël, A. Iwanicki, D. Foulger, and S. J. Séror. 2000. Characterization of PrpC from Bacillus subtilis, a member of the PPM phosphatase family. J. Bacteriol. 182:5634-5638.

Obuchowski, M. 2005. [Serine-threonine protein phosphatases from Bacillus subtilis] Postępy Biochem. 51:95-104.

Ochman, H., and L. M. Davalos. 2006. The nature and dynamics of bacterial genomes. Science 311: 1730-1733.

Oshima, K., S. Kakizawa, H. Nishigawa, H. Y. Jung, W. Wei, S. Suzuki, R. Arashida, D. Nakata, S. Miyata, M. Ugaki, et al. 2004. Reductive evolution suggested from the complete genome sequence of a plant-pathogenic phytoplasma. Nat. Genet. 36:27-29.

Papazisi, L., T. S. Gorton, G. Kutish, P. F. Markham, G. F. Browning, D. K. Nguyen, S. Swartzell, A. Madan, G. Mahairas, and S. J. Geary. 2003. The complete genome sequence of the avian pathogen Mycoplasma gallisepticum strain R(low). Microbiology 149:2307-2316.

Pennisi, E. 2005. Synthetic biology remakes small genomes. Science 310:769-770.

Philips, B. J., J.-X. Meguer, J. Redman, and E. H. Baker. 2003. Factors determining the appearance of glucose in upper and lower respiratory tract secretions. Intensive Care Med. 29:2204-2210. 
Pilo, P., E. M. Vilei, E. Peterhans, L. Bonvin-Klotz, M. H. Stoffel, D. Dobbelaere, and J. Frey. 2005. A metabolic enzyme as a primary virulence factor of Mycoplasma mycoides subsp. mycoides Small Colony. J. Bacteriol. 187:6824-6831.

Pollack, J. D., A. J. Merola, M. Platz, and R. L. Booth Jr. 1981. Respiration-associated components of Mollicutes. J. Bacteriol. 146:907-913.

Pollack, J. D., M. A. Myers, T. Dandekar, and R. Herrmann. 2002. Suspected utility of enzymes with multiple activities in the small genome Mycoplasma species: The replacement of the missing "household" nucleoside diphosphate kinase gene and activity by glycolytic kinases. OMICS 6:247-257.

Pompeo, F., Y. Granet, J.-P. Lavergne, C. Grangeasse, S. Nessler, J.-M. Jault, and A. Galinier. 2003. Regulation and mutational analysis of the HPr kinase/phosphorylase from Bacillus subtilis. Biochemistry 42:6762-6771.

Poolman, B., J. Knol, B. Mollet, B. Nieuwenhuis, and G. Sulter. 1995. Regulation of bacterial sugar- $\mathrm{H}^{+}$symport by phosphoenolpyruvate-dependent enzyme I/HPr-mediated phosphorylation. Proc. Natl. Acad. Sci. U S A 92:778-782.

Postma, P. W., J. $\quad$ W. Lengeler, and J. $\quad$ R. Jacobson. 1993. Phosphoenolpyruvate:carbohydrate phosphotransferase systems of bacteria. Microbiol. Rev. 57:543-594.

Pour-El, I., C. Adams, and F. C. Minion. 2002. Construction of mini-Tn4001tet and its use in Mycoplasma gallisepticum. Plasmid 47:129-137.

Razin, S., D. Yogev, and Y. Naot. 1998. Molecular biology and pathogenicity of mycoplasmas. Microbiol. Mol. Biol. Rev. 62:1094-1156.

Razin, S. 1999. Adherence of pathogenic mycoplasmas to host cells. Biosci. Rep. 19: 367372.

Regula, J. T., B. Ueberle, G. Boguth, A. Görg, M. Schnölzer, R. Herrmann, and R. Frank. 2000. Towards a two-dimensional proteome map of Mycoplasma pneumoniae. Electrophoresis 21: 3765-3780.

Reizer, J., C. Hoischen, F. Titgemeyer, C. Rivolta, R. Rabus, J. Stülke, D. Karamata, M. H. Saier Jr. and W. Hillen. 1998. A novel protein kinase that controls carbon catabolite repression in bacteria. Mol. Microbiol. 27:1157-1169.

Reynolds, A. E., J. Felton, and A. Wright. 1981. Insertion of DNA activates the cryptic $b g l$ operon of E. coli K12. Nature 293:625-629.

Roberts, M. C., and G. E. Kenny. 1987. Conjugal transfer of transposon Tn916 from Streptococcus faecalis to Mycoplasma hominis. J. Bacteriol. 169:3836-3839. 
Robino, P., A. Alberti, M. Pittau, B. Chessa, M. Miciletta, P. Nebbia, D. Le Grand, and S. Rosati. 2005. Genetic and antigenic characterization of the surface lipoprotein P48 of Mycoplasma bovis. Vet. Microbiol. 109:201-209.

Rouch, D. A., M. E. Byrne, Y. C. Kong, and R. A. Skurray. 1987. The aac-aphD gentamicin and kanamycin resistance determinant of Tn4001 from Staphylococcus aureus: expression and nucleotide sequence analysis. J. Gen. Microbiol. 133: 30393052 .

Sambrook, J., E. F. Fritsch, and T. Maniatis. 1989. Molecular cloning: a laboratory manual, $2^{\text {nd }}$ ed. Cold Spring Harbor Laboratory, Cold Spring Harbor, N.Y.

Sasaki, Y., J. Ishikawa, A. Yamashita, K. Oshima, T. Kenri, K. Furuya, C. Yoshino, A. Horino, T. Shiba, T. Sasaki, et al. 2002. The complete genomic sequence of Mycoplasma penetrans, an intracellular bacterial pathogen in humans. Nucleic. Acids Res. 30:5293-5300.

Schilling, O., I. Langbein, M. Müller, M. Schmalisch, and J. Stülke. 2004. A proteindependent riboswitch controlling ptsGHI operon expression in Bacillus subtilis: RNA structure rather than sequence provides interaction specificity. Nucl. Acids Res. 32:2853-2864.

Schirmer, F., S. Ehrt, and W. Hillen. 1997. Expression, inducer spectrum, domain structure, and function of MopR, the regulator of phenol degradation in Acinetobacter calcoaceticus NCIB8250. J. Bacteriol. 179:1329-1336.

Schmalisch, M. H. 2004. Regulation der Glucoseaufnahme und -verwertung in Bacillus subtilis durch reversible Proteinphosphorylierungen. $\mathrm{PhD}$ thesis, University of Erlangen.

Schumacher, M. A., G. S., Allen, M. Diel, G. Seidel, W. Hillen, and R. G. Brennan. 2004. Structural basis for allosteric control of the transcription regulator CcpA by the phosphoprotein HPr-Ser46-P. Cell 118:731-741.

Scott, J. R., F. Bringel, D. Marra, G. Van Alstine, and C. K. Rudy. 1994. Conjugative transposition of Tn916: preferred targets and evidence for conjugative transfer of a single strand and for a double-stranded circular intermediate. Mol. Microbiol. 11:10991108.

Scott, J. R., and G. G. Churchward. 1995. Conjugative transposition. Annu. Rev. Microbiol. 49:367-397.

Shi, L. 2004. Manganese-dependent protein O-phosphatases in prokaryotes and their biological functions. Front. Biosci. 9:1382-1397. 
Simoneau, P., C.-M. Li, S. Loechel, R. Wenzel, R. Herrmann, and P.-C. Hu. 1993. Codon reading scheme in Mycoplasma pneumoniae revealed by the analysis of the complete set of tRNA genes. Nucl. Acids Res. 21:4967-4974.

Smiley, B. K., and F. C. Minion. 1993. Enhanced readthrough of opal (UGA) stop codons and production of Mycoplasma pneumoniae P1 epitopes in Escherichia coli.Gene 134:33-40.

Stambursky, C., J. Renaudin, and J. M. Bove. 1991. First steps towards a virus-derived vector for gene cloning and expression in spiroplasmas, organisms which read UGA as a tryptophan codon: synthesis of chloramphenicol acetyltransferase in Spiroplasma citri. J. Bacteriol. 173:2225-2230.

Steinhauer, K., T. Jepp, W. Hillen, and J. Stülke. 2002a. A novel mode of control of Mycoplasma pneumoniae HPr kinase/phosphatase activity reflects its parasitic life style. Microbiology 148:3277-3284.

Steinhauer, K., G. S. Allen, W. Hillen, J. Stülke, and R. G. Brennan. 2002b. Crystallization, preliminary X-ray analysis and biophysical characterization of HPr kinase/phosphatase of Mycoplasma pneumoniae. Acta Cryst. Sect. D 58:515-518.

Stuilke, J., M. Arnaud, G. Rapoport, and I. Martin-Verstraete. 1998. PRD - A protein domain involved in PTS-dependent induction and carbon catabolite repression of catabolic operons in bacteria. Mol. Microbiol. 28:865-874.

Stülke, J., and W. Hillen. 1999. Carbon catabolite repression in bacteria. Curr. Opin. Microbiol. 2:195-201.

Stülke, J., and W. Hillen. 2000. Regulation of carbon catabolism in Bacillus species. Annu. Rev. Microbiol. 54:849-880.

Stülke, J., and M. Schmalisch. 2004. The bacterial phosphotransferase system: A perfect link of sugar transport and signal transduction. Topics Curr. Genet. 9:179-205.

Thevenot, T., D. Brochu, C. Vadeboncoeur, and I. R. Hamilton. 1995. Regulation of ATPdependent P-(Ser)-HPr formation in Streptococcus mutans and Streptococcus salivarius. J. Bacteriol. 177:2751-2759.

Thiaucourt, F., L. Dedieu, J. C. Maillard, P. Bonnet, M. Lesnoff, G. Laval, and A. Provost. 2003. Contagious bovine pleuropneumonia vaccines, historic highlights, present situation and hopes. Dev. Biol. (Basel) 114:147-160.

Turinsky, A. J., F. J. Grundy, J. H. Kim, G. H. Chambliss, and T. M. Henkin. 1998. Transcriptional activation of the Bacillus subtilis ackA gene requires sequences upstream of the promoter. J. Bacteriol. 180:5961-5967. 
Ueberle, B., R. Frank, and R. Herrmann. 2002. The proteome of the bacterium Mycoplasma pneumoniae: comparing predicted open reading frames to identified gene products. Proteomics 2: 754-764.

Vadeboncoeur, C., D. Brochu, and J. Reizer. 1991. Quantitative determination of the intracellular concentration of the various forms of HPr, a phosphocarrier protein of the phosphoenolpyruvate: sugar phosphotransferase system in growing cells of oral streptococci. Anal. Biochem. 196:24-30

Vadeboncoeur, C., M. Frenette, and L. A. Lortie. 2000. Regulation of the pts operon in low G+C Gram-positive bacteria. J. Mol. Microbiol. Biotechnol. 2:483-490.

Vasconcelos, A. T., H. B. Ferreira, C. V. Bizarro, S. L. Bonatto, M. O. Carvalho, P. M. Pinto, D. F. Almeida, L. G. Almeida, R. Almeida, L. Alves-Filho, et al. 2005. Swine and poultry pathogens: the complete genome sequences of two strains of Mycoplasma hyopneumoniae and a strain of Mycoplasma synoviae. J. Bacteriol. 187:5568-5577.

Vilei, E. M., and J. Frey. 2001. Genetic and biochemical characterization of glycerol uptake in Mycoplasma mycoides subsp. mycoides SC: its impact on $\mathrm{H}_{2} \mathrm{O}_{2}$ production and virulence. Clin. Diagn. Lab. Immunol. 8:85-92.

Vissa, V. D., and P. J. Brennan. 2001. The genome of Mycobacterium leprae: a minimal mycobacterial gene set. Genome Biol. 2:1023.

Voelker, L. L., and K. Dybvig. 1996. Gene transfer in Mycoplasma arthritidis: transformation, conjugal transfer of Tn916, and evidence for a restriction system recognizing AGCT. J. Bacteriol. 178:6078-6081.

Voigt, B., T. Schweder, D. Becher, A. Ehrenreich, G. Gottschalk, J. Feesche, K. H. Maurer, and M. Hecker. 2004. A proteomic view of cell physiology of Bacillus licheniformis. Proteomics 4:1465-90.

Waites, K. B., and D. F. Talkington. 2004. Mycoplasma pneumoniae and its role as human pathogen. Clin. Microbiol. Rev. 17:697-728.

Waldo, R. H. 3rd, P. L. Popham, C. E. Romero-Arroyo, E. A. Mothershed, K. K. Lee, and D. C. Krause. 1999. Transcriptional analysis of the $h m w$ gene cluster of Mycoplasma pneumoniae. J. Bacteriol. 181:4978-85.

Waldo, R. H. 3rd, J. L. Jordan, and D. C. Krause. 2005. Identification and complementation of a mutation associated with loss of Mycoplasma pneumoniae virulence-specific proteins B and C. J. Bacteriol. 187: 747-751.

Warner, J. B., and J. S. Lolkema. 2003. CcpA-dependent carbon catabolite repression in bacteria. Microbiol. Mol. Biol. Rev. 67:475-490. 
Washio, T., J. Sasayama, and M. Tomita. 1998. Analysis of complete genomes suggests that many prokaryotes do not rely on hairpin formation in transcription termination. Nucl. Acids Res. 26:5456-5463.

Wasinger, V. C., J. D. Pollack, and I. Humphery-Smith. 2000. The proteome of Mycoplasma genitalium. Chaps-soluble component. Eur. J. Biochem. 276:1571-1582.

Weiner, J. 3rd, R. Herrmann, and G. F. Browning. 2000. Transcription in Mycoplasma pneumoniae. Nucl. Acids Res. 28:4488-4496.

Weiner, J. 3rd, C. U. Zimmerman, H. W. H. Göhlmann, and R. Herrmann. 2003. Transcription profiles of the bacterium Mycoplasma pneumoniae grown at different temperatures. Nucl. Acids Res. 31:6306-6320.

Westberg, J., A. Persson, A. Holmberg, A. Goesmann, J. Lundeberg, K. E. Johansson, B. Pettersson, and M. Uhlen. 2004. The genome sequence of Mycoplasma mycoides subsp. mycoides SC type strain PG1T, the causative agent of contagious bovine pleuropneumonia (CBPP). Genome Res. 14:221-227.

Wetzstein, M., U. Völker, J. Dedio, S. Lobau, U. Zuber, M. Schiesswohl, C. Herget, M. Hecker, and W. Schumann. 1992. Cloning, sequencing, and molecular analysis of the dnaK locus from Bacillus subtilis. J. Bacteriol. 174:3300-3310.

Willby, M. J., and D. C. Krause. 2002. Characterization of a Mycoplasma pneumoniae hmw3 mutant: implications for attachment organelle assembly. J. Bacteriol. 184: 30613068 .

Yamao, F., A. Muto, Y. Kawauchi, M. Iwami, S. Iwagami, Y. Azumi, and S. Osawa. 1985. UGA is read as tryptophan in Mycoplasma capricolum. Proc. Natl. Acad. Sci. USA 82:2306-2309.

Ye, J. J., and M. H. Saier Jr. 1995. Cooperative binding of lactose and the phosphorylated phosphocarrier protein $\mathrm{HPr}(\mathrm{Ser}-\mathrm{P})$ to the lactose/H+ symport permease of Lactobacillus brevis. Proc. Natl. Acad. Sci. USA 92:417-421.

Ye, J. J., and M. H. Saier Jr. 1996. Regulation of sugar uptake via the phosphoenolpyruvate-dependent phosphotransferase systems in Bacillus subtilis and Lactococcus lactis is mediated by ATP-dependent phosphorylation of seryl residue 46 in HPr. J. Bacteriol. 178:3557-3563.

Zhu, P.-P., N. Nosworthy, A. Ginsburg, M. Miyata, Y.-J. Seok, and A. Peterkofsky, 1997. Expression, purification, and characterization of Enzyme IIA ${ }^{\text {glc }}$ of the phosphoenolpyruvate:sugar phosphotransferase system of Mycoplasma capricolum. Biochemistry 36:6947-6953. 
Zigangirova, N. A., V. N. Gershanovich, I. V. Rakovskaya, O. I. Barchatova, and A. L. Gintsburg. 2003. Correlation between activity of the phosphoenol-pyruvate-dependable phosphotransferase system (PTS) and synthesis of adhesion P1 protein in Mycoplasma pneumoniae. Mol. Gen. Mikrobiol. Virusol. 2:10-13.

Zimmerman, C. U., and R. Herrmann. 2005. Synthesis of a small, cysteine-rich, 29 amino acids long peptide in Mycoplasma pneumoniae. FEMS Microbiol. Lett. 253:315-321.

Zimmerman, C. U., and R. Herrmann. 2006. Transcriptome analysis of Mycoplasma pneumoniae subtypes M129 and FH during hydrogen peroxide induced oxidative stress. Proceedings of the International Organisation of Mycoplasmology, Cambridge, UK. 


\section{Supplementary Material}

\section{Oligonucleotides}

Tab. 6: Oligonucleotides

\begin{tabular}{|c|c|c|}
\hline Name & Sequence $5^{\prime} \rightarrow 3^{\prime \#}$ & Description \\
\hline SH1 & AGAAGATTCAAGTAGTCGTTAAAG & $p t s H$ probe fw \\
\hline \multirow[t]{2}{*}{$\mathrm{SH} 2$} & CTAATACGACTCACTATAGGGAGATGCTTTAATAGCA & pts $H$ probe rev \\
\hline & TTTAGTGCCTC & \\
\hline $\mathrm{SH} 3$ & GAGTACCCGGATTAAAGCGGG & $h p r K$ probe fw \\
\hline \multirow[t]{2}{*}{ SH4 } & CTAATACGACTCACTATAGGGAGACATTAACTGGATT & $h p r K$ probe rev \\
\hline & TCGGTGCGCTG & \\
\hline SH5 & CAGGTAACGGTGCTGGTTCG & $g l p F$ probe fw \\
\hline \multirow[t]{2}{*}{ SH6 } & CTAATACGACTCACTATAGGGAGAATTGCAGTACCAG & glpF probe rev \\
\hline & TAGCGGC & \\
\hline SH7 & GTTTTAATAGTTGGCGGTGGTG & $g l p D$ probe $\mathrm{fw}$ \\
\hline \multirow[t]{2}{*}{ SH8 } & CTAATACGACTCACTATAGGGAGAAGCATAATGACCT & glpD probe rev \\
\hline & GCAGCATC & \\
\hline SH9 & AAGAATTCCGTTGTACTAGTTAAG & $c l p B$ promoter fragment fw $(E c o \mathrm{RI})$ \\
\hline SH10 & AААATCCATATGTTTTATCCССТTTCTTTG & $c l p B$ promoter fragment rev $(N d e I)$ \\
\hline \multirow[t]{2}{*}{ SH11 } & GTAAACGCATATGGTACAAAAAGAAATGATTAATAA & recA gene fw $(N d e \mathrm{I})$ \\
\hline & 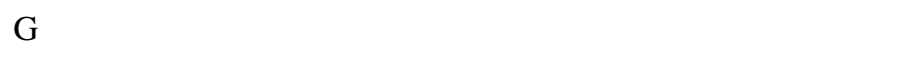 & \\
\hline \multirow[t]{2}{*}{ SH12 } & ACGCATATGCATCACCATCACCATCACATGGTACAAA & recA gene fw (NdeI), N-terminal \\
\hline & AAGAAATGATTAATAAG & $\mathrm{His}_{6}$-tag \\
\hline SH13 & TTGAATTCTGTAAACGTTCCTCTTATC & recA gene rev (EcoRI) \\
\hline SH14 & ATATGAATTCGTCAGTGCCCAACATTAAC & $\begin{array}{l}\text { MPN083 promoter fragment fw } \\
(\text { EcoRI) }\end{array}$ \\
\hline SH15 & TATAGCGGCCGCTACTCTATTTTAACTCTTTAGAG & $\begin{array}{l}\text { MPN083 promoter fragment rev } \\
(\text { Not } \mathrm{I})\end{array}$ \\
\hline SH16 & $\begin{array}{l}\text { ATATGCGGCCGCGAAAGCGGCCGTACCGTGGGGTCA } \\
\text { GT }\end{array}$ & $\begin{array}{l}\text { N-terminal fragment of the } h p r K \\
\text { gene, antisense orientation fw (NotI) }\end{array}$ \\
\hline SH17 & ATATCTAGAATGAAAAAGTTATTAGTCAAGG & $\begin{array}{l}\text { N-terminal fragment of the } h p r K \\
\text { gene, antisense orientation rev }(X b a \mathrm{I})\end{array}$ \\
\hline SH18 & ATATGAATTCTTTATCTCATGATGTCATCTAG & luxS gene $S$. aureus fw (EcoRI) \\
\hline SH19 & ATATGGATCCTGGTTCTCAAATAAATCGGAC & luxS gene $S$. aureus rev (BamHI) \\
\hline SH20 & GCTCCAGGGATGAATGCC & $p f k$ probe fw \\
\hline \multirow[t]{2}{*}{ SH21 } & CTAATACGACTCACTATAGGGAGACCACAATGGCGA & $p f k$ probe rev \\
\hline & CCCATC & \\
\hline $\mathrm{SH} 22$ & GCACCAATTAACGAAGGCG & ptsI probe fw \\
\hline \multirow[t]{2}{*}{$\mathrm{SH} 23$} & CTAATACGACTCACTATAGGGAGAAATTTCCAGTGAA & ptsI probe rev \\
\hline & CGCGCC & \\
\hline $\mathrm{SH} 24$ & CAGGTCAACGCTTATGATCG & nox probe $1 \mathrm{fw}$ \\
\hline
\end{tabular}


10. Supplementary material

\begin{tabular}{|c|c|c|}
\hline Name & Sequence $5^{\prime} \rightarrow 3^{\prime \#}$ & Description \\
\hline SH25 & $\begin{array}{l}\text { CTAATACGACTCACTATAGGGAGAGTCACCTGTTTAC } \\
\text { CACACTG }\end{array}$ & nox probe 1 rev \\
\hline SH26 & TCGGTGTCAATCACGCC & nox probe $2 \mathrm{fw}$ \\
\hline SH27 & $\begin{array}{l}\text { CTAATACGACTCACTATAGGGAGAGCCCACAATGGCT } \\
\text { ACTG }\end{array}$ & nox probe 2 rev \\
\hline SH28 & GTTTGACGGCCTTGTGATG & inside $t k t$ gene \\
\hline SH29 & ATGAGTGAGCTAACTCACAG & $\begin{array}{l}\text { screening primer for transposon } \\
\text { insertions }\end{array}$ \\
\hline SH30 & CAATACGCAAACCGCCTC & $\begin{array}{l}\text { screening primer for transposon } \\
\text { insertions }\end{array}$ \\
\hline SH31 & GTCAATGCTGGCAGTAGC & ackA probe $\mathrm{fw}$ \\
\hline SH32 & $\begin{array}{l}\text { CTAATACGACTCACTATAGGGAGACACCGTTACCCAA } \\
\text { GTGAC }\end{array}$ & ackA probe rev \\
\hline SH33 & CATTAACGATGAGGTGCTC & $\operatorname{clp} B$ probe fw \\
\hline SH34 & $\begin{array}{l}\text { CTAATACGACTCACTATAGGGAGATACCAAGGCACTG } \\
\text { TCAAAG }\end{array}$ & $\operatorname{clp} B$ probe rev \\
\hline SH35 & $\begin{array}{l}\text { CTAATACGACTCACTATAGGGAGAATGAAAAAGTTAT } \\
\text { TAGTCAAGG }\end{array}$ & $\begin{array}{l}\text { probe for antisense } h p r K \text { mRNA rev } \\
\text { (in combination with SH16) }\end{array}$ \\
\hline SH36 & AACGTGTTCAAAGTGCTGG & pta probe fw \\
\hline SH37 & $\begin{array}{l}\text { CTAATACGACTCACTATAGGGAGATGTTTTCCGCTAC } \\
\text { AACTGC }\end{array}$ & pta probe rev \\
\hline SH38 & GTAGCACTCATTGGTTCTG & ldh probe fw \\
\hline SH39 & $\begin{array}{l}\text { CTAATACGACTCACTATAGGGAGATTCACCTAACACA } \\
\text { TATGCTTG }\end{array}$ & $l d h$ probe rev \\
\hline SH40 & ACTTTTTTATTTGACTACGTTTC & ackA promoter fragment (-279) fw \\
\hline SH41 & ACAATTGGAATTTGATCGAGC & $\begin{array}{l}\text { ackA promoter fragment }(+66) \text { rev, } \\
\text { extension primer }\end{array}$ \\
\hline SH42 & TCTTCTGTTCTGCTCTCGG & $l d h$ promoter fragment $(-216) \mathrm{fw}$ \\
\hline SH43 & ATGGCAGCGTAGAGAAAGC & $\begin{array}{l}l d h \text { promoter fragment }(+87) \text { rev, } \\
\text { extension primer }\end{array}$ \\
\hline SH44 & TATTTAAGTACTATAATAAGGGTAACTATTGCCG & lacZ gene of pAC5 fw (ScaI) \\
\hline SH45 & GAACTAGTACATAATGGATTTCCTTAC & lacZ gene of pAC5 rev (SpeI) \\
\hline SH46 & AGAATTCAAACTGCATCGTGGTATCTG & $\begin{array}{l}\text { ldh promoter fragment }(-160) \mathrm{fw} \\
(E c o \mathrm{RI})\end{array}$ \\
\hline SH47 & TAGGATCCGCGTAGAGAAAGCTGGTGC & $\begin{array}{l}\text { ldh promoter fragment }(+81) \mathrm{rev} \\
(\text { Bam } \mathrm{HI})\end{array}$ \\
\hline SH48 & ATGGATCCTTCATAACTAATTTATTCAAGC & $\begin{array}{l}\text { ldh promoter fragment }(+25) \mathrm{rev} \\
(\text { Bam } \mathrm{HI})\end{array}$ \\
\hline SH49 & TAGAATTCTTTTCCTTTTATGTTGAGAGC & $\begin{array}{l}\text { ldh promoter fragment }(-118) \mathrm{fw} \\
(E c o \mathrm{RI})\end{array}$ \\
\hline
\end{tabular}


10. Supplementary material

\begin{tabular}{|c|c|c|}
\hline Name & Sequence $5^{\prime} \rightarrow 3^{\prime \#}$ & Description \\
\hline SH50 & TAGAATTCTTGGCAGCAGGTTTTATTTAG & $\begin{array}{l}\text { ldh promoter fragment }(-84) \mathrm{fw} \\
(E c o \mathrm{RI})\end{array}$ \\
\hline SH51 & TAGAATTCTCAATTGGGAACAGTAAATG & $\begin{array}{l}\text { ldh promoter fragment }(-53) \mathrm{fw} \\
(\text { EcoRI) }\end{array}$ \\
\hline SH52 & GTGGTCAATCCGCAATAC & MPN139 containing fragment fw \\
\hline SH53 & CAGTTATTTAGGCGGATCG & MPN139 containing fragment rev \\
\hline SH54 & AAAGGATCCATGAAGAGTCTTAAAGTAGCAC & $l d h$ gene fw $($ Bam HI) \\
\hline SH55 & AAAAGCTTACTAATTCTTATAGTTTAGCTAAC & ldh gene rev (HindIII) \\
\hline SH56 & ATATATCCGCGGATGAAGAGTCTTAAAGTAGCAC & $l d h$ gene fw (ScaII) \\
\hline SH57 & AAGGATCCACTAATTCTTATAGTTTAGCTAAC & $l d h$ gene rev (BamHI) \\
\hline SH58 & AGAATTCGTTAATAATGATGATTGAAGC & $\begin{array}{l}\text { ackA promoter fragment }(-219) \mathrm{fw} \\
(E c o \mathrm{RI})\end{array}$ \\
\hline SH59 & TAGGATCCTTGTGATAATCAAACAATTGG & $\begin{array}{l}\text { ackA promoter fragment }(+79) \text { rev } \\
(\text { Bam } \mathrm{HI})\end{array}$ \\
\hline SH60 & TATACAATGCTACACCATCG & thyA probe $\mathrm{fw}$ \\
\hline SH61 & $\begin{array}{l}\text { CTAATACGACTCACTATAGGGAGACTCATTGGGATTT } \\
\text { CAACTAG }\end{array}$ & thyA probe rev \\
\hline SH62 & TAGAATTTTATGGTGGTAGAG & aac-ahpD probe fw \\
\hline SH63 & $\begin{array}{l}\text { CTAATACGACTCACTATAGGGAGAACACTATCATAAC } \\
\text { САСТАCC }\end{array}$ & $a a c-a h p D$ probe rev \\
\hline SH64 & GCTTTAGTTGGCAATAATTCC & $\operatorname{prpC}$ containing fragment $\mathrm{fw}$ \\
\hline SH65 & CTTCTTCCAGTTGTTGTCG & $\operatorname{prpC}$ containing fragment rev \\
\hline SH66 & AAA $\underline{\text { GTCGACATGGACAGCACCAACCAAAAC }}$ & $\operatorname{prpC}$ gene fw (SalI) \\
\hline SH67 & AAGCTAGCTTAGTGCCATTGTTTTAAATTAATCAAG & $\operatorname{prpC}$ gene rev $(\mathrm{Nhe} \mathrm{I})$ \\
\hline SH68 & P-GCAAAACATTTGGACCTTTTGGG & $\operatorname{prpC} \mathrm{A} 375 \mathrm{G}$ \\
\hline SH69 & AAGCATTCAGCGTTTATCTC & thyA promoter fragment fw \\
\hline SH70 & CTTGCAAAATAAGCGAATAAC & thyA promoter fragment rev \\
\hline SH71 & AACGGTGGTATATCCAGTG & $\begin{array}{l}\text { sequencing primer for pWH844 } \\
\text { constructs (anneals behind NheI site) }\end{array}$ \\
\hline SH72 & TTTTACCAAGTCCTTTACAGTC & $\begin{array}{l}\text { downstream transposon insertion site } \\
\text { of GMP68 }\end{array}$ \\
\hline SH73 & $\begin{array}{l}\text { CTAATACGACTCACTATAGGGAGAGACCATCAGAGC } \\
\text { ACAACAG }\end{array}$ & prpC probe rev \\
\hline SH74 & АСТССТTCAАСССАACAAGTC & MPN474 probe fw \\
\hline SH75 & $\begin{array}{l}\text { CTAATACGACTCACTATAGGGAGACTTGCAATTGTTG } \\
\text { TAACTGCG }\end{array}$ & MPN474 probe rev \\
\hline SH76 & $\begin{array}{l}\text { CTAATACGACTCACTATAGGGAGACCAATAAAGATA } \\
\text { AAGTCGTAATC }\end{array}$ & $\begin{array}{l}\text { ldh probe (covering } 5^{\prime} \text { part until } \\
233^{\text {rd }} \text { nucleotide) rev }\end{array}$ \\
\hline SH77 & ATATCCGCGGCGATGGACAGCACCAACCAAAAC & MPN247 gene fw (SacII) \\
\hline SH78 & AACCCGGGTTAGTGCCATTGTTTTAAATTAATCAAG & MPN247 gene rev (XmaI) \\
\hline
\end{tabular}


10. Supplementary material

\begin{tabular}{|c|c|c|}
\hline Name & Sequence $5^{\prime} \rightarrow 3^{\prime \#}$ & Description \\
\hline SH79 & ATATCCGCGGCGATGGCACTAAATTTAAAGATTGG & MPN248 gene fw (SacII) \\
\hline SH80 & ATGGATCCTTACGAATGGACAACTACCC & MPN248 gene rev (BamHI) \\
\hline SH81 & P-GATTTGGCGCAATGGCAAACCG & MPN248 A969G \\
\hline SH82 & ATGGATCCATGGCACAAAAAACATTTAAAG & $p t s H_{B s u}$ gene fw $($ BamHI) \\
\hline SH83 & ATAAAGCTTCTCGCCGAGTCCTTCG & $p t s H_{B s u}$ gene rev (HindIII) \\
\hline SH84 & P-GAAGGTAACATCAAGGCGATCATCAACTTAATGTC & $p t s H_{M p n}$ T139G $($ Ser46 $\rightarrow$ Ala $)$ \\
\hline SH85 & TAGGATCCCCAATAAAGATAAAGTCGTAATC & $\begin{array}{l}\text { ldh promoter fragment }(+239) \text { rev } \\
(\text { Bam } \mathrm{HI})\end{array}$ \\
\hline SH86 & ATGGATCCAGTTTAGCTAACTTAATGTTGTC & $l d h$ gene rev $($ Bam $\mathrm{HI})$ \\
\hline SH87 & AAAATCTGACTTTACTTTAAGC & screening for MPN239::Tn strains fw \\
\hline SH88 & GGTCAAGTTATGCAAAGAAC & $\begin{array}{l}\text { screening for MPN239::Tn strains } \\
\text { rev }\end{array}$ \\
\hline SH89 & TAGAGCTCGATGGCACTAAATTTAAAGATTGG & MPN248 gene fw ( $\mathrm{SacI})$ \\
\hline SH90 & TAATTATCTTCAGGATCAAAGAC & $\begin{array}{l}\text { screening for } l d h \text { promoter } \\
\text { transposon insertions fw }\end{array}$ \\
\hline SH91 & AATTTAACTACCCGACAAGCC & screening for $h r c A::$ Tn strains fw \\
\hline SH92 & GGAGCTAGTGGTTTTACCAC & screening for $h r c A:: T n$ strains rev \\
\hline CD13 & AAACATATGGCTAGCTGGAGCCACCCGCAGTTC & sequencing of pGP172 constructs \\
\hline $\mathrm{CH} 7$ & $\begin{array}{l}\text { AAAAGTCGACATGGATCTAAAACAACAATACATTCTT } \\
\text { G }\end{array}$ & glpK gene fw (SalI) \\
\hline $\mathrm{CH} 8$ & TATAAAGCTTGTCTTAGTCTAAGCTAGCCCATTTTAG & $g l p K$ gene rev (HindIII), A1512G \\
\hline $\mathrm{CH} 9$ & AAAAGTCGACATGGATCTAAAACAAC & glpK gene fw (SalI) \\
\hline $\mathrm{CH} 10$ & TATAAAGCTTGTCTTAGTCTAAGCTAG & glpK gene rev (HindIII) \\
\hline $\mathrm{CH} 11$ & P-GATCCCTTAGAAATTTGGTCAGTCCAATTAG & $g l p K$ A165G \\
\hline $\mathrm{CH} 12$ & P-CCATTGTGTTATGGAACAAAGAAAATGGTTTG & glpK A273G \\
\hline $\mathrm{CH} 13$ & P-CACTAAGATTGCTTGGATCTTGGAAAATGTTC & glpK A438G \\
\hline $\mathrm{CH} 14$ & P-CCTGGTTAATTTGGAAACTAACGGGTG & glpK A522G \\
\hline $\mathrm{CH} 15$ & P-CCATGACATGGTCACAAGAGTTAGGC & glpK A606G \\
\hline $\mathrm{CH} 16$ & P-TACCGAGTCATTGGTCTACTAGTGC & glpK A705G \\
\hline $\mathrm{CH} 17$ & P-CCTTAAAGTGGTTAAGGGATAGTCTTAAGG & glpK A966G \\
\hline $\mathrm{CH} 18$ & P-GCAGTTAATTATTGGAAGGACACTAAACAAC & $g l p K$ A1386G \\
\hline CH19 & P-GAAATCAAAGCGTTGGAACGAAGCTG & glpK A1482G \\
\hline JS39 & TCTATCAACAGGAGTCCA & sequencing of pWH844 constructs \\
\hline KS9 & AAAGTCGACATGAAAAAGTTATTAGTCAAGGAG & screening for $h p r K:: T n$ strains fw \\
\hline KS10 & $\begin{array}{l}\text { ATTAAGCTTGGTCTGCTACTAACACTAGGATTCATCTT } \\
\text { TTTTACG }\end{array}$ & screening for $h p r K:: T n$ strains rev \\
\hline PAC5R & CTGCAAGCGATAAGTTGG & sequencing of pGP353 constructs \\
\hline pWH844fv & Afw TATGAGAGGATCGCATCACCAT & sequencing of pWH844 constructs \\
\hline
\end{tabular}




\section{Plasmids}

Tab. 7: Plasmids

\begin{tabular}{|c|c|c|c|}
\hline Name & Description & Resistance & Reference \\
\hline pAG3 & overexpression of $B$. subtilis His $_{6}$-PtsI & ampicillin & Galinier et al., 1997 \\
\hline pGP172 & overexpression of Strep-tagged proteins & ampicillin & Merzbacher et al., 2004 \\
\hline \multirow[t]{2}{*}{ pGP204 } & overexpression of $M$. pneumoniae His $_{6^{-}}$ & ampicillin & Steinhauer et al., 2002 \\
\hline & HPrK/P & & \\
\hline \multirow[t]{2}{*}{ pGP217 } & overexpression of $M$. pneumoniae His $_{6^{-}}$ & ampicillin & Steinhauer et al., 2002 \\
\hline & $\mathrm{HPr}$ & & \\
\hline \multirow[t]{2}{*}{ pGP253 } & pWH844 + glpK gene $(\mathrm{CH} 7 / \mathrm{CH} 8)$ via & ampicillin & Hames et al., 2005 \\
\hline & SalI/HindIII & & \\
\hline \multirow[t]{3}{*}{ pGP254 } & pWH844 + glpK gene $(\mathrm{CH} 7 / \mathrm{CH} 10)$ with & ampicillin & Hames et al., 2005 \\
\hline & all TGA codons converted into TGG & & \\
\hline & codons via SalI/HindIII & & \\
\hline \multirow[t]{2}{*}{ pGP350 } & pMT85 + MPN083 promoter fragment & gentamicin/kanamycin & \\
\hline & (SH14/SH15) via EcoRI/NotI & & \\
\hline \multirow[t]{2}{*}{ pGP351 } & pGP350 + N-terminal hprK fragment & gentamicin/kanamycin & \\
\hline & (SH16/SH17) via $N o t \mathrm{I} / \mathrm{XbaI}$ & & \\
\hline \multirow[t]{2}{*}{ pGP352 } & pMK4 + S. aureus luxS gene & ampicillin/chloramphenicol & \\
\hline & (SH18/SH19) via EcoRI/BamHI & & \\
\hline \multirow[t]{2}{*}{ pGP353 } & pMT85 + promoterless lac $Z$ gene of & gentamicin/kanamycin & Halbedel \& Stülke, \\
\hline & pAC5 (SH44/SH45) in via SpeI/AleI & & 2006 \\
\hline \multirow[t]{2}{*}{ pGP354 } & pGP353 + ldh promoter fragment & gentamicin/kanamycin & Halbedel \& Stülke, \\
\hline & $(-160 \ldots+81)$ via $E c o \mathrm{RI} /$ BamHI & & 2006 \\
\hline \multirow[t]{2}{*}{ pGP355 } & pGP353 + ldh promoter fragment & gentamicin/kanamycin & \\
\hline & $(-118 \ldots+81)$ via Eco RI/BamHI & & \\
\hline \multirow[t]{2}{*}{ pGP356 } & pGP353 + ldh promoter fragment & gentamicin/kanamycin & \\
\hline & $(-84 \ldots+81)$ via $E c o \mathrm{RI} /$ Bam HI & & \\
\hline \multirow[t]{2}{*}{ pGP357 } & pGP353 + ldh promoter fragment & gentamicin/kanamycin & \\
\hline & $(-53 \ldots+81)$ via $E c o \mathrm{RI} /$ Bam HI & & \\
\hline \multirow[t]{2}{*}{ pGP358 } & pGP353 + ldh promoter fragment & gentamicin/kanamycin & \\
\hline & $(-160 \ldots+25)$ via $E c o \mathrm{RI} / B a m \mathrm{HI}$ & & \\
\hline \multirow[t]{2}{*}{ pGP359 } & pGP353 + ldh promoter fragment & gentamicin/kanamycin & \\
\hline & $(-118 \ldots+25)$ via Eco RI/BamHI & & \\
\hline \multirow[t]{2}{*}{ pGP360 } & pGP353 + ldh promoter fragment & gentamicin/kanamycin & \\
\hline & $(-84 \ldots+25)$ via EcoRI/BamHI & & \\
\hline \multirow[t]{2}{*}{ pGP361 } & pGP353 + ldh promoter fragment & gentamicin/kanamycin & \\
\hline & $(-53 \ldots+25)$ via $E c o \mathrm{RI} /$ BamHI & & \\
\hline \multirow[t]{2}{*}{ pGP362 } & pET3-c $+l d h$ promoter fragment & ampicillin & \\
\hline & $(-160 \ldots+81)$ via $E c o \mathrm{RI} /$ BamHI & & \\
\hline pGP363 & pGP362 digested with HindIII (loss of $l d h$ & ampicillin & \\
\hline
\end{tabular}




\begin{tabular}{|c|c|c|c|}
\hline Name & Description & Resistance & Reference \\
\hline pGP364 & $\begin{array}{l}\text { core promoter region) followed by self- } \\
\text { ligation } \\
\text { pGP353 + ldh promoter fragment of } \\
\text { pGP363 via SH46/SH47 and }\end{array}$ & gentamicin/kanamycin & $\begin{array}{l}\text { Halbedel \& Stülke, } \\
2006\end{array}$ \\
\hline pGP365 & $\begin{array}{l}\text { EcoRI/Bam HI } \\
\text { pGP353 + ldh promoter fragment of } \\
\text { pGP363 (SH46/SH48) via EcoRI/BamHI }\end{array}$ & gentamicin/kanamycin & \\
\hline pGP366 & $\begin{array}{l}\text { pWH844 + truncated hprK allele of } \\
\text { GPM51 (KS9/SH30) via SalI/NheI }\end{array}$ & ampicillin & Halbedel et al., 2006 \\
\hline pGP367 & $\begin{array}{l}\text { pGP353 + ackA promoter fragment } \\
(-219 \ldots+79) \text { via EcoRI/BamHI }\end{array}$ & gentamicin/kanamycin & \\
\hline pGP368 & $\begin{array}{l}\text { pWH844 + ldh gene (SH54/SH55) via } \\
\text { BamHI/HindIII }\end{array}$ & ampicillin & \\
\hline pGP369 & $\begin{array}{l}\text { pWH844 + prpC gene (SH66/SH67) via } \\
\text { SalI/NheI }\end{array}$ & ampicillin & \\
\hline pGP370 & $\begin{array}{l}\text { pWH844 + prpC gene }(\mathrm{A} 375 \mathrm{G}) \text { via } \\
\text { SalI/NheI }\end{array}$ & ampicillin & Halbedel et al., 2006 \\
\hline pGP371 & $\begin{array}{l}\text { pWH844 + ptsH1 gene of B. subtilis } \\
\text { QB5223 (SH82/SH83) via }\end{array}$ & ampicillin & \\
\hline pGP372 & $\begin{array}{l}\text { BamHI/HindIII } \\
\text { pWH844 + ptsH1 gene of M. pneumoniae } \\
(\mathrm{KS} 34 / \mathrm{SH} 84 / \mathrm{KS} 35) \text { via SalI/HindIII }\end{array}$ & ampicillin & \\
\hline pGP373 & $\begin{array}{l}\text { pGP353 + ldh promoter-gene fragment } \\
(\mathrm{SH} 46 / \mathrm{SH} 85) \text { via EcoRI/BamHI }\end{array}$ & gentamicin/kanamycin & \\
\hline pGP374 & $\begin{array}{l}\text { pGP353 + ldh promoter-gene fragment } \\
(\mathrm{SH} 46 / \mathrm{SH} 86) \text { via EcoRI/BamHI }\end{array}$ & gentamicin/kanamycin & \\
\hline pGP611 & $\begin{array}{l}\text { overexpression of } M \text {. pneumoniae Strep- } \\
\text { HPrK/P }\end{array}$ & ampicillin & Merzbacher et al., 2004 \\
\hline pMT85 & mini-transposon delivery vector & gentamicin/kanamycin & $\begin{array}{l}\text { Zimmerman \& } \\
\text { Herrmann, } 2005\end{array}$ \\
\hline pWH844 & overexpression of $\mathrm{His}_{6}$-tagged proteins & ampicillin & Schirmer et al., 1997 \\
\hline
\end{tabular}




\section{Strains}

Tab. 8: Strains

\begin{tabular}{|c|c|c|}
\hline Name & Genotype & Reference/construction ${ }^{\#}$ \\
\hline \multicolumn{3}{|l|}{ Escherichia coli } \\
\hline DH5 $\alpha$ & $\begin{array}{l}\text { recAl endA1 gyrA96 thi hsdR17 } \mathrm{r}_{\mathrm{K}-} \mathrm{m}_{\mathrm{K}+} \text { relAl } \\
\text { supE44 } \Phi 80 \Delta \text { lacZDM15 } \Delta(\text { lacZYA-argF }) \mathrm{U} 169\end{array}$ & Sambrook et al., 1989 \\
\hline BL21(DE3) & $\begin{array}{l}\text { F- lon ompT } r_{B} m_{B} h s d S \text { gal (cIts857ind } 1 \text { Sam7 nin5 } \\
\text { lacUV5-T7 gene1) }\end{array}$ & Sambrook et al., 1989 \\
\hline NM522 & $\begin{array}{l}\text { supE thi-1 } \Delta(\text { lac-proAB }) \Delta(\text { mcrB-hsdSM }) 5\left(\mathrm{r}_{\mathrm{K}-} \mathrm{m}_{\mathrm{K}-}\right) \\
{\left[\mathrm{F}^{\prime} \text { proAB }_{\text {lacI }}{ }^{q} \mathrm{Z} \Delta \mathrm{M} 15\right]}\end{array}$ & Gough \& Murray, 1983 \\
\hline \multicolumn{3}{|c|}{ Mycoplasma pneumoniae } \\
\hline M129 (ATCC 29342) & wild type & \\
\hline GPM50 & MPN083'-'hprK(295...1) & pGP351 $\rightarrow$ M129 \\
\hline GPM51 & hprK::Tn & Halbedel et al., 2006 \\
\hline GPM52 & $g l p D:: \operatorname{Tn}$ & \\
\hline GPM53/1 ...53/5 & 'lacZ & Halbedel \& Stülke, 2006 \\
\hline GPM54/1 ...54/5 & $l d h(-160 \ldots+81)^{\prime}-' l a c Z$ & Halbedel \& Stülke, 2006 \\
\hline GPM55 & $l d h(-118 \ldots+81)^{\prime}-' l a c Z$ & pGP355 $\rightarrow$ M129 \\
\hline GPM56 & $l d h(-84 \ldots+81)^{\prime}-{ }^{\prime} l a c Z$ & pGP356 $\rightarrow$ M129 \\
\hline GPM57 & $l d h(-53 \ldots+81)^{\prime}-' l a c Z$ & pGP357 $\rightarrow$ M129 \\
\hline GPM58 & $l d h(-160 \ldots+25)^{\prime}-' l a c Z$ & pGP358 $\rightarrow$ M129 \\
\hline GPM59 & $l d h(-118 \ldots+25)^{\prime}-{ }^{\prime} l a c Z$ & pGP359 $\rightarrow$ M129 \\
\hline GPM60 & $l d h(-84 \ldots+25)^{\prime}-{ }^{\prime} l a c Z$ & pGP360 $\rightarrow$ M129 \\
\hline GPM61 & $l d h(-53 \ldots+25)^{\prime}-l a c Z$ & pGP361 $\rightarrow$ M129 \\
\hline GPM64/1 ..64/5 & $\operatorname{ldh}(-160 \ldots-85-+1 \ldots+81)^{\prime}-' l a c Z$ & Halbedel \& Stülke, 2006 \\
\hline GPM65 & $\operatorname{ldh}(-160 \ldots-85-+1 \ldots+25)^{\prime}-' \operatorname{lac} Z$ & pGP365 $\rightarrow$ M129 \\
\hline GPM66 & MPN139::Tn & \\
\hline GPM67/1 ..67/4 & $\operatorname{ack} A(-219 \ldots+79)^{\prime}-' l a c Z$ & pGP367 $\rightarrow$ M129 \\
\hline GPM68 & $\operatorname{prp} C:: \operatorname{Tn}$ & Halbedel et al., 2006 \\
\hline GPM69 & $l d h:: \mathrm{Tn}$ & \\
\hline GPM70 & MPN474::Tn & \\
\hline
\end{tabular}

${ }^{\#} \rightarrow$ indicates transformation 


\section{Curriculum vitae}

\section{Personal Information}

Date of birth:

$20^{\text {th }}$ august 1978

Place of birth:

Havelberg, Germany

Nationality:

German

Parents:

Dr. Bernd Halbedel and Ursula Halbedel

\section{School Education}

$\begin{array}{ll}1985-1987 & \text { Karl-Liebknecht-Schule Ilmenau } \\ 1987-1991 & \text { Rosa-Luxemburg-Schule Ilmenau } \\ 1991-1993 & \text { Lindenberg-Gymnasium Ilmenau } \\ 1993-1997 & \text { Goethe-Gymnasium Ilmenau }\end{array}$

07/1997 Abitur

\section{Community Service}

$1997-1998$

Kreiskrankenhaus Ilmenau

\section{Scientific Education}

$1998-2003$

study of human biology, University of Greifswald

$2002-2003$

diploma thesis in the group of Prof. Michael Hecker

University of Greifswald

thesis title:

"Functional characterization of the luxS gene of Staphylococcus aureus"

10/2003 - 10/2006 PhD project "Regulation of HPr phosphorylation in Mycoplasma pneumoniae"

Dept. of General Microbiology (Prof. Dr. Jörg Stülke)

University of Göttingen

03/2004-02/2006 sholarship holder of a Kekulé stipend of the Fonds der Chemischen Industrie 